\title{
Uma comparação de métodos de classificação aplicados à detecção de fraude em cartões de crédito
}

\author{
Manoel Fernando Alonso Gadi
}

DisSERTAÇÃO APRESENTADA

$\mathrm{AO}$

Instituto DE MATEMÁticA E Estatística

DA

Universidade De SÃo Paulo

PARA

OBTENÇÃO DO TÍTULO

$\mathrm{DE}$

Mestre em CiÊnCIAS

Área de Concentração: Ciência da Computação
Orientador: Prof. Dr. Alair Pereira do Lago

São Paulo, maio de 2008 


\title{
Uma comparação de métodos de classificação aplicados à detecção de fraude em cartões de crédito
}

\author{
Este exemplar corresponde à redação \\ final da dissertação devidamente corrigida \\ e defendida por Manoel Fernando Alonso Gadi \\ e aprovada pela Comissão Julgadora.
}

Banca Examinadora:

- Prof. Dr. Alair Pereira do Lago (orientador) - IME-USP.

- Prof. Dr. Fernando José Von Zuben - FEEC - Unicamp.

- Prof. Dr. Leandro Nunes de Castro - Mackenzie. 


\section{Resumo}

Em 31 de janeiro de 2002, a renomada revista Nature [Kla02], de forte impacto no meio científico, publicou uma reportagem sobre o assunto de sistemas imuno-baseados. Entre as diversas aplicações ali apontadas, encontramos a detecção de transações fraudulentas em sistemas transacionais. Ali era apontada a possibilidade de futuro uso comercial de sistemas imunobaseados para detecção de fraude em sistemas transacionais já para o ano de 2003. Apesar disso, desconhecemos trabalho científico que aplica Sistemas Imunológicos Artificiais em detecção de fraude financeira. Este trabalho relata os resultados bastante satisfatórios da aplicação de um sistema imunobaseado (AIS) ao problema da deteção à fraude em sistemas de transações em cartão de créditos. De fato, trabalhos sobre detecção de fraude em geral são raros, como aponta Phua et al. [PLSG05], em particular no mercado de cartões de crédito. Phua et al. indicam a ausência de uma base de dados pública para aplicação de diversos métodos como a causa principal desse baixo número de publicações. Duas das publicações mais importantes sobre o assunto e que relatam resultados de suas implementações, são [MTV00] que compara Redes Neurais e Redes Bayesianas na detecção de fraude em cartões de crédito, chegando a um resultado favorável às Redes Bayesianas e [SFL $\left.{ }^{+} 97\right]$, que propôs o método AdaCost. Este trabalho se soma aos dois no sentido de publicar pesquisa em deteção a fraude em cartões de crédito.

Ademais, apesar da não disponibilidade dos dados e das implementações, reproduzimos os resultados de Maes e ampliamos o leque de comparações de forma a comparar os métodos de Redes Neurais, Redes Bayesianas, mas também Sistemas Imunológicos Artificiais, Árvores de Decisão e até mesmo o simples Naive Bayes. Reproduzimos de certa forma os resultados de [SFL $\left.{ }^{+} 97\right]$ ao constatar que o uso de uma metaheurística sensível a custo, de fato generalizada a partir da generalização feita do método AdaBoost para o AdaCost, aplicada aos diversos métodos testados melhora susbtancialmente os resultados obtidos, exceto para Naive Bayes.

Nossa análise levou em consideração a natureza dos dados serem fortemente desbalanceados, bem como a necessidade de um ajuste paramétrico, eventualmente através de algoritmos genéticos, para obter os melhores resultados de cada um dos métodos sendo comparados. 


\section{Abstract}

In 2002, January the 31st, the famous journal Nature [Kla02], with a strong impact in the scientific environment, published some news about immune based systems. Among the different considered applications, we can find detection of fraudulent financial transactions. One can find there the possibility of a commercial use of such system as close as 2003, in a British company. In spite of that, we do not know of any scientific publication that uses Artificial Immune Systems in financial fraud detection. This work reports results very satisfactory on the application of Artificial Immune Systems (AIS) to credit card fraud detection. In fact, scientific financial fraud detection publications are quite rare, as point out Phua et al. [PLSG05], in particular for credit card transactions. Phua et al. points out the fact that no public database of financial fraud transactions is available for public tests as the main cause of such a small number of publications. Two of the most important publications in this subject that report results about their implementations are the prized [MTV00], that compares Neural Networks and Bayesian Networks in credit card fraud detection, with a favored result for Bayesian Networks and [SFL ${ }^{+}$97], that proposed the method AdaCost. This thesis joins both these works and publishes results in credit card fraud detection. Moreover, in spite the non availability of Maes data and implementations, we reproduce the results of their and amplify the set of comparisons in such a way to compare the methods Neural Networks, Bayesian Networks, and also Artificial Immune Systems, Decision Trees, and even the simple Naïve Bayes. We reproduce in certain way the results of $\left[\mathrm{SFL}^{+} 97\right]$ when we verify that the usage of a cost sensitive meta-heuristics, in fact generalized from the generalization done from the AdaBoost to the AdaCost, applied to several tested methods substantially improves it performance for all methods, but Naive Bayes.

Our analysis took into account the skewed nature of the dataset, as well as the need of a parametric adjustment, sometimes through the usage of genetic algorithms, in order to obtain the best results from each compared method. 


\section{Agradecimentos}

Agradeço a Deus, que me guiou pelos caminhos que levaram a produzir esse trabalho, em especial, agradeço a Ele por permitir que tudo acontecesse de maneira incrivelmente planejada para que houvesse tempo hábil para que tudo fosse produzido. Agradeço, ao meu pai Osvaldo, que apesar de ter falecido durante a confecção deste trabalho, apoiou bastante enquanto vivo, à minha mãe Lourdes, que se esforçou em tudo para me dar o suporte necessário para que não desviasse minha atenção do trabalho nos momentos finais, a minha namorada Carolina, que me ajudou muito sempre estando perto para me suportar mesmo quando esteve longe estudando Inglês no Canadá. Também contei com a compreensão das minhas duas irmãs que estiveram tão presentes em alguns momentos.

Sou eternamente grato ao professor Alair Pereira do Lago pela dedicação empenhada, pela compreensão e por todos os momentos de aconselhamento profissional e pessoal que desprovido de qualquer interesse se prestou a me conceder. Sou grato também aos professores Roberto Marcondes e Nami Kobayashi por terem me apoiado para esse trabalho, o primeiro com recomendações e apoios imprescindíveis para a realização dessa pesquisa, e a segunda por todo o acompanhamento que exerceu sobre mim durante a graduação que sucumbiu no interesse pelo mestrado. Não poderia deixar de mencionar e agradecer os professores Joao Eduardo Ferreira e Yoshiharu Kohayakawa, que, nos últimos testes, cederam poder computacional muito importante.

Obrigado à Credicard, nas pessoas de Ricardo Leite Raposo, Xidi Wang e Jacqueline David, por terem me incentivado e cedido tempo para que eu cursasse as disciplinas. Agradeço ao Santander, na pessoa de Eduardo Santo, por entender e ceder-me tempo extra para finalização desse trabalho.

Meu agradecimento a todos os amigos que, de alguma forma, me apoiaram na dissertação, alguns deles até sofreram comigo 
no final. Meu muito obrigado especial ao André Sanches, Aydin Ilhan, Charlie Nakagawa, Samir Reis e Tarcisio Tadeu. Não poderia esquecer de pedir desculpas ao Ronaldo Castellano por não comparecer ao casamento dele em virtude da finalização da dissertação.

Sou grato também ao Francisco Tega e Eduardo Costa, que apesar de não saberem, tiveram influência forte na manutenção de minha motivação para finalização desse trabalho. 


\section{Sumário}

1 Introdução 11

2 O Mercado de Cartões de Crédito e Prevenção à Fraude 14

2.1 O Mercado de Cartões de Crédito . . . . . . . . . . . . . . . 14

2.1.1 No Brasil . . . . . . . . . . . . . . . . . 15

2.1.2 Tipos de Cartão de Crédito . . . . . . . . . . . . . . 16

2.1.3 Funcionamento do Cartão de Crédito . . . . . . . . . . 16

2.1.4 Autorização numa operação de Cartão de Crédito . . . 18

2.1.5 Os tipos de dispositivos de captura disponíveis . . . . . 19

2.2 Definindo Fraude . . . . . . . . . . . . . . . . . . . . . . 21

2.2.1 Alguns tipos de fraude . . . . . . . . . . . . . 21

2.2.2 Código Penal Brasileiro . . . . . . . . . . . . . . . . . . 25

2.3 Introdução a Prevenção à Fraude em Cartões de Crédito . . . 26

2.3.1 As principais modalidades de fraude . . . . . . . . 26

2.3.2 Custos tangíveis da fraude (financeiros) . . . . . . . . 28

2.3.3 Custos intangíveis da fraude (não financeiros) . . . . . 28

2.3.4 Ciclo de Prevenção à Fraude . . . . . . . . . . . . . . . 29

3 Reconhecimento de padrões aplicado na detecção de Fraude 31

3.1 Dados desbalanceados (Skewed data) . . . . . . . . . . . . 32

3.2 Dados ausentes (Missing data) . . . . . . . . . . . 33

3.3 Tipo de dados utilizados em prevenção à fraude . . . . . . . . 33

3.4 Estruturação dos dados . . . . . . . . . . . . . . . . . 35

3.4.1 Categorização (Discretização ou Grouping) . . . . . . . 36

3.5 Amostragem . . . . . . . . . . . . . . . . 37

3.6 Medidas de desempenho . . . . . . . . . . . . . . . . . . 38

3.7 A relação entre a organização dos dados e os métodos .. . 39 
4 Os métodos de classificação comparados - uma visão geral 43

4.1 Árvores de Decisão (DT) . . . . . . . . . . . . . . . . . 45

4.1.1 Exemplo da indução de um Árvore de Decisão. . . . . . 46

4.1.2 Parâmetros de indução de uma árvore de decisão. . . . 49

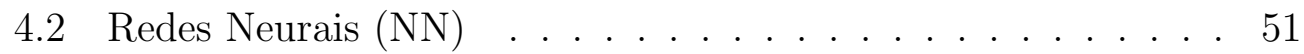

4.2 .1 Sistema Nervoso Humano $(\mathrm{SNH})$. . . . . . . . . . 51

4.2 .2 O histórico . . . . . . . . . . . . . . . 53

4.2.3 Modelo Generalizado das ANNs . . . . . . . . . . . 58

4.2.4 O Algoritmo de Backpropagation . . . . . . . . . . . 59

4.3 Redes Bayesianas $(\mathrm{BN}) \ldots \ldots$. . . . . . . . . . . . . . 62

4.3 .1 Noções de Probabilidade . . . . . . . . . . . . . . . 62

4.3 .2 Probabilidade Condicional . . . . . . . . . . . . . 64

4.3 .3 Teorema de Bayes . . . . . . . . . . . . . . . . . . . 65

4.3.4 Probabilidade Conjunta . . . . . . . . . . . . . 66

4.3.5 Redes Bayesianas . . . . . . . . . . . . . 67

4.3.6 Construção da Rede Bayesiana ........ . 70

4.4 Naive Bayes $(\mathrm{NB}) \ldots \ldots \ldots . \ldots 74$

4.4.1 A aprendizagem . . . . . . . . . . . . . . 75

4.5 Sistemas Imunológicos Artificiais (AIS) . . . . . . . . . 76

4.5.1 Imunologia . . . . . . . . . . . . . . . . 77

4.5.2 Seleção Negativa . . . . . . . . . . . . . . . . . . 86

4.5.3 Seleção Clonal . . . . . . . . . . . . . . . . . . . . . 86

4.5 .4 Rede Imunológica . . . . . . . . . . . . . . . . . . 87

4.6 Aprendizagem Sensível ao Custo e Meta Heurística . . . . . 87

4.6 .1 Meta Heurística . . . . . . . . . . . . . . . . . . 88

4.6 .2 MetaCost . . . . . . . . . . . . . . . . . 88

4.6.3 CostSensitiveClassifier . . . . . . . . . . . . . . . . 89

4.6.4 Nossa opção para o algoritmo de aprendizagem com custo . . . . . . . . . . . . . . . . 90

4.7 Algoritmo Genético (GA) $\ldots \ldots \ldots 90$

4.7 .1 Histórico . . . . . . . . . . . . . . . . . . . 90

4.7 .2 Introdução . . . . . . . . . . . . . . . . . . . 99 91

4.7 .3 O Algoritmo . . . . . . . . . . . . . . . . 92

5 Parte experimental $\quad 95$

5.1 Preparação dos dados . . . . . . . . . . . . . . . . . 95

5.1.1 Avaliação dos casos como fraude e não-fraude . . . . . 96

5.1 .2 Amostragem Estratificada . . . . . . . . . . . . . . 98 
5.1 .3 A transformação . . . . . . . . . . . . . . . . . . . . . 98

5.2 Simulação no ambiente Weka . . . . . . . . . . . . . . . 101

5.2 .1 Começando . . . . . . . . . . . . . . . . . . . . 102

5.2.2 Execução simples de linha de comando . . . . . . . . . 103

5.2 .3 Execução via ambiente visual . . . . . . . . . . . . . . 103

5.3 Metodologia de Testes . . . . . . . . . . . . . . . . . . . 109

5.3 .1 Aferindo o GA . . . . . . . . . . . . . . . . . 112

5.4 O uso do GA . . . . . . . . . . . . . . . . . . 112

5.5 Descrição do GA - para otimização dos parâmetros dos metódos 115

5.6 Descrição de uma execução dos Métodos no Weka . . . . . . 118

5.7 Função Objetivo . . . . . . . . . . . . . . . . . . . . . . . . 119

5.7 .1 Matriz de Confusão . . . . . . . . . . . . . . . . . . . . 119

5.7 .2 Principais indicadores . . . . . . . . . . . . . . 120

5.7 .3 Custos . . . . . . . . . . . . . . . . . . . . . 121

5.7 .4 Nossa função objetivo . . . . . . . . . . . . . . . . . 121

5.7 .5 O custo ajustado . . . . . . . . . . . . . . . 122

5.8 Uma breve discução sobre os parâmetros . . . . . . . . . . . 124

5.8 .1 Árvore de Decisão . . . . . . . . . . . . . . . . . . . . 125

5.8 .2 Redes Neurais . . . . . . . . . . . . . . . . . . . . . . . 125

5.8 .3 Naive Bayes . . . . . . . . . . . . . . . . . . . . . . 127

5.8.4 Redes Bayesianas . . . . . . . . . . . . . . . . . 127

5.8.5 Sistemas Imunolóligicos Artificiais . . . . . . . . . . . 128

6 Relatório dos resultados obtidos e Análise 131

6.1 Resultados parâmetros default . . . . . . . . . . . . . . 132

6.1.1 Parâmetros default - Execução padrão . . . . . . . . . 132

6.1.2 Parâmetros default - Execução Sensível ao Custo . . . 135

6.2 Resultados da otimização dos parâmetros . . . . . . . . . . 137

6.2.1 Resultados GA Execução Padrão . . . . . . . . . . . . . 137

6.2.2 Resultados GA sensível ao custo . . . . . . . . . . . . . 141

6.3 Discussão sobre os parâmetros ótimos - Execução Padrão . . . 144

6.3.1 Busca Semi-Exaustiva por parâmetros estáveis - NN

Execução Padrão. . . . . . . . . . . . . . . . . . . . . . 148

6.3.2 Busca Semi-Exaustiva por parâmetros estáveis - AIS

Execução Padrão. . . . . . . . . . . . . . . . . . . . . 152

6.4 Discussão sobre os parâmetros ótimos - Sensível ao custo . . . 155

6.4.1 Busca Semi-Exaustiva por parâmetros estáveis - NN

sensível ao custo. . . . . . . . . . . . . . . 157 
6.4.2 Busca Semi-Exaustiva por parâmetros estáveis - AIS sensível ao custo. . . . . . . . . . . . . . . 159

6.5 Sumário dos resultados. . . . . . . . . . . . . . . . . . 161

$\begin{array}{llr}7 & \text { Conclusões } & 169\end{array}$

8 Trabalhos Futuros 172

9 Anexos 181

9.1 Demonstrações . . . . . . . . . . . . . . . . . . . . . . . 181

9.2 Figuras e Tabelas . . . . . . . . . . . . . . . . 182 


\section{Capítulo 1}

\section{Introdução}

Nos anos recentes tem se observado o surgimento de vários algoritmos bio-inspirados para resolução de problemas de classificação e otimização, podemos citar Ant Colony [MGdL01], Redes Neurais [Ros62] e Sistemas Imunológicos Artificiais [dCT02b] e [dCZ].

Os estudos do sistema nervoso humano e de outros sistemas presentes em organismos vivos têm servido como fonte de inspiração para o desenvolvimento científico em várias frentes. Na inteligência artificial, várias pesquisas tentam criar sistemas artificiais para simular o funcionamento do sistema nervoso humano para, dessa forma, tomar decisões consideras inteligentes. Em janeiro de 2002, a renomada revista Nature [Kla02] publicou uma reportagem sobre sistemas imuno-baseados, elencando suas diversas aplicações, dando um enfoque especial a sua aplicação na proteção de computadores contra intrusos e na detecção de transações fraudulentas em sistemas transacionais. Essa mesma reportagem já aponta o futuro uso comercial de sistemas imunobaseados para detecção de fraude em sistemas transacionais para o ano de 2003. Apesar disso, não conhecemos trabalho cientifico que aplica Sistemas Imunológicos Artificiais em detecção de fraude. De fato, trabalhos sobre detecção de fraude em geral são raros, como aponta Phua et al. [PLSG05] em seu Survey. Ele indica a ausência de uma base de dados pública para aplicação de diversos métodos como a causa principal desse baixo número de publicações. Duas das publicações mais importantes sobre o assunto são [MTV00] que compara Redes Neurais e Redes Bayesianas na detecção de fraude em cartões de crédito, chegando a um resultado favorável as Redes Bayesianas, e [SFL $\left.{ }^{+} 97\right]$ que iniciou por apresentar um trabalho bastante relevante sobre detecção de fraude, porém finalizou por obter mais conclusões 
sobre a detecção de intrusos em redes de computadores.

Os objetivos deste trabalho foram: a aplicação de Sistemas Imunológicos Artificiais a dados de cartões de crédito, com a reprodução dos resultados obtidos por [MTV00] em relação a Redes Neurais e Redes Bayesianas, e uma comparação que incluísse, além desses, os métodos Naive Bayes e Árvores de Decisão. Essa comparação deveria levar em conta particularidades desses dados, por exemplo, o fato deles serem desbalanceados e por possuírem custos de falso positivo e negativo muito distintos. Também deveria levar em conta a necessidade de um ajuste paramétrico adequado para os diversos métodos envolvidos.

Prevenção à fraude é um assunto que sempre despertou interesse e investimento das instituições financeiras. O advento de novas tecnologias como telefone, redes de auto-atendimento (ATM - Automated teller machine) e sistemas de cartões de crédito incrementaram muito o volume de perda dos bancos. Nesses últimos anos, as fraudes em ambiente virtuais, principalmente a personificação (roubo de identidade) na Internet, têm levado os bancos para um ambiente no qual a investigação é muito mais difícil. Vivenciamos o nascimento de um novo paradigma que foca esforços na prevenção, em contraposição à velha ordem de que a repressão ao crime é mais importante que a prevenção. Veremos, no Capítulo 2, uma introdução do ambiente do mercado de cartões de crédito e algumas de suas especificidades e, posteriormente, introduziremos como a prevenção neste mercado é praticada.

Nesse contexto de prevenção à fraude, surgem importantes aliados na detecção de operações suspeitas: os Sistemas de Reconhecimento de Padrões (SRP) [TK06]. Os SRPs são capazes de aprender através de informações anteriores e classificar novas observações do evento em classes pré-determinadas ${ }^{1}$. Esses sistemas se utilizam do conhecimento adquirido, supondo que o fenômeno ocorrido se repita no futuro, para impedir que a fraude se realize. Isso será abordado em mais detalhes no Capítulo 3, onde falaremos sobre reconhecimento de padrões aplicados na detecção de fraude ${ }^{2}$.

O combate à fraude é um problema especialmente difícil do ponto de vista de modelagem estatística. São muitos os casos de operações legais até a observação de uma operação ilegal, pois se trata de um ambiente em que as classes (operações fraudulentas e operações legais) têm tamanhos desbalan-

\footnotetext{
${ }^{1}$ Atualmente, implementações de SRPs podem verificar milhares de transações por segundo, o que seria inviável para ser feito manualmente.

${ }^{2} \mathrm{Na}$ seção 3.7 em particular, apresentamos uma descrição resumida sobre os trabalhos que consideramos mais relevantes na área.
} 
ceados (skewed). Outro possível complicador em algumas áreas diz respeito à verificação de que um caso suspeito é de fato uma fraude. Tal verificação pode ser impossível ou de custo proibitivo. Isso também ocorre, guardadas as devidas proporções, no combate aos terroristas e às guerrilhas.

Neste trabalho, apresentamos e comparamos cinco dos principais métodos de SRP, aplicando-os na classificação de casos como suspeitos de serem fraudulentos ou legítimos, são eles: Árvores de Decisão, Naive Bayes, Redes Bayesianas, Redes Neurais e Sistemas Imunológicos Artificiais. Reservamos o Capítulo 4 para apresentarmos uma visão geral sobre cada um deles.

Como será visto no Capítulo 5, nossa comparação baseou-se em critérios de custos da fraude, ademais executamos otimizações utilizando um algoritmo genético para ajustar os parâmetros, a fim de atingir o melhor modelo possível gerado por cada método. Para verificar a convergência do algoritmo genético, realizamos uma busca exaustiva no espaço de parâmetros possíveis para o método de Árvores de Decisão.

Nossas execuções chegaram a resultados conclusivos quanto à ordem de redução de custos dos modelos gerados pelos métodos e a conjuntos de parâmetros melhor ajustados aos nossos dados para cada um deles. No capítulo 6, apresentamos um relatório de procedimentos, que nos levaram a estes resultados e as análises realizadas. Na seção 6.5 apresentamos um sumário mais rico em informação numérica dos resultados obtidos, encaminhandonos às conclusões finais que estão numa forma um pouco mais sintetizada, bem como mais generalizada, no capítulo 7 .

No capítulo 8, comentamos sobre as perspectvas de trabalhos futuros. 


\section{Capítulo 2}

\section{O Mercado de Cartões de Crédito e Prevenção à Fraude}

A missão de nosso trabalho foi a comparação de diversos métodos de classificação em dados desbalanceados. Nossos dados, provenientes de transações com Cartões de Crédito contendo transações fraudulentas e legítimas, representaram um terreno vasto para nossa pesquisa, como será visto nas partes seguintes. Reservamos este capítulo para contextualizar o leitor sobre o mercado de cartões de crédito, sua criação no mundo e no Brasil, descrevendo o funcionamento do cartão de crédito do ponto de vista técnico e operacional; na seqüência, tentamos definir e exemplificar o que é uma fraude; por fim, descrevemos uma parte do funcionamento da área de prevenção à fraude em uma instituição financeira.

Alertamos que esse capítulo não traz informação do ponto de vista computacional.

\subsection{O Mercado de Cartões de Crédito}

O Cartão de Crédito [LS02] no mundo segundo [His] surgiu nos Estados Unidos da América na década de 1920. Estas primeiras formas de cartões se assemelhavam em muito aos cartões de afinidades oferecidos hoje por redes de lojas de roupas, supermercados e postos de gasolina. Tais cartões eram oferecidos aos clientes mais fiéis, mantendo crédito para eles e eliminando o comércio fiado para os demais.

Em 1950, surgiu o primeiro Cartão de Crédito moderno, ainda sem o 
plástico que conhecemos hoje. O Diners Club era aceito, em seu lançamento, por 27 conceituados restaurantes nos EUA. Até hoje, o Diners Club continua como um dos grandes cartões desse mercado.

Em 1958, entram em cartaz dois outros cartões que se tornariam gigantes. A American Express lança o American Express Card, que logo veio a se chamar Amex, e o Bank of America lança o BankAmericard, que hoje é mundialmente conhecido como Visa.

Somente oito anos depois, em 1966, outro dos gigantes de hoje nasceu. Um conglomerado de bancos, conhecido como Interbank Card Association lançou o cartão que hoje conhecemos como MasterCard.

\subsubsection{No Brasil}

O mercado de Cartões de Crédito no Brasil seguiu o seguinte histórico:

1. 1954: O empresário tcheco Hanus Tauber (precursor dos cartões no Brasil), comprou nos Estados Unidos a franquia do Diners Club, propondo sociedade no cartão com o empresário Horácio Klabin.

2. 1956: Lançado no Brasil o cartão Diners Club, sendo a princípio um cartão de compra e não um cartão de crédito.

3. 1968: Lançado o primeiro cartão de crédito de banco, chamava-se ELO e foi criado pelo Banco Bradesco.

4. 1970: Foi fundada a Credicard, primeira emissora de cartões de crédito do país.

5. 1971: Formação de uma empresa pertencente a 23 bancos que, associados ao cartão internacional BankAmericard, lançaram o cartão Elo.

6. 1971: Foi fundada, no Rio de Janeiro, a Associação Brasileira das Empresas de Cartões de Crédito e Serviços - ABECS.

7. 1974: A sede da ABECS foi transferida para São Paulo.

8. 1977: A associação dos bancos foi desfeita e cada banco passou a emitir o seu cartão de crédito.

9. 1983: Foi lançado o cartão de débito. 
10. 1984: A Credicard compra o Diners Club no Brasil.

11. 1989: Lançado o primeiro cartão instantâneo de pagamento de benefício do INSS.

12. 1990: No governo Fernando Collor de Mello ocorre a abertura para o uso do cartão de crédito no exterior.

13. 1994: Plano Real acentua crescimento do cartão de crédito. Com a inflação baixa, a sobretaxa antes cobrada sobre transações pagas com esse meio de pagamento deixa aos poucos de existir, tornando o cartão de crédito um meio de pagamento muito atrativo.

\subsubsection{Tipos de Cartão de Crédito}

Atualmente, os tipos mais comuns de cartões encontrados são:

1. Nacional (Local): Operando somente no país origem do cartão.

2. Internacional (International): Funcionamento nacional e internacional, porém com serviços restritos.

3. Ouro (Gold): Funcionamento nacional e internacional, e com cesta de vantagem superior ao cartão internacional em viagens e programas de recompensas, porém apresenta anuidade superior ao internacional.

4. Platina (Platinum): Funcionamento nacional e internacional, e com cesta de vantagem contendo tudo que o Emissor é capaz de oferecer, porém apresenta maior anuidade dentre todos e a renda mínima para obter o produto é a mais alta.

Apesar da utilização desses tipos de cartão ser simples no ponto de vista do cliente, o operacionalização exige a participação de uma complexa organização entre os agentes.

\subsubsection{Funcionamento do Cartão de Crédito}

O Cartão de crédito moderno tem cinco agentes bem definidos envolvidos em seu funcionamento:

Portador (Card Holder), Estabelecimento (Merchant), Adquirente (Acquire), Bandeira (Brand) e Emissor (Issuer). 
1. Portador (Card Holder): o portador do Cartão de Crédito é o cliente, pessoa possuidora do Cartão, responsável por iniciar o funcionamento do sistema quando decide fazer algum pagamento ou saque lançando mão deste meio de pagamento eletrônico.

2. Estabelecimento (Merchant): o estabelecimento, aqui, diz respeito a qualquer empresa ou pessoa jurídica credenciada para aceitação de Cartão de Crédito através de um equipamento específico para esse propósito.

3. Adquirente (Acquire): a principal função dessa empresa é credenciar, supervisionar e repassar os valores de compras/saques aos estabelecimentos que aceitam Cartão de Crédito. Responsável pela implantação e manutenção dos dipositivos de captura de transação, chamadas de POS (Point of Sales) e dos softwares de captura das transações.

As principais receitas dos Adquirentes são: o financiamento dos lojistas (RAV - Recebimento adiantado de valores - empréstimo feito por ele ao lojista, adiantando a receita que o lojista tem a receber do adquirente); o intercâmbio, parte percentual de cada transação que passa pelo sistema de Cartão de Crédito que é dividida entre o Adquirente; a Bandeira e o Emissor daquele cartão segundo critérios de negociação específicas; e por último, o aluguel mensal dos equipamentos ou softwares de captura de transações.

No Brasil, quase todas as Bandeiras (Visa, MasterCard, Amex, Aura, HiperCard, dentre outras) possuem Adquirente próprio, ou seja, cada Adquirente possui monopólio da filiação para uma determinada Bandeira, de modo que cada pequeno ou grande estabelecimento comercial tem que negociar e locar dispositivos de capturas de transação de cada um destes monopólios. Discussões ainda embrionárias no governo brasileiro tentam melhor regular o livre comércio no setor.

4. Bandeira (Brand): Originalmente ela foi responsável por todas as funções no Cartão de Crédito, e isso ainda acontece na Bandeira Amex, mas para as outras, suas funções são:

(a) Definir regras e políticas (Relacionamento entre emissores e adquirentes).

(b) Operar rede global de telecomunicações (Private Networks - não virtuais) garantindo interoperabilidade. 
(c) Executar Marketing Institucional.

(d) Pesquisar e desenvolver novas tecnologias/serviços.

As principais receitas das bandeiras vêm do intercâmbio, dos contratos de concessão para os Emissores e Adquirentes operarem a rede (Bandeira) em questão, tarifa para tráfego de documentos em papel, e por último, de multas aplicadas pelo não cumprimento de regras e prazos.

5. Emissor (Issuer): Os Emissores são, em sua maioria numérica, bancos responsáveis por distribuírem os Cartões de Créditos aos seus clientes após aprovação de risco de crédito por políticas próprias de cada instituição. No Brasil, até 2005, boa parte dos Cartões de Créditos emitidos pertenciam a emissores independentes dos bancos de varejo. Os principais emissores independentes eram Credicard (hoje dividida entre o Citibank e Itaú), Fininvest (Pertencente ao Unibanco) e ibi.

As principais receitas dos emissores vêm do financiamento rotativo dos clientes, do intercâmbio, das anuidades e de seguros ou serviços agregados ao produto Cartão.

Todos esses agentes interagem através do processo de autorização de uma transação, que ocorre, por exemplo, quando um portador executa uma compra em estabelecimento comercial.

\subsubsection{Autorização numa operação de Cartão de Crédito}

A Figura 2.1 mostra um exemplo de um cliente utilizando seu Cartão de Crédito em um estabelecimento comercial, que transmite a transação para o adquirente e deste para a Bandeira. A Bandeira envia para o Emissor do cartão que utilizando critérios de crédito próprios, como disponibilidade de limite, cliente em atraso ou apontamento no sistema de detecção à fraude, pode decidir por aprovar, negar ou referir uma transação. Transações referidas são transações onde se pede que o cliente entre em contato com o Emissor ou Bandeira (dependendo da localidade), para que se faça confirmações de dados do portador. Após o Emissor decidir o que ele quer que seja feito com essa transação, essa resposta retorna todo ciclo, chegando de volta ao estabelecimento, onde o cliente a visualiza. E tudo isso deve ocorrer em limite de tempo definido que gira em torno de 10 segundos. 


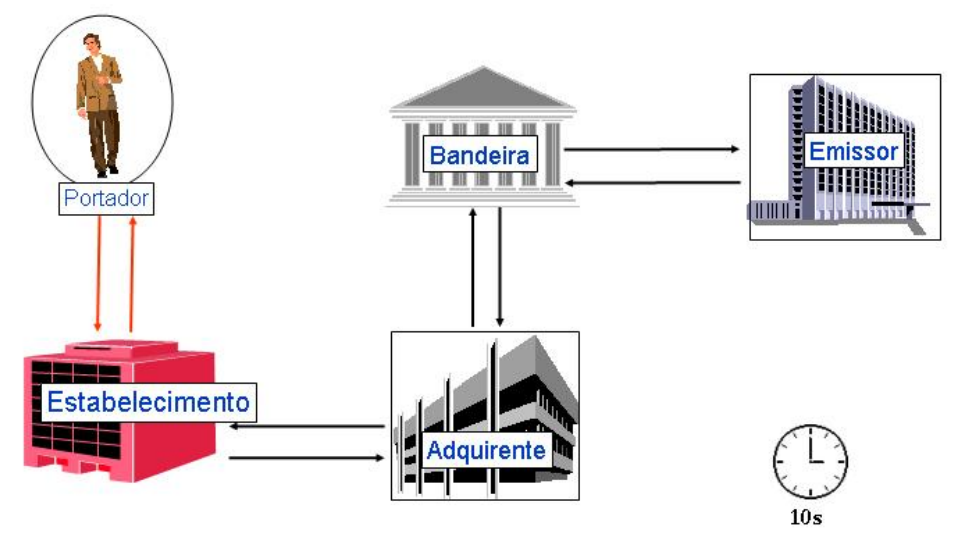

Figura 2.1: Sistema de autorização normal

Existem muitos detalhes dos sistemas autorizadores de Cartões de Crédito que são interessantíssimos, usando muitas técnicas sofisticadas de comunicação, algoritmos paralelos, criptografia e algoritmos para evitar intrusos. Estes sistemas pretendem ser os mais seguros contra invasão via computadores externos dentre todos os sistemas bancários.

Em especial, o sistema de autorização de Cartões de Crédito carrega em si algumas inteligências de negócio muito competentes que os mantém disponíveis por muito mais tempo que qualquer outro sistema bancário, uma delas é conhecida como regras de STAND-IN.

\subsubsection{Os tipos de dispositivos de captura disponíveis}

Em um processo de autorização em Cartões de Crédito a transação se inicia através da captura dos dados do cartão e da compra utizando-se de alguns tipos dispositivos, esses dispositivos podem ser de diversas formas e tipos, abaixo enumeramos alguns existentes hoje:

1. POS (Point of Sale): neste sistema a transação utiliza máquina eletrônica, chamada de POS ${ }^{1}$. Existem POS com e sem fio.

\footnotetext{
${ }^{1}$ Esse é o modelo de captura mais difundido no Brasil, quase $100 \%$ das transações são
} 


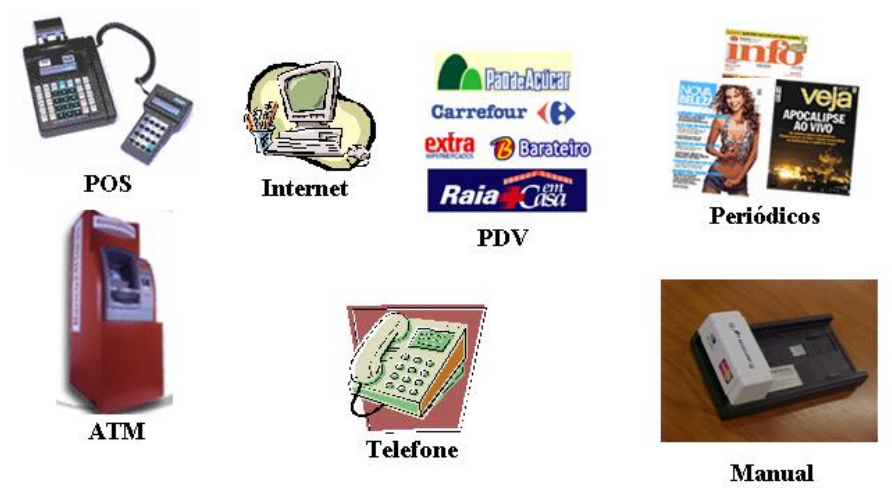

Figura 2.2: Maneiras de entrada de uma transação

2. Manual: Transação mecânica manual através do aparelho conhecido como "mata pulga" em estabelecimentos comerciais, as transações ficam gravadas em um papel utilizando papel carbono como tinta para escrita e copiando os dados em auto-relevo do cartão. ${ }^{2}$

3. Telefone:

(a) Após uma transação por "mata pulga" há a necessidade de entrar em contato pelo telefone com o Adquirente para requisitar o código da autorização.

(b) Compra por telefone sem a presença física do cartão.

4. ATM (Caixa eletrônico de auto-atendimento):

(a) Saque CASH.

(b) Pagamento de contas com cartão de crédito.

capturadas dessa forma.

${ }^{2}$ Grande parte dos comerciantes brasileiros usam esse aparelho para contingência na inatividade do POS. Bastante utilizado em países como Bolívia e Peru. 
5. Internet: Compra em sites de venda na Internet.

6. Periódicos: Arquivo para processamento em Batch (processamento em um horário de baixo movimento bancário) contendo cartões para faturamento, enviado pelas editoras ou outros (provedor de Internet, cash managment, pedágios).

7. PDV: São os caixas eletrônicos que se comunicam com um POS especial, o qual emite a transação para o adquirente, muito utilizado em supermercado e empresas com muitos pontos de recebimento.

\subsection{Definindo Fraude}

Richard et al. [BH02] toma emprestado a definição do dicionário Oxford que caracteriza fraude como sendo: “- Ato criminoso; uso de representação falsa para conseguir vantagens injustas."

O site Wikipedia traz uma definição bastante completa e ampla de fraude que tomamos a liberdade de reproduzir neste trabalho.

Definição - wikipedia: Em Direito Penal, fraude é o crime ou ofensa de deliberadamente enganar outros com o propósito de prejudicá-los, usualmente para obter propriedade ou serviços dele ou dela injustamente. Fraude pode ser efetuada através de auxílio de objetos falsificados. No meio acadêmico, fraude pode se referir a fraude científica - a falsificação de descobertas científicas através de condutas inapropriadas - e, de uso comum, fraude intelectual significa a falsificação de uma posição assumida ou sugerida por um escritor ou interlocutor, dentro de um livro, controvérsia ou debate, ou uma idéia apresentada enganosamente para esconder conhecidas fraquezas lógicas. Fraude jornalística implica numa noção similar, a falsificação de "furos" jornalísticos. Fraudes podem ser cometidas através de muitos métodos, incluindo fraude de correspondência, por telefone, por meios de redes de computadores e por internet.

\subsubsection{Alguns tipos de fraude}

Nesta seção descreveremos alguns exemplos de tipos fraude comuns no mercado, alguns diretamente ligados aos eventos de fraude de nossa pesquisa, são eles: Fraude virtual (com uso de cartão de crédito), Phishing Scam (para 
roubo de informação de cartão de crédito), Clonagem (de cartão de crédito), Botnets ou Redes de Robôs (para roubo de informação de cartão de crédito), Pharming (para roubo de informação de cartão de crédito) e Banco Fantasma (para roubo de informação de cartão de crédito). Elencamos outros três não ligados a cartão de crédito, mais que achamos que seriam bons representantes das outras fraudes, a falsificação ou adulteração de cheques; o esquema da Nigéria e os falsos prêmios de loteria.

Fraude virtual:

As fraudes virtuais são fraudes efetuadas através da internet e que usualmente utilizam-se de softwares espiões. No Brasil, em 2005, esse tipo de fraude gerou um prejuízo recorde de $\mathrm{R} \$ 300$ milhões às instituições financeiras, entre elas os bancos e administradoras de cartões. A perda de 2005 representa $12 \%$ dos $R \$ 2,5$ bilhões faturados pelo comércio eletrônico brasileiro no período.

Fonte: http://www.wikipedia.com

Phishing Scam:

O Phishing Scam serve para capturar dados de identificação de uma pessoa, como nome, CPF e endereço para uso posterior por um fraudador. Suas características consistem basicamente no envio de e-mails fraudulentos, no qual o autor convence o usuário a baixar e executar um programa malicioso. Muitas vezes, o e-mail finge ser uma mensagem autêntica, proveniente de uma grande empresa, trazendo uma boa formatação, logotipos e outras características da empresa. Em outras ocasiões, é apenas um assunto curioso que leva a vítima a efetuar o download e executar o arquivo.

Fonte: http://linhadefensiva.uol.com.br

Clonagem:

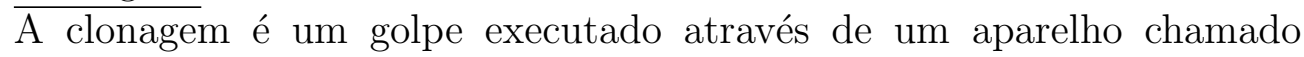
"chupa-cabra", utilizado por golpistas para sugar os dados dos cartões de crédito com o fim de cloná-los. Esses equipamentos são eventualmente encontrados em postos de gasolina ou outros estabelecimentos de grande movimento. Os dados do cartão são copiados para o dispositivo de captura de transações, são autenticados e posteriormente são inseridos em cartões virgens, os quais serão utilizados nos crimes.

Fonte: http://www.fraudes.org

Botnets ou Redes de Robôs:

As Botnets são formadas a partir de programas (os bots ou robôs), que possuem características de Cavalos-De-Tróia e Worms. Esses programas geralmente invadem os computadores explorando brechas de segurança ou 
induzem usuários desavisados a instalá-los em suas máquinas. Os computadores invadidos são, então, levados a se conectar a canais de IRC (Internet Relay Chat), uma rede de bate-papo online que aceita comandos de determinados softwares. Um atacante que controle tais canais consegue controlar também os computadores infectados com os bots e direcioná-los às ações maléficas que desejar. Estas ações incluem: ataques distribuídos de negação de serviço (DDoS); envio de spam; captura de dados privados no segmento de rede comprometido com o bot; captura do que é digitado no teclado do computador invadido; instalação de programas (adwares) para exibição de publicidade online e disseminação de novos softwares maliciosos.

Fonte: http://www.hsbc.com.br

Pharming:

O termo Pharming, que tem sido definido equivocadamente como uma evolução do Phishing Scam, pode ser compreendido como um método malicioso de desviar o acesso a um site de seu respectivo servidor legítimo. Quando alguém digita o endereço do site do banco em que tem conta (por exemplo, www.banco.com.br) este endereço é transformado pelo servidor DNS no número IP do servidor Web do banco, suponhamos 200.255.255.255. Quem faz esta transformação de nomes em números geralmente é o servidor DNS do provedor do usuário. Se este servidor estiver vulnerável a esse tipo de ataque, o usuário poderá ser redirecionado a uma página falsa hospedada, no servidor 80.000.000.001, que esteja sob controle de um golpista. Se a página falsa tiver sido especialmente preparada e for uma cópia fiel a página da banco, o cliente da instituição poderá inserir seus dados privados sem se dar conta de ter sido levado a um site fraudulento.

Fonte: http://www.hsbc.com.br

Banco Fantasma:

Com o advento da Internet e a difusão do uso da Internet Banking, tais bancos têm maior facilidade em aplicar os golpes. Eles apresentam-se freqüentemente como modernos bancos internacionais ou Offshore (operações de bancos nacionais no exterior) via Internet. Oferecem serviços variados que vão do Private Banking (serviço de investimentos e administração de patrimônios) até financiamentos internacionais para projetos ou capital de giro. Freqüêntemente, alguém apresenta-se como representante ou diretor de um destes bancos, propondo operações.

Fonte: http://www.fraudes.org

Falsificação ou adulteração de cheques:

$\overline{\mathrm{A} \text { falsificação trata-se de fazer cópias }}$ de documentos com intuíto de se 
passarem por originais, a exemplo de falsificação de talões de cheques ou contratos de negócio. Utilizando dados extraídos de um cheque roubado ou simplesmente os dados bancários roubados de alguém, os golpistas podem clonar (fazer cópias de boa qualidade ou, às vezes, redesenhar) talões inteiros de cheques imprimindo-os com uma impressora a jato de tinta ou laser de boa qualidade.

A adulteração consta em uma alteração de algum documento em favorecimento do golpista. Um exemplo deste golpe é a caneta que apaga. Na hora de preencher o cheque o golpista oferece uma caneta hidrográfica do tipo que apaga facilmente com uma simples borracha, como se fosse lápis.

Fonte: http://www.fraudes.org

Esquema da Nigéria:

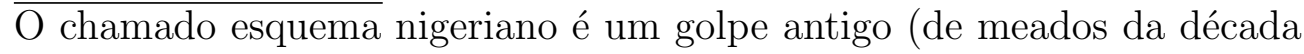
de 1920) que foi transportado do correio normal para o fax e, depois, para a Internet. Em geral, a mensagem é de alguém em algum país (normalmente africano, como Nigéria, Serra Leoa, Costa do Marfim) que pede ajuda para tirar do país uma enorme soma de dinheiro que estaria trancada por algum problema legal ou político prometendo uma rica recompensa em troca da ajuda. A vítima entrega seus dados bancários e é solicitada a pagar algumas taxas para a liberação dos valores. Só depois de perder muito dinheiro é que percebe ter sido enganada. A mensagem costuma vir em inglês, mas no Brasil já surgiu uma tradução do golpe nigeriano, com os mesmos argumentos, mas com o texto em português.

Fonte: http://www.hsbc.com.br

Falsos prêmios de loteria:

Muito parecidas com o esquema nigeriano, as fraudes que utilizam prêmios, loterias e concursos também são antigos golpes adaptados para a tecnologia atual. As mensagens são enviadas para muitas pessoas, embora dêem a impressão de serem personalizadas, e comunicam que o destinatário foi contemplado em um sorteio, ganhou na loteria ou foi escolhido para receber com exclusividade determinado produto ou benefício. Para que possa receber o prêmio, a pessoa deve pagar algumas taxas ou fornecer seus dados pessoais. Também são usados nomes de prêmios e concursos reais, como a loteria tradicional de Natal na Espanha, El Gordo, que recebe apostas do mundo inteiro e é uma das mais utilizadas para este tipo de fraude.

Fonte: http://www.hsbc.com.br 


\subsubsection{Código Penal Brasileiro}

Por fim, no Código Penal Brasileiro, a fraude está declarada sob o artigo $\mathrm{n}^{\circ} 171$.

CAPÍTULO VI DO ESTELIONATO E OUTRAS FRAUDES

Art. 171 - Obter, para si ou para outrem, vantagem ilícita, em prejuízo alheio, induzindo ou mantendo alguém em erro, mediante artifício, ardil, ou qualquer outro meio fraudulento: Pena - reclusão, de um a cinco anos, e multa.

$\S 1^{\circ}$ - Se o criminoso é primário, e é de pequeno valor o prejuízo, o juiz pode aplicar a pena conforme o disposto no art. $155, \S 2^{\circ}$.

$\S 2^{\circ}$ - Nas mesmas penas incorre quem:

Disposição de coisa alheia como própria

I - vende, permuta, dá em pagamento, em locação ou em garantia coisa alheia como própria; Alienação ou oneração fraudulenta de coisa própria

II - vende, permuta, dá em pagamento ou em garantia coisa própria inalienável, gravada de ônus ou litigiosa, ou imóvel que prometeu vender a terceiro, mediante pagamento em prestações, silenciando sobre qualquer dessas circunstâncias; Defraudação de penhor

III - defrauda, mediante alienação não consentida pelo credor ou por outro modo, a garantia pignoratícia, quando tem a posse do objeto empenhado; Fraude na entrega de coisa

IV - defrauda substância, qualidade ou quantidade de coisa que deve entregar a alguém; Fraude para recebimento de indenização ou valor de seguro

V - destrói, total ou parcialmente, ou oculta coisa própria, ou lesa o próprio corpo ou a saúde, ou agrava as conseqüências da lesão ou doença, com o intuito de haver indenização ou valor de seguro; Fraude no pagamento por meio de cheque

VI - emite cheque, sem suficiente provisão de fundos em poder do sacado, ou lhe frustra o pagamento.

$\S 3^{\circ}$ - A pena aumenta-se de um terço, se o crime é cometido em detrimento de entidade de direito público ou de instituto de economia popular, assistência social ou beneficência. 


\subsection{Introdução a Prevenção à Fraude em Cartões de Crédito}

Nesta seção descreveremos as modalidades de fraude que ocorrem no universo de cartões de crédito, enumeraremos os custos financeiros e não financeiros que uma fraude pode gerar a uma instituição, no final mostraremos com geralmente as equipes de prevenção à fraude [Mon04] se dividem em equipe em uma estrutura do tipo ciclo, chamado de ciclo de prevenção à fraude.

Iniciamos enumerando as principais modalidades de fraude.

\subsubsection{As principais modalidades de fraude}

1. Perda ou Roubo: O cliente perde seu cartão ou tem seu cartão roubado, e alguma pessoa não autorizada tenta realizar transações com ele. Como normalmente o fraudador desconhece o limite de crédito disponível do cliente, o que se observa é uma seqüência de transações de valores pequenos e algumas transações negadas de valores maiores que o disponível até que se descubra alguma transação que caiba no limite de crédito.

2. Extravio de Cartão pelo correio ou entregador (NRI - Never Received Issuance): Esse tipo de fraude ocorre quando o cartão é extraviado antes que chegue as mãos do cliente de destino. Esse tipo de fraude é pouco comum, pois os cartões trafegam bloqueados e o fraudador precisa dos dados do cliente honesto para desbloqueá-lo.

3. Fraude de Proposta (FA - Fraud Application): Um fraudador tenta criar uma pessoa fictícia ou usa dados roubados de alguma pessoa para abrir uma conta de cartão de crédito. Na vasta maioria das vezes, o endereço apresentado diverge do endereço do cliente honesto, que muitas vezes nunca entrou em contato com a instituição. Modelos de Fraud Application e cruzamentos de informações com bureaus ${ }^{3}$ internos e externos (como a Serasa e o ACSP) são altamente eficazes para detecção.

\footnotetext{
${ }^{3}$ No mercado financeiro um bureau é uma instituição responsável pela operacionalização de algum compartilhamento de informação. Esse bureau pode ser interno, onde o compartilhamento acontece entre departamentos de uma mesma empresa, ou externo, onde o compartilhamento se dá entre as diferentes empresas associadas ao bureau.
} 
Depois que um falso cliente ingressa em uma instituição é muito difícil identificar que se trata de um fraudador, entretanto, quando identificada, esse tipo de fraude permite praticar a repressão, pois pode-se requisitar que o falso cliente compareça a agência para receber o cartão e ser preso em flagrante.

4. Invasão de Conta (ATO - Account Take Over): O fraudador em posse dos dados de um cartão de crédito e de dados pessoais de um cliente honesto pode se dirigir a uma instituição e tentar se passar por esse cliente, e pedir um cartão de crédito para que ele faça uso.

5. Falsificação Manual (MC - Manual Counterfeit): Qualquer tipo de adulteração de documento. No cartão de crédito pode ocorrer com a adulteração do comprovante de venda (CV) de autorizações manuais antes de enviá-los pelo correio para o Adquirente. Esse tipo de fraude é pouco comum em cartões de crédito no Brasil, pois a vasta maioria de transações são digitais, e trata-se de uma fraude que só beneficiaria o comerciante mal intencionado.

6. Falsificação Eletrônica (Skimming): A falsificação eletrônica ocorre quando o fraudador, em posse de algum equipamento eletrônico parecido com o POS, faz cópia da trilha (dados impressos na tarja magnética) do cartão de crédito, e posteriormente gera um clone desse cartão.

7. MOTO - Mail Order Or Telephone Order (Internet): Em posse dos dados do cartão de crédito (sem ter o cartão) o fraudador tenta fazer uso desses dados para realizar compras através da Internet ou telefone.

Deste ponto para frente, desconsideraremos do objeto de nosso estudo as transações fraudulentas cuja origem sejam NRI, FA e MC, pois essas modalidades possuem técnicas específicas muito mais eficientes que métodos de classificação para evitá-las, iniciando por controles manuais e internos mais rígidos, penalidades mais efetivas e detecção via informação coincidente.

A seguir enumeramos alguns exemplos de custos financeiros e não financeiros que uma transação fraudulenta pode trazer para a instuição ou para o cliente da instituição. 


\subsubsection{Custos tangíveis da fraude (financeiros)}

1. Perdas de Fraude: Perda financeira decorrente do uso indevido do cartão.

2. Investigação: Custo da investigação e prisão do fraudador.

3. Re-emissão do Cartão e Entrega.

4. Chamadas no atendimento a clientes.

5. Intercâmbio (Requisições e disputas com as Bandeiras): Em alguns casos é possível recuperar a perda financeira, mas esse processo tem um custo.

6. Custo das transações referidas: Tarifa paga à bandeira para cada transação negada por desconfiança de fraude, quando a quantidade de negadas por esse motivo ultrapassa um certo ponto de corte.

7. Cancelamento de Cartões: clientes cancelando seus cartões e migrando para concorrência.

8. Custos de boletim de proteção com as Bandeiras: Custo para inclusão e manutenção de números de cartões na "lista negra" mantida nas Bandeiras.

9. Potencial redução de receitas.

10. Redução de Market Share: Redução do tamanho da instituição e perda de posição para algum concorrente.

\subsubsection{Custos intangíveis da fraude (não financeiros)}

1. Insatisfação do Cliente.

2. Sentimento de violação e vulnerabilidade em relação à Empresa.

3. Ameaça ao negócio e às pessoas ligadas a ele (funcionários e terceiros).

4. Perda de lealdade à marca e às Bandeiras. 
5. Custo de Oportunidade: O investidor (sócio) da instituição poderia estar investindo seu dinheiro em algo menos arriscado do ponto de vista de fraude, podendo obter maior retorno do investimento (ROI).

Para evitar ou reduzir os impactos desses custos sobre o négocio, as empresas geralmente estruturam uma área de prevenção à fraude em um formato circular.

\subsubsection{Ciclo de Prevenção à Fraude}

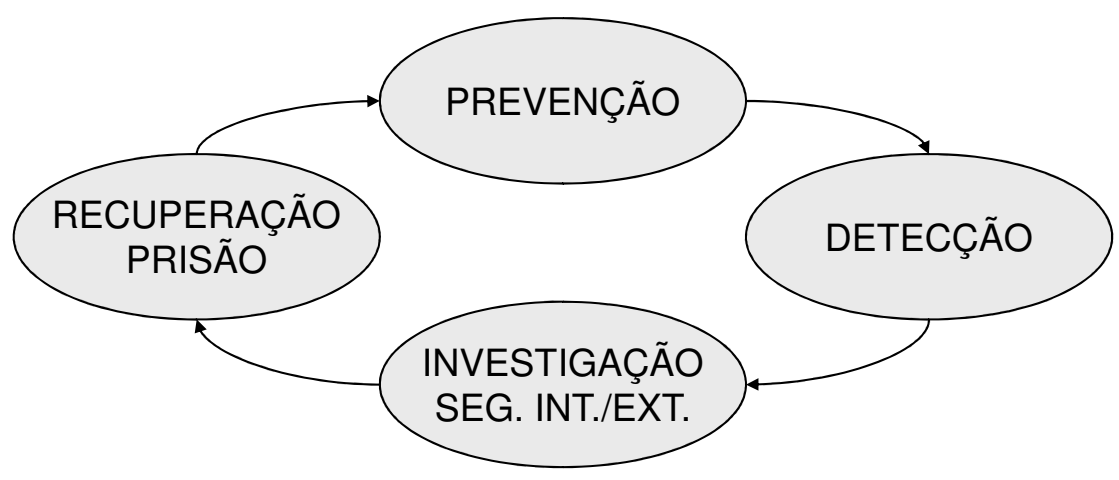

Figura 2.3: Ciclo de fraude

O ciclo de fraude, figura 2.3, corresponde a um anel contínuo e ininterrupto que passa da prevenção para detecção, depois investigação e recuperação.

1. Prevenção: opera no âmbito da construção de sistemas e regras para que pessoas maliciosas não consigam sequer tentar alguma fraude.

2. Detecção: é responsável por identificar e classificar uma transação potencialmente fraudulenta como sendo uma fraude no menor tempo 
possível. A detecção de fraude possui dois principais modos, o modo Automático e o modo Manual. ${ }^{4}$

3. Investigação: É responsável por investigar como uma determinada fraude ocorreu, descrevendo para as outras áreas o Modus Operandis (modo de operação) do fraudador. Em várias empresas coordena junto com a Prevenção as alterações sistêmicas ou de procedimento para que aquele Modus Operandis seja extirpado da instituição.

Uma outra atribuição importantíssima dessa área é a investigação e identificação do fraudador.

4. Recuperação (intercâmbio): área responsável por tentar a recuperação do valor financeiro perdido da seguradora, da Bandeira, ou do estabelecimento comercial, ou ainda, devolver a cobrança ao cliente caso seja verificado que a transação realmente foi realizada por este. Essa disputa respeita regras bem estipuladas e regidas pela Bandeira.

Apesar de descrevermos todas as partes do ciclo, nossos testes constam de comparações de técnicas usadas, ou com potencial de serem usadas, na detecção de fraude (ver figura 2.3), e será isso que faremos nos cápitulos seguintes, começando por descrever o reconhecimento de padrão aplicado na detecção de fraude, na sequência mostraremos os cinco métodos testados e depois o resultado das comparações.

\footnotetext{
${ }^{4}$ Manteremos nossa atenção no modo automático, conduzido por softwares incumbidos de classificar as transações segundo uma pontuação (Score) de potencial fraude, e posteriormente uma ação é tomada baseada nessa pontuação. No modo manual, um funcionário do Emissor entra em contato com o cliente. Neste contato, usualmente telefônico, é feita a confirmação da procedência da transação suspeita.
} 


\section{Capítulo 3}

\section{Reconhecimento de padrões aplicado na detecção de Fraude}

Os sistemas de reconhecimento de padrão [TK06] são ferramentas capazes de aprender através de informações anteriores e classificar novas observações do evento em classes pré-determinados, usando para isso o conhecimento adquirido com informação passada supondo que o fenômeno ocorrido se repetirá no futuro.

O assunto de reconhecimento de padrões é bastante amplo e mereceria vários livro se fôssemos abordar todos os aspectos relacionados, mesmo se restringíssemos o assunto somente a reconhecimento de padrões relacionado à detecção de fraude, ainda assim, teríamos assunto para um livro. De tal maneira, que nos restou selecionar alguns dos assuntos das áreas de reconhecimento de padrões e modelagem que cremos ser de extrema importância para a compreensão dos testes que nos propusemos neste trabalho. O primeiro assunto a tratarmos discorre sobre dados desbalanceados, que em detecção de fraude é uma constante. Em seguida, tratamos de dados ausentes, que é um problema de alto impacto quando lidamos com dados desbalanceados. Depois falamos sobre algumas das variáveis que em nossa experiência costumamos encontrar no mercado para classificação de transações como prováveis fraudes e transações tipicamente legítimas. Na seção seguinte citamos, segundo nossa experiência, algumas das tipificações de variáveis mais comumente encontradas em detecção de fraude, e em seguida mostramos como geralmente são feitas as categorizações das variáveis contínuas ou das variáveis discretas em novas variáveis com um número reduzido de categorias. Posteriormente, discutimos sobre amostragem, com um especial foco ao conjunto de bases de 
desenvolvimento e validação. Em seguida apresentamos um breve resumo do que encontramos sobre as medidas de desempenho mais usadas na literatura. E, finalmente, na última seção do cápitulo, mostramos que estamos utilizando a metodologia de desenvolvimento de modelos conhecida como modelagem supervisionada, e mostramos outros dois tipos de metodologias passíveis de serem arquitetadas, porém com menor eficácia.

\subsection{Dados desbalanceados (Skewed data)}

O problema da detecção de fraude é essencialmente um problema com dados desbalanceados. Dados desbalanceados acontecem em uma base de dados quando, em alguma das classes, ocorre um número muito superior que as demais.

Em instituiçoes financeiras, temos muitas transações legítimas, para encontrar uma única transação de fraude. A dimensão média deste número no mercado brasileiro deve girar em torno de 5 transações fraudulentas para cada 10000 transações legítimas. Essa informação não é muito difundida no mercado, o número mais comum é em volume financeiro que gira em torno de $\mathrm{R} \$ 12,00$ de fraude para cada $\mathrm{R} \$ 10.000,00$ em compras ou saques, chamamos esse dado corriqueiramente de 12bps (lê-se: doze basis points).

Esse desbalanceamento é um fator que se torna modelagem nesse ambiente mais díficil, principalmente porque testes estatísticos clássicos como $\mathrm{P}$-valor costumam indicar boa aderência para um modelo que considere todas as transações como legítimas, mesmo que nenhuma fraude tenha sido evitada por esse modelo.

Outro problema é a variabilidade. Devido à baixa quantidade de fraudes, geralmente enfrentamos o problema da alta variabilidade que torna os modelos clássicos pouco duráveis ou em muitas vezes ineficientes até em um teste de reamostragem da base de desenvolvimento.

No mercado costuma-se usar duas estratégias para lidar com dados desbalanceados:

1. No action: Consta em simplesmente ignorar a existência do problema.

2. Reponderação: Escolher todas as transações dos cartões onde houve fraude $(\mathrm{F})$ e todas as transações de um número $\mathrm{L}$ de cartões onde não houve fraude. Fazer $\mathrm{L}=9^{*} \mathrm{~F}$, dessa forma será obtido um número de $10 \%$ de transações fraudulentas na base de desenvolvimento. Alguém 
pode preferir usar uma base mais balanceada, porém isso se torna muito perigoso quando elimina em muito o comportamento dos cartões não fraudados. Outro ponto importante a ser observado é que em uma base de desenvolvimento artificialmente balanceada as medidas de desempenho já não refletem a realidade.

Ademais, usa-se métodos não tradicionais para construção de modelos para aplicações em deteç̧ão de fraude. Haja visto que que os métodos de regressão linear ou logística, bastantante utilizados em diversas aplicações em instituições financeiras, baseiam-se em testes de P-valor, que para dados desbalanceados geralmente chegam a modelos que classificam todas as transações como legítimas.

\subsection{Dados ausentes (Missing data)}

O problema de dados ausentes que geralmente apresenta pouca importância quando falamos em bases balanceadas, torna-se de importância bastante relevante quando lidamos com dados desbalanceados.

Para dados desbalanceados, não é incomum, caso desavisadamente criemos uma variável contendo uma categoria cuja valoração represente um valor ausente (missing), e essa categoria de valor ausente apresente uma alta força no modelo final.

Como nosso foco foi comparar diversos métodos de classificação, resolvemos evitar esse problema em nossa modelagem selecionando apenas variáveis que não possuíam qualquer valor ausente. Isso afastou uma influência ou um erro indesejado nos modelos que teria atrapalhado nossas comparações.

\subsection{Tipo de dados utilizados em prevenção à fraude}

Nenhum dos artigos sobre detecção à fraude que encontramos [PLSG05, BH02, MTV00, vH05, MkTVM01] apresenta qualquer indicação relevante sobre que tipo de informação é utilizada para detecção da fraude em cartões de crédito. Verificamos que no caso de [vH05] foi apresentada alguma discussão sobre variáveis utilizadas em detecção de fraude em telefonia, mas para o caso de cartões de crédito, nos arriscamos a dizer que essa não discussão 
sobre variáveis se deve principalmente a segurança dos sistemas de proteção das empresas e também a fatores de sigilo bancário.

Abaixo enumeramos algumas das principais classes de informação utilizadas para detecção e para cada classe são apresentados alguns exemplos de possíveis variáveis preditoras.

1. Demográficas do cliente:

(a) Lista de variáveis que se relacionam à praça (cidade ou região) de origem do cartão.

(b) Data de expiração do cartão.

(c) Variante do cartão.

(d) Limite.

(e) MOB (months on book).

2. Demográficas do estabelecimento:

(a) Lista de variáveis que se relacionam a praça (cidade ou região).

(b) MCC (Ramo do estabelecimento).

(c) Porte do estabelecimento (isso é possível ser identificado através de uma correta leitura da tabela de MCCs).

(d) Indicador de é ou já foi POU (Point of Utilization).

(e) Indicador de é ou já foi POC (Point of Compromise).

3. Perfil do Cliente:

(a) Lista de MCC mais utilizados por esse cliente.

(b) Ticket médio.

(c) Ocupação média.

(d) Valor de Pico nos últimos 12 meses.

(e) Indicador de uso anterior na Internet.

(f) Indicador de uso anterior internacional.

(g) Indicador de uso anterior em MOTO. 
(h) Indicador Transactor (cliente que paga a fatura em sua totalidade)/Revolver (cliente que paga parte da fatura, entre o mínimo e o total, rolando o saldo com juros para o próximo mês).

4. Perfil de Fraude:

(a) O país/cidade pertence a uma lista de países em quarentena?

(b) É uma transação real seguida de um teste anterior?

5. De Velocidade:

(a) Tempo desde a última transação.

(b) Número de transações (negadas/aprovadas) na última hora.

(c) Número de transações (negadas/aprovadas) no último dia.

(d) Número de transações (negadas/aprovadas) no último mês.

(e) Montante utilizado (aprovado) na última hora.

(f) Montante utilizado (negado) na última hora.

(g) Montante utilizado (aprovado) no último dia.

(h) Montante utilizado (negado) no último dia.

(i) Montante utilizado (aprovado) no último mês.

(j) Montante utilizado (negado) no último mês.

\subsection{Estruturação dos dados}

Os dados dentro de um banco de dados podem, sem perda de generalidade, ser considerados de três formas [BL97]:

1. Contínuos: Dados numéricos contínuos. Exemplos: 12.2, 133, ou Pi. Possuem ordem, e casas decimais.

2. Ordinais: Representam categorias com ordem, isto é, dada uma constante qualquer, é sempre possível determinar qual é a constante que a precede, ou qual é a constante que lhe sucede. Exemplo: $1=$ Cartão Nacional, 2 = Internacional, $3=$ Ouro e $4=$ Platinum. 
3. Categóricos: Representam categorias sem ordem. Exemplo: sexo (Masculino ou Feminino são valorações para o atributo sexo, porém não possuem ordem).

Devido ao grande número de métodos e vários deles lidarem bem apenas com dados categorizados, utilizamos a categorização para permitir a comparação entre esses diversos métodos.

\subsubsection{Categorização (Discretização ou Grouping)}

Para os nossos testes consideramos categorizar as variáveis em no máximo 10 grupos, de 0 até 9 , no intuito de manter cada categoria com percentual razoável de transações, além disso, um único dígito para cada atributo é providencial para o método AIS.

Para determinar como fazer as quebras, executamos as estratégias que consideramos mais apropriada para cada variável dentre as três indicadas abaixo [LS02]:

1. Faixas de tamanho fixo (binning): Podemos quebrar uma variável contínua x que varia entre 0 e 99 em 10 grupos de tamanho 10. Caso algum grupo fique com menos de $5 \%$ da população original, recomendamos que o grupo seja dividido em 9 quebras, e caso o problema persista, execute menos quebras até que todos os grupos tenham pelo menos $5 \%$ dos casos. Observe que isso sempre é válido para o caso em que existe apenas 1 grupo.

2. Quebra em percentil: Este tipo de quebra garante que tenhamos o mesmo percentual, por exemplo, $10 \%$, em cada faixa. Para isso precisamos fazer faixas de tamanhos variáveis. Um Algoritmo para encontrar tais quebras pode ser:

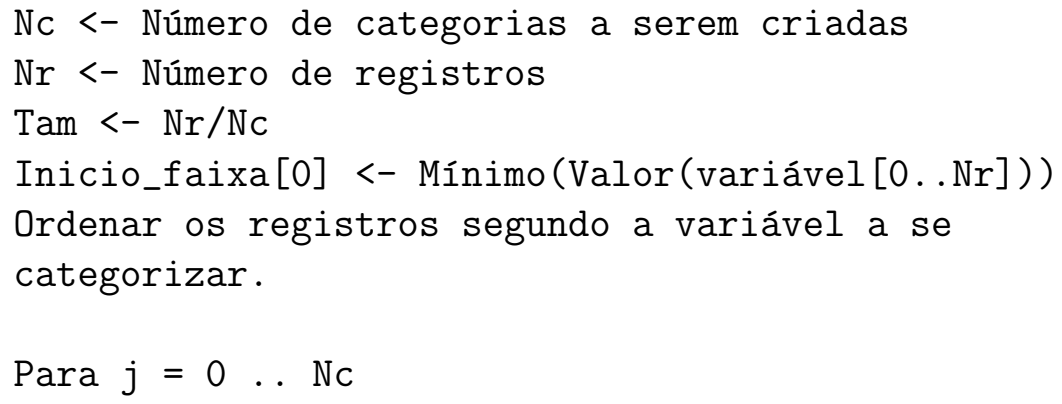




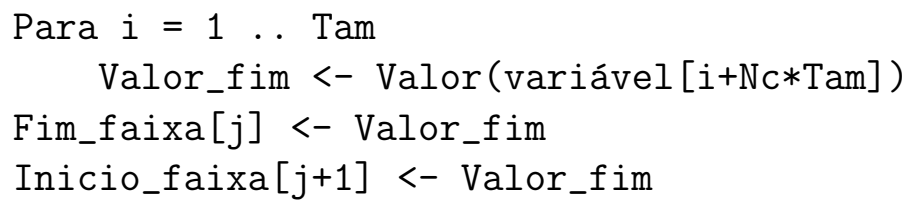

3. Quebra usando análise bi-variada: Esse último método consta em tentar fazer quebras que melhor separem os valores da variável resposta. É bom lembrar que a nossa variável resposta é fraude/não fraude.

Para fazer esse tipo de categorização é importante verificar um crescimento ou decrescimento da odds ratio (quantidade de fraude dividido pela quantidade de não fraude, chamada por alguns autores como razão de chance) com o crescimento do valor da variável a ser categorizada. Caso isso não seja possível, esse é um forte indício que essa variável deva ser descartada. Um método usualmente usado para escolher variáveis a serem utilizadas na modelagem é conhecido como método Stepwise ou Stepwise Regression, esse é um método de regressão iterativo que inclui variáveis preditoras de maneira automática baseado em um teste estatístico, usualmente teste $\mathrm{F}$ ou teste T. Para mais detalhes ver [Sta88].

\subsection{Amostragem}

Quando criamos um modelo, precisamos, antes de investir dinheiro, saber se ele é um modelo que tem uma boa previsão. Para facilitar essa tarefa é recomendado a quebra da base de dados em dois subconjuntos, em nosso caso optamos por $70 \%$ para desenvolvimento e $30 \%$ para validação do modelo. É importante garantir que as proporções das classes de fraude e de não fraude se repitam em cada uma das bases (desenvolvimento e validadação). Para fazer isso podemos fazer uma amostra estratificada, isto é, separam-se as classes em dois grupos $\mathrm{F}$ e $\mathrm{NF}$, tomam-se aleatoriamente $70 \%$ de cada grupo para a amostra de desenvolvimento e $30 \%$ de cada grupo para a amostra de validação.

Após esse teste, que é conhecido como desenvolvimento e validação, uma terceira base de dados pode ser usada. Essa base deve ser construída nos mesmos conceitos da base anterior que fora quebrada em duas, porém essa nova base terá uma data de referência posterior à primeira, ou seja, ela conterá dados mais recentes, e aplicaremos nosso 
modelo a essa base medindo seu desempenho (Escolhemos chamar essa parte de avaliação da aplicação). Essa técnica é especialmente útil, pois sabemos que os modelos de detecção à fraude se deterioram rapidamente, porém não se encontram artigos mostrando como medir o tempo de deterioração do modelo ${ }^{1}$.

\subsection{Medidas de desempenho}

As medidas de desempenho mais comuns encontradas em nossas leituras foram acurácia (ou assertividade total) que corresponde a quantidade de casos classificados corretamente dividido pelo total de casos, o percentual de falso positivo (False Positive Rate) que em nosso caso de detecção de fraude corresponde a quantidade de casos classificados como fraude mas que na verdade não são fraudes, o percentual de falso negativo (False Negative Rate) que em nosso caso de detecção de fraude corresponde a quantidade de casos classificados como não fraude mas que na verdade são fraudes.

Além dessas medidas, em estatística, existem três maneiras importantes usadas para avaliar o desempenho de modelos, são elas: O teste Kolmogorov-Smirnov (KS) [CLR67], o coeficiente de Gini (Gini) [Gin12] e a curva Roc (ROC Curve) [Spa89], o teste Kolmogorov-Smirnov é usado para determinar se duas distribuições acumuladas, digamos distribuição percentual acumulada de fraudes e distribuição percentual acumulada de não fraudes, diferem uma da outra, o valor do KS corresponde ao valor da máxima diferença dos percentuais acumulados entre as duas distribuições. O Coeficiente de Gini é uma medida de desigualdade que consiste em um número entre 0 e 1 , onde 0 corresponde à completa igualdade entre as distribuições acumuladas e 1 corresponde à completa desigualdade. Uma curva ROC é uma demonstração bidimensional da performance de um classificador (pode ser facilmente visualizado com uma curva semelhante a uma $\ln (\mathrm{x})$ em um gráfico bidimensional). O método mais comum para realizar comparações usando

\footnotetext{
${ }^{1}$ Em nossos testes iniciamos pensando em realizar uma avaliação do tempo de deterioração para cada uma dos métodos comparados neste trabalho. Porém com o passar do tempo o escopo do trabalho cresceu muito que resolvemos deixar essa parte para trabalhos futuros.
} 
curva Roc é a redução da curva a um valor escalar, para isso calcula-se a área abaixo da curva ROC (AUC - area under the curve) $)^{2}$. Para mais detalhes sobre essas medidas ver [Sta88, WF05].

Em detecção de fraude, outras duas medidas também são geralmente usadas, são elas [Mon04]: O Hit Rate e o Detection Rate. O Hit Rate (confiança ou confidence) corresponde ao percentual de fraude dentre os casos classificados com fraude e a Detection Rate (Cobertura) corresponde ao percentual de fraudes classificadas como fraude em relação ao total de fraude.

Na medida em que avançamos em nosso trabalho, em leituras como [SFL $\left.{ }^{+} 97\right]$, em conversas com especialistas e em primeiros resultados, avaliamos que para nosso caso seria mais apropriado usarmos uma medida de comparação que levasse em conta a diferença de custo entre um falso positivo e um falso negativo, em especial porque observamos que para as nossas amostras essa diferença de custo era de 100:1, discutiremos essa função objetivo em mais detalhes posteriormente.

\subsection{A relação entre a organização dos da- dos e os métodos}

Uma parte importante da modelagem consta em entender os dados disponíveis e decidir os métodos mais apropriados para essa aplicação. Phua et al. [PLSG05] descreve em seu trabalho os tipos de informações que podemos ter sobre um determinado fenômeno e quais métodos são mais utilizados em cada uma das situações. Como será visto mais adiante nosso trabalho usou aprendizagem supervisionada, de modo que achamos importante reservar esta seção para trazer um breve resumo da descrição apresentada por Phua et al. sobre a organização de dados, e em particular, uma explicação sobre modelagem supervisionada.

Outro trabalho importante, é de Stolfo et al. [SFL $\left.{ }^{+} 97\right]$. Neste artigo os autores apontam algumas das principais dificuldades das pesquisas

\footnotetext{
${ }^{2}$ Uma observação interessante sobre a AUC, é que a AUC é uma porção do quadrado de área 1 (espaço ROC), portanto, seus valores variam entre 0.0 e 1.0. Entretanto, como classificadores piores que os aleatórios não são encontrados no espaço ROC, não existem classificadores com AUC menor que 0.5 (0.5 é a área de uma classificador aleatório).
} 


\begin{tabular}{|c|c|c|c|}
\hline \multicolumn{4}{|c|}{ Base de desenvolvimento e validação } \\
\hline \multicolumn{3}{|c|}{ Atributos } & \multirow{2}{*}{ Classe } \\
\hline Variável 1 & Variável 2 & Variável N & \\
\hline \multicolumn{3}{|c|}{$A=$ atributos das relações fraude } & $\mathrm{B}=$ indicador de fraude \\
\hline \multicolumn{3}{|c|}{$\mathrm{C}=$ atributos das transações legais } & $\mathrm{D}=$ indicador de transação legal \\
\hline
\end{tabular}

\begin{tabular}{|c|c|c|c|}
\hline \multicolumn{4}{|c|}{ Base de aplicação } \\
\hline \multicolumn{3}{|c|}{ Atributos } & \multirow{2}{*}{ Classe } \\
\hline Variável 1 & Variável 2 & Variável N & \\
\hline \multicolumn{3}{|c|}{$\begin{array}{c}\mathrm{E}=\text { atributos das transações em momento posterior ao } \\
\text { desenvolvimento do modelo }\end{array}$} & ? \\
\hline \multicolumn{3}{|c|}{$\begin{array}{c}\mathrm{F}=\text { atributos das transações legais em momento posterior } \\
\text { ao desenvolvimento do modelo }\end{array}$} & $?$ \\
\hline
\end{tabular}

Figura 3.1: Separação dos dados, adaptado de [PLSG05]

em prevenção à fraude, que vão desde o desbalaceamento dos dados até o não compartilhamento dos dados entre as empresas por razões mercadológicas. O intuíto deste artigo foi utilizar-se de alguns métodos para mostrar que um rebalanceamento 50\% (fraudulentas) X 50\% (legítimas) apresenta resultados melhores segundo o critério de redução de falso positivo e falso negativo do que as classes em sua proporção real. Em outro trabalho com participação do autor principal [FSZC99], levou-se também em consideração a diferença entre os custos dos diferentes tipos de erros (falso positivo e falso negativo), enquanto ao mesmo tempo, apresentou pela primeira vez um algoritmo totalmente otimizado para essa tarefa, o Adacost, uma adaptação do Adaboost lidando com custo. Em anos mais recentes, descobriu-se que esses princípios usados para transfomar o Adaboost em Adacost podem ser usados para implementar meta-heurísticas capazes de tornar um método não baseado em custo em um método baseado em custo. O software Weka ${ }^{3}$ disponibiliza duas implementações o CostSensitiveClassifier e o MetaCost ${ }^{4}$ ambos capazes de realizar essa tranformação.

\section{Modelos Supervisionados, não supervisionados e semi- supervisionados. [PLSG05] Chamamos de modelos supervisiona-}

\footnotetext{
${ }^{3}$ Para mais detalhes ver seção de introdução ao Weka mais a frente.

${ }^{4}$ Para mais detalhes ver seção sobre meta-heurísticas mais a frente.
} 
dos aqueles que se utilizam da informação da classe a que cada registro pertence para o desenvolvimento do modelo. Uma modelagem supervisionada usa portanto as informações do tipo ( A, B, C e D) na figura 3.1. Onde A corresponde aos dados das transações fraudulentas, B corresponde ao indicador de fraude, $\mathrm{C}$ corresponde aos dados das transações legítimas e D corresponde ao indicador de transação legítima.

[PLSG05] relata que o uso de desenvolvimento e validação e o uso da marcação da classe fraude/não-fraude é o tipo de estratégia de modelagem mais utilizada nos artigos de detecção da fraude. Além disso, aponta que a maioria das aplicações em detecção de fraude são feitas em Cartões de Crédito, devido à facilidade que ausência de senha proporciona e porque no mundo todo o sistema de Cartões de Crédito é o mais automático dentre todos os outros. Segundo o artigo quase todas as técnicas podem ser utilizadas em uma estratégia supervisionada (quando se possui o marcador fraude/não-fraude), mas as mais encontradas com aplicações em detecção da fraude são Redes Neurais, Redes Bayesianas, Árvores de Decisão e SVMs.

Em contraposição, chamamos de modelos não supervisionados aqueles que não se utilizam da informação da classe a que cada registro pertence para o desenvolvimento do modelo. Uma modelagem não supervisionada usa portanto as informações do tipo (A e C) na figura 3.1, geralmente observa-se a utilização dessa metodologia quando algo impede ou torna de custo elevado a observação da variável objetivo. Segundo [PLSG05], modelos não supervisionados são piores que os modelos supervisionados, porém o artigo aponta que existem bons resultados em trabalhos que combinam esses dois tipos de estruturação dos dados, um exemplo apontado foi o uso de métodos de clusterização associada ao uma modelagem supervisionada para cada um desses clusteres, o artigo afirma que clusterização é a técnica não supervisionada mais utilizada.

Por fim, temos os modelos semi-supervisionadas, muito comuns na área médica, onde obtemos na grande maioria dados apenas dos pacientes doentes, se quisermos fazer um paralelo com nosso trabalho, seria um modelo que usasse apenas as informações das transações de fraudulentas (A). Segundo [PLSG05], esse tipo de combinação dos dados não é efetivo para avaliação do risco de fraude, porém afirma, que podese aplicar algoritmos como Cluster [BL97] ou Market Basket Analisys 
(MBA) [BL97] para identificar e entender o perfil das transações realizadas por fraudadores. 


\section{Capítulo 4}

\section{Os métodos de classificação comparados - uma visão geral}

Neste capítulo falaremos sobre os cinco métodos de classificação que comparamos neste trabalho. Iniciamos por uma breve discussão sobre a terminologia e, posteriormente, reservamos uma seção para descrever cada um dos métodos: Árvores de Decisão, Redes Neurais, Redes Bayesianas, Naive Bayes e Sistemas Imunológicos Artificiais. Aqui, introduzimos os métodos de maneira mais próxima da teoria, não nos atentando a fatores relacionados às implementações. Mais à frente, em um outro capítulo, descreveremos os parâmetros disponíveis nas implementações desses métodos no Weka, nesse momento discutiremos pontos mais práticos das implementações dos algoritmos.

O Weka é um ambiente para descoberta de conhecimento, feito em Java. Ele possui implementações de diversos métodos de classificação e segmentação (clustering). Além desse ambiente, adotamos o livro [WF05] que descreve o software como referência principal de nosso trabalho, pois ele traz detalhes sobre o funcionamento do Weka e sobre as implementações dos algoritmos, é rico na descrição teórica dos métodos que testamos, e discute assuntos relevantes aos nossos testes, dois exemplos são: Aprendizagem sensível ao custo e Meta Heurística.

Esse capítulo é baseado em uma junção de alguns artigos com o livro e, 
sempre que possível, os termos foram adaptados aos encontrados neste, de modo que referências nem sempre estarão explícitas.

No final desse capítulo, reservamos espaço para descrever o Algoritmo Genético (GA) que, apesar de não ser um método de classificação, e parecer fora de contexto para esse capítulo, utilizamo-lo para um ajuste paramétrico do métodos de classificação, como será visto em mais detalhes à frente.

Uma pequena discussão conceitual sobre terminologia

Definir os conceitos associados aos algoritmos dos quais participam Árvores de Decisão, Redes Neurais, Redes Bayesianas, Naive Bayes e Sistemas Imunológicos Artificiais se mostrou um trabalho árduo. O principal problema encontrado foi o de atribuir nome a cada parte envolvida no processo. Muitas são as áreas que se utilizam dos cinco algoritmos que comparamos, e não é difícil encontrar nomes distintos atribuídos às tarefas que esses algoritmos exercem, ou mesmo atribuir nomes às classes que esses algoritmos pertencem. Podemos citar alguns exemplos de nomes que encontramos em nossas leituras: Métodos de Aprendizagem Computacional, Métodos de Aprendizagem de Máquina, Métodos de Reconhecimento de Padrões, Método de Classificação, Classificador e Técnicas de Modelagem. Quando olhamos o software Weka, por exemplo, vemos que o termo utilizado para agrupar esses algoritmos é Classificador.

Nós optamos por não usar o termo Classificador para esses algoritmos $^{1}$, pois esses são algoritmos capazes de treinar um Classificador (modelo capaz de classificar, distinguir entre fraude / não fraude) e não classificar uma observação em uma dada classe, em outras palavras, esses algoritmos recebem como entrada uma base de dados e devolve como saída um modelo, que, esse, podemos chamar de um Classificador. Definimos usar o termo Método de Classificação por entendermos que esse é um termo aceito entre os profissionais da área de Reconhecimento de Padrões. Do mesmo modo, optamos pelo termo Modelo quando tratamos do objeto de saída destes Métodos de Classificação.

\footnotetext{
${ }^{1}$ Árvores de Decisão, Redes Neurais, Redes Bayesianas, Naive Bayes e Sistemas Imunológicos Artificiais.
} 


\section{1 Árvores de Decisão (DT)}

Para Murthy et al. [MOK98] a idéia básica da construção de uma Árvore de Decisão é a quebra do problema em subproblemas mais simples a cada etapa e para Safavian et al. [SL91] a cada nível que descemos, menor é a população participante daquele nó e estamos mais perto de classificarmos aquele nó como classe $\mathrm{A}$ ou $\mathrm{B}$.

Conforme descreve Sobral [Sob03] árvore de decisão é uma hierarquia de nós internos e externos que são conectados por ramos. Os nós internos são apontados como nós-decisórios ou nós-intermediários, e são esses nós a unidade de tomada de decisão que avalia através de teste lógico qual será o próximo nó-descendente ou filho. Em contraste, o artigo aponta que os nós externos não têm nó-descendente, e que eles são conhecidos como nós-folhas ou nós-terminais, e a eles são associados uma classe.

Em geral, o procedimento de classificação em uma árvore de decisão é o seguinte: apresenta-se um conjunto de dados, referêntes a um registro da base de dados, ao nó raiz da árvore; dependendo do resultado do teste lógico usado pelo nó, a árvore ramifica-se para um dos nós-filhos, este procedimento é repetido neste nó para onde a árvore se ramificou e ramifica-se novamente para um dos nós-filhos, e esse procedimento é repetido até que um nó-terminal seja alcançado. Por fim, atribui-se a classe predominante desse nó ao registo que acaba de ser classificado (por exemplo, em nosso caso poderia se tratar de um nó terminal onde predominantemente temos casos de fraude, neste caso classificaríamos a autorização como potencialmente fraudulenta). A repetição deste procedimento caracteriza a recursividade da árvore de decisão.

Em nossos testes usamos árvores de decisão binária, onde cada nóintermediário divide-se exatamente em dois nós descendentes: o nó esquerdo e o nó direito. Quando os dados satisfazem o teste lógico do nó-intermediário, seguem para o nó esquerdo e quando não satisfazem seguem para o nó direito. Logo, uma decisão é sempre interpretada como verdadeira ou falsa.

Uma árvore pode facilmente ser criada usando a estratégia de divisão e conquista, quando quebra o problema em partes menores. Para implementar essa estratégia, uma variável de quebra precisa ser escolhida 
para ser colocada na então raiz da árvore, e podermos executar a quebra no estilo top-down. O livro apresenta que em sua implementação o valor de informação (infovalue - information value) é usado para escolher a melhor variável para quebra por se tratar de uma das melhores maneiras conhecidas para realizar tal tarefa, devemos escolher a variável com o maior infovalue.

Para os próximos cálculos, faz-se necessário apresentarmos os dados da previsão de tempo relacionadas ao clima apropriado ou não apropriado para jogar tênis conforme exemplo bastante elucidativo presente no livro [WF05]:

\subsubsection{Exemplo da indução de um Árvore de De- cisão.}

Arquivo weather.arff

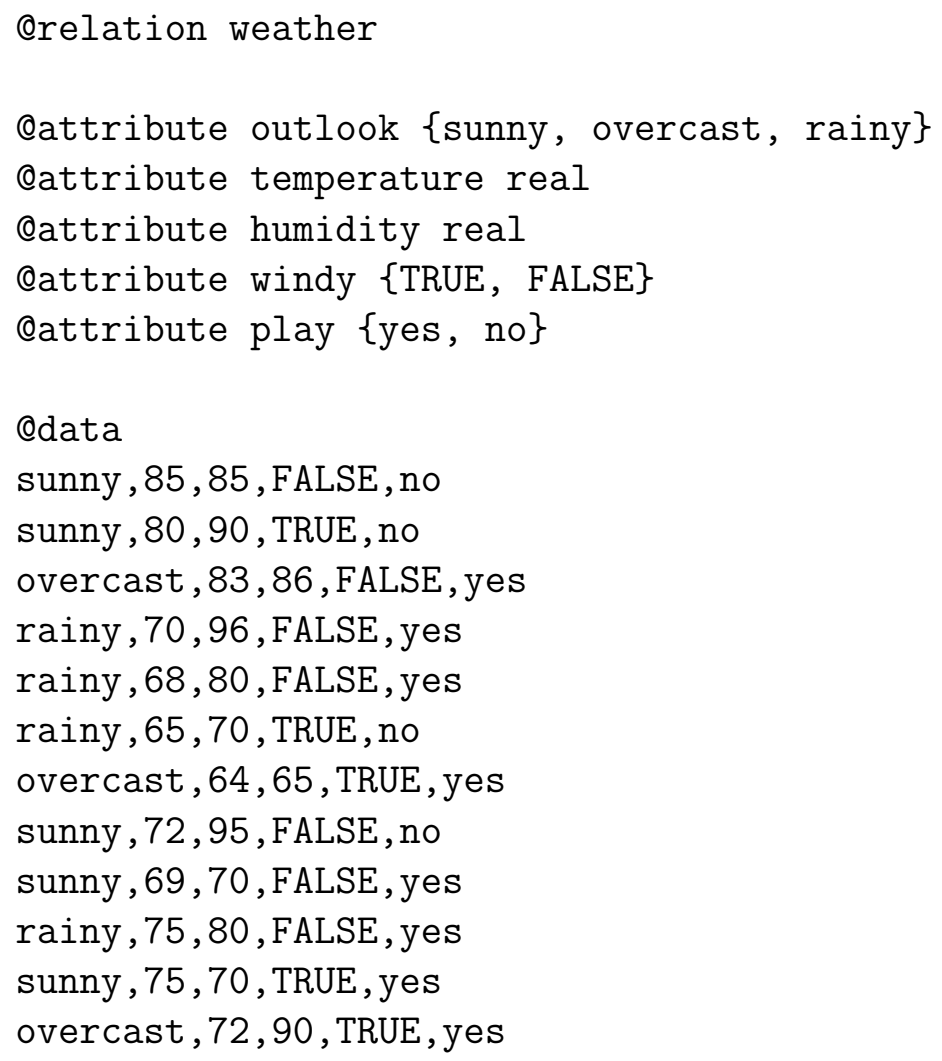


overcast, 81,75, FALSE, yes

rainy , 71,91 , TRUE, no

\begin{tabular}{ccccc}
\hline \hline outlook & temperature & humidity & windy & play \\
\hline sunny & 85 & 85 & FALSE & no \\
sunny & 80 & 90 & TRUE & no \\
overcast & 83 & 86 & FALSE & yes \\
rainy & 70 & 96 & FALSE & yes \\
rainy & 68 & 80 & FALSE & yes \\
rainy & 65 & 70 & TRUE & no \\
overcast & 64 & 65 & TRUE & yes \\
sunny & 72 & 95 & FALSE & no \\
sunny & 69 & 70 & FALSE & yes \\
rainy & 75 & 80 & FALSE & yes \\
sunny & 75 & 70 & TRUE & yes \\
overcast & 72 & 90 & TRUE & yes \\
overcast & 81 & 75 & FALSE & yes \\
rainy & 71 & 91 & TRUE & no \\
\hline \hline
\end{tabular}

Tabela 4.1: Tabela weather.arff, retirado de [WF05]

A tabela 4.1 mostra esses dados de uma maneira mais legível.

O infovalue é uma abreviação de information value (valor da informação), e é definido através da função entropia. A entropia, $H$, de uma variável aleatória X é medida através do montante de incerteza associada aquela variável X. Abaixo vemos a maneira de calcular o infovalue através da entropia.

$$
\begin{aligned}
& \text { infovalue }\left(N_{1}, N_{2}, \ldots, N_{n}\right)=\operatorname{entropy}\left(p_{1}, p_{2}, \ldots, p_{n}\right) \\
& =-p_{1} * \log _{2}\left(p_{1}\right)-p_{2} * \log _{2}\left(p_{2}\right) \ldots-p_{n} * \log _{2}\left(p_{n}\right)
\end{aligned}
$$

onde

$$
p_{i}=N_{i} / \operatorname{sum}\left(N_{j}\right), j=1 \ldots n, i=1 \ldots n
$$

exemplo :

$$
\text { infovalue }([2,3,4])=\operatorname{entropy}(2 / 9,3 / 9,4 / 9)
$$




$$
=-2 / 9 * \log _{2}(2 / 9)-3 / 9 * \log _{2}(3 / 9)-4 / 9 * \log _{2}(4 / 9)
$$

e esse resultado é usualmente escrito em "bits", até porque infovalue $(1 / 2,1 / 2)=$ 1bit.

Na tabela 4.1, temos 14 registros, sendo 9 sim e 5 não, então temos o seguinte infovalue total:

$$
\begin{gathered}
\text { infovalue }([9,5])=-9 / 14 * \log _{2}(9 / 14)-5 / 14 * \log _{2}(5 / 14) \\
=0.940 \text { bits }
\end{gathered}
$$

Se tentassemos usar outlook como variável para quebra, teríamos a seguinte situação (onde para a categoria sunny temos 2 sim joga e 3 não joga, para overcast 4 sim e 0 não e para rainy temos 3 sim e 2 não):

$$
\begin{aligned}
& \text { outlook ----sunny------ (2/3) (yes/no) } \\
& \text { l |------overcast----- }(4 / 0) \text { (yes/no) } \\
& \text { I-----------rainy-------(3/2) (yes/no) } \\
& \begin{array}{c}
\text { info }([2,3])=0.971 \text { bits } \\
\text { info }([4,0])=0 \text { bits } \\
\text { info }([3,2])=0.971 \text { bits }
\end{array}
\end{aligned}
$$

Onde, info([4,0]) é igual a zero por definição. Podemos agora calcular a média ponderada de infovalue como sendo:

$$
\begin{gathered}
\text { infovalue }([2,3],[4,0],[3,2])=(5 / 14) * \text { infovalue }([2,3]) \\
+(4 / 14) * \text { infovalue }([4,0])+(5 / 14) * \text { infovalue }([3,2])=0.693 \text { bits }
\end{gathered}
$$

Finalmente, podemos calcular o infogain (ganho de informação) como sendo:

$$
\begin{aligned}
\text { infogain }(\text { outlook })= & \text { infovalue }([9,5])-\text { infovalue }([2,3],[4,0],[3,2]) \\
& =0.940-0.693=0.247 \text { bits }
\end{aligned}
$$


Se repetirmos o mesmo procedimento para as outras variáveis teremos:

$$
\begin{gathered}
\text { infogain }(\text { temperature })=0.029 \text { bits } \\
\text { infogain }(\text { humidity })=0.152 \text { bits } \\
\text { infogain }(\text { windy })=0.048 \text { bits }
\end{gathered}
$$

Como o outlook obteve o maior infogain (ganho de informação), selecionamolo para ser a variável de quebra nesta etapa.

Para uma árvore não binária, teríamos agora outros três subproblemas para otimizar.

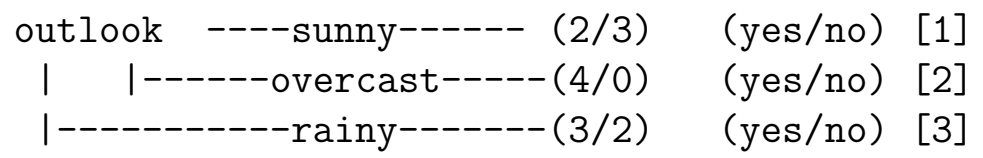

O primeiro é o sunny [1], com 5 registros, 2 sim e 3 não; o segundo é o overcast [2], com 4 elementos, todos $\operatorname{sim}^{2}$; e o terceiro é o rainy [3], com 5 elementos, 3 sim e 2 não.

\subsubsection{Parâmetros de indução de uma árvore de de- cisão.}

O algoritmo de indução da Árvore de Decisão consta em continuar executando essas quebras até que uma das condições de parada seja atingida (Poda), em nosso trabalho a Poda é definida por duas condições de parada o suporte (support) invocado pela op̧̧ão -M e a confiança (confidence) invocada pela opção -C.

O suporte corresponde ao número mínimo de elementos permitidos em um determinado nó, seja ele um nó-intermediário ou terminal. Algumas implementações definem o suporte como relativo, por exemplo, como $1 \%$ do total de registros da base de dados; outras o definem em número absoluto de observações, por exemplo, 5 registros. Caso um

\footnotetext{
${ }^{2}$ Reparem que a decisão para esse subproblema é simples e igual a parar e atribuir a esse nó terminal a classe SIM.
} 
determinado nó possua um número inferior de elementos que o suporte, esse nó sofre poda e é eliminado, ou seja, seu nó pai, em uma árvore binária, torna-se um nó terminal. Tratando-se de uma árvore não binária, retorna-se ao nó pai e agrupa-se a categoria a ser podada a uma outra categoria cuja a relação de casos das classes (por exemplo, fraude e não-fraude) seja a mais próxima possível. Entretanto, caso reste apenas uma categoria após esse agrupamento, torna-se, o nó-pai, um nó-terminal e atribui-se a ele o nome da classe predominante. No Weka esse parâmetro é invocado pela opção -M, e nessa implementação o suporte é implementado como número absoluto de registros em um determinado nó.

A confiança corresponde a assertividade da árvore quando usada em sua totalidade. Para classificar, ela é calculada através da relação entre a quantidade de uma categoria sobre o total, exemplo: 4 fraudes de um total de 10 dá uma assertividade de 40\%. No Weka esse parâmetro é invocado pela opção -C, e nessa implementação a opção -C define a melhora da confiança, ou seja, se usamos o valor $0.3(30 \%)$ e, se em nossa base temos $96 \%$ de transações legítimas e $4 \%$ de transações fraudulentas, o algoritmo precisará de mais de $98 \%$ de registros de uma determinada classe para classificá-lo como dessa classe.

Em um teste executado, para uma base com $96 \%$ de transações legítimas, conseguimos a seguinte avaliação do percentual de registros classificados corretamente (RCC) na base de desenvolvimento:

$$
\begin{aligned}
& \text {-C } 0.01 \Rightarrow \% R C C=95.8015 \backslash \% \text { (Erro de classificação sem redução). } \\
& \text {-C } 0.05 \Rightarrow \% \text { RCC }=97.3919 \backslash \% \text { (Erro de classificação } 37.88 \backslash \% \text { menor). } \\
& \text {-C } 0.10 \Rightarrow \% \text { RCC }=97.4555 \backslash \% \text { (Erro de classificação } 39.40 \backslash \% \text { menor). } \\
& \text {-C } 0.15 \Rightarrow \% \text { RCC }=97.5509 \backslash \% \text { (Erro de classificação } 41.67 \backslash \% \text { menor). } \\
& \text {-C } 0.20 \Rightarrow \% \text { RCC }=97.5509 \backslash \% \text { (Erro de classificação } 41.67 \backslash \% \text { menor). } \\
& \text {-C } 0.25 \Rightarrow \% \text { RCC }=97.7099 \backslash \% \text { (Erro de classificação } 45.45 \backslash \% \text { menor). } \\
& \text {-C } 0.30 \Rightarrow \% \text { RCC }=98.2188 \backslash \% \text { (Erro de classificação } 57.58 \backslash \% \text { menor). } \\
& -\mathrm{C} 0.35 \Rightarrow \% \text { RCC }=98.2500 \backslash \% \text { (Erro de classificação } 58.32 \backslash \% \text { menor). } \\
& \text {-C } 0.40 \Rightarrow \% \text { RCC }=98.4097 \backslash \% \text { (Erro de classificação } 62.12 \backslash \% \text { menor). } \\
& \text {-C } 0.45 \Rightarrow \% \text { RCC }=98.4733 \backslash \% \text { (Erro de classificação } 63.64 \backslash \% \text { menor). } \\
& -C 0.49 \Rightarrow \% \text { RCC }=98.9186 \backslash \% \text { (Erro de classificação } 74.24 \backslash \% \text { menor). }
\end{aligned}
$$

Por fim temos que a confiança igual a 0.01 (1\%) que representa uma maior poda, pois a árvore quase não precisa ser expandida para atingir 
esse estágio, enquanto a confiança igual a 0.49 (49\%) representa menor prunning, pois é necessário uma grande expansão da árvore.

\section{$4.2 \quad$ Redes Neurais (NN)}

Antes de entrarmos no assunto de redes neurais artificiais traremos uma breve introdução sobre o funcionamento das Redes Neurais biológicas, mais especificamente no ser humano. Após esta introdução, elencaremos alguns dos acontecimentos históricos relevantes envolvidos com o estudo das redes neurais que se confundem, em muito, com a própria pesquisa em inteligência artificial. Além de todas as referência citadas no decorrer dessa seção, destacamos o livro [Hay99] como uma das referências mais completas no assunto.

\subsubsection{Sistema Nervoso Humano (SNH)}

O sistema nervoso humano é formado por um número gigante de neurônios: estima-se que somente o cérebro contenha aproximadamente 10 bilhões deles. A comunicação entre esses neurônios acontece através das sinapses; as sinapses transmitem estímulos através de diferentes concentrações de $\mathrm{Na}+$ (Sódio) e K+ (Potássio).

A figura 4.1 mostra a célula fundamental do Sistema Nervoso, o neurônio. Ele é capaz de produzir e conduzir impulsos elétricos, neste caso, chamados de impulsos nervosos.

Os neurônios podem ser compreendidos se o dividirmos em três regiões com funções distintas:

- Os dendritos, filamentos relativamente curtos e extremamente ramificados;

- O corpo celular, região de maior volume onde se encontra o núcleo da célula;

- O axônio, uma região filamentosa única e alongada que emerge a partir do corpo celular e se ramifica em sua extremidade. 


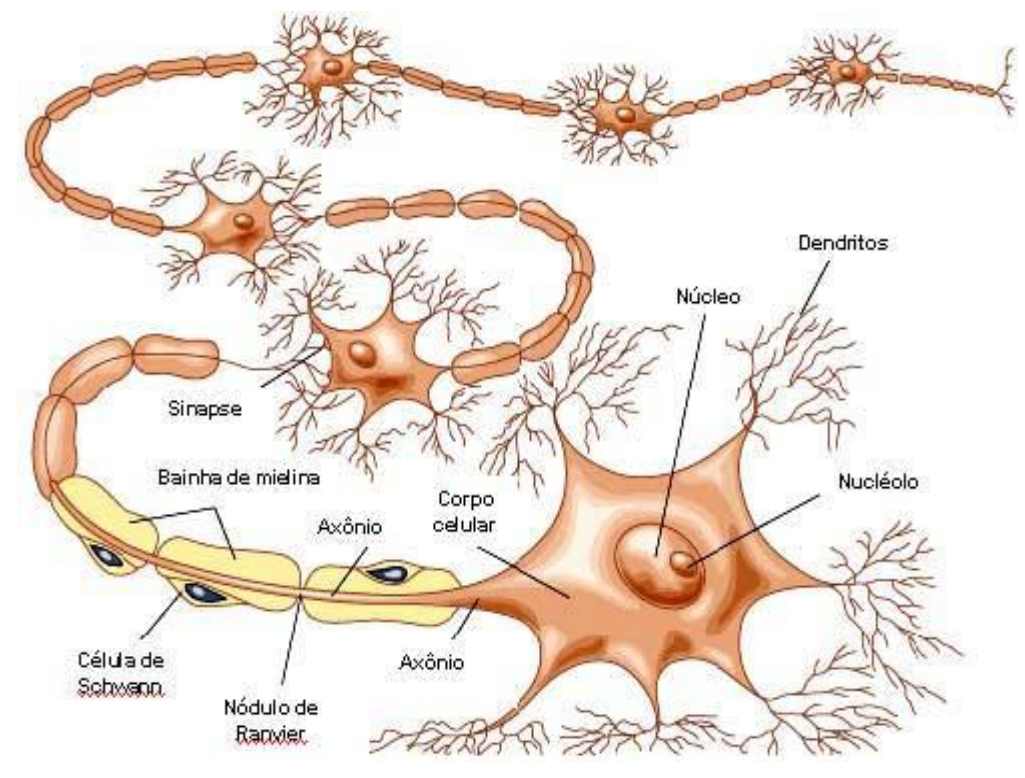

Figura 4.1: Esquema dos constituintes da célula neural. Retirado de [Amo08]

O impulso sempre percorre o neurônio iniciando pelos seus dendritos, ditos receptores de informação, passando pelo corpo celular. Estes são responsáveis por coletar e combinar as informações vindas de outros neurônios ou de outros sistemas (exemplo: sensores de tato, visão). Por fim, indo em direção à saída temos o axônio. Esta última região é envolvida pelas células de Schwann, que produzem ao seu redor a bainha de mielina. A mielina é um lipídio que age como isolante elétrico otimizando a condução do impulso nervoso pelo axônio. Entre uma célula de Schwann e outra existe um curto setor desprovido de mielina com aparência de um estrangulamento. Cada um destes setores é denominado um nódulo de Ranvier.

Além dos neurônios, o tecido nervoso possui as chamadas células da glia ou neuróglia. Incapazes de gerar e propagar pulsos elétricos, mas importantes na manutenção das condições adequadas à sobrevivência dos neurônios no tecido, fornecendo-lhes sustentação, nutrição e proteção contra agentes patogênicos. 


\subsubsection{O histórico ${ }^{3}$ das ANNs}

Agora que temos uma pequena idéia do funcionamento do neurônio, podemos introduzir a evolução do estudo em redes neurais (ou redes neuronais).

Primeiro apresentamos uma seqüência de artigos publicados que mostram bem a evolução da pesquisa nessa área, e principalmente os principais colaboradores dessa evolução.

1943: McCulloch e Pitts, sugeriam pela primeira vez a construção de uma máquina inspirada no funcionamento do cérebro humano.

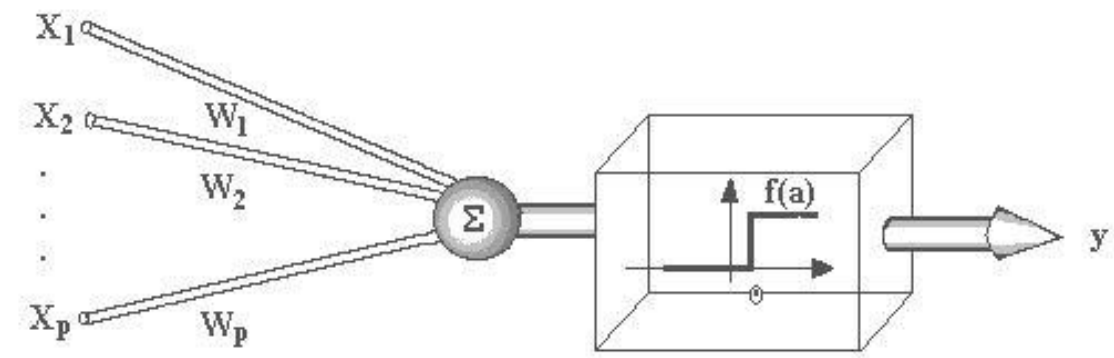

Figura 4.2: Neurônio artificial projetado por McCulloch. Retirado de [TK00]

O fisiologista Warrem McCulloch interpretou o funcionamento do neurônio biológico como sendo um circuito de entradas binárias combinadas por uma soma ponderada (com pesos) produzindo uma entrada efetiva.

No modelo geral de neurônio (figura 4.2) as entradas ponderadas $W_{i} X_{i}$ são combinadas usando uma função $F$, para produzir um estado de ativação do neurônio (correspondente à freqüência de descarga de pulsos do neurônio biológico). As entradas $\left(X_{j}\right)$ chegam através dos dendritos, tem um peso $\left(W_{i}\right)$ atribuído pela sinapse e, após sua adição, um único valor de saída é retornado. Esse valor de saída pode ser copiado para vários outros neurônios, mas todos os modelos neurais artificiais desde o princípio até hoje somente produzem um único valor de saída.

1949: Donald Hebb escreveu o livro intitulado "The Organization of

\footnotetext{
${ }^{3}$ Histórico adaptado de [TK00]
} 
Behavior" (A Organização do Comportamento). Neste livro, o autor apresenta a idéia que o condicionamento psicológico clássico está presente em qualquer espécie animal; isso se dá devido ao fato de que esta é uma propriedade de neurônios individuais. Hebb traduziu matematicamente a sinapse dos neurônios biológicos.

Regra de Hebb - Declaração de Hebb: "Quando um axônio de uma célula $\mathrm{A}$ está eminente de excitar a célula $\mathrm{B}$ e recorrentemente ou contumazmente participa da ativação desta, um processo de crescimento ou mudança metabólica ocorre em uma ou ambas as células, de forma a aumentar eficiência de A ativar B."

Uma leitura prática dessa regra é: Se dois neurônios, um de cada lado de uma sinapse, são ativados sincronamente, então a "força" daquela sinapse deve ser aumentada. Em contra partida, se dois neurônios, um de cada lado de uma sinapse, são ativados assincronamente, então aquela sinapse dever ser enfraquecida.

1951: Mavin Minsky criou o primeiro neuro computador conhecido como Snark. Apesar de um sucesso técnico, esta máquina nunca chegou a executar qualquer processamento de funções interessantes na prática.

1956: em "Darthmouth College" nasceram dois paradigmas da Inteligência Artificial. A Inteligência Artificial Simbólica estuda a manipulação de símbolos, essa manipulação simbólica pretende simular conhecimento (e inferir conclusões) empregando sistemas baseados em regras. Por outro lado, a Lógica Conexionista pretende estudar e simular o funcionamento do cérebro humano. Os conexionistas acreditam que se formos capazes de criar um sistema que simule o funcionamento do cérebro humano, seremos capazes de aprender, assimilar, errar e aprender com seus erros.

1957: ROSENBLATT concebeu o perceptron, neurônio usado no reconhecimento de caracteres.

A figura 4.3 mostra a rede proposta em 1957 por Rosenblatt composta por neurônios do tipo perceptron, que no ano seguinte ficou disposta no livro Principles of Neurodynamics. Rosenblatt, pela primeira vez, 


\section{Camada de Saída}

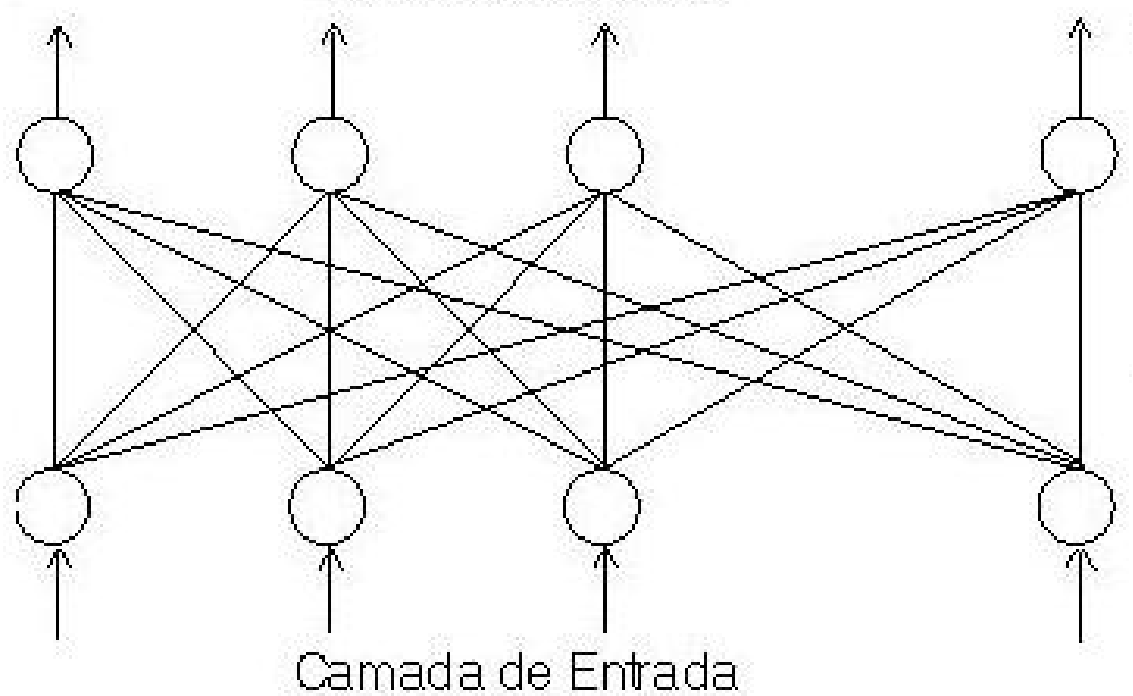

Figura 4.3: Rede de perceptrons proposta por Rosemblatt. Retirado de [TK00]

mostrou uma estrutura neural em forma de camadas, uma camada de entrada em outra de saída

1958: Frank Rosenblatt, Charles Wightman et al. criaram o primeiro neuro computador a obter sucesso, batizado de Mark I Perceptron. Seu interesse principal era reconhecimento de padrões.

1960: Widrow e Hoff apresentaram uma estrutura com uma pequena modificação na topologia apresentada por Rosemblatt criando o que viria a ser chamado de camadas intermediárias. A rede ADALINE(ADAptative LINear Element) e o MADALINE(Many ADALINE) perceptron utilizou saídas analógicas em uma arquitetura de três camadas.

A figura 4.4 mostra a topologia multicamada ADALINE e MADALINE.

1962: WIDROW desenvolveu um processador para redes neurais e fundou a primeira empresa de circuitos neurais digitais, a Memistor 


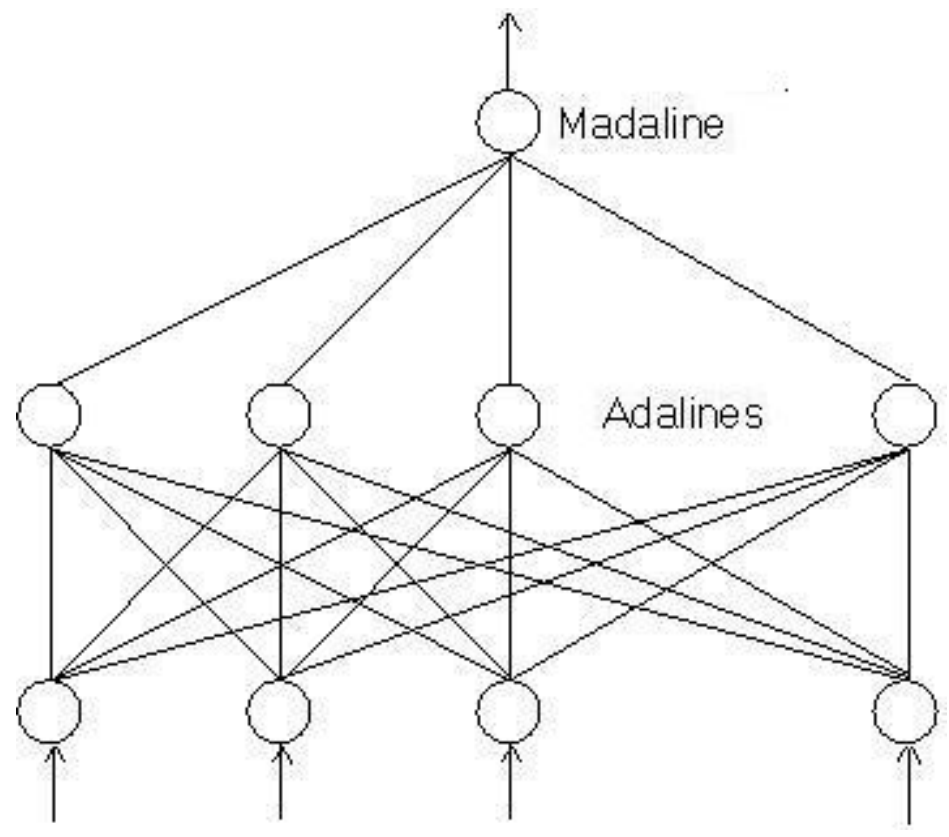

Figura 4.4: Redes ADALINE e MADALINE. Retirado de [TK00]

Corporation.

1969: Redução significativa das verbas destinadas à pesquisa de redes neurais. Causada principalmente pelo não cumprimento de etapas ambiciosas de projetos com alto nível de financiamento. Esses fatores desmotivaram tanto os governos quanto a iniciativa privada ao investimento na pesquisa.

1974: Werbos lançou as bases para o algoritmo de retropropagação (backpropagation).

1982: Terminaram os anos negros para toda a área de sistemas conexionistas. Foi então que em 1983 Ira Skurnick, um administrador de programas da DARPA (Defense Advanced Research Projects Agency), decidiu ouvir os argumentos da neurocomputação e seus projetistas e, divergindo dos caminhos tradicionais dos conhecimentos convencionais, iniciou pesquisas nesta área. Outro influente cientista que emergiu nessa área foi o renomado físico John Hopfield, que persuadiu, através 
de seus resultados e sua importante reputação, diversos de seus pares a unirem-se nesta área emergente de pesquisa.

1986: David Rumelhart e James McClelland publicaram o livro "Parallel Distributed Processing" (Processamento Distribuído Paralelo) que impulsionou explosivamente a pesquisa. Neste mesmo ano, Rumelhart, Hinton e Williams introduziram o poderoso método Backpropagation.

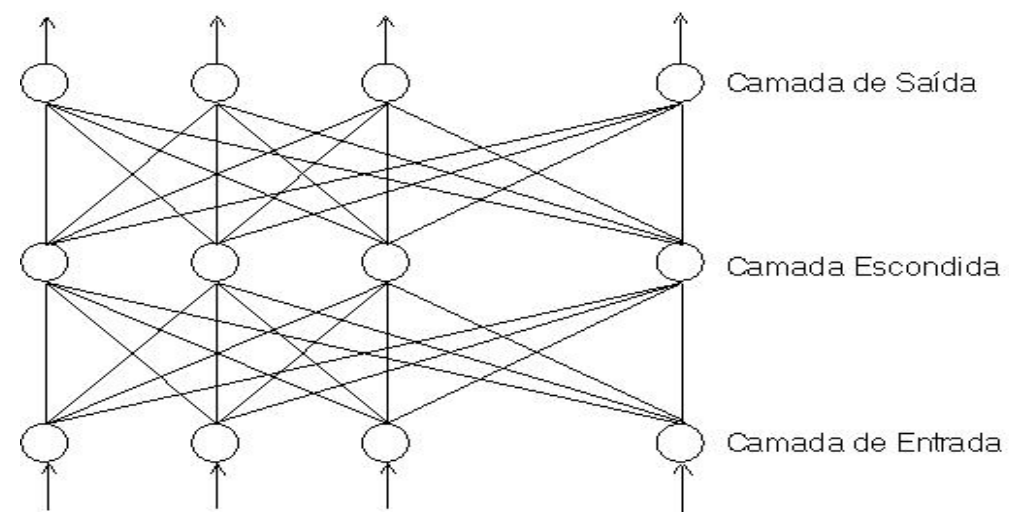

Figura 4.5: Estrutura do método Backpropagation. Retirado de [TK00]

A figura 4.5 mostra um exemplo da topologia multicamada, cujas conexões sinápticas têm seus pesos ajustados pelo algoritmo de Backpropagation (RHW86), é importante observar que essa topologia pode ser desenhada com mais que uma camada escondida (Hidden Layer). O advento dessa camada intermediária se deveu, principalmente, à incapacidade de uma rede só com camadas de entrada e saída resolver problemas linearmente não separáveis.

A figura 4.6 mostra uma função simples que não pode ser separada linearmente.

1987: Ocorreu em São Francisco a primeira conferência de redes neurais em tempos modernos, a IEEE International Conference on Neural Networks.

1989: Fundação da International Neural Network Society (INNS). 

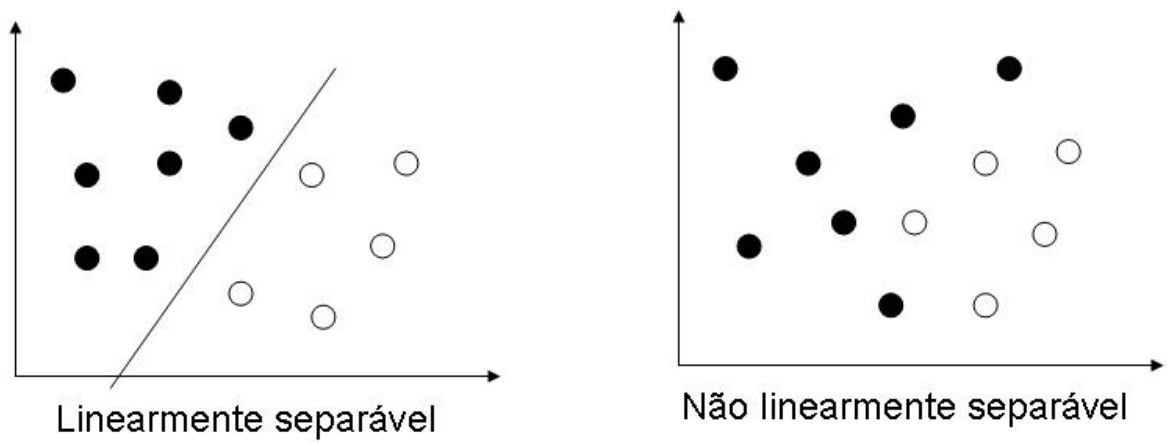

Figura 4.6: Exemplo de função não linearmente separável - Adaptado da Aula 7 - Inteligência Computacional - Prof. A. C. G. Thomé - UFRJ $2003 / 2$

1990: Criação do Neural Computation e do IEEE Transactions on Neural Networks. Neste ponto, uma observação importante que deve ser feita é sobre topologia cujas camadas de um nível superior podem ser usadas como entrada para uma camada de nível inferior. Essa topologia é dita, recorrente, cria-se a possibilidade de atividades na rede sem que haja estímulo exterior.

\subsubsection{Modelo Generalizado das ANNs}

Conforme descreveu Bittencourt [Bit01], pode-se obter uma generalização do neurônio de McCulloch e Pitts. Nesse modelo generalizado o nível de ativação passa a ser definido por uma função g qualquer:

$$
\phi_{i}=g\left(X_{i}, \ldots, X_{n}\right)
$$

A função de ativação passa a ser uma f limitada qualquer. Porém é interessante que essa função seja contínua para eliminarmos as restrições do modelo binário de McCulloch e Pitts, ou seja, sua saída ser 0 ou 1 não admitindo nenhum valor intermediário e sendo de mudança brusca e, o pior de tudo, não sendo diferenciável em todos os pontos.

Abaixo, apresentamos duas das funções f mais utilizadas: 
função semi-linear

$$
f(x)= \begin{cases}0, & \text { Se } x<\alpha_{\min } \\ m x+1, & \text { Se } \alpha_{\min } \leq x \leq \alpha_{\max } \\ f_{\max }, & \text { Se } x>\alpha_{\max }\end{cases}
$$

Função sigmoidal

$$
f(x)=\frac{f_{\max }}{1+\exp ^{-x}}
$$

A grande vantagem da utilização da função sigmoidal é seu caráter contínuo, derivável em qualquer ponto.

\subsubsection{O Algoritmo de Backpropagation}

O processo que apresentaremos abaixo é conhecido como processo incremental, onde na fase de treinamento apresentamos um conjunto de variáveis de entrada para a rede e valor desejado como resposta para essa instância, sendo que, para cada instância na base de treinamento, o valor calculado como saída será comparado ao valor desejado e, posteriormente, será computado o erro global da rede, que influenciará na correção dos pesos no passo de retropropagação.

$1^{a}$ - Propagação: Depois de apresentado o padrão de entrada, a resposta de uma unidade é propagada como entrada para as unidades na camada seguinte, até a camada de saída, onde é obtida a resposta da rede e o erro é calculado;

$2^{a}$ - Retropropagação (backpropagation): Desde a camada de saída até a camada de entrada, são feitas alterações nos pesos sinápticos.

Apesar de não haver garantias que a rede forneça uma solução ótima para o problema, este processo é muito utilizado por apresentar uma boa solução para o treinamento de Perceptrons Multi - Camadas.

Resumo do Algoritmo 
(a) Inicialização: Inicialize os pesos sinápticos ${ }^{4}$ aleatoriamente, com valores no intervalo $[-0,1 ; 0,1]$;

(b) Apresentação dos Exemplos de Treinamento:

Treinamento "on-line": Para cada exemplo do conjunto de treinamento, efetue os passos $c$ e $d$.

Treinamento "em lote": Para cada "safra" do conjunto de treinamento, efetue os passos $c$ e $d$.

(c) Computação para Frente ( Propagação ): Depois de apresentado o exemplo do conjunto de treinamento $T=\{(x(n), d(n)\}$, sendo $x(n)$ a entrada apresentada à rede e $d(n)$ a saída desejada, calcule o valor da ativação $v_{j}$ e a saída para cada unidade da rede $\mathrm{j}$, da seguinte forma:

$v_{j}=\sum_{i=1}^{m} w_{j i} x_{i}+b$, para o cálculo do valor da ativação e

$f\left(v_{j}\right)=\frac{f_{\max }}{1+\exp ^{-a v_{j}}}$, para o cálculo da saída $y$ da unidade $\mathrm{k}$, utilizando a função sigmóide, como no exemplo, ou uma outra função se necessário.

Utiliza-se a saída das unidades de uma camada como entradas para a seguinte, até a última camada. A saída das unidades da última camada será a resposta da rede.

(d) Calcule o Sinal de Erro: Fazendo a saída $y_{j}=O_{j}(n)$, será $O_{j}(n)$ a resposta da rede, calcule o sinal de erro através da seguinte fórmula:

$e_{j}(n)=d_{j}(n)-O_{j}(n)$, onde $d_{j}(n)$ é a saída desejada com resposta para cada unidade na interação $(n)^{5}$.

(e) Computação para Trás ( Retropropagação ): Calcule os erros locais, $\delta$, para cada unidade, desde a camada de saída até a de

\footnotetext{
${ }^{4}$ Pesos sinápticos correspondem aos pesos $w_{i}$ de entrada de cada neurônio.

${ }^{5}$ Este sinal de erro será utilizado para computar os valores dos erros das camadas anteriores e fazer as correções necessárias nos pesos sinápticos.
} 
entrada. O gradiente local é definido por:

$\delta_{j}(n)=e_{j}(n) O_{j}(n)\left(1-O_{j}(n)\right)$, para a unidade da camada de saída ou $\delta_{j}(n)=O_{j}(n)\left(1-O_{j}(n)\right) \sum \delta_{k} w_{j k}$, para as unidades das demais camadas.

Onde:

$O_{j}\left(1-O_{j}\right)$ - é a derivada da função de ativação em função do argumento, i.e., valor de ativação;

$\delta_{k}$ - é o erro das unidades da camada anterior conectadas a unidade $\mathrm{j}$;

$w_{j k}$ - são os pesos das conecções com a camada anterior.

Após o cálculo dos erros de cada unidade, calcule o ajuste dos pesos de cada conexão segundo a regra delta generalizada e atualize os pesos:

$\Delta w_{k j}(n+1)=\alpha \Delta w_{k j}(n)+\eta \delta_{j} y_{j}$, para o cálculo dos ajustes dos pesos

Faça:

$w(n+1)=w(n)+\Delta w_{k j}(n)$, para atualizar os pesos sinápticos

Onde:

$\alpha$ - é a constante de momentun, quando $\alpha=0$, esta função funciona como a regra delta comum;

$\eta$ - é a taxa de aprendizado;

$\delta_{j}$ - é o erro da unidade;

$y_{j}$ - é a saída produzida pela unidade $\mathrm{j}$;

(f) Interação: Refaça os itens $c, d$ e $e$ referentes à propagação, cálculo do erro e retropropagação, apresentando outros estímulos de entrada, até que sejam satisfeitas as condições de treinamento; as quais podem ser:

- O erro da rede está baixo, sendo pouco alterado durante o treinamento;

- O número máximo de ciclos de treinamento foi alcançado. 


\subsection{Redes Bayesianas (BN)}

Conforme nos descreve Maes et al. [MkTVM01], Redes Bayesianas são grafos acíclicos dirigidos que representam dependências entre variáveis em um modelo probabilístico.

A pesquisa em Redes Bayesianas se intensificaram na década de 90 . Desde então, diversos problemas envolvendo incertezas nas muitas áreas têm usado essa técnica, podemos exemplificar: diagnóstico médico (Heckerman 1990, Franklin 1989), aprendizado de mapas (Dean 1990), interpretação de linguagem (Goldman 1989), visão (Levitt, 1989).

As redes bayesianas são baseadas em probabilidade condicional, de modo que as duas primeiras seções deste capítulo trazem uma noção de probabilidade e de probabilidade condicional, noção essa utilizada na seção seguinte, onde apresentamos o teorema de Bayes, que acrescido das noções de probabilidade conjunta nos torna capazes de apresentarmos a estrutura da Rede Bayesiana na seção 4.3.5 e sua construção na seção subseqüênte.

\subsubsection{Noções de Probabilidade}

"A principal vantagem de raciocínio probabilístico sobre raciocínio lógico é o fato de que agentes podem tomar decisões racionais mesmo quando não existe informação suficiente para se provar que uma ação funcionará" [Cha91].

- Agentes em Lógica de Primeira Ordem (ou em qualquer outra lógica determinística) enfrentam dificuldades em situações práticas em que:

- O agente não tem acesso a todo o ambiente devido o seu tamanho;

- O agente tem uma compreensão incompleta ou incorreta do ambiente (erros de leitura).

- Nestes casos, o conhecimento do agente pode apenas prover um grau de crença nas sentenças relevantes.

- Exemplo: $P($ Cárie|Dor de Dente $)=0.6$ (60\% de chance de uma dor de dente ser uma Cárie). 
Quando lidamos com falta de informação, começamos a nos deparar com incertezas. Necessitamos então a criação de conectivos que manipulem esses níveis de incerteza (ou certeza) e não mais valores booleanos simplesmente. Com esses conectivos seria possível tratar as frases: "Eu tenho probabilidade 0.8 de fazer um bom seminário de Sistemas Baseados em Conhecimento" ou "A probabilidade de um trabalho final de representação em Protégé ser bom é 0.5". Comparativamente, poderíamos dizer que a lógica probabilística estende a lógica proposicional, no sentido da probabilidade 1 representar verdadeiro e probabilidade 0 representar falso.

Então temos:

- Que um conectivo associa às sentenças um grau de crença numérico entre 0 e 1

- Contudo, cada sentença ou é verdadeira ou é falsa;

- Um grau de crença é uma probabilidade, que pode ser:

- A priori (incondicional): calculado antes de o agente receber percepções

* Ex. $P($ Cárie $=$ verdadeiro $)=P($ Cárie $)=0.5$

- Condicional: calculado de acordo com as evidências disponíveis

* Evidências: percepções que o agente recebeu até agora

* Ex: $P($ Cárie $\mid$ dor de dente $)=0.8$

- $P($ Cárie $\mid \neg$ dor de dente $)=0.3$

Em adição:

- A probabilidade $\mathrm{P}(\mathrm{A})$ de um evento a é um número dentro do intervalo $[0,1]$ :

- $\mathrm{P}(\mathrm{A})=1$ se e somente se A é certo.

- Se A e B são mutuamente exclusivos, então: $P(A \vee B)=$ $P(A)+P(B)$

Em nosso exemplo, considerando que cárie denota a proposição de que um paciente em particular tenha pelo menos uma cárie, então: $\mathrm{P}$ (cárie) $=0.5$, significa dizer que, na ausência de outra informação, o sistema assinalará a probabilidade 0.5 ao evento ser cárie. 
Proposições podem assumir o domínio booleano \{verdadeiro, falso\}, neste caso, a expressão $P($ Cárie $)$ pode ser vista como sendo $P($ Cárie $=$ verdadeiro $)$ e, analogamente, $P(\neg$ Cárie $)=P($ Cárie $=$ falso $)$. Outra forma muito comum de mostrar as probabilidades é contendo igualdade, assim como descrito nos dados de Tempo do Weka (Weather.data) [WF05]:

- $P($ Tempo $=$ Ensolarado $)=0.7$;

- $P($ Tempo $=$ Chuvoso $)=0.2$

- $P($ Tempo $=$ Nublado $)=0.1$.

\subsubsection{Probabilidade Condicional}

Diferente da probabilidade simples, a probabilidade condicional $P(A \mid B)$ $=\mathrm{x}$, pode ser interpretada como: "Dado que o evento $\mathrm{B}$ ocorreu, a probabilidade do evento A ocorrer é x", lê-se em português como "probabilidade de A dado B" ou simplesmente "p de A dado B".

- Probabilidade condicional (a posteriori) de A dado que B ocorreu é definida por:

- $P(A \mid B)=P(A, B) / P(B)$, quando $P(B)>0$, sendo $P(A, B)=$ $P(A \cap B)$.

Obs: A probabilidade condicional possibilita inferência sobre uma proposição desconhecida A dada a evidência B.

Retomando nosso exemplo, temos:

- Ex: $P($ Cárie $\mid$ dor de dente $)=0.8$, indicando que a probabilidade de um paciente com dor de dente possuir uma cárie é de 0.8 .

Um fato importante aqui é que somente podemos utilizar $P(A \mid B)$ quando apenas a informação $B$ está disponível. Quando temos os eventos A e B, não podemos usar $P(a \mid b)$, pois A já é verdade, ou quando temos que outro evento $\mathrm{C}$ também é verdade, ou seja, $\mathrm{B}$ e C são verdadeiros, então não podemos usar $P(A \mid B)$, e sim usar $P(A \mid B, C)$. Claro que se A não depende de C então $P(A \mid B, C)=P(A \mid B)$. 


\subsubsection{Teorema de Bayes}

Com o insumo anterior sobre probabilidade condicional, podemos enunciar o teorema das probabilidades totais, que dará origem ao corolário conhecido como Teorema de Bayes.

Teorema das Probabilidades Totais

Seja uma partição do espaço amostral $\Omega$ :

$$
A_{1}, A_{2}, \ldots, A_{n}
$$

Para qualquer evento B pertencente a este espaço amostral $\Omega$, podemos escrever sua probabilidade como :

$$
P(B)=P\left(B \cap A_{1}\right)+P\left(B \cap A_{2}\right)+\ldots+P\left(B \cap A_{n}\right)
$$

e usando a definição de probabilidade condicional;

$$
P(B)=P\left(B \mid A_{1}\right) P\left(A_{1}\right)+P\left(B \mid A_{2}\right) P\left(A_{2}\right)+\ldots+P\left(B \mid A_{n}\right) P\left(A_{n}\right)
$$

Teorema de Bayes

O teorema de Bayes mostra que a probabilidade condicional de um evento $A_{i}$ dado um outro evento B pode ser calculada através da probabilidade condicional inversa e das probabilidades totais dos eventos A e B, conforme mostra a equação de Bayes a seguir:

$$
P\left(A_{i} \mid B\right)=\frac{P\left(B \mid A_{i}\right) P\left(A_{i}\right)}{P(B)}
$$

Em anexo na seção 9.1, mostramos a demontração desse teorema e seu corolário.

Exemplo de aplicação do Teorema de Bayes (ou Regra de Bayes)

O exemplo mais clássico de aplicação da Regra de Bayes é o que envolve torcicolo e meningite. Vamos mostrá-lo para elucidar a utilização da fórmula. 
Considere $\mathrm{S}$ como sendo o evento de um paciente ter torcicolo e $\mathrm{M} \mathrm{o}$ evento de um paciente ter meningite. E seja $P(S)=\frac{1}{20}$ a probabilidade incondicional de um paciente ter torcicolo e respectivamente, $P(M)=$ $\frac{1}{50000}$ a probabilidade incondicional de um paciente ter meningite.

Além disso, suponhamos que possamos calcular $P(S \mid M)$, ou seja, a probabilidade de um paciente ter torcicolo dado que ele tem meningite, e que ela vale $P(S \mid M)=0.5$ (probabilidade de ter torcicolo tendo meningite)

Observe que essa probabilidade não é difícil de ser verificada, pois, em um consultório, um médico sempre recebe pacientes doentes ficando fácil ele calcular a incidência de qualquer sintoma que deseje.

Por fim, podemos inferir, usando a Regra de Bayes, qual é a probabilidade de um paciente, com torcicolo, ter meningite.

$P(M \mid S)=P(S \mid M) * \frac{P(M)}{P(S)}=0,5 * \frac{\frac{1}{50000}}{\frac{1}{20}}=0,0002=0,02 \%$

Concluindo que a probabilidade de alguém que tem rigidez no pescoço ter meningite é de $0,02 \%$.

Em implementações computacionais desse teorema, usa-se o que conhecemos distribuição conjunta das variáveis para obtermos mais facilmente as matrizes de probabilidades condicionais.

\subsubsection{Probabilidade Conjunta}

Seja X uma variável aleatória com $n$ estados possíveis, $x_{1}, \ldots, x_{n}, e P(X)$ a distribuição de probabilidades para estes estados:

$P(X)=\left(a_{1}, \ldots, a_{n}\right)$; onde $a_{i}$ é a probabilidade de X estar no estado i, $P\left(X=x_{i}\right)=a_{i}$ e $\sum a_{i}=1, \operatorname{com} a_{i} \geqslant 0, i=1, \ldots, n$.

Seja a variável Y uma outra variável aleatória que possui os estados $b_{1}, \ldots b_{m}$, então $\mathrm{P}(\mathrm{X}, \mathrm{Y})$ representa uma tabela $n \times m$ contendo os valores $P\left(a_{i}, b_{i}\right)$. Uma possível tabela podería ser, por exemplo:

Agora, pode-se calcular a probabilidade condicional $P(X \mid Y)$ como sendo:

$$
P\left(X=a_{i} \mid Y=b_{j}\right)=\left(P\left(X=a_{i} \wedge Y=b_{j}\right) / \sum_{q=1}^{n} P\left(X=a_{q} \wedge Y=b_{j}\right)\right)
$$




\begin{tabular}{lccc}
\hline \hline & $\mathrm{Y}=1$ & $\mathrm{Y}=2$ & $\mathrm{Y}=3$ \\
\hline $\mathrm{X}=1$ & $22.9 \%$ & $8.6 \%$ & $8.6 \%$ \\
$\mathrm{X}=2$ & $34.3 \%$ & $20.0 \%$ & $5.7 \%$
\end{tabular}

Tabela 4.2: Tabela de Probabilidade Conjunta X x Y

Resultando a seguinte tabela de probabilidade condicional:

\begin{tabular}{cccc}
\hline \hline $\mathrm{X}$ & $\mathrm{Y}=1$ & $\mathrm{Y}=2$ & $\mathrm{Y}=3$ \\
\hline 1 & $40 \%$ & $30 \%$ & $60 \%$ \\
2 & $60 \%$ & $70 \%$ & $40 \%$ \\
\hline
\end{tabular}

Tabela 4.3: Tabela de Probabilidade Condicional $X \mid Y$

\subsubsection{Redes Bayesianas}

Redes Bayesianas são grafos acíclicos direcionados, mostrando as relações de causalidade entre as variáveis [Cha91]. Nestes grafos, os nós são as variáveis (atributos) e os arcos representam os relacionamentos de influência entre essas variáveis.

De um ponto de vista estritamente matemático, uma Rede Bayesiana é uma representação compacta de uma tabela de conjunção de probabilidades do universo do problema. Por outro lado, Redes Bayesianas fornecem um modelo gráfico que representa de forma simples as relações de causalidade das variáveis de um sistema.

Uma Rede Bayesiana é definida por:

- Um conjunto de variáveis (nós) e um conjunto de arcos ligando as variáveis.

- Cada variável possui um conjunto limitado de estados mutuamente exclusivos.

- As variáveis e arcos formam um grafo dirigido sem ciclos (DAG). 
- Para cada variável A que possui como pais $B_{1}, \ldots, B_{n}$, existe uma tabela $P\left(A \mid B_{1}, \ldots, B_{n}\right)^{6}$.

Um exemplo muito famoso de Redes Bayesianas é o exemplo de João, Maria e o alarme contra ladrões de [Cha91].

O Enunciado pode ser descrito como: "Você instalou um alarme de assaltos em casa. Este alarme é razoavelmente de confiança na detecção de assaltantes, mas também responde ocasionalmente a pequenos tremores de terra. Além disso, você tem dois vizinhos, João e Maria, a quem pediu que lhe telefonassem para o emprego quando ouvissem o alarme. O João telefona sempre que ouve o alarme, mas por vezes confunde o toque do telefone com o alarme e também telefona. Por outro lado, a Maria gosta de ouvir música bastante alta e por vezes não ouve o alarme tocar. Dada a evidência de quem telefonou ou não, gostaríamos de estimar a probabilidade de ter ocorrido um assalto.".

A figura 4.7 mostra a topologia para esse domínio apresentada em [Cha91]. Um fato importante que é apontado é que não há nenhuma indicação de que Maria está ouvindo música e nem de que o telefone pode atrapalhar João e, segundo esse artigo, esses fatos estão implicitamente associados às incertezas relacionadas entre os arcos Soa Alarme e João Liga, e Soa Alarme e Maria Liga.

Tendo o grafo acima, dizemos que possuímos a topologia da rede (ou a conectividade da rede), de tal forma que somos capazes de calcular a tabela de probabilidades condicionais para cada nó.

Os nós L e T são dito entradas (inputs) do sistema pois é necessária informação para início da propagação das probabilidades na rede. Iniciaremos por calcular a probabilidade intermediária de o alarme soar.

A parte superior da figura 4.8 mostra a combinação de fatos dos inputs que geram probabilidades distintas do alarme soar. A primeira coluna da tabela inferior da figura 4.8 mostra a probabilidade calculada do alarme soar dada a observação das variáveis de entrada.

A figura 4.9 mostra a rede bayesiana e suas respectivas probabilidades, onde:

\footnotetext{
${ }^{6}$ De modo que se A não possui um pai, então sua probabilidade se resume à probabilidade incondicional $\mathrm{P}(\mathrm{A})$, que é caso particular de $P(A \mid)$ ou $P(A \mid \Omega)$, onde $\Omega$ representa o universo todo de observação.
} 


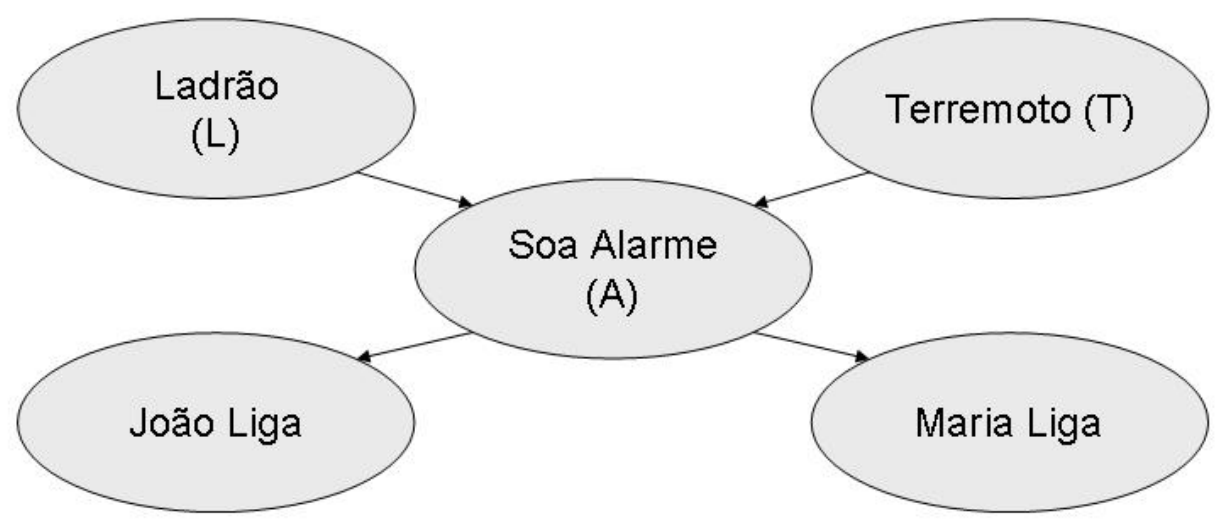

Figura 4.7: Estrutura exemplo - Alarme. Adaptado de [Cha91]

- $\mathrm{P}(\mathrm{L})$ é a probabilidade incondicional de um ladrão aparecer.

- $\mathrm{P}(\mathrm{T})$ é a probabilidade incondicional de um terremoto acontecer.

- $\mathrm{P}(\mathrm{A})$ é a probabilidade condicional dadas as observações de Ladrão e Terremoto.

- $\mathrm{P}(\mathrm{J})$ é a probabilidade condicional de João ligar dado que o alarme soou ou não soou.

- $\mathrm{P}(\mathrm{M})$ é a probabilidade condicional de Maria ligar dado que o alarme soou ou não soou.

Se quisermos calcular a probabilidade de João ligar, dado que temos 


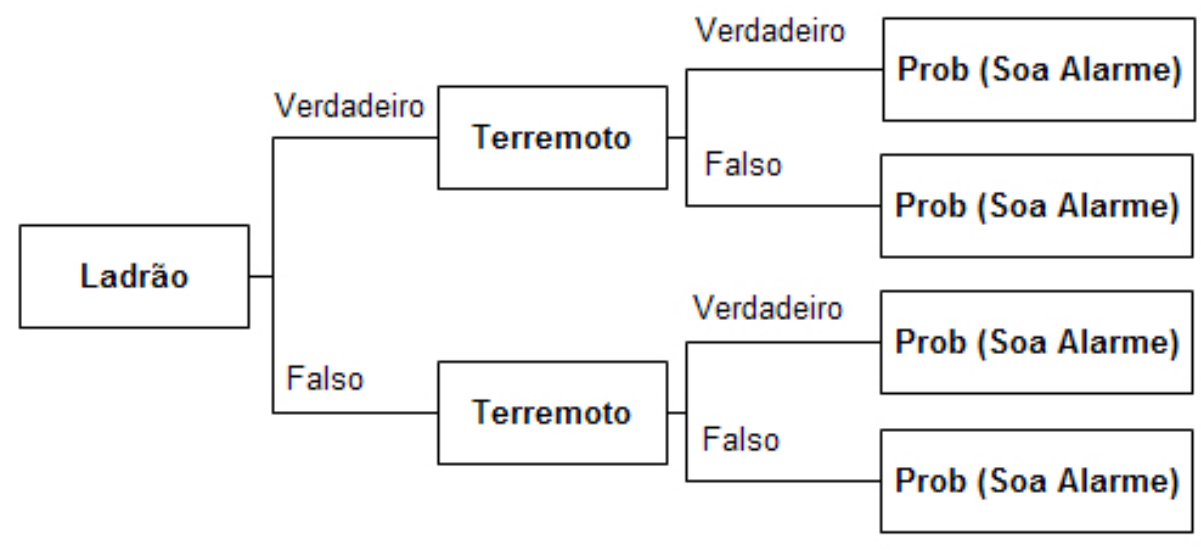

\begin{tabular}{|c|c|c|c|}
\cline { 3 - 4 } \multicolumn{2}{c|}{} & \multicolumn{2}{c|}{$\mathrm{P}(\mathbf{A} \mid \mathbf{L}, \mathrm{T})$} \\
\hline Entrada 1 & Entrada 2 & $\mathrm{V}$ & $\mathrm{F}$ \\
\hline Ladrão & Terremoto & 0,95 & 0,05 \\
\hline Ladrão & Não Terremoto & 0,95 & 0,05 \\
\hline Não Ladrão & Terremoto & 0,29 & 0,71 \\
\hline Não Ladrão & Não Terremoto & 0,001 & 0,999 \\
\hline
\end{tabular}

Figura 4.8: Tabela de Probabilidade do alarme soar

um ladrão na casa e não houve terremoto. Temos:

$$
P(J)=P(J \mid A) * P(A \mid R \cap \neg T)=0,95 * 0,9=0,855 \text { ou } 85,5 \%
$$

E se quisermos calcular uma probabilidade invertida, digamos a probabilidade do evento em que o alarme toca mas não houve assalto nem terremoto e que João e Maria telefonaram, temos:

$$
\begin{gathered}
P(J \cap M \cap A \cap L \cap \neg T)=P(J \mid A) * P(M \mid A) * P(A \mid L \cap \neg T) * P(\neg L) * P(\neg T)= \\
0.9 * 0.7 * 0.001 * 0.999 * 0.998=0.00062 \text { ои } 0.062 \%
\end{gathered}
$$

\subsubsection{Construção da Rede Bayesiana}

Na implementação de redes bayesianas, podem ocorrer três casos: 


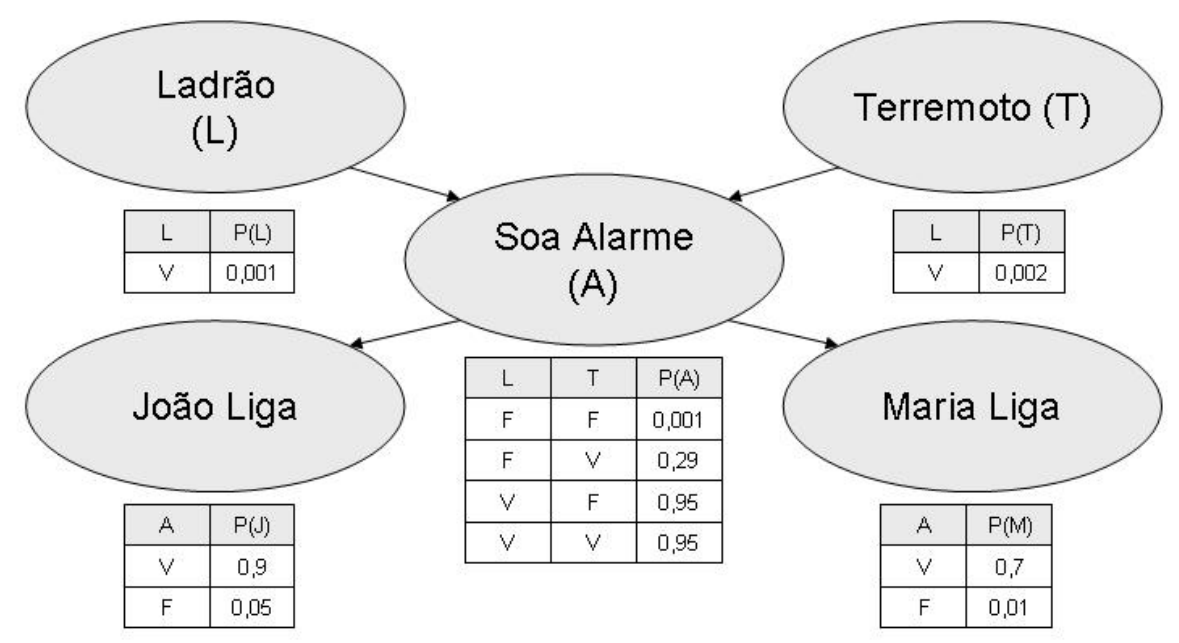

Figura 4.9: Topologia com a Probabilidade do alarme soar. Adaptado de [Cha91]

(a) A estrutura é conhecida e todas as variáveis são observáveis nos dados de treinamento. Neste caso, as probabilidades condicionais são estimadas a partir das freqüências relativas observadas nos dados.

(b) A estrutura é conhecida e nem todas as variáveis são observáveis nos dados: Existem métodos que procuram aprender as probabilidades a partir dos dados. (Ex.: gradiente ascendente).

(c) A estrutura é desconhecida: Existem métodos que procuram aprender a estrutura da rede (Ex.: Algoritmo K2) 
Judea Pearl em seu livro [Pea00] apresenta um dos principais algoritmos para construção de uma Rede Bayesiana através do critério que ele batizou de d-Separation(direction-dependent separation).

d-Separação: duas variáveis A e C de uma rede bayesiana são dseparadas se todo caminho não-direcionado entre $\mathrm{A}$ e $\mathrm{C}$ possui uma variável B cuja conexão no caminho esteja bloqueada.

- Conexão Serial ( $A \rightarrow B \rightarrow C$ ): A e C são bloqueados se B está instanciada.

- Conexão Divergente $(A \leftarrow B \rightarrow C$ ): A e C são bloqueados se $\mathrm{B}$ está instanciada.

- Conexão Convergente ( $A \rightarrow B \leftarrow C$ ): A e C são bloqueados se nem $B$ nem seus descendentes receberam qualquer evidência.

Podemos de uma maneira menos formal dizer que duas variáveis A e $\mathrm{B}$ de uma rede bayesiana estão d-Separadas se A não tem influência sobre B, e vice-versa.

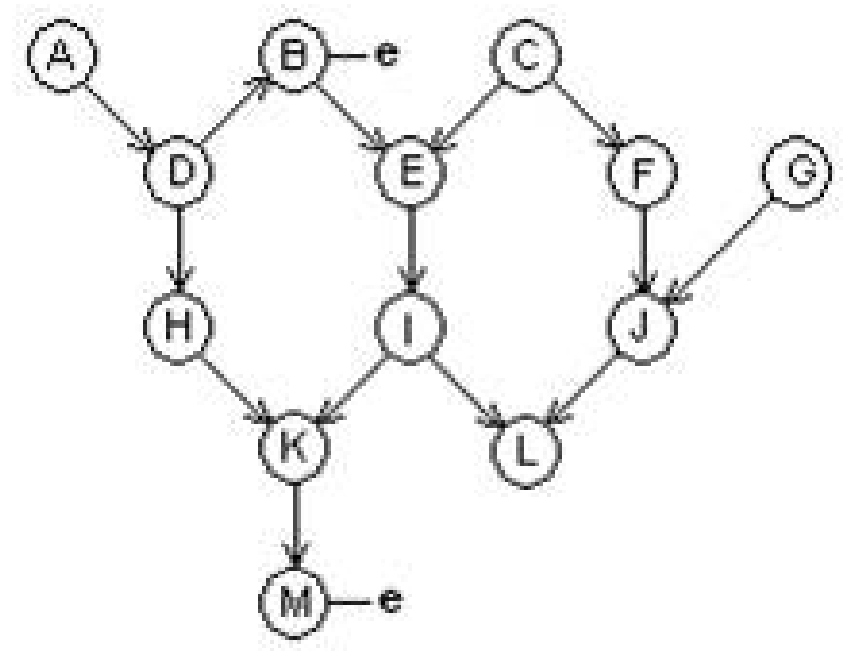

Figura 4.10: Exemplo de d-Separação. Adaptado de [Pea00] 
Exemplo: Se supormos as variáveis B e M instanciadas na figura 4.10, então a variável A está d-separada apenas da variável $\mathrm{G}$, já que D-B-E, I-L-J e F-J-G são exemplos de bloqueios para os três caminhos possíveis.

Marques [Mar] apresenta um exemplo de construção matemática da rede bayesiana, exemplo que reproduizimos abaixo.

Para construção, o artigo utiliza a seguinte equação para calcular o valor de uma entrada:

$$
P\left(x_{1}, \ldots, x_{n}\right)=\prod P\left(x_{i} \mid \operatorname{Pais}\left(X_{i}\right)\right) \text { para } 0 \geq i \geq n
$$

Além disso, cada entrada da tabela de conjunção de probabilidades pode ser calculada a partir da conjunção das variáveis atribuídas aos devidos valores, $P\left(X_{1}=x_{1} \cap \ldots \cap X_{n}=x_{n}\right)$, ou $P\left(x_{1}, \ldots, x_{n}\right)$.

$P\left(x_{1}, \ldots, x_{n}\right)=\prod P\left(x_{i} \mid \operatorname{Pais}\left(X_{i}\right)\right)$ para $0 \geq i \geq n$, será reescrita para: $P\left(x_{1}, \ldots, x_{n}\right)=P\left(x_{n} \mid x_{n-1}, \ldots x_{1}\right) P\left(x_{n-1}, \ldots x_{1}\right)$

Este processo é repetido, reduzindo cada conjunção de probabilidades em uma probabilidade condicional e uma conjunção menor.

$$
\begin{gathered}
P\left(x_{1}, \ldots, x_{n}\right)=P\left(x_{n} \mid x_{n-1}, \ldots x_{1}\right) P\left(x_{n-1} \mid x_{n-2}, \ldots x_{1}\right) \ldots P\left(x_{2} \mid x_{1}\right) P\left(x_{1}\right)= \\
\prod P\left(x_{i} \mid x_{i-1}, \ldots x_{1}\right) \text { para } 0 \geq i \geq n
\end{gathered}
$$

Comparando a equação com 4.2, o artigo observa que a especificação de uma tabela de conjunção de probabilidades é equivalente com a declaração geral:

$$
P\left(X_{i} \mid X_{i-1}, \ldots, X_{1}\right)=P\left(X_{i} \mid \operatorname{Pais}\left(X_{i}\right)\right) \text { para Pais }\left(X_{i}\right) \subseteq\left\{x_{i-1}, \ldots x_{1}\right\}
$$

Uma rede Bayesiana é a representação correta de um domínio se, e somente se, cada nó é condicionalmente independente de seus predecessores, dado seu pai. Portanto, para se construir uma rede cuja estrutura represente devidamente o domínio do problema, é necessário que para todo nó da rede esta propriedade seja atendida. Intuitivamente, 
os pais de um nó $X_{i}$ devem conter todos os nós $X_{1}, \ldots, X_{i-1}$ que influenciem diretamente $X_{i}$. Assim, é possível, por exemplo, determinar que a seguinte igualdade é verdadeira:

$P($ MariaLig $\mid$ JoaoLig, Alarme, Terremoto, Ladrão $)=P($ MariaLig $\mid$ Alarme $)$

Por fim, o artigo [Mar] apresenta um possível algoritmo para construção da Rede Bayesiana, como sendo:

(a) Escolha um conjunto de variáveis $X_{i}$ que descrevam o domínio.

(b) Escolha uma ordem para as variáveis.

(c) Enquanto existir variáveis:

i. Escolha uma variável $X_{i}$ e adicione um nó na rede.

ii. Determine os nós Pais $\left(X_{i}\right)$ dentre os nós que já estejam na rede e que satisfaçam a equação 4.3.

iii. Defina a tabela de probabilidades condicionais para $X_{i}$.

O fato de que cada nó é conectado aos nós mais antigos na rede garante que o grafo será sempre acíclico.

\subsection{Naive Bayes (NB)}

A Naive Bayes (classificador ingênuo) é um caso especial de uma Rede Bayesiana, onde a topologia é conhecida, nesta topologia todas as variáveis pertencem ao modelo e elas estão conectadas unicamente a variável independente (variável da classe fraude/legítima).

Assim como BN, NB também é baseado na aplicação do teorema de Bayes, porém nesse segundo caso assumindo forte independência entre as variáveis explicativas ${ }^{7}$. Podemos entender NB como sendo um subproblema de $\mathrm{BN}$ no que diz respeito à topologia. Como uma $\mathrm{BN}$ permite dependência entre as variáveis explicativas, então podemos ter: Renda $\rightarrow$ StatusFamiliar $\rightarrow$ CompraUmCarroCaro ${ }^{8}$. Uma

\footnotetext{
${ }^{7}$ Variáveis explicativas são as variáveis que são usadas pelo modelo para estimar a variável dependente ou objetivo.

${ }^{8}$ Lê-se: que a compra de um carro caro está associada ao status familiar, e por sua vez o status familiar está associado a renda.
} 
NB, por outro lado, supõem independência entre as variáveis explicativas, neste caso teríamos: StatusFamiliar $\rightarrow$ CompraUmCarroCaro e Renda $\rightarrow$ CompraUmCarroCaro.

Outra diferença importante na topologia é que em uma BN, uma variável explicativa pode ser considerada de nenhum efeito sobre a variável dependente ${ }^{9}$, já na NB estima-se a influência de todas as variáveis explicativas na predição da variável dependente, na seção seguinte apresentamos o funcionamento do processo de aprendizagem de uma NB.

\subsubsection{A aprendizagem}

O classificador padrão NB para um dado conjunto de variáveis $X_{1}, X_{2} \ldots X_{n}$ é o estado, ou classe, $c_{j} \in C$ cuja probabilidade seja máxima para essa dada entrada.

Abstratamente, temos que a classe $c_{j}$ da variável dependente $\mathrm{C}$ (no nosso trabalho $\mathrm{C}=$ [fraude,legítima]) está relacionada com todas as variáveis explicativas de 1 até $n$. Ou seja:

$$
p\left(C \mid X_{1}, \ldots, X_{n}\right)
$$

Aplicando o teorema de Bayes chegamos a:

$$
p\left(C \mid X_{1}, \ldots, X_{n}\right)=\frac{p(C) p\left(X_{1}, X_{2}, \ldots, X_{n} \mid C\right)}{p\left(X_{1}, X_{2}, \ldots, X_{n}\right)}
$$

Como o denominador da equação não depende de $\mathrm{C}$, e no final pegaremos como classe padrão a classe com maior probabilidade, podemos então dispensar essa parte da equação. Além disso, podemos aplicar a definição da probabilidade condicional.

$p\left(C, X_{1}, X_{2} \ldots, X_{n}\right)$

$=p(C) p\left(X_{1}, X_{2} \ldots, X_{n} \mid C\right)$

$=p(C) p\left(X_{1} \mid C\right) p\left(X_{2}, \ldots, X_{n} \mid C, X_{1}\right)$

$=p(C) p\left(X_{1} \mid C\right) p\left(X_{2} \mid C, X_{1}\right) p\left(X_{3}, \ldots, X_{n} \mid C, X_{1}, X_{2}\right)$

$=p(C) p\left(X_{1} \mid C\right) p\left(X_{2} \mid C, X_{1}\right) p\left(X_{3} \mid C, X_{1}, X_{2}\right) p\left(X_{4}, \ldots, X_{n} \mid C, X_{1}, X_{2}, X_{3}\right)$

\footnotetext{
${ }^{9}$ Variável dependente é a variável cuja saída do modelo pretende estimar, também conhecida como variável objetivo.
} 
Como a suposição mais forte para NB é a independência, podemos aplicar a regra da independência: $p\left(X_{i} \mid C, X_{j}\right)=p\left(X_{i} \mid C\right)$, de modo que o modelo final poderá ser expresso por:

$$
p\left(C, X_{1}, X_{2}, \ldots, X_{n}\right)=p(C) p\left(X_{1} \mid C\right) p\left(X_{2} \mid C\right) \ldots p\left(X_{n} \mid C\right)=p(C) \prod_{i=1}^{n} p\left(X_{i} \mid C\right)
$$

Isso significa que sobre a suposição de independência temos:

$$
P\left(C \mid X_{1}, X_{2}, \ldots, X_{n}\right)=\frac{P(C) \prod_{i=1}^{n} P\left(X_{i} \mid C\right)}{P\left(X_{1}, \ldots, X_{n}\right)}
$$

O classificador então escolhe a classe $c_{i}\left(\mathrm{c}_{i} \in C\right)$ com maior probabilidade segundo a avaliação da equação 4.4 para uma determinada instância de entrada. Esse método é conhecido como maximum a posteriori ou regra MAP e pode ser descrito como a aplicação da seguinte equação de maximização:

$$
\operatorname{argmax}_{c_{j}} P\left(C=c_{j}\right) \prod_{j=1}^{n} P\left(X_{i}=x_{i} \mid C=c_{j}\right)
$$

\subsection{Sistemas Imunológicos Artificiais (AIS)}

Os sistemas humanos têm servido como fonte de inspiração para o desenvolvimento científico em várias frentes, na inteligência artificial várias pesquisas tentam criar sistemas artificiais para simular o funcionamento dos sistemas humanos para dessa forma tomar decisões consideras inteligentes. Um exemplo importante disso foi o fato de que em janeiro de 2002 a renomada revista Nature [Kla02] publicou uma reportagem sobre o assunto de sistema imuno-baseados, elencando suas diversas aplicações, dando um enfoque especial a sua aplicação na proteção de computadores contra intrusos e na detecção de transações fraudulentas em sistemas transacionais. Essa mesma reportagem já apontava o futuro uso comercial de sistemas imuno-baseados para deteç̧ão de fraude em sistemas transacionais para o ano de 2003. 
Essas abstrações do sistema imunológico humano (HIS - Human Immune System) deram origem ao estudo do sistema imunológico artificial (AIS - Artificial Immune System). Uma sequência de trabalhos estudando os conceitos, princípios e propriedades; e propondo aplicações para essa técnica tem sido apresentada desde 1996. Detecção de anomalias (Dasgupta, 1996), detecção de falhas (Bradley, 2000), segurança de computadores (Hofmayer, 2000), mineração de dados (Knight, 2002).

Um dos principais trabalhos que nos baseamos para esse trabalho foi a implementação de um modelo robusto para segurança de redes de computadores (CASTRO, 2001; CASTRO e TIMMIS, 2002).

Todos essas aplicações tem inspirado a àrea de pesquisa denominada imunologia computacional.

Iniciamos esse cápitulo trazendo conceitos de imunologia e, na sequência, conceituamos o AIS e sua aplicações. Demos uma maior cobertura de conteúdo a essa técnica pois essa é uma técnica relativamente nova e geralmente desconhecida.

\subsubsection{Imunologia}

O artigo 'Artificial Immune System' de L. N. de Castro and J. Timmis [dCT02b] é pioneiro em trazer a abstração da Imunologia para um método de classificação, e nós acreditamos que esse é um método de grande potencial para detecção da fraude. Este cápitulo sobre imunologia do Sistema Imunológico Humano é uma adatação dos textos de Castro (2001) [dCT02b] e a dissertação de mestrado de Machado (2005) [Mac05], as figuras foram retiradas do texto de Machado (2005) que também se baseou em Castro (2001) para cria-las, adapta-las ou traduzi-las.

O Sistema Imunológico Humano (HIS) consiste em um conjunto de órgãos, células e moléculas que são responsáveis pela defesa do corpo contra ataques de invasores externos, tais como bactérias, vírus ou parasitas. Os Sistemas Imunológicos Artificiais (AIS) foram criados com base nesses conceitos do HIS.

A base da ação do HIS está centrada em diferenciar moléculas e células do próprio corpo (antígenos próprios) das estrangeiras (antígenos não 
próprio). Essa diferenciação se fixa em padrões, com a conseqüente detecção e eliminação de elementos patogênicos.

O HIS é inteligente e após um primeiro contato com o intruso e a sua posterior eliminação, guarda o conhecimento adquirido em uma memória imunológica. Assim, em um futuro encontro com a enfermidade, sua resposta pode ser mais rápida e eficaz.

As respostas desse Sistema dividem-se em duas classes: INATA ou ADAPTATIVA. A primeira, mais rápida, generaliza sua ação, não enfatizando a diferenciação dos agentes patogênicos. Quem age são os Fagócitos ou Granulócitos. A resposta Adaptativa, num primeiro contato com o patógeno é mais lenta. Porém, num segundo, tem sua ação acelerada, já que utiliza as informações guardadas e diferencia o agente patogênico, dando respostas especializadas. Quem age são os Linfócitos, constantes em nosso Sistema Linfático.

Na Anatomia do Sistema Imunológico Humano, órgãos, células e moléculas possuem funções específicas e se ajudam para a detecção e eliminação e patogenias. Os órgãos linfóides são classificados em Primários e Secundários. Os primeiros são responsáveis pela produção e maturação de linfócitos, incluindo o timo e a medula óssea. Os Secundários são os órgãos onde os linfócitos estimulam a produção de anticorpos, entre os quais citam-se as adenóides, baço, placas de peyer, apêndice, linfonodos e vasos linfáticos.

- Órgãos linfóides primários:

- Medula óssea: É o órgão responsável pela geração de elementos sangüíneos. É o local onde se desenvolvem as células B e células-tronco.

- Timo: Local onde as células T se desenvolvem.

- Órgãos linfóides secundários:

- Amígdalas e adenóides: Local onde estão presentes grandes quantidades de células linfóides.

- Linfonodos: Ambiente onde ocorre a resposta imunológica adaptativa.

- Apêndice e Placas de Peyer: Linfonodos especializados contendo células imunológicas destinadas à proteção do sistema gastrointestinal; 


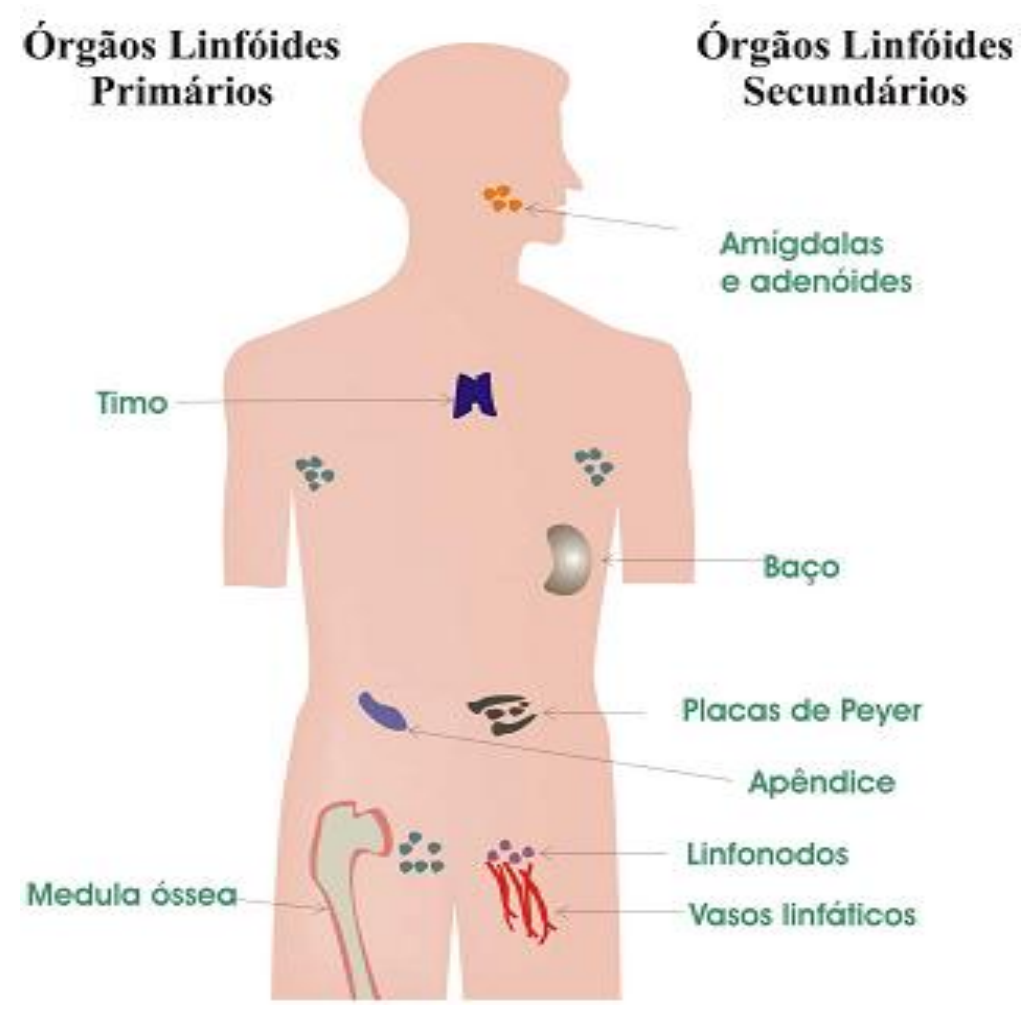

Figura 4.11: Anatomia do Sistema Imunológico Humano. Retirado de [Mac05].

- Baço: Possui a função de remover as células sangüíneas envelhecidas e combater organismos que invadem a corrente sangǘnea ou são levados por ela até o baço.

- Vasos linfáticos: Rede de canais que transporta a linfa para o sangue e órgãos linfóides. Os vasos aferentes drenam o líquido dos tecidos e carregam as células portadoras dos antígenos dos locais de infecção para os órgãos linfáticos.

Como dito anteriormente, as células pertencentes ao Sistema Imunológico têm suas respostas classificadas como Inatas ou Adaptativas. Observe o esquema da figura 4.12:

(a) Fagócitos: São grandes células brancas que digerem microorganismos invasores e outras partículas. Possuem a capacidade de expor 


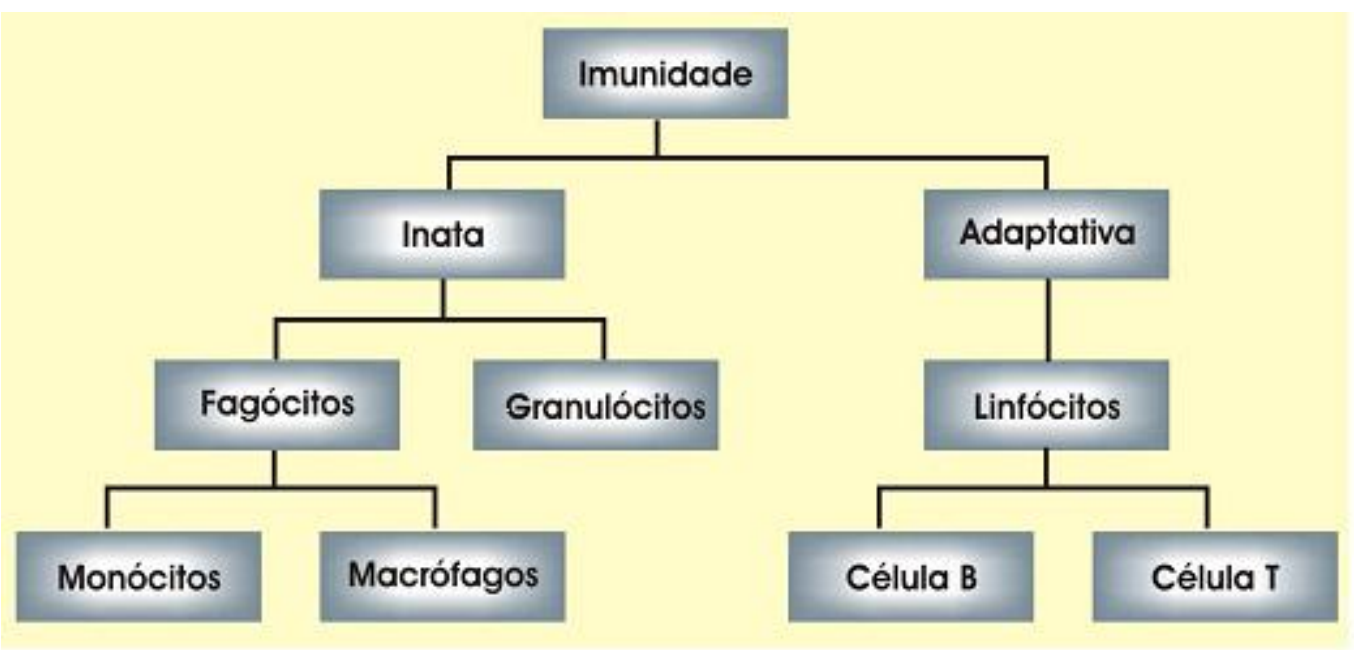

Figura 4.12: Hierarquia de Células do Sistema Imunológico. Retirado de [Mac05].

os antígenos para as células linfóides.

(b) Monócitos: Células que circulam no sangue e se tornam macrófagos ao entrarem nos tecidos.

(c) Macrófagos: Atuam, principalmente, como coletores de resíduos e como células reguladoras no desenvolvimento de respostas imunológicas.

(d) Granulócitos: Atuam ingerindo patógenos e na defesa contra parasitas.

(e) Linfócitos: São pequenas células de glóbulos brancos que possuem como responsabilidade a especificação das atividades do sistema imunológico. Duas importantes derivações são as células B e as células T. Por meio dessas células, o HIS realiza o reconhecimento de patogenias, implementa as respostas imunológicas e cria sua memória imunológica.

(f) Células B: São células que amadurecem e crescem fora do timo, e trabalham principalmente secretando substâncias solúveis chamadas de anticorpos dentro dos fluídos do corpo, também conhecido como imunidade humoral.

(g) Células T: Essa classe de linfócitos atua diretamente sobre células do corpo atacadas por viroses, parasitas ou fungos. Atua, assim 
como as células B, no reconhecimento de antígenos.

O HIS possui diversos níveis de defesa. A pele é o primeiro deles. Quando um patógeno consegue ultrapassar essa barreira física, ele ainda enfrenta as barreiras bioquímicas, as quais podem eliminar ou criar ambientes desfavoráveis aos diversos tipos de invasores. Se, mesmo assim, o intruso não for destruído, as células ativam a resposta imune Inata, que tem como protagonista o Macrófago. A última barreira do organismo fica a cargo da resposta imune Adaptativa, aqui os Linfócitos agem com ações especializadas a cada tipo de patógeno. Observe a figura 4.13 :

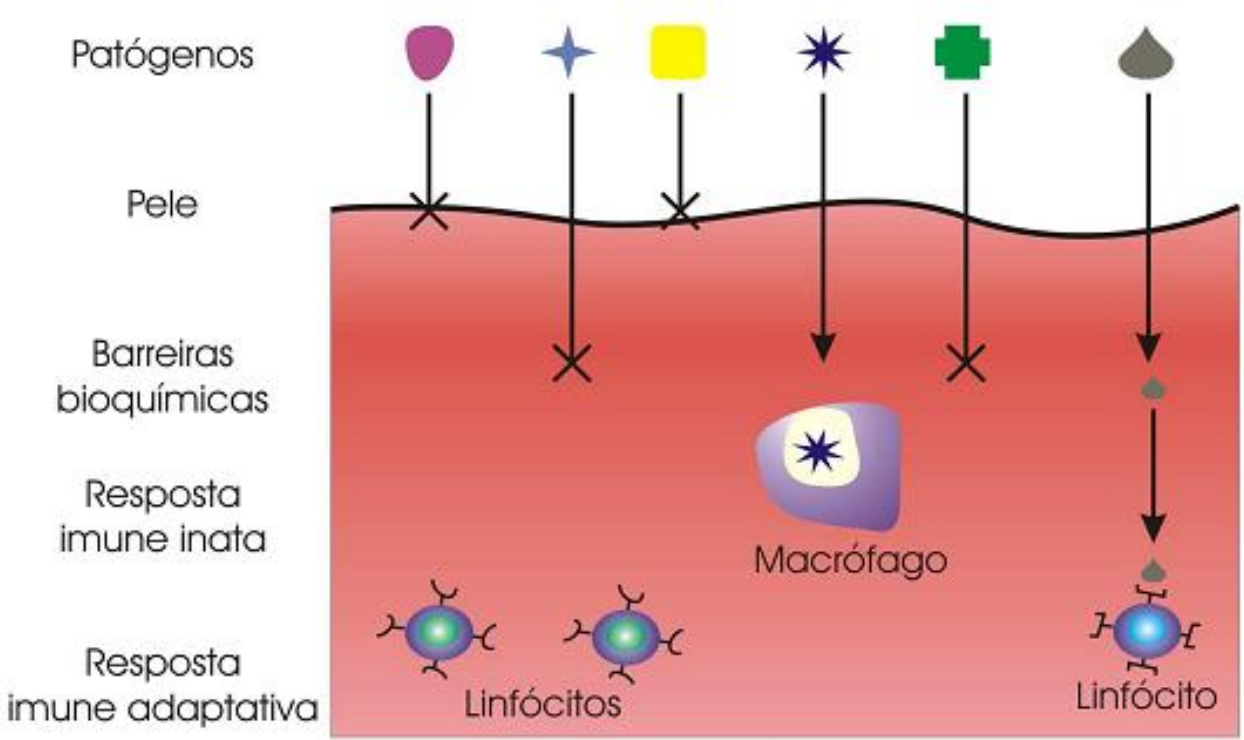

Figura 4.13: Barreiras do Sistema Imunológico Humano. Retirado de $[\mathrm{Mac} 05]$.

O reconhecimento de padrões, importantíssimo na ativação da resposta contra patógenos, se dá através da presença de moléculas receptoras na superfície das células imunológicas, das quais se destacam as células $\mathrm{B}$ e células T. Essas células são parecidas, mas se diferenciam quanto à sua forma de identificação dos antígenos e função. As células B são capazes de reconhecer os antígenos livres em solução (como no sangue), enquanto as células $\mathrm{T}$ requerem que os antígenos sejam apresentados por células acessórias. Observe a ilustração 4.14 : 


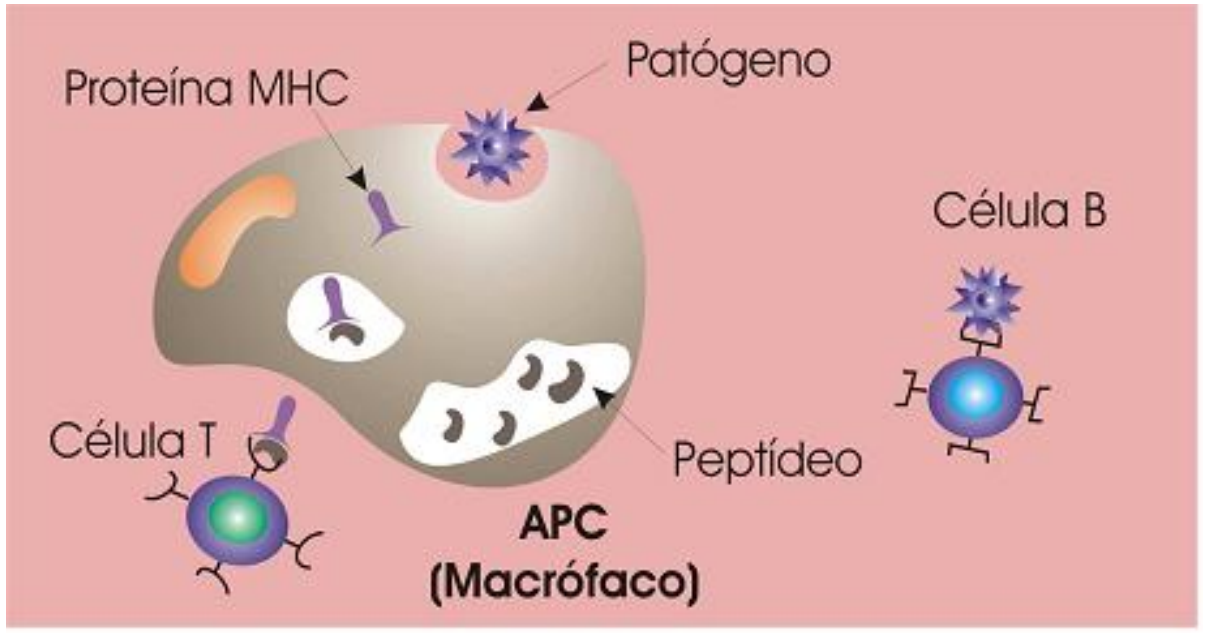

Figura 4.14: Reconhecimento pelos receptores das células T e B. Retirado de [Mac05].

O reconhecimento de antígenos e sua classificação em próprio (self) ou não-próprio (nonself) é imprescindível para a ativação de respostas imunológicas. As moléculas que fazem essa classificação são chamadas de MHC (Complexo de Histocompatibilidade Principal). Existem duas grandes classes de moléculas de MHC, denominadas MHC Classe I e MHC Classe II.

As moléculas da Classe I são encontradas em todas as células e detectam outras que tenham sido infectadas com um parasita e que precisam ser eliminadas para evitar infecções. As moléculas da Classe II se encontram nas células acessórias, tais como células B e macrófagos.

O HIS apresenta alguns mecanismos, tais como Seleção Clonal, Seleção Positiva, Seleção Negativa, entre outros. Assim, permite-se a produção de células imunocompetentes, evitando doenças auto-imunes.

Na teoria da Seleção Clonal e Maturação por Afinidade ocorre a eliminação ou inativação dos novos linfócitos diferenciados capazes de reagir com padrões antigênicos expressos por elementos do próprio organismo e a interação de uma molécula estranha com um receptor de linfócito capaz de se ligar a essa molécula leva à ativação linfocitária. Ocorre também a restrição fenotípica de um padrão para cada célula diferenciada e retenção deste padrão pelos descendentes clonais. Por fim, a 
geração de variações genéticas aleatórias, por intermédio de um mecanismo de hipermutação somática, expressas sob a forma de diversos tipos de anticorpos.

A Seleção Positiva das células T se baseiam na premissa de que todas as células T devam reconhecer antígenos associados a moléculas MHCSelf que formam os complexos MHC/peptídeo. Para isso, é necessário selecionar as células $\mathrm{T}$ cujos receptores sejam capazes de reconhecer e se ligar às moléculas $\mathrm{MHC} /$ peptídeo de antígenos próprio. A Seleção Positiva das células $\mathrm{T}$ visa assegurar que o sistema imunológico seja capaz de reconhecer antígenos não-próprio no contexto de moléculas MHC/peptídeo de antígenos próprio. Como resultado do reconhecimento e ligação ao antígeno, e auxílio da célula T-Helper, os linfócitos B em proliferação sofrem hipermutações. As células filhas mutantes que se ligam mais eficientemente ao antígeno são selecionadas para expansão e, portanto, resgatadas da morte celular.

A Seleção Negativa pode ocorrer nos órgãos linfóides centrais ou periféricos. Os órgãos linfóides primários são projetados para não permitir a entrada de antígenos próprio, enquanto os órgãos linfóides secundários são projetados para filtrar e concentrar os elementos não-próprios, promovendo reações co-estimulatórias a uma resposta imunológica. A Seleção Negativa das células T ocorre dentro do Timo. A interação das células $\mathrm{T}$ imaturas como os ligantes do $\mathrm{MHC} /$ peptídeo dos antígenos próprios resulta na morte (deleção clonal) daquelas células T que forem auto-reativas.

A tolerância promovida pelas células T seria insuficiente para a proteção contra doenças auto-imunes. Células B imaturas dentro da medula óssea também são sensíveis a uma indução de tolerância por seleção negativa, caso elas encontrem um antígeno na ausência dos sinais coestimulatórios liberados principalmente pelas células T.

A figura 4.15 ilustra, os mecanismos básicos de defesa do Sistema Imunológico.

As propriedades do HIS baseiam-se na Detecção, Diversidade, Aprendizado e Tolerância. A Detecção se dá através das reações químicas e físicas entre os receptores das células imunológicas e os epítopos localizados na superfícies dos agentes patogênicos. A força de ligação ou qualidade de reconhecimento entre um receptor e um epítopo é con- 


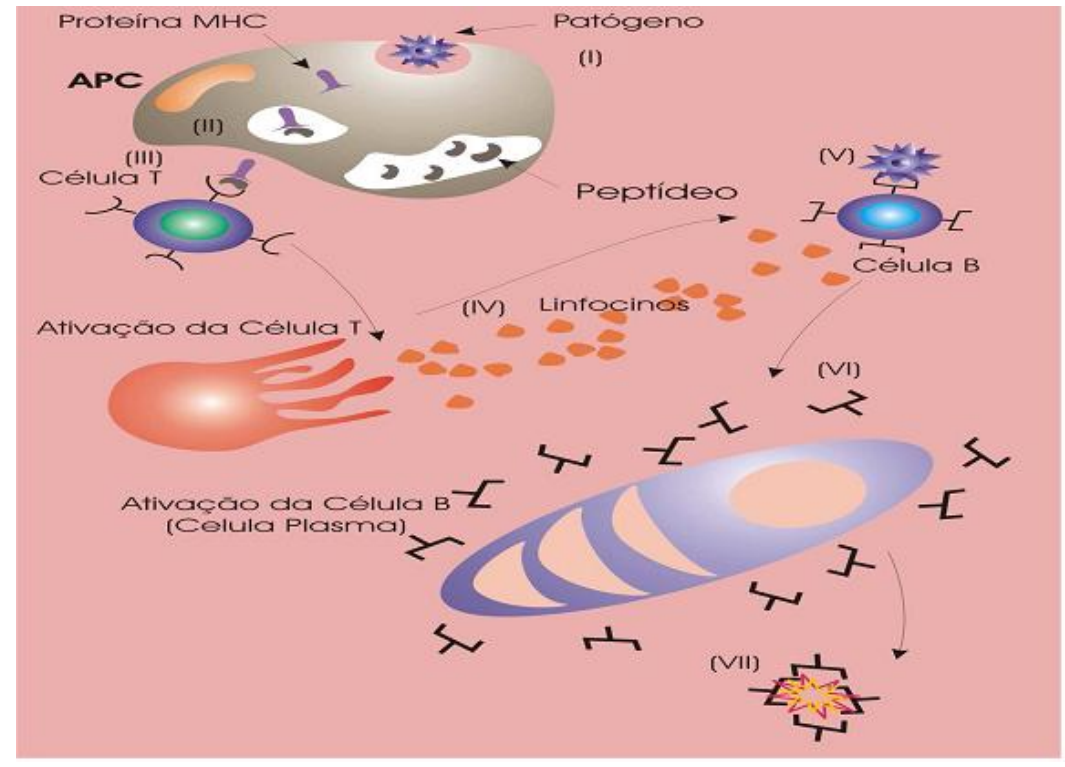

Figura 4.15: Mecanismos Básicos de Defesa do Sistema Imunológico Humano. Retirado de [Mac05].

ceituada como Afinidade. A noção de Diversidade também é de fundamental importância dentro do processo. Como o corpo humano não gera tantas proteínas quanto os possíveis agentes patogênicos, o HIS promove uma renovação constante de linfócitos, os quais se utilizam da memória imunológica que torna mais rápida a ação contra antígenos não-próprios. O Aprendizado se dá com na mutação das células B. A cada mutação, a células-filha trazem novos receptores, diferentes da célula-mãe, conseqüentemente, diferentes níveis de afinidade. Quanto maior essa afinidade, mais semelhante é o clone e mais eficiente é o linfócito na eliminação da infecção. A retenção da informação codificada nas células B constitui a memória imunológica, possibilitando uma reação mais rápida da segunda vez que a mesma patogenia ou uma outra similar seja encontrada. Na Tolerância, as moléculas que assinalam uma célula como própria são codificadas em seções do cromossoma MHC, diversidade conhecida como polimorfismo. Essas moléculas determinam a quais antígenos um organismo é capaz de reagir e com qual intensidade. Essa propriedade permite que as células imunológicas se reconheçam mutuamente e comuniquem-se. 
Todos esses preceitos provenientes da bioquímica humana serviram como base para o desenvolvimento do AIS. Desde 1994, as pesquisas computacionais têm crescido no âmbito dos mecanismos adaptativos evolucionários para a proteção de organismos contra patógenos estrangeiros. Entre as diferentes áreas que estão aplicando AIS, citamse: Métodos computacionais inspirados em princípios imunológicos, sistemas imunológicos artificiais aplicados ao reconhecimento de padrões, sistemas baseados em imunologia para a detecção de falhas e anomalias, modelos de redes imunológicas e suas aplicações, sistemas multi-agentes baseados em imunologia, abordagens multi-agentes para a modelagem e simulação de sistemas imunológicos, sistemas auto-organizados baseados em imunologia, sistemas baseados em imunologia para o desenvolvimento de inteligência coletiva, métodos de classificação baseados em imunologia, sistema imunológico como protótipo para sistemas autônomos descentralizados, abordagens imunológicas para vida artificial, abordagens imunológicas para segurança de sistemas de informação, abordagens imunológicas para proteção contra vírus e vermes computacionais, metáforas imunológicas para aprendizagem de máquina, computação imunológica para mineração de dados (data mining), sistemas imunológicos artificiais aplicados à segurança de redes e detecção de intrusão (CASTRO, 2001).

Um AIS é composto por 3 importantes fatores:

Maturação da Afinidade: que ocorre através da ordenação das $\mathrm{ARB}^{10}$ segundo a sua afinidade com intrusos, nessa etapa a manutenção de uma quantidade grande de ARBs limiar baixo para afinidade.

Memória Imunológica: a memória imunológica corresponde a seleção dos ARBs com afinidade superior a um certo limiar para serem usados como matrizes para a execução da próxima geração.

Tolerância ao Próprio: essa tolerância é um mecanismo poderoso para evitar que o sistema destrua o próprio corpo, chamamos esse efeito

\footnotetext{
${ }^{10}$ Uma B-Cell também é conhecida computacionalmente como ARB (Artificial Recognition Ball)
} 
de auto-imune. Computacionalmente falando, a fim de evitar o efeito auto-imune intrudiu-se o mecanismo conhecido como Seleção Negativa.

\subsubsection{Seleção Negativa}

O algoritmo da seleção negativa se dá da seguinte forma:

(a) Gerar aleatoriamente elementos candidatos (c) usando a representação adotada;

(b) Comparar os elementos de $\mathrm{C}$ com os elementos de $\mathrm{P}$ (self set), então, se o match ocorrer, descartar o elemento de C. Caso contrário, guarde este elemento de $\mathrm{C}$ no conjunto de detectores (M).

\subsubsection{Seleção Clonal}

Quando uma célula B reconhece um antígeno não-próprio (nonself antigen) com certa afinidade, ela se prolifera produzindo anticorpos em alto volume, usando mutação e clonagem (sem crossover), além disso, células B com alta afinidade serão células de memória com maior tempo de vida. Quanto maior a afinidade maior o numero de filhos e vice-versa e quanto maior a afinidade menor a mutação e vice-versa.

Algoritmo CLONALG:

(a) Aleatoriamente inicializar a população de indivíduos (M);

(b) Para cada padrão de $\mathrm{P}$ calcule a afinidade com cada elemento de $\mathrm{M}$;

(c) Selecione os N1 elementos de maior afinidade de M e crie copias deles proporcionalmente com a afinidade;

(d) Mute todas as copias de maneira indiretamente proporcional à afinidade;

(e) Adicione à população $M$ todos os elementos gerados em 3 e 4 e selecione N2 desses elementos para serem memórias do sistema;

(f) Repita os passos de 2 a 5 até que algum critério de parada, à sua escolha, seja verificado; 


\subsubsection{Rede Imunológica}

Uma rede imunológica consta de um método capaz de se auto-ativar no caso do reconhecimento de células estranhas no organismo, ao mesmo tempo em que suprimi um anticorpo no caso de auto-identificação (algumas doenças alérgicas).

Dado um conjunto de padrões $(\mathrm{P})$ o algoritmo básico é dado por:

(a) Aleatoriamente inicializar a população da rede;

(b) Para cada padrão em P, aplique o algoritmo memória CLONALG que retornará $\left(\mathrm{M}^{*}\right)$ células de memória e suas coordenadas para o antígeno atual;

(c) Determinar a afinidade entre todos os elementos de $\mathrm{M}^{*}$;

(d) Eliminar todos, mantendo apenas um elemento de $\mathrm{M}^{*}$ cuja afinidade seja maior que um dado valor. A razão para esse processo é a eliminação da redundância;

(e) Concatenar todos os indivíduos do passo 4 com os indivíduos apresentados em $\mathrm{P}$ no início da computação. Isso resultará em uma maior população de indivíduos de memória M;

(f) Determinar a afinidade entre todos os elementos da população $\mathrm{M}$ e suprima todos, mantendo apenas um daqueles que se autoreconhece;

(g) Repita os passo de 2 a 6 . Até que algum critério seja verificado, como um mínimo de reconhecimento de padrão ou erro de classificação.

\subsection{Aprendizagem Sensível ao Custo e Meta Heurística}

Anterioriormente descrevemos como usar o custo para avaliar o desempenho de um modelo, descrevemos uma função que leva em consideração a diferença entre os tipos de erro, falso positivo e falso negativo. Nesta seção, iremos descrever como podemos utilizar a informação de custos distintos no desenvolvimetno dos modelos, descreveremos 
primeiro o que é uma meta heurística e em seguida, descrevemos duas meta heurísticas implementadas no Weka [WF05] para tornar o modelo ajustado ao custo. A primeira maneira, re-amostra com reposição e reclassifica as instâncias (MetaCost), e a segunda, altera a proporção das classes criando fazendo com que essa nova proporção represente o custo de cada uma das classes (CostSensitiveClassifier),

\subsubsection{Meta Heurística}

Em nossas leituras encontramos diferentes definições para meta heurística, principalmente quando mudávamos entre os diversos campos da inteligência artificial ou da otimização. Esse desencontro nos levou a trazer aqui uma definição que se assemelha muito mais a interpretação dada pelo livro do Weka ao termo do que de outras áreas.

Meta heurística, como usado pelo Weka, corresponde a um algoritimo que pode ou não executar transformações sobre a base de dados de entrada; e em seguida, execute uma ou mais vezes um dado método de classificação; e por fim, compile em uma única saída as diversas saídas de todas as execuções do passo anterior.

Ainda segundo a interpretação dada pelo livro do Weka, um algortimo só é considerado uma meta heurística caso ele possa ser executado sem que qualquer alteração seja necessária nos métodos de classificação, e mais que isso, um método só é considerado uma meta heurística se ele suporta todos os métodos de classificação sem restrição ${ }^{11}$. E como última regra, o Weka exige que uma meta heurística possua entrada e saída padrão do Weka, assim como os demais métodos.

\subsubsection{MetaCost}

O algoritmo MetaCost se baseia no uso de outro algoritmo chamado Bagging, de modo que antes de definirmos o algoritmo MetaCost vamos apresentar o algoritmo Bagging.

\footnotetext{
${ }^{11}$ Claro que isso só ocorre no Weka pois tanto a entrada como saída dos métodos possuem padrão bem definido.
} 
O Bagging é um método de re-amostragem que gera $\mathrm{N}$ amostras com reposição de mesmo tamanho da população fornecida são sorteadas. Esse processo com reposição causa repetição entre indivíduos ${ }^{12}$. Para cada uma dessas $\mathrm{N}$ amostras um novo modelo é desenvolvido; cada instância da entrada é submetida a cada um desses N modelos, então um veredicto sobre a classe que essa instância pertence é dada por votação ${ }^{13}$. O livro aponta também que, em vez do algoritmo simplesmente retornar a classe que uma determinada instância pertence, ele pode retornar o percentual de vezes que uma classe foi escolhida pelos diversos modelos. Isso pode ser interpretado como sendo a probabilidade do individuo pertencer a tal classe $^{14}$

A implementação do MetaCost no Weka corresponde primeiro a execução do algoritmo Bagging. Com o retorno do Bagging que é a probabilidade da instância fazer parte de uma dada classe - mais a matriz de custos, o MetaCost pode definir um ponto de corte que minimize o custo global para todas as instâncias. Após esse passo, seguindo o ponto de corte atrás definido, as instâncias são reclassificadas com a classe que minimize o custo global. Então um novo modelo, usando essa nova classificação, é gerado ${ }^{15}$.

\subsubsection{CostSensitiveClassifier}

Além do Meta Cost, o livro do Weka, traz o algoritmo CostSensitiveClassifier, esse algoritmo pode ser criado de duas formas distintas: a primeira corresponde a balancear a quantidade de instâncias de cada classe na amostra de treinamento de acordo com o custo atribuído para cada uma dessas classes através de reamostragem (geralmente com replicação dos casos menos freqüentes); e a segunda, utilizando a matriz de custo, e a probabilidade de um individuo pertencer a uma classe; esse custo é usado para fazer uma ponderação (ou reajuste) do modelo para minimizar o custo global em vez da classe mais provável. Segundo

\footnotetext{
${ }^{12}$ Segundo o livro Weka, essa repetição causa uma variabilidade que torna o modelo gerado por bagging mais robusto.

${ }^{13} \mathrm{O}$ livro aponta que essa votação pode ser ponderada por algum fator, porém em sua implementação essa votação é uma contagem simples.

${ }^{14}$ Essa é maneira que o algoritmo MetaCost trabalha no Weka.

${ }^{15}$ Repare que esse novo modelo indiretamente minimiza o custo global.
} 
o livro do Weka o algoritmo CostSensitiveClassifier implementa ambas possibilidades de algoritmo e usará uma ou outra implementação dependendo do método escolhido para a modelagem.

\subsubsection{Nossa opção para o algoritmo de aprendiza- gem com custo}

Analisando ambas as opções, o MetaCost e o CostSensitiveClassifier, optamos pelo segundo. Isso porque o primeiro possui fatores aleatórios intrínsecos ao método que não nos permite uma reprodução exata a posteriori dos resultados, apesar de ser, segundo Weka, mais robusto.

\subsection{Algoritmo Genético (GA)}

Diferente dos métodos anteriores, os algoritmos genéticos não se enquadram em métodos de classificação, mas sim em algoritmos de otimização, e foi exatamente esse sentido dado à aplicação desse algoritmo em nosso trabalho, usamos o GA para ajustar os parâmetros utilizados pelos métodos NN e AIS para conseguirmos modelos melhores. Devido a esse uso do GA decidimos reservar essa seção para descrever alguns aspectos que achamos relevantes sobre esse algoritmo.

\subsubsection{Histórico}

Os sites $[\mathrm{MM}]$ e $[\mathrm{dLFdC}]$ descrevem um breve histórico sobre o algoritmo genético que cremos ser pertinente ao presente trabalho.

Segundo essas fontes, no Século XIX os naturalistas acreditavam que cada espécie havia sido criada separadamente por um ser supremo ou através de geração espontânea. O trabalho do naturalista Carolus Linnaeus levou a acreditar na existência de uma certa relação entre as espécies. Por outro lado, Thomas Robert Malthus propôs que fatores ambientais tais como doenças e carência de alimentos limitavam o crescimento de uma população.

Os sites apontam que no Século XX após anos de observações e experimentos, Charles Darwin apresentou em 1858 sua teoria de evolução 
através de seleção natural e que por volta de 1900, nasceu a moderna teoria da evolução que combina a genética e as idéias de Darwin e Wallace sobre a seleção natural, criando o princípio básico de Genética Populacional:

Nessa teoria moderna da evolução, apontam que a variabilidade entre indivíduos de uma população de reprodução sexuada é produzida pela mutação e pela recombinação genética (cross-over). E, segundo eles, este princípio foi desenvolvido durante os anos 30 e 40, por biólogos e matemáticos de importantes centros de pesquisa.

Em 1975, John Holland [Hol75] publicou um livro reunindo importantes resultados na área e nos anos 80, David Goldberg, aluno de Holland, conseguiu o primeiro sucesso em aplicação industrial de Algoritmos Genéticos.

Taillarda et al. [rDTGGP01] apresentam um estudo completo argumentando como os algoritmos iterativos em otimização podem ser vistos de uma maneira unificada, em outras palavras, tem o mesmo princípio, as diferenças principais residem então na maneira de executar cada passo da iteração, em especial esse trabalho mostra como GA e outros algortimos possuem uma estrutura similar.

\subsubsection{Introdução}

Em computação, o algoritmo de otimização, também conhecido com algoritmo evolutivo, GA é uma abstração da metafórica do algoritmo evolutivo dos cruzamentos de DNAs na reprodução sexuadas dos vertebrados. Uma abstração da mutação, do Cross-Over e da duplicação são trazidas para dentro desse potente algoritmo heurístico de otimização. Algumas referência atuais podem ser encontradas nos artigos [GK02] e [rDTGGP01]. Um algoritmo genético (GA) é particularmente utilizado na procura de soluções aproximadas em problemas de otimização ou busca.

Algoritmos genéticos são uma classe particular de algoritmos evolutivos que usam técnicas inspiradas pela biologia evolutiva como hereditariedade, mutação, seleção natural e recombinação (ou crossing over).

Algoritmos genéticos são implementados como uma simulação de computador em que uma população de representações abstratas de solução 
é selecionada em busca de soluções melhores.

O algoritmo geralmente se inicia através da criação de um repertório inicial de soluções (também chamados de DNAs). Esse geralmente pequeno repertório é criado atráves da criação aleatória de algumas "strings de DNA". Os demais passos do algoritmo são chamados de gerações, em cada geração, a adaptação de cada solução na população é avaliada, e apenas os indivíduos melhores "adaptados" permacem para sofrerem recombinações ou mutações para formar uma nova população. E essa nova população é usada como entrada para a próxima geração que selecionará os melhores indivíduos e repetirá a recombinação ou mutação, e assim sucesivamente até que alguma condição de parada seja atingida. ${ }^{16}$

\subsubsection{O Algoritmo}

Os Algoritmos genéticos são em geral algoritmos simples e fáceis de serem implementados. Segue abaixo um trecho de pseudo-código descrevendo um algoritmo genético:

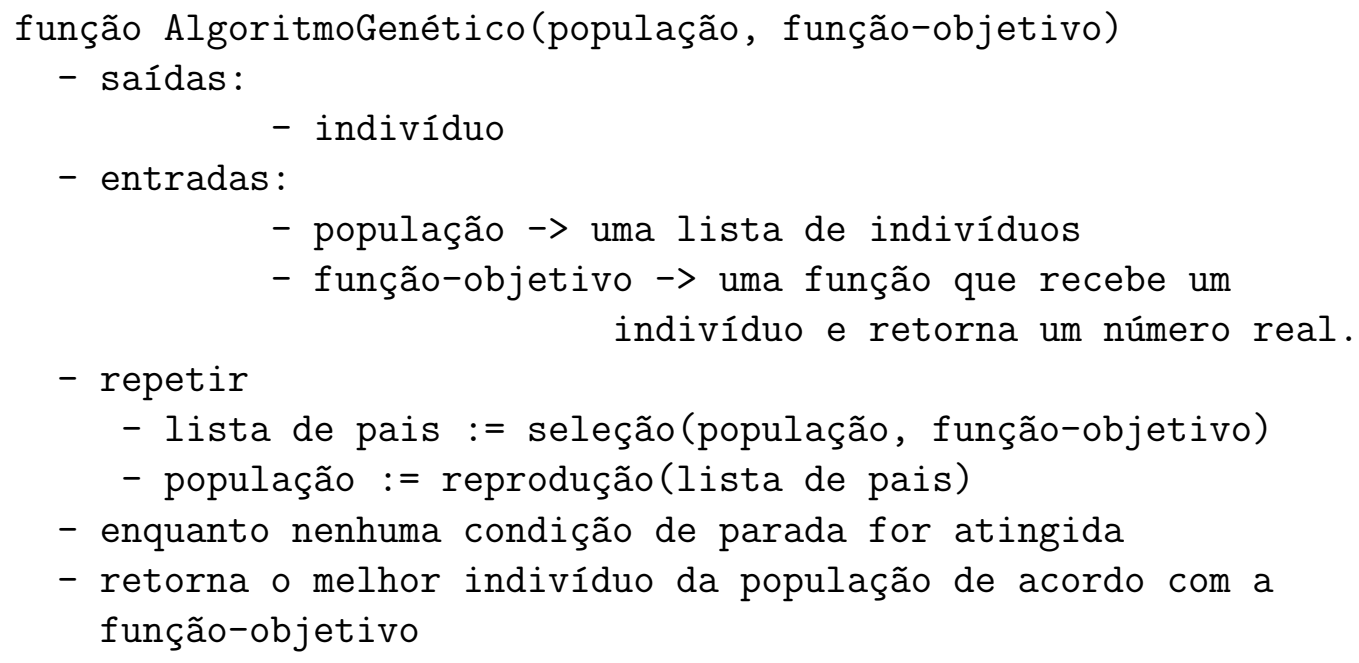

\footnotetext{
${ }^{16}$ As principais diferenças entre o AIS e GA são que o AIS possui seleção negativa, não possui Cross-over e o grau de mutação é inversamente proporcional à diferença de afinidade máxima do sistema de uma geração para a outra.
} 
A função objetivo é o objeto de nossa otimização. Pode ser um problema de otimização, um conjunto de teste para "identificar os indivíduos mais aptos", ou mesmo uma "caixa preta" onde sabemos apenas o formato das entradas e nos retorna um valor inteiro ou real que queremos maximizar ou minimizar.

A grande vantagem dos algoritmos genéticos está no fato de não precisarmos saber como funciona esta função objetivo, apenas tê-la disponível para ser aplicada aos indivíduos e comparar os resultados. O indivíduo é meramente um portador do seu código genético. O código genético é uma representação do espaço de busca do problema a ser resolvido, em geral na forma de seqüências de bits. Por exemplo, para otimizações em problemas cujos valores de entrada são inteiros positivos de valor menor que 255 podemos usar 8 bits, com a representação binária normal. Problemas com múltiplas entradas podem combinar as entradas em uma única seqüência de bits, ou trabalhar com mais de um cromossomo, cada um representando uma das entradas. O código genético deve ser uma representação capaz de representar todo o conjunto dos valores no espaço de busca, e precisa ter tamanho finito.

A seleção também é outra parte chave do algoritmo. Em geral, usa-se o algoritmo de seleção por roleta, onde os indivíduos são ordenados crescentemente ou decrescentemente de acordo com a função-objetivo para o problema de maximização (ou minimização). A escolha é feita selecionando os melhores $\mathrm{N}$ primeiros elementos, dessa forma supõemse escolher como pais os mais bem adaptados, sem deixar de lado a diversidade dos menos adaptados.

A reprodução, tradicionalmente, é divididas em três etapas: acasalamento, recombinação e mutação. O acasalamento é a escolha de dois indivíduos (geralmente dois indivíduos aleatoriamente escolhidos do conjunto de DNAs melhores adaptados) para se reproduzirem. A recombinação, ou crossing-over é um processo que imita o processo biológico homônimo na reprodução sexuada: os descendentes recebem em seu código genético parte do código genético do pai e parte do código da mãe. Esta recombinação garante que os melhores indivíduos sejam capazes de trocar entre si as informações que os levam a ser mais aptos a sobreviver, e assim gerar descendentes ainda mais aptos. Por último vêm as mutações, que são feitas com probabilidade a mais baixa possível, e tem como objetivo permitir maior variabilidade genética na 
população, impedindo que a busca fique estagnada em um mínimo local. É geralmente recomendado que a população seja incremental, isto é, que a nova população pós-reprodução possua os novos filhos e todos os antigos para garantirmos que a cada geração o algoritmo para o caso de uma maximização sempre cresca ou pelo menos mantenha o atual valor do ponto ótimo, isso é geralmente chamado de método não decrescente ${ }^{17}$

\footnotetext{
${ }^{17}$ Neste momento pedimos licença para sair um pouco do texto, para expressar umas palavras do Orientador dessa dissertação cujo conteúdo tanto ele como eu compartilhamos. O Alair uma vez escreveu que a analogia entre o GA e a vida real termina quando se elimina a morte natural a que cada indivíduo está sujetio, existindo somente a morte seletiva dos mais fracos controlada aleatoriamente por quem define a função objetivo, eu me arrisco a ir mais além deixando uma dúvida minha, será que Deus detém essa função objetivo e tudo que ele deseja com o ser humano é selecionar os mais aptos?
} 


\section{Capítulo 5}

\section{Parte experimental}

A parte experimental de nosso trabalho iniciou-se quando recebemos e transformamos os dados provenientes de Cartão de Crédito do Banco em variáveis para a nossa modelagem, parte que foi seguida da definição da metodologia de testes que utilizamos em nossas comparações: o GA. Nesse capítulo, abordamos com maior nível de detalhes o GA, a função objetivo e a aprendizagem sensível ao custo.

$\mathrm{Na}$ última seção, discutimos sobre a funcionalidade e o domínio dos parâmetros associados a cada método.

\subsection{Preparação dos dados}

Nossa pesquisa recebeu apoio de um banco importante no mercado de Cartões de Crédito brasileiro. Em princípio, a identidade do banco e a base de dados original, seriam disponibilizadas, mas em virtude de alterações acionárias e estatutárias bastante relevantes nesta empresa, decidimos por tratar esse banco doravante simplesmente como Banco e deixarmos disponível para consulta apenas as bases de dados da etapa 4 que explicaremos em detalhes em seguida.

Recebemos do Banco uma base contendo 41647 registros. Cada registro representa uma autorização de um cartão de crédito, ou seja, contendo apenas transações aprovadas. As transações negadas por quaisquer critérios de fraude ou crédito foram expurgadas dessa base antes de 
chegarmos a esse número de 41647 registros. As autorizações contidas nessa base ocorreram dentro do mês de julho, agosto e setembro de 2004, exatamente entre os dias 14/07/2004 e 12/09/2004, conforme mostra a figura 5.1 na variável data da autorização, totalizando 2 meses de janela de observação.

\subsubsection{Avaliação dos casos como fraude e não-fraude}

Ainda sob jurisdição do Banco, ficou decido que a seguinte regra se aplica bem para avaliação das autorizações como fraudulentas ou legítimas:

- Se houver uma contestação (não reconhecimento da realização) da transação por parte do cliente nos 2 meses subseqüentes à data da transação, chamado de período de performance, então essa transação é considerada fraudulenta. A contestação é considerada como sendo fraudulenta se ela for identificada pelo Banco ou pelo cliente.

- Se não houver uma contestação da transação por parte do cliente nos 2 meses subseqüentes a data da transação, então essa transação é considerada legítima, mesmo que ela venha ser contestada um dia após a data considerada como limitante.

Exemplos:

(a) Se uma autorização foi realizada em 14/07/2004 e foi contestada até 13/09/2004, então é fraudulenta.

(b) Se uma autorização foi realizada em 12/09/2004 e foi contestada até 11/11/2004, então é fraudulenta.

(c) Se uma autorização foi realizada em 02/08/2004 e foi NÃO foi contestada até 01/10/2004, então é legítima.

(d) Se uma autorização foi realizada em 14/07/2004 e foi contestada somente em 20/09/2004, então é legítima.

Podemos ver pelo exemplo 2, que, para garantir a conformidade da base com o critério de classificação, é necessário esperar até no mínimo dia 12/11/2004 para se obter todas as contestações até às 23 horas e 59 


\begin{tabular}{|c|c|c|c|c|c|}
\hline Nome da variável original & Valor Mínimo & Valor Máximo & Etapa 1 & Etapa 2 & Nome da variável na Etapa 2 \\
\hline 0) Número do Estabelecimento & 0 & SABRE INC JJ & $\mathrm{x}$ & & \\
\hline 1) Nome do Estabelecimento & "ELEGANTE MAGAZIN & ZUZA CONFECCOES & $\mathrm{x}$ & & \\
\hline 2) Data da Autorização & $14 / 7 / 2004$ & 12/9/2004 & $\mathrm{x}$ & & \\
\hline 3) Hora da Autorização & 0 & 235951 & $\mathrm{x}$ & & \\
\hline 4) Ramo Internacional Estabelecimento & 0 & 9751 & $\mathrm{x}$ & $\mathrm{x}$ & $\mathrm{mcc}$ \\
\hline 5) Cep do Estabelecimento & 0 & 999999990 & $\mathrm{x}$ & $\mathrm{x}$ & cep \\
\hline 6) Valor Autorizado em R $\$$ - Detalhe & 0 & 27485,9 & $\mathrm{x}$ & $\mathrm{x}$ & valor $\mathrm{R} \$$ \\
\hline 7) Valor Autorizado em US\$ - Detalhe & 0 & 2927,26 & $\mathrm{x}$ & & \\
\hline 8) POS (Point of Sale) Entry Mode & 0 & 902 & $\mathrm{x}$ & $\mathrm{x}$ & pos - entry mode \\
\hline 9) Valor Limite em R \$ - Detalhe & 0 & 212100 & $\mathrm{x}$ & $\mathrm{x}$ & limite credito \\
\hline 10 Código da Bandeira & 1 & 20 & $\mathrm{x}$ & $\mathrm{x}$ & codigo bandeira \\
\hline 11) Descrição da Bandeira & VISA INTERNATIONAL & VISA & $\mathrm{x}$ & & \\
\hline 12) Código da variante & 1 & 6 & $\mathrm{x}$ & $\mathrm{x}$ & codigo variante \\
\hline 13)Descrição da variante & ELECTRONIC & PLATINUM & $\mathrm{x}$ & $\mathrm{x}$ & variante \\
\hline 14) Score de Fraude & 0 & 999 & $\mathrm{x}$ & $\mathrm{x}$ & score \\
\hline 15) Código para VIP & A & $\mathrm{L}$ & $\mathrm{x}$ & $\mathrm{x}$ & flag vip \\
\hline 16) Tipo de produto & 1 & 3846 & $\mathrm{x}$ & & \\
\hline 17) Código do Tipo de Pessoa & F & $\mathrm{J}$ & $\mathrm{x}$ & $\mathrm{x}$ & cod. tipo pessoa \\
\hline 18) Código do País & 0 & 858 & $\mathrm{x}$ & $\mathrm{x}$ & cod. pais \\
\hline 19) Descrição do Motivo da Autorização & $\begin{array}{c}\begin{array}{c}\text { AUTORIZACAO APROVADA E } \\
\text { INCLUIDA }\end{array} \\
\end{array}$ & $\begin{array}{c}\text { VALOR DA AUTORIZACAO } \\
\text { INVALIDO } \\
\end{array}$ & $\mathrm{x}$ & & \\
\hline 20) Estado do Estabecimento & 0 & WI & $\mathrm{x}$ & $\mathrm{x}$ & estado estab \\
\hline 21) Numero do Cartão & - & - & $\mathrm{x}$ & & \\
\hline 22) Quantidade de Parcelas - Detalhe & 0 & 12 & $\mathrm{x}$ & $\mathrm{x}$ & qtde parcelas \\
\hline 23) Flag Parcelado & 0 & 1 & $\mathrm{x}$ & $\mathrm{x}$ & flag parvelado \\
\hline 24)Valor UltimaTransacao & 0 & 6144,16 & $\mathrm{x}$ & $\mathrm{x}$ & valor ultima acao \\
\hline 25) Velocidade Em Minutos & -917 & 67893 & $\mathrm{x}$ & $\mathrm{x}$ & velocidade em minutos \\
\hline 26) Útimo Ramo & 0 & 9751 & $\mathrm{x}$ & $\mathrm{x}$ & ultimo ramo \\
\hline 27) Ultimo Pais & 0 & 858 & $\mathrm{x}$ & $\mathrm{x}$ & ultimo pais \\
\hline 28) Ultimo Estabelecimento & 0 & SABRE INC JJ & $\mathrm{x}$ & 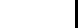 & \\
\hline 29) CEPAnterior & 0 & 9999999900 & $\mathrm{x}$ & $x$ & ultimo cep \\
\hline 30) Score de Fraude Anterior & 0 & 999 & $\mathrm{x}$ & $\mathrm{x}$ & ultimo score \\
\hline 31) Diferenca Score de Fraude Atual Anterior & -998 & 991 & $\mathrm{x}$ & $x$ & diferenca score \\
\hline 32) Valor Trans Atual Sobre Limite & 0 & 192,31 & $\mathrm{x}$ & $x$ & vl_trans/limite \\
\hline 33)GBI de Fraude & 0 & 1 & $\mathrm{x}$ & $\mathrm{x}$ & flag fraude \\
\hline
\end{tabular}

Figura 5.1: Filtragem das variáveis pouco relevantes para modelagem 
minutos do dia 11/11/2004, fato que permite saber que a autorização do último exemplo poderia já ter sido avaliada como fraudulenta.

Após discussão com a equipe de modelagem do Banco, descobrimos que os dois critérios poderiam ser usados para definir o período de performance, mas eles preferiram manter uma janela de período de performance homogênea para todas as transações, mesmo que isso desprezasse alguma informação conhecida sobre as classes até o momento.

Algo que não deve ter passado despercebido aos mais atentos é que, ao se dizer que uma autorização é fraudulenta, têm-se 100\% (ou quase isso, devido aos casos de confusão que o cliente pensa não ter sido ele que realizou a compra e depois se lembra que foi realmente ele) de certeza da classe a que ela pertence, mas, segundo esse critério, quando afirmamos que uma transação é legítima, não podemos afirmar isso de fato, apenas podemos afirmar que ela ainda não foi identificada como fraudulenta. Porém, na prática isso tem pouca relevância, pois segundo dados passados informalmente pelo próprio Banco, até $80 \%$ das fraudes ocorridas são identificadas como fraudulentas no período de 2 meses.

\subsubsection{Amostragem Estratificada}

Após a definição que caracteriza uma transação como fraudulenta ou legítima, a última ação do Banco foi a seleção amostral dos registros a serem enviadas para nosso estudo, essa etapa constou de duas tarefas:

(a) A primeira foi uma amostragem aleatória dos números de cartões a serem analisados neste período, não se atentando ao fato do cartão ter ou não realizado transação nesses dias.

(b) A segunda diz respeito a amostra estratificada pela classe transação fraudulenta e legítima. Das transações selecionadas no ítem anterior, foram selecionadas $10 \%$ das transações avaliadas como legítimas e $100 \%$ das transações avaliadas como fraudulentas.

\subsubsection{A transformação}

Com a base efetivamente em nossas mãos, a figura 5.4 mostra como

foi feita a preparação dos dados até que eles chegassem ao Weka. Essa 


\begin{tabular}{|c|c|c|c|c|c|c|c|c|c|}
\hline $\begin{array}{l}\text { Número } \\
\text { da } \\
\text { variavel }\end{array}$ & $\begin{array}{c}\text { Nome variável na } \\
\text { etapa } 2\end{array}$ & $\begin{array}{c}\text { Tipo dado } \\
\text { (X=categorico, } \\
\text { 9=numérico } \\
\text { continuo) }\end{array}$ & Valor original & $\begin{array}{c}\text { Categoria } \\
\text { Nova }\end{array}$ & $\begin{array}{l}\text { Número } \\
\text { da } \\
\text { variavel }\end{array}$ & $\begin{array}{c}\text { Nome variável na etapa } \\
2\end{array}$ & $\begin{array}{c}\text { Tipo dado } \\
\text { (X=categorico, } \\
9=\text { numérico } \\
\text { continuo) }\end{array}$ & Valor original & $\begin{array}{c}\text { Categoria } \\
\text { Nova }\end{array}$ \\
\hline 4 & $\mathrm{mcc}$ & $x$ & 7933 & 14 & 18 & cod. pais & $x$ & 858 & 2 \\
\hline 4 & $\mathrm{mcc}$ & $\mathrm{x}$ & 7991 & 14 & 20 & estado estab. & $x$ & 0 & 0 \\
\hline$\ldots$ & $\ldots$ & $\ldots$ & $\ldots$ & $\ldots$ & 20 & estado estab. & $\mathrm{x}$ & 0 & 0 \\
\hline 4 & $\mathrm{mcc}$ & $x$ & 9402 & 22 & $\ldots$ & $\ldots$ & $\ldots$ & $\ldots$ & $\ldots$ \\
\hline 5 & cep & $x$ & 0 & 0 & 20 & estado estab. & $x$ & WI & 9 \\
\hline 5 & cep & $x$ & 1 & 1 & 22 & qtde parcelas & $x$ & 0 & 0 \\
\hline$\ldots$ & $\ldots$ & $\ldots$ & $\ldots$ & $\ldots$ & 22 & qtde parcelas & $\mathrm{x}$ & 10 & 3 \\
\hline 5 & cep & $x$ & 99 & 9 & $\ldots$ & $\ldots$ & $\ldots$ & $\ldots$ & $\ldots$ \\
\hline 6 & valor $\mathrm{R} \$$ & 9 & 17.2 & 1 & 22 & qtde parcelas & $\mathrm{x}$ & 9 & 3 \\
\hline 6 & valor $\mathrm{R} \$$ & 9 & 22.9 & 2 & 23 & flag parvelado & $x$ & 0 & 0 \\
\hline$\ldots$ & $\ldots$ & $\ldots$ & $\ldots$ & $\ldots$ & 23 & flag parvelado & $x$ & 1 & 2 \\
\hline 6 & valor $\mathrm{R} \$$ & 9 & $\inf$ & 9 & 24 & valor ultima acao & 9 & 0 & 0 \\
\hline 8 & pos - entry mode & $x$ & 0 & 0 & 24 & valor ultima acao & 9 & 15.76 & 1 \\
\hline 8 & pos - entry mode & $x$ & 1 & 1 & $\ldots$ & $\ldots$ & $\ldots$ & $\ldots$ & $\ldots$ \\
\hline$\ldots$ & $\ldots$ & $\ldots$ & $\ldots$ & $\ldots$ & 24 & valor ultima acao & 9 & inf & 6 \\
\hline 8 & pos - entry mode & $x$ & 902 & 5 & 25 & velocidade em minutos & 9 & 0 & 0 \\
\hline 9 & limite credito & 9 & 550 & 0 & 25 & velocidade em minutos & 9 & 67 & 1 \\
\hline 9 & limite credito & 9 & 800 & 1 & $\ldots$ & $\ldots$ & $\ldots$ & $\cdots$ & $\ldots$ \\
\hline$\ldots$ & $\ldots$ & $\ldots$ & $\ldots$ & $\ldots$ & 25 & velocidade em minutos & 9 & inf & 6 \\
\hline 9 & limite credito & 9 & inf & 9 & 26 & ultimo ramo & $x$ & 0 & 0 \\
\hline 10 & codigo bandeira & $x$ & 1 & 0 & 26 & ultimo ramo & $x$ & 1711 & 1 \\
\hline 10 & codigo bandeira & $x$ & 20 & 1 & $\ldots$ & $\ldots$ & $\ldots$ & $\ldots$ & $\ldots$ \\
\hline$\ldots$ & $\ldots$ & $\ldots$ & $\ldots$ & $\ldots$ & 26 & ultimo ramo & $x$ & 9402 & 22 \\
\hline 10 & codigo bandeira & $x$ & 5 & 3 & 27 & ultimo pais & $x$ & 0 & 0 \\
\hline 12 & codigo variante & $x$ & 1 & 0 & 27 & ultimo pais & $x$ & 124 & 1 \\
\hline 12 & codigo variante & $x$ & 2 & 1 & $\ldots$ & $\ldots$ & $\ldots$ & $\ldots$ & $\ldots$ \\
\hline$\ldots$ & $\ldots$ & $\ldots$ & $\ldots$ & $\ldots$ & 27 & ultimo pais & $x$ & 858 & 2 \\
\hline 12 & codigo variante & $x$ & 6 & 4 & 29 & ultimo cep & $x$ & 0 & 0 \\
\hline 13 & variante & $x$ & ELECTRONIC & 0 & 29 & ultimo cep & $x$ & 1 & 1 \\
\hline 13 & variante & $x$ & GOLD & 1 & $\ldots$ & $\ldots$ & $\ldots$ & $\ldots$ & $\ldots$ \\
\hline$\ldots$ & $\ldots$ & $\ldots$ & $\ldots$ & $\ldots$ & 29 & ultimo cep & $x$ & 99 & 9 \\
\hline 13 & variante & $x$ & PLATINUM & 4 & 30 & ultimo score & 9 & 0 & 0 \\
\hline 14 & score & 9 & & 0 & 30 & ultimo score & 9 & 9 & 1 \\
\hline 14 & score & 9 & 9 & 1 & $\ldots$ & $\ldots$ & $\ldots$ & $\ldots$ & $\ldots$ \\
\hline$\ldots$ & $\ldots$ & $\ldots$ & $\ldots$ & $\ldots$ & 30 & ultimo score & 9 & inf & 8 \\
\hline 14 & score & 9 & inf & 8 & 31 & diferenca score & 9 & -14 & 0 \\
\hline 15 & flag vip & $\mathrm{x}$ & 0 & 0 & 31 & diferenca score & 9 & & 1 \\
\hline 15 & flag vip & $\mathrm{x}$ & 206 & 1 & $\ldots$ & $\ldots$ & $\ldots$ & $\ldots$ & $\ldots$ \\
\hline$\ldots$ & $\ldots$ & $\ldots$ & $\ldots$ & $\ldots$ & 31 & diferenca score & 9 & inf & 4 \\
\hline 15 & flag vip & $x$ & L & 5 & 32 & vl_trans/limite & 9 & .36 & 0 \\
\hline 17 & cod. tipo pessoa & $x$ & $\mathrm{~F}$ & 1 & 32 & Vl_trans/limite & 9 & .63 & 1 \\
\hline 17 & cod. tipo pessoa & $x$ & $\mathrm{~J}$ & 2 & $\ldots$ & $\ldots$ & $\ldots$ & $\ldots$ & $\ldots$ \\
\hline 18 & cod. pais & $\mathrm{x}$ & 0 & 0 & 32 & vl_trans/limite & 9 & inf & 9 \\
\hline 18 & cod. pais & $x$ & 124 & 1 & 33 & flag fraude & $x$ & 0 & 0 \\
\hline$\ldots$ & $\ldots$ & $\ldots$ & $\ldots$ & $\ldots$ & 33 & flag fraude & $x$ & 1 & 1 \\
\hline
\end{tabular}

Figura 5.2: Categorização 


\begin{tabular}{|c|c|c|c|c|c|}
\hline Base & \# Desenvolvimento & \# Validaçăo & \# Total & $\%$ Desenvolvimento & \% validação \\
\hline 1 & 28.988 & 12.659 & 41.647 & $69,6 \%$ & $30,4 \%$ \\
\hline 2 & 29.104 & 12.543 & 41.647 & $69,9 \%$ & $30,1 \%$ \\
\hline 3 & 29.149 & 12.498 & 41.647 & $70,0 \%$ & $30,0 \%$ \\
\hline 4 & 29.220 & 12.427 & 41.647 & $70,2 \%$ & $29,8 \%$ \\
\hline 5 & 29.126 & 12.521 & 41.647 & $69,9 \%$ & $30,1 \%$ \\
\hline 6 & 29.089 & 12.558 & 41.647 & $69,8 \%$ & $30,2 \%$ \\
\hline 7 & 29.212 & 12.435 & 41.647 & $70,1 \%$ & $29,9 \%$ \\
\hline 8 & 28.990 & 12.657 & 41.647 & $69,6 \%$ & $30,4 \%$ \\
\hline 9 & 29.228 & 12.419 & 41.647 & $70,2 \%$ & $29,8 \%$ \\
\hline
\end{tabular}

Figura 5.3: Quebra - desenvolvimento e validação

Preparação das Bases de dados

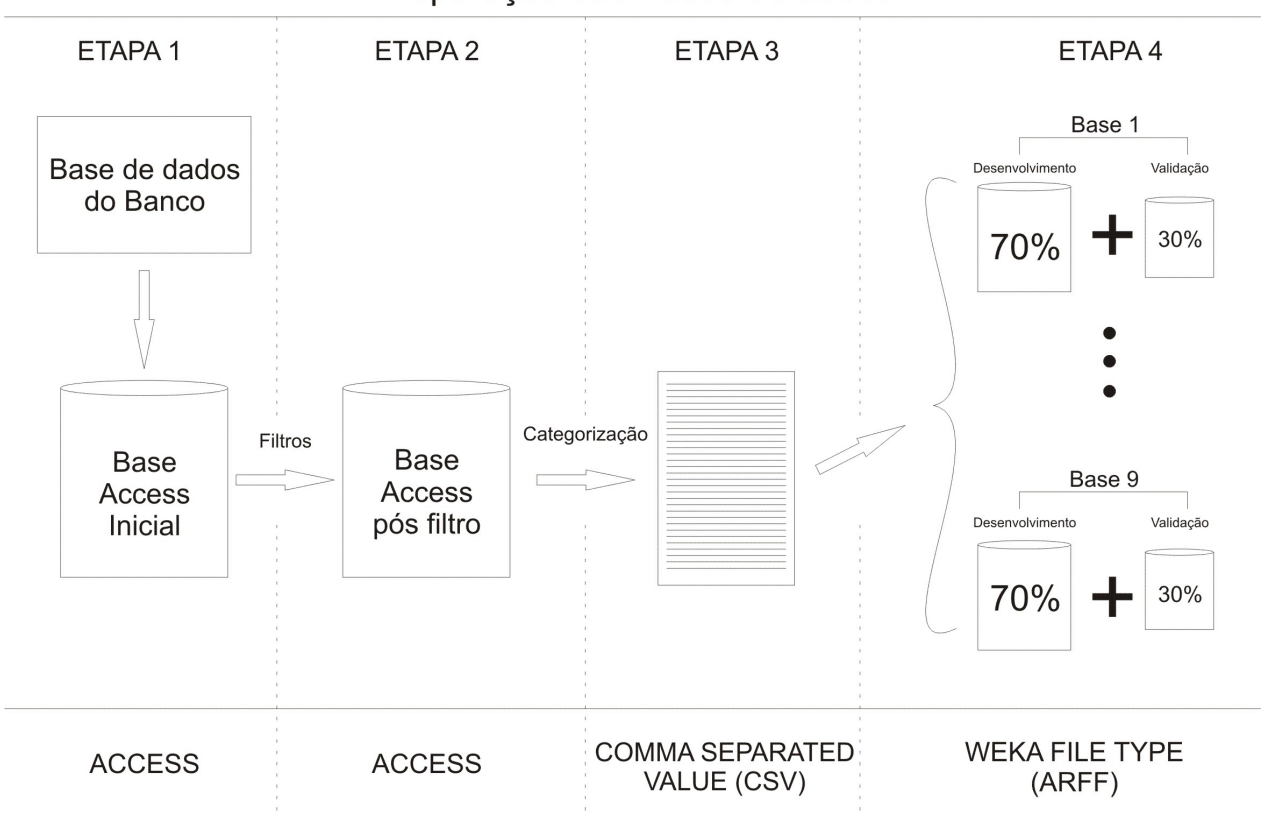

Figura 5.4: Preparação das bases de dados 
preparação pode ser ilustrada em quatro etapas.

(a) Na primeira etapa, importamos a base de dados para dentro de um programa facilitador para visualizá-los, e executamos algumas freqüências sobre eles. Logo após esse primeiro contato, decidimos que algumas variáveis não precisariam ser consideradas para a modelagem. A figura 5.1 mostra como foi feito a filtragem das variáveis relevantes para modelagem, as que possuem x na Etapa 2 foram as variáveis que permaneceram para a etapa seguinte.

(b) Na segunda etapa, deu-se a categorização de todas as variáveis. A figura 5.2 traz uma amostra de uma tabela "de-para" da transformação dos dados. Todas as variáveis foram categorizadas em, no máximo, 10 categorias, cuja valoração varia de 0 a 9 , exceto a variável Ramo de Estabelecimento (MCC) ${ }^{1}$.

(c) A terceira etapa constou em transformar a base categorizada do item anterior, em formato separado por vírgula (.csv).

(d) A quarta etapa foi responsável por gerar 3 conjuntos de bases. Cada conjunto possuindo um par de bases, uma base com $70 \%$ das observações usadas doravante para desenvolvimento dos modelos (amostra de treinamento - training set), e outra base com as demais $30 \%$ das observações para validação dos modelos (amostra de teste - test set), a figura 5.3 mostra o resultado de número de registros resultante em cada par de bases.

Após esse processo de amostragem, todas as bases foram convertidas para o formato proprietário do Weka (.arff)

\subsection{Simulação no ambiente Weka}

O livro [WF05] foi adotado como pilar para nosso trabalho. Esse livro traz em si detalhes de diversos métodos de aprendizado computacional, e além disso, disponibiliza implementações de todos os métodos discutidos em seu site na World Wide Web (www.cs.waikato.ac.nz/ml/weka),

\footnotetext{
${ }^{1}$ A variável Ramo do Estabelecimento (MCC) recebeu 32 categorias a fim de se enquadrar em uma categorização já comum no mercado de Cartão de Crédito conhecida como Ramo de Atividade (TCC).
} 
em um programa chamado Weka, em nosso trabalho usamos a versão 3-4-11 desse software.

Weka vem de Waikato Environment for Knowledge Analysis, desenvolvido na universidade de Waikato na Nova Zelândia, que, segundo a documentação do próprio Weka, "Weka" rima com Méca, e Weka é um pássaro pacífico encontrado nas ilhas da Nova Zelândia.

Esse sistema foi todo desenvolvido em Java, uma linguagem orientada a objeto que está disponível para os maiores sistemas operacionais no mercado. A documentação aponta que o software foi testado nos sitemas operacionais Linux, Windows, e Macintosh. Em adição, as implementações providas clamam por ser o estado-da-arte dos algoritmos de aprendizado que podem ser aplicados em bases de dados vias linha de comando.

\subsubsection{Começando}

\begin{tabular}{|c|c|c|c|c|c|c|}
\hline \multicolumn{6}{|c|}{$\begin{array}{l}\text { - Microsonh Excel-weather.csw [Read-Only] } \\
\text { - File Edit Yiew Insert Format Iools Dato Window Help }\end{array}$} & $\because \div$ \\
\hline & A & B & C & D & E & \\
\hline 1 & outlook & \multicolumn{2}{|c|}{ temperatui humidity } & windy & play & \\
\hline \multicolumn{7}{|l|}{2} \\
\hline 3 & sunny & 85 & 85 & FALSE & no & \\
\hline 4 & sunny & 80 & 90 & TRUE & no & \\
\hline 5 & overcast & 83 & 86 & FALSE & yes & \\
\hline 6 & rainy & 70 & 96 & FALSE & yes & \\
\hline 7 & rainy & 68 & 80 & FALSE & yes & \\
\hline 8 & rainy & 65 & 70 & TRUE & no & \\
\hline 9 & overcast & 64 & 65 & TRUE & yes & \\
\hline 10 & sunny & 72 & 95 & FALSE & no & \\
\hline 11 & sunny & 69 & 70 & FALSE & yes & \\
\hline 12 & rainy & 75 & 80 & FALSE & yes & \\
\hline 13 & sunny & 75 & 70 & TRUE & yes & \\
\hline 14 & overcast & 72 & 90 & TRUE & yes & \\
\hline 15 & overcast & 81 & 75 & FALSE & yes & \\
\hline 16 & rainy & 71 & 9 & TRUE & no & \\
\hline \multicolumn{7}{|l|}{17} \\
\hline \multicolumn{7}{|l|}{18} \\
\hline \multicolumn{7}{|l|}{19} \\
\hline 20 & & & & $* 1$ & & \\
\hline
\end{tabular}

(a)

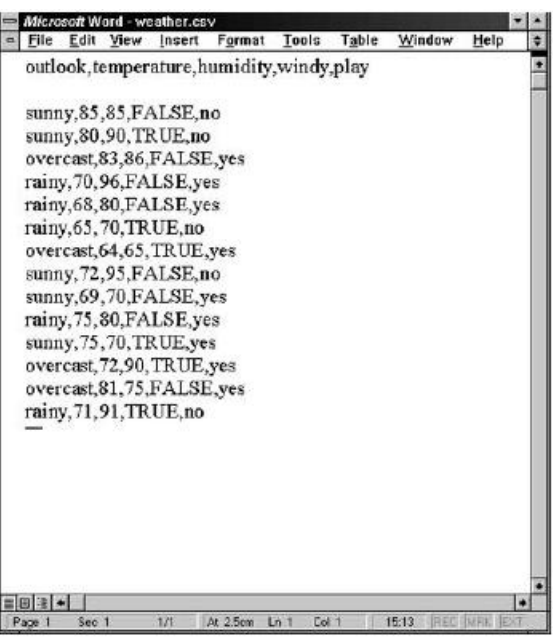

(b)

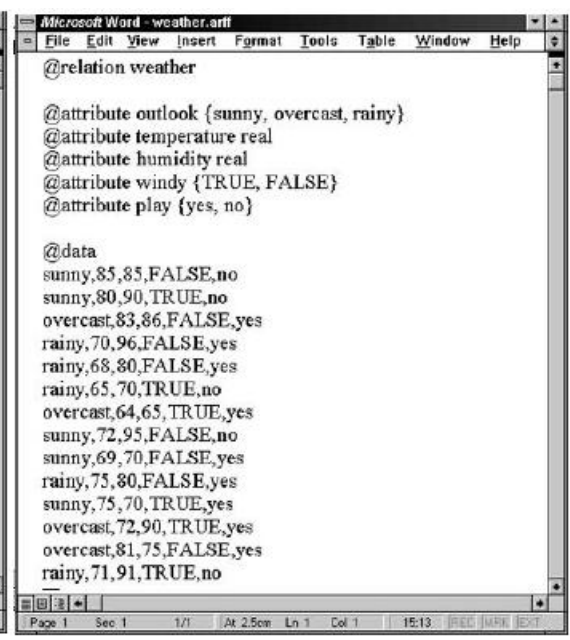

(c)

Figura 5.5: Formato ARFF.

Dados dispostos para testes, geralmente, encontram-se em bases de dados, planilhas ou textos puros. O Weka possui um formato próprio de base de dados, o ARFF, descrito na seção 2.4 do livro. A figura 5.5, 
retirada do próprio livro do Weka, mostra como foi realizada a transformação dos dados de previsão de tempo, chamado de weather.arff. Para essa transformaçao, tomou-se como estrada um arquivo CSV, Comma Separated Value, (viasulizada à esquerda da figura 8) criado através do próprio Weka, na versão visual, uma tabela em formato ARRF.

\subsubsection{Execução simples de linha de comando}

Com os dados dispostos no formato proprietário do Weka, a modelagem pode ser feita de diversas formas. As principais são no ambiente visual do Weka ou através de linha de comando no Shell ou DOS. Uma possível linha de comando seria a linha que segue abaixo, onde o algoritmo de Árvores de Decisão conhecido como C4.5 é implementado e aqui no Weka ele é chamado de $\mathrm{J} 4.8$, J diz respeito à implementação ter sido feita pelo autores do Weka e não do autor original do C4.5 e 8 pois trata-se da $\mathrm{C} 4.5$ revisão 8, mais detalhes podem ser encontrado na seção 6.1 do livro.

java weka.classifiers.j48.J48 -t weather.arff

A figura 5.6 mostra a saída encontrada após a execução. A primeira parte do arquivo de saída apresenta o nome do método executado e as opções (ou parâmetros) usadas para o método, neste teste como não foi definido qualquer parâmetro, então foram usados os parâmetros padrão, e eles foram omitidos da saída.

A segunda parte do arquivo apresenta uma impressão do modelo gerado pelo método, para este exemplo é mostrada a estrutura da árvore, as quantidades de nós folhas e a quantidade total de nós.

Assim como discutido na seção 5.1 do livro, a terceira parte do arquivo apresenta medidas de performance avaliadas sobre os próprio dados de desenvolvimento.

\subsubsection{Execução via ambiente visual}

Dando seqüência ao funcionamento do Weka, mostramos nessa subseção o funcionamento básico do software Weka em seu ambiente visual, cita- 
J48 pruned tree

outlook = sunny

| humidity <= 75: yes (2.0)

humidity > 75: no $(3.0)$

outlook = overcast: yes $(4.0)$

outlook = rainy

| windy = TRUE: no $(2.0)$

| windy = FALSE: yes $(3.0)$

Number of Leaves : 5

size of the tree : 8

$===$ Error on training data $===$

Correctly Classified Instances

Incorrectly Classified Instances

Mean absolute error

Root mean squared error

Total Number of Instances

$===$ Confusion Matrix $===$

a b <-- classified as

$90 \mid \mathrm{a}=$ yes

$05 \mid b=$ no

$===$ Stratified cross-validation $===$

Correctly Classified Instances

Incorrectly Classified Instances

Mean absolute error

$9 \quad 64.2857 \%$

$5 \quad 35.7143 \%$

Root mean squared error

Total Number of Instances

$===$ Confusion Matrix $===$
a b <-- classified as
\begin{tabular}{ll|l}
7 & 2 & $\mathrm{a}=$ yes
\end{tabular}
$32 \mid b=$ no

Figura 5.6: Exemplo de saída do weka J4.8 - Árvore de Decisão 
mos as quatro diferentes maneiras de desenvolver um modelo através deste software, e por fim, apresentamos um exemplo de modelagem usando a opção Explorer de desenvolvimento.

O primeiro passo para executar a modelagem no Weka é iniciar o software. Ao abri-lo, a primeira tela é a denominada Weka GUI Chooser, que permite a escolha do modo de uso do software.

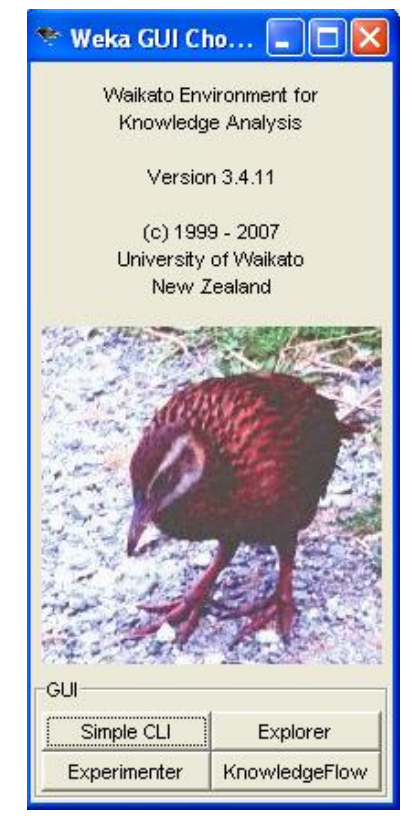

\section{Figura 5.7: Tela inicial Weka}

O Weka apresenta em sua tela inicial quatro opções de execução. A primeira é o Simple CLI, uma interface de linha de comando; a segunda é o Explorer, uma interface visual para testes e execuções interativas; a terceira é o Experimenter, uma interface para comparação de métodos segundo alguns critérios disponíveis no software; e a quarta, e última, é o KnowledgeFlow, um workflow que permite conectar em série ou em paralelo as saídas dos métodos às entradas de outros, além de transformações nos dados, ganhando um potencial enorme na capacidade de modelagem. Para essa explicação introdutória, escolhemos o Explorer por esse ser o mais simples para usuários iniciantes. Então, clicando-se sobre o botão Explorer abrir-se-á a seguinte janela:

Antes de iniciarmos qualquer trabalho com dados, precisamos carregar 


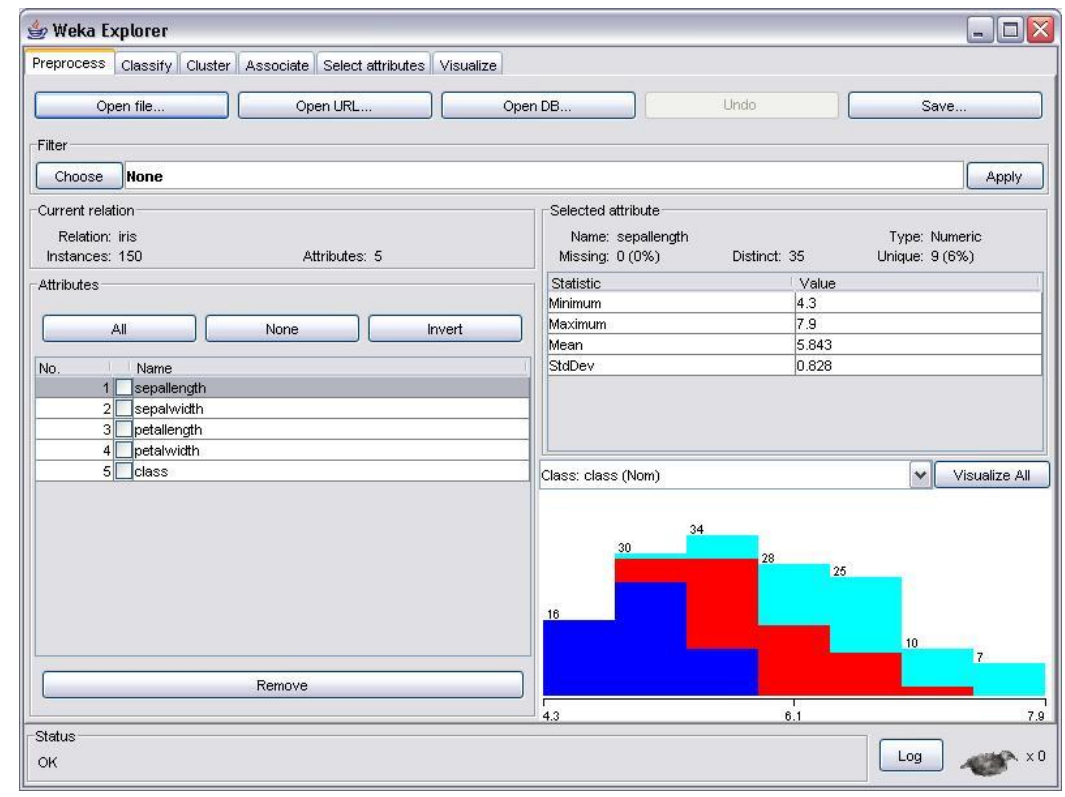

Figura 5.8: Weka Explorer Iris data

a base de dados no Weka. Para tanto, basta clicar em Open file ..., na janela de pré-processo - figura 5.8, e escolher um arquivo de dados. Para o nosso exemplo, vamos escolher o arquivo de dados da Iris, iris.arff que se encontra no subdiretório data. A figura 5.8 mostra o que ocorrerá com a janela após a abertura da base de dados. Nessa janela estará disposta algumas informações relevantes sobre o conteúdo do arquivo como: Número de instâncias (150), Número de atributos (5), e algumas estatísticas sobre os atributos, mostradas uma de cada vez após o click do mouse sobre o nome dele. No caso de desejarmos visualizar todos os histogramas ao mesmo tempo, basta clicarmos o botão Visualize All, à direita, na parte inferior da janela.

A figura 5.9 nos ajuda a compreender melhor o exemplo, permitindonos identificar o Sepal e Petal, e mostrando as três variedades de Iris disponíveis na natureza. O exemplo disposto através dos dados do arquivo iris.arff pretende criar um modelo para identificar a variedade (classe) que uma flor de Iris pertence usando informações como Sepallength (comprimento da folha; essa folha parece uma pétala caída), Sepalwidth (largura da folha), Petallength (comprimento da pétala), 


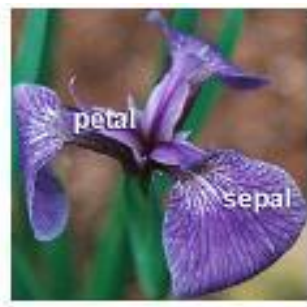

Petal e Sepal

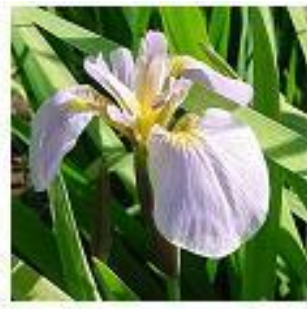

Iris-setosa

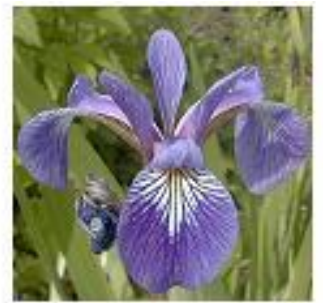

Iris-versicolor

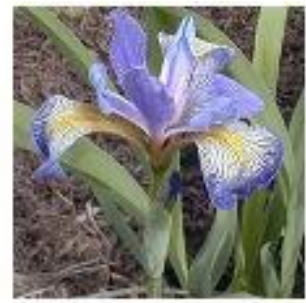

Iris-virginica

Figura 5.9: Flores de Iris

Petalwidth (largura da pétala). Nesse exemplo, as classes de saída possíveis são: Iris-setosa, Iris-versicolor ou Iris-virgínica.

$\underline{\text { Classificação }}$

Para realizar a classificação no ambiente visual do Weka, começamos por clicar na aba Classify, isso nos trará um cardápio com diversas opções de classificadores que podemos usar. Devemos perceber que existem quatro opções de testes do modelo que estamos gerando. O "Use training set" significa que o Weka avaliará o resultado do modelo na própria base de dados oferecida para treinamento; com o "Supplied test set" podemos avaliar o modelo gerado em base de dados diferente da usada no treinamento; com o "Cross-validation", a base de treinamento será quebrada aleatoriamente em $\mathrm{N}$ pedaços e o modelo será testado em cada um desses pedaços separadamente; por último, com o "Percentage split", podemos definir o percentual da base de treinamento que será separada aleatoriamente para treinamento, sendo o restante utilizado para teste. Clicando no botão "Choose" na aba "Classifier", pode-se escolher o método que se deve usar para criar o modelo de classificação, para exemplificar, utilizamos o método de Árvore de Decisão como os parâmetros padrão.

A figura 5.10 mostra o resultado visual obtido ao submetermos a base de dados de exemplo da flor de Iris ao método de Árvore de Decisão usando o software Weka. E o classificador obtido como saída é o seguinte:

petalwidth $<=0.6:$ Iris-setosa $(50.0)$ 


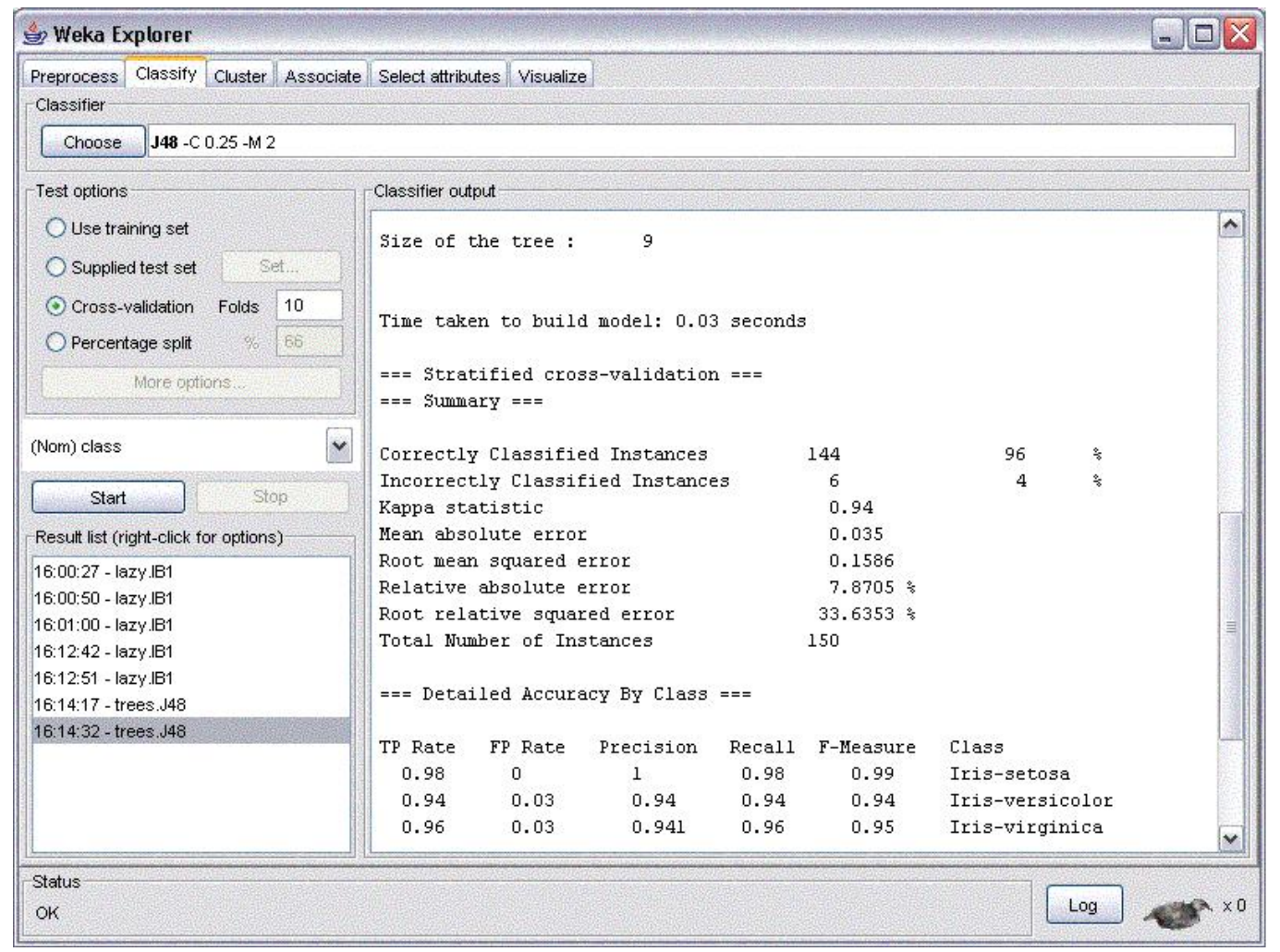

Figura 5.10: Resultado da execução Árvore de Decisão

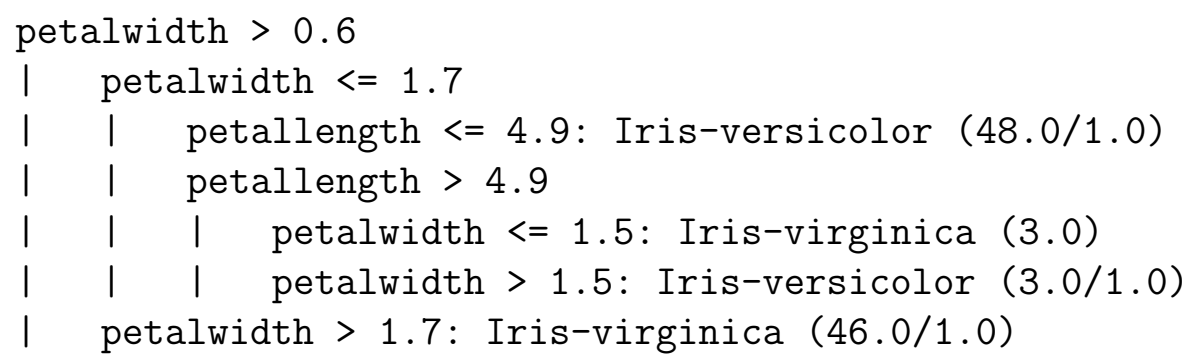

Que podemos interpretar como:

Se petalwidth menor ou igual a 0.6 então podemos afirmar que a flor é Iris-setosa;

\section{Senão}

Se petalwidth menor ou igual a 1.7 então 


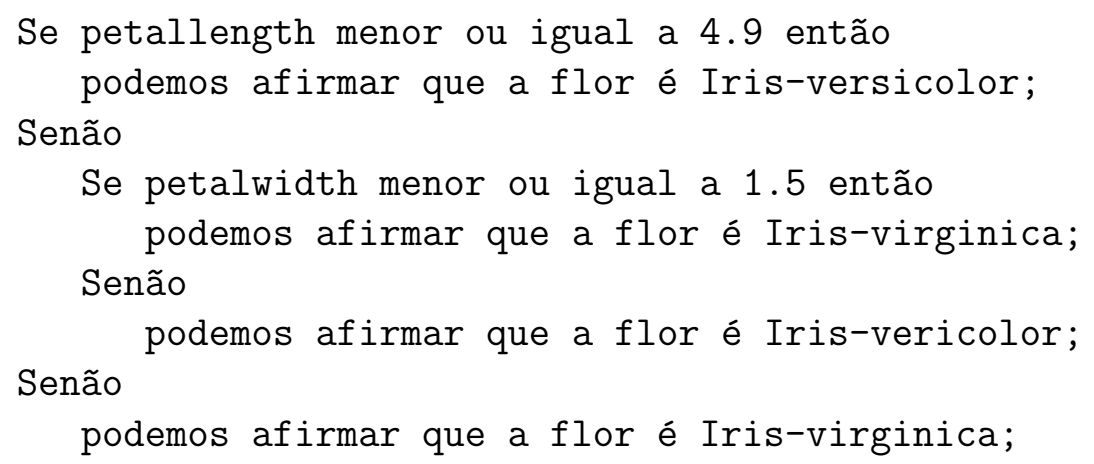

O Weka também disponibiliza algumas importantes estatísticas de desempenho do classificador gerado na(s) base(s) de teste. Duas delas são o percentual de instâncias classificadas corretamente. Neste caso, foram 144 de 150 (96\%), e a matriz de confusão que mostra como foram classificados os casos e a quais classes eles realmente pertenciam.

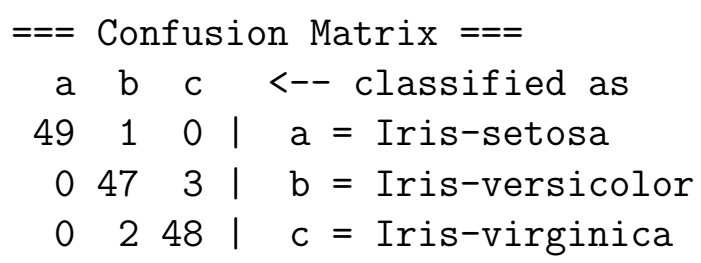

\subsection{Metodologia de Testes}

No início do nosso trabalho, planejavamos comparar apenas dois métodos. Iríamos confrontar Redes Neurais e Sistemas Imunológicos Artificiais. Em pouco tempo de trabalho, expandimos nossos estudos para outros métodos, e foi durante a qualificação que nos defrontamos com uma pergunta difícil de ser respondida: como testar diversos métodos possuindo um número de parâmetros tão grande e uma variação em quantidade tão grande de um método para outro. Tivemos contato com alguns textos sobre o assunto, em especial ao [AR05]. Esse texto traz uma comparação entre métodos de reconhecimento de imagem, confronta cinco diferentes filtros para reconhecimento de imagens $(a=$ Steerable, $b=$ Quadrature steerable, $c=$ Real Gabor,$d=$ Complex Gabor e $e=$ Line operator). Cada um dos cinco métodos possui apenas 
um parâmetro a ser variado, no texto o autor apresenta um segundo parâmetro que deve ser variado, esse parâmetro é interferência (noise), que vem a existência devido o fato do autor não possuir muitas imagens para identificação, então o autor produz cópias alteradas da imagem matriz usando esse parâmetro de interferência.

O texto apresenta uma busca exaustiva em todo o espaço de valorações dos parâmetros ${ }^{2}$. Em outras palavras foi avaliado a função $g(f, n, \theta)^{3}$ para todos parâmetros possíveis em $\Omega$, onde cada execução da função g retornou, segundo o texto, um valor que correspondia a área sob o gráfico da curva Receiver Operating Characteristics (ROC) ${ }^{4}$.

Por fim, o texto apresenta cinco gráficos bidimensionais, em forma de curva de nível, um para cada filtro (ver figura 5.11). Através desse gráfico de curva de nível, o texto calcula área do gráfico $\rho$ que apresenta um valor de AUC maior que $0.9^{5}$. Comparando todos os filtros segundo esse valor de $\rho$, o artigo aponta como filtro mais robusto o filtro com maior $\rho$.

Avaliamos a utilização de uma metodologia parecida a que fora apresentada anteriormente, porém nos deparamos com fatores impeditivos à realização desses testes, dois dos métodos que estamos comparando, NN e AIS, possuem um número elevado de parâmetros a ser testado, e para alguns desses parâmetros, o domínio pode atingir milhares de valores possíveis. Esse fato nos obrigou a trabalhar de maneira não exaustiva como no texto anterior; executamos em vez disso, buscas pelo conjunto de parâmetros que melhorem a assertividade ${ }^{6}$ do modelo gerado pelo

\footnotetext{
${ }^{2}$ Repare que na prática corresponde a uma busca em apenas um parâmetro, pois o outro funciona como um parâmetro de substituição da imagem submetida ao reconhecimento.

${ }^{3} \mathrm{f}=$ filtro $\in($ Steerable, Quadrature steerable, Real Gabor, Complex Gabor, Line operator $) ; n=$ interferência(noise); $\theta=$ parâmetro específico para a técnica $\mathrm{f}$

${ }^{4}$ Uma curva ROC é uma demonstração bidimensional da performance de um classificador (pode ser facilmente visualizado com uma curva semelhante a uma $\ln (\mathrm{x})$ em um gráfico bidimensional). Para comparar classificadores o texto reduziu a curva ROC a um valor escalar. O método mais comum para realizar esta redução é calcular a área abaixo da curva ROC (AUC - area under the curve), e foi este o método utilizado.

Uma observação interessante sobre a AUC, é que a AUC é uma porção do quadrado de área 1 (espaço ROC), portanto, seus valores variam entre 0.0 e 1.0. Entretanto, como classificadores piores que os aleatórios não são encontrados no espaço ROC, não existem classificadores com AUC menor que 0.5 (0.5 é a área de uma classificador aleatório).

${ }^{5} \mathrm{O}$ texto chama esse valor de faixa de detecção.

${ }^{6}$ Segundo alguns critérios que serão discutido mais a frente.
} 


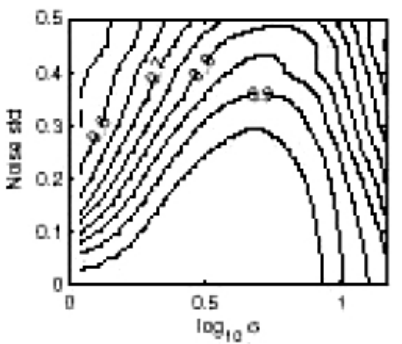

(a)

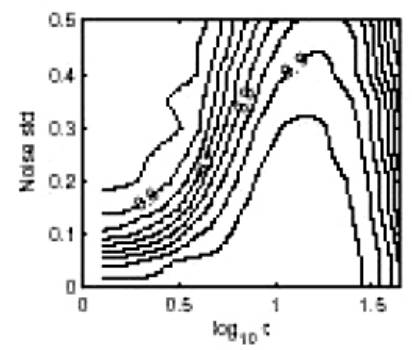

(c)

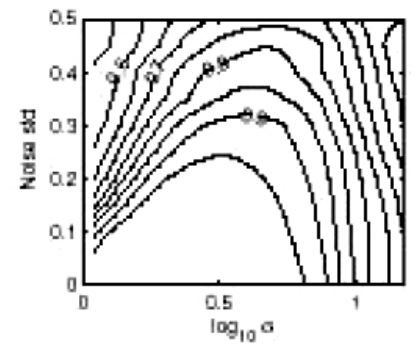

(b)

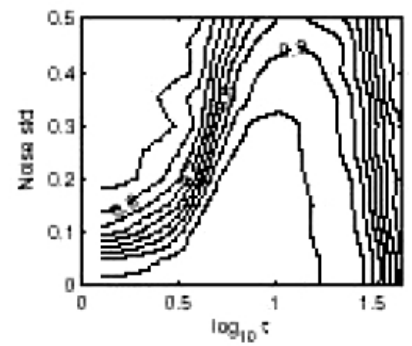

(d)

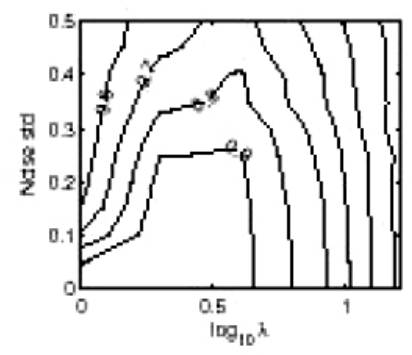

(e)

Figura 5.11: Curva de nivel - Retirado de [AR05]

método utilizando GA. A fim de verificar a acurácia do GA que utilizamos, escolhemos a DT para executar uma validação da convergência do GA. Escolhemos o DT pois este possui apenas dois parâmetros a confiança $(-\mathrm{C})$ de domínio $[0,00 ; 0,49]$ e o suporte de domínio $[1 ; 100]$ $(-\mathrm{M})^{7}$; de modo que temos um $\Omega$ com 4900 pontos $^{8}$ possíveis.

${ }^{7}$ Para mais detalhes sobre os parâmetros retornar a descrição teórica de Árvores de Decisão.

${ }^{8}$ Tivemos que restringir o nosso universo, o limitante 100 para o suporte foi escolhido muito superior a valores que apresentavam bons desempenhos em nossos teste, de modo que reparou-se que o ótimo nunca atingia valores de suporte grandes; a precisão de 0,01 


\subsubsection{Aferindo o GA}

A figura 5.12 mostra em sua parte superior esquerda um gráfico de curva de nível ${ }^{9}$ onde é possível notar que o ponto ótimo encontra-se no parâmetro C $0.49 \mathrm{M}$ 1, isso quer dizer na prática que temos para essa nossa base um árvore permitindo um valor bem baixo de elementos por nó (1) e exigindo que apenas 51\% (1 - 0.49) dos elementos do nó pertençam a uma determinada classe, para assim afirmar que esse nó é dessa classe. Na parte superior direita da figura 5.12 é possível ver uma legenda que mostra que como os gráficos estão dispostos, tendo o suporte no eixo das abscissas (eixo x) e a confiança no eixo das ordenadas (eixo y). Na parte superior central vemos uma ampliação do gráfico na parte superior esquerda.

$\mathrm{Na}$ parte inferior da figura 5.12 vemos duas execuções do GA com duas funções objetivo ${ }^{10}$ (cujo ótimo era coincidente em C 0.49 M 1), e vemos que em ambos os casos o ótimo foi obtido, o que mostra que uma otimização via um algoritmo genético pode ser suficiente para uma boa comparação.

Mas ainda não satisfeitos, repetimos completamente esse teste para mais outras três bases ${ }^{11}$ do nosso conjunto de bases a fim de verificar se o resultado era consistente. A figura 5.13 mostra como o resultado obtido foi satisfatório.

\subsection{O uso do GA}

Agora que sabemos que nossa implementação do GA convergiu pelo menos para as DTs. Reservamos essa seção para explicar o algoritmo.

\footnotetext{
para a confiança foi tomada por restrição de tempo para explorar um universo de maior. ${ }^{9}$ Gráfico com avaliação da função Custo = PerdaMédiaPorFraude * NumeroFraudeNaoDetectada + $\quad$ CustoLigagaoTelefõnica * NumeroDeTransacõesClassifComoFraude.

${ }^{10} \mathrm{~A}$ primeira função não levava o custo em consideração, enquanto a segunda levava. Repetimos esse teste duplamente pois queríamos garantir que o GA funcionasse independente da função que estivessemos avaliando, mas é verdade que com o passar do trabalho desistimos da função que não leva o custo consideração. Para mais detalhes ver seção Função Objetivo

${ }^{11}$ as bases 3,4 e 5; a base 2 refere-se a base da execução anterior
} 


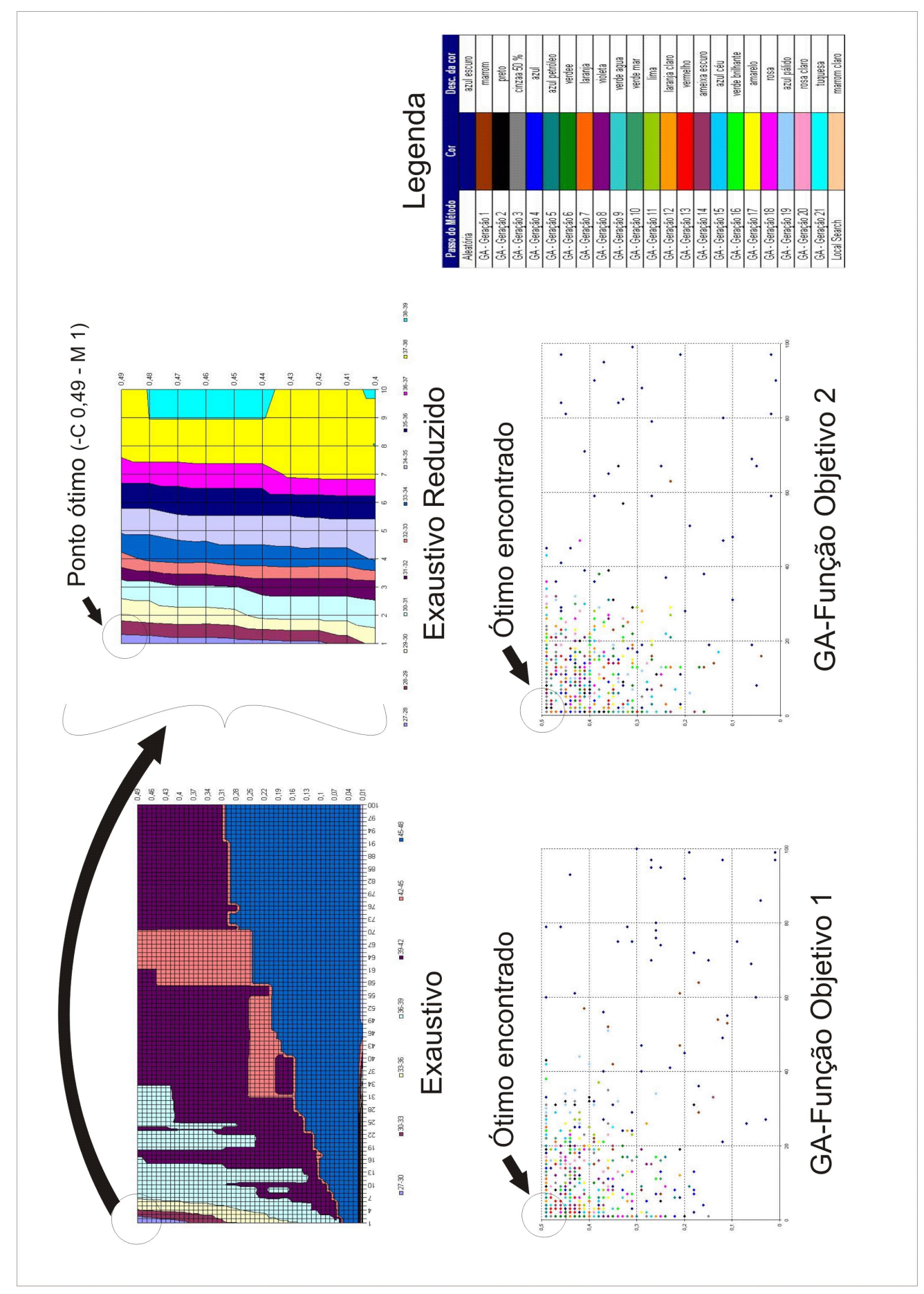

Figura 5.12: Aferindo a execução do GA 


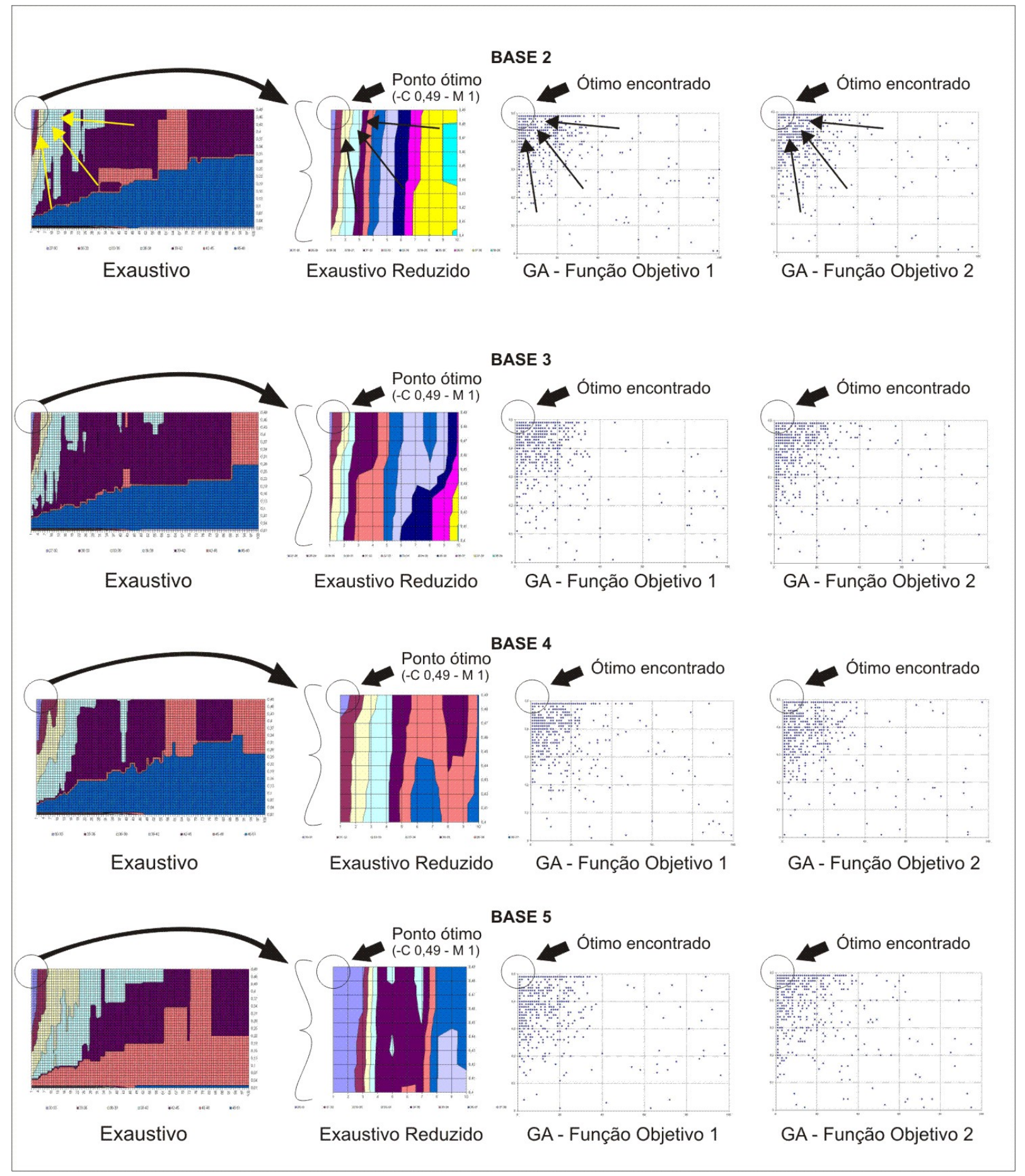

Figura 5.13: Aferindo a execução do GA - 4 bases 
Na prática, não usamos GA para Árvore de Decisão, Redes Bayesianas e nem Bayes Ingênuo, pois não havia tal necessidade, já que o primeiro possuia um número reduzido de parâmetros e um espaço de estado $\Omega$ que fomos capaz de explorar, o segundo sim possuia um número elevado de combinações (um grande espaço de estados $\Omega$ ), porém o tempo de execução de cada conjunto de parâmetro era muito baixo ${ }^{12}$, isso nos permitiu executar uma busca exaustiva; o terceiro, Bayes Ingênuo, não possui parâmetros, o que dispensou portanto qualquer busca.

Executamos, portanto, o GA para os métodos Redes Neurais e Sistemas Imunológicos Artificiais pois estes possuem um número elevado de parâmetros e o tempo de execução que inviabilizava uma busca exaustiva.

\subsection{Descrição do GA - para otimização dos parâmetros dos metódos}

A figura 5.14 mostra como executamos nosso algoritmo para busca dos melhores parâmetros, tanto para NN quanto para AIS. Primeiro executamos 50 repetições escolhendo aleatoriamente os parâmetros e executando os métodos, isso pode ser visualizado na parte superior esquerda da figura.

Segundo, executamos 20 gerações do GA, onde ordenamos as soluções por ordem crescente de custo (do menor ao maior) e geramos 15 novos candidatos a cada geração, o primeiro candidato corresponde a uma combinação $^{13}$ entre o segundo e o primeiro melhores da geração anterior, o segundo candidato corresponde a uma combinação entre o terceiro e um entre o segundo e o primeiro escolhido aleatoriamente, o décimo quinto candidato corresponde a uma combinação entre o décimo sexto e um entre o décimo quinto e o primeiro escolhido aleatoriamente.

E por fim, a terceira parte, chamada de Local Search mostra a parte

\footnotetext{
${ }^{12}$ Tempo médio para uma execução no Weka: DT $=40$ segundos $/ \mathrm{NN}=10$ minutos / $\mathrm{BN}=10$ segundos $/ \mathrm{NB}=3$ segundos $/ \mathrm{AIS}=25$ minutos.

${ }^{13}$ As partes GA - Cross Over 1 e 2 mostram uma amostra das combinações que fizemos a cada geração para criar os novos candidatos do algoritmo genético. A parte GA - Mutação mostra como geramos mutação em uma única direção.
} 


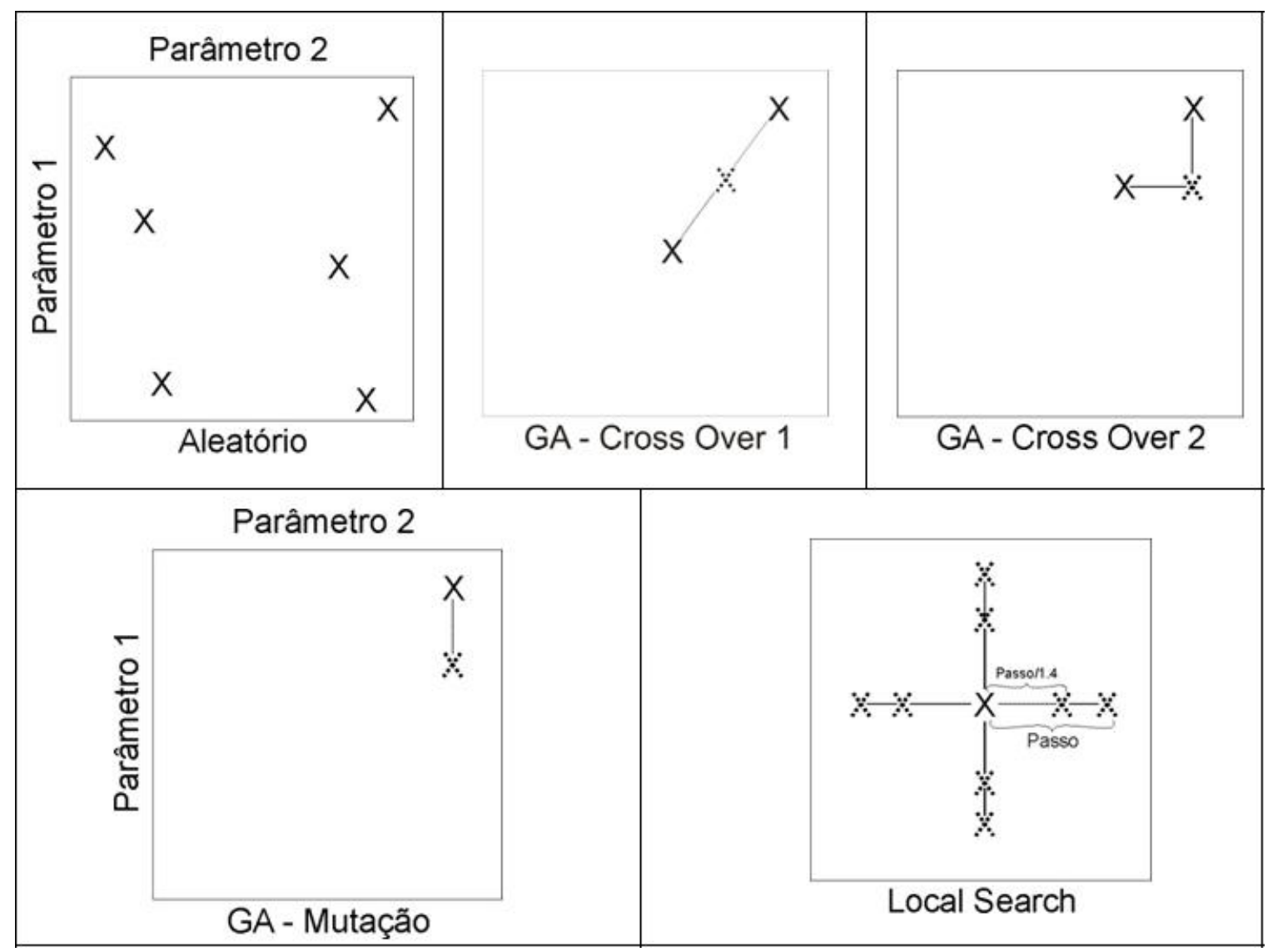

Figura 5.14: GA para otimização dos parâmetros

final do nosso algoritmo de otimização, que logo após terminar o algoritmo genético, executa uma busca local ao redor do ponto ótimo, e, caso haja um ponto melhor em alguma das direções, nosso algoritmo move o ponto ótimo para este novo ponto, e repete a busca local, até que não se encontre um outro ponto melhor que o ótimo atual.

A seguir apresentamos uma parte do código usado para a simulação do algoritmo genético para Redes Neurais que utilizamos (chamamos ele de GA oxigenado devido as partes que chamamos de fusão $\left.{ }^{14}\right)$, este trecho abaixo corresponde a alteração do parâmetro Taxa de Aprendizado

\footnotetext{
${ }^{14}$ Essa parte de fusão fez-se necessária para acelerar a convergência dos parâmetros para o AIS, que em princípio apresentaram problemas de convergência.
} 
(Learning Rate - $\eta$ na parte teórica).

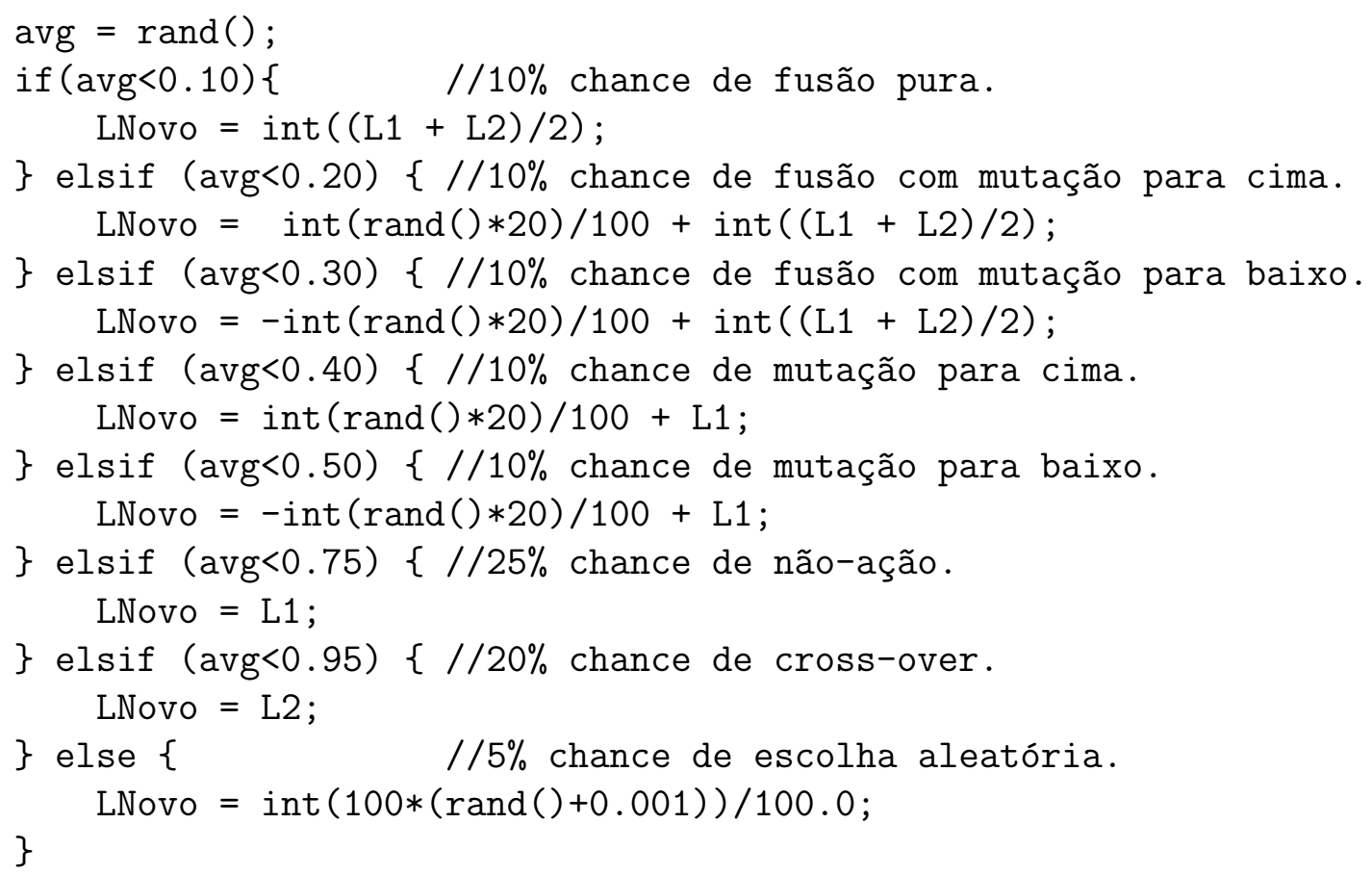

L1 representa a coordena L (Taxa de Aprendizado) de um dos melhores candidatos da geração passada do algoritmo genético. L2 representa a coordena L de um outro dos melhores candidatos da geração passada do algoritmo. LNovo representa a coordena $\mathrm{L}$ do novo candidato criado nesta geração. rand() é a função que gera números aleatórios entre 0 e 1.0 .

Assim como a Taxa de Aprendizado foi alterada, nosso algoritmo possui partes que alteram os outros parâmetros de cada método, no total variamos 5 de 7 parâmetros para NN e 7 de 9 parâmetros para AIS, um importante fato foi que permitimos (probabilisticamente) que todos os parâmetros pudessem sofrer alteração em uma mesma geração, e que pelo desenho do código acima pode-se notar que com o passar das gerações (probabilisticamente) isso deixa de acontecer ${ }^{15}$.

\footnotetext{
${ }^{15}$ Repare que com a convergência L1 e L2 passam a ser iguais, então a chance de não mudança de um parâmetro cresce de $25 \%$ para $55 \%=10 \%+25 \%+20 \%$.
} 


\subsection{Descrição de uma execução dos Métodos no Weka}

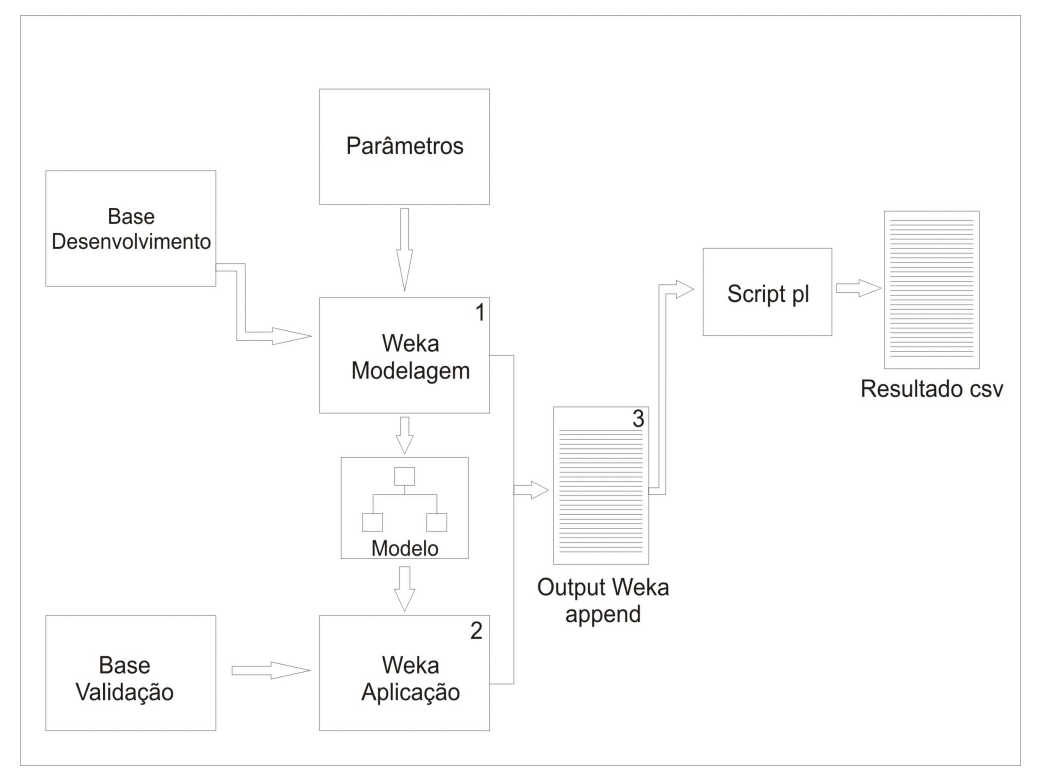

Figura 5.15: Execução de 1 passo do algoritmo

A figura 5.15 mostra em detalhes como funcionou uma execução dos métodos de modelagem em nossos testes. A parte 1 da figura 5.15 diz respeito a parte de construção do modelo executado pelo Weka.

Abaixo vemos um exemplo de uma parte da linha de comando para a Rede Neural:

weka.classifiers.functions.MultilayerPerceptron -L 0.2 -M 0.24 -N 500 -V 4 -S 0 -E 1 -H 15

O Weka, através do parâmetro -t, está habilitado a desenvolver o modelo em uma base de desenvolvimento (com $70 \%$ das observações), no nosso caso usamos essa opção para todos os quatro métodos testados. Após essa primeira parte, o Weka passa (internamente no seu código) o modelo para a parte 2 onde ele executa a validação do modelo, para tanto, nós passamos ao Weka usando o parâmetro -T, uma base de 
validação (com 30\% das observações). Posteriormente, o Weka gera um arquivo de saída contendo as estatísticas do modelo criado. Após o Weka ter gerado seu arquivo de saída, nosso Script interpretava-o extraindo as informações mais relevantes e criava um arquivo.csv contendo para cada linha o resultado de uma execução do Weka.

Uma das estatísticas mais relevantes para nossos testes foi a Matriz de Confusão (Confusion Matrix) pois com ela pudemos construir as nossas duas funções objetivo que discutiremos a seguir.

Exemplo completo da linha de comando para a Rede Neural poderia ser:

nice /usr/bin/java -cp weka.jar -Dfile.encoding=IS08859-1

weka.classifiers.functions. MultilayerPerceptron -L 0.2 -M $0.24 \backslash$

-N 500 -V 4 -S 0 -E 1 -H 15 -t ./bases/base_desenv_02.arff ।

-T ./bases/base_validacao_02.arff > ./resultados/statistics_02

\subsection{Função Objetivo}

Para discutirmos nossa função objetivo precisamos entender primeiro alguns conceitos, são eles: matriz de confusão, principais indicadores e custo de fraude.

\subsubsection{Matriz de Confusão}

Abaixo temos um trecho da saída da execução do Weka para Árvores de Decisão com parâmetros: -C 0.49 -M 100 para a base 2.

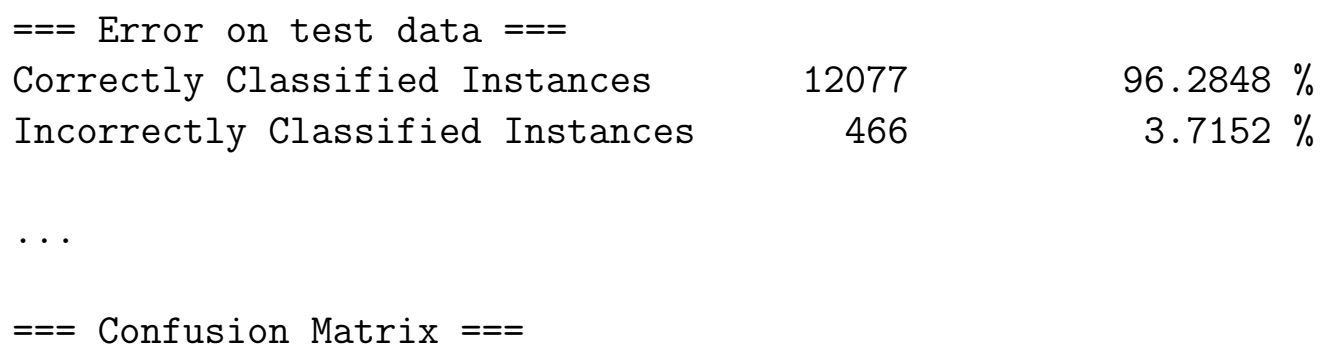




$\begin{array}{clc}\mathrm{a} & \mathrm{b} \quad<- & \text { classified as } \\ 12022 & 54(\mathrm{FP}) & \mathrm{a}=\mathrm{N} \\ 412(\mathrm{FN}) & 55 & \mathrm{~b}=\mathrm{S}\end{array}$

Na matriz acima temos um total de 12543 registros, a diagonal principal define a quantidade de registros corretamente classificados $(12022+55=12077)$. A diagonal invertida define a quantidade de registros classificados de maneira errada $(54+412=466)$. O que nos leva a um percentual dos registros classificados corretamente (PRCC) igual a 96,2848\% (12077/12543) e a um percentual dos registros classificados incorretamente (PRCI) igual a $3,7152 \%(466 / 12543)$.

\subsubsection{Principais indicadores}

A posição linha $=1$ e coluna $=2$ da matriz mostra que temos 54 falsos positivos, pois o algoritmo desconfiou que poderia se tratar de 54 fraudes (dito positivo) mas de fato trata-se de 54 transações legítimas, portanto um erro (dito falso).

Podemos com isso definir o que chamamos de Hit Rate no mercado de prevenção à Fraude (conhecido também como Assertividade ou Acurácia) como sendo $55 /(54+55)=50,5 \%$, total de registros fraudulentos classificados como fraude dividido pelo total de registros classificados como fraude. Podemos também definir o que chamamos de False Positive Rate (FPR) como sendo $54 /(54+55)=49,5 \%$, total de registros legais classificados como fraude dividido pelo total de registros classificados como fraude.

A posição linha $=2$ e coluna $=1$ da matriz mostra que temos 412 falsos negativos, pois o algoritmo não desconfiou que poderia se tratar de uma fraude (dito negativo) mas de fato trata-se de uma fraude, portanto um erro (dito falso).

Podemos com isso definir o que chamamos de Detection Rate no mercado de prevenção à Fraude (conhecido também como cobertura), como sendo $55 /(412+55)=11,8 \%$, total de registros fraudulentos classificados como fraude dividido pelo total de registros fraudulentos. Podemos também definir o que chamamos de False Negative Rate (FNR), como sendo $412 /(412+55)=88,2 \%$, total de registros fraudulentos NÃO classificados como fraude dividido pelo total de registros fraudulentos. 


\subsubsection{Custos}

Para nosso trabalho utilizamos outros dois conceitos referentes ao custo financeiros relativos as fraudes, o primeiro é o custo da detecção à fraude que é definido como sendo $(54+55) * \mathrm{Avg}_{-} \mathrm{Cprev}^{16}$, supondo Avg_Cprev $=\mathrm{R} \$ 1,00$, teríamos $\mathrm{R} \$ 109,00$ de custo para prevenir essas 55 fraudes de ocorrerem.

O segundo custo é o custo de perda por fraude que é definido como 412 * Avg_FraudLoss ${ }^{17}$, supondo Avg_FraudLoss $=\mathrm{R} \$ 100,00$, teríamos R $\$$ 41.200,00 de autorizações fraudulentas passando sem serem detectadas e gerando perda financeira.

\subsubsection{Nossa função objetivo}

No princípio de nossos trabalhos, após poucas conversas, já descartamos o uso de uma função objetivo que usasse o PRCC. Descartamos esse indicador por entender que ele não se atenta a dois fenômenos muito relevantes em nossa base de dados. O primeiro diz respeito à base que é muito desbalanceada, então o fato de se obter um PRCC de $96.2848 \%$ pode ser visualmente muito bom, mas se atentarmos ao fato de nossa base possuir 3,7232\% (467/12543) casos fraudulentos, acertaríamos em $96,2768 \%$ das vezes se simplesmente dissermos que todos os casos da base são legítimos, o que, neste caso, levaria ao mesmo resultado dizer que todos os casos são fraudes a se fazer qualquer verificação através deste modelo. O segundo fenômeno não levado em conta diz respeito a diferença de custo entre um falso positivo e um falso negativo. Uma função objetivo PRCC considera esses custos iguais, mas na vida real eles têm uma diferença bastante elevada. É de se esperar que em uma companhia comum eles tenham uma relação de 1 para 100, se perde 100 vezes mais se não ligarmos para um caso conhecido fraudulento do que o custo para se ligar para um caso que desconfiamos.

\footnotetext{
${ }^{16}$ Onde Avg_Cprev é igual ao custo médio de um caso analisado pela área de prevenção à fraude, esse custo leva em conta o custo de pessoal alocado para analisar o caso, o custo de locação de prédio e depreciação do computador e outros equipamentos, e mais importante: o custo da telefonia para contar o cliente.

${ }^{17}$ Onde Avg_FraudLoss é o ticket médio (valor médio em reais) das transações confirmadas como fraudulentas.
} 
Então criamos duas funções objetivo.

A versão 1 é o produto dos logaritmos da Hit Rate e Detection Rate:

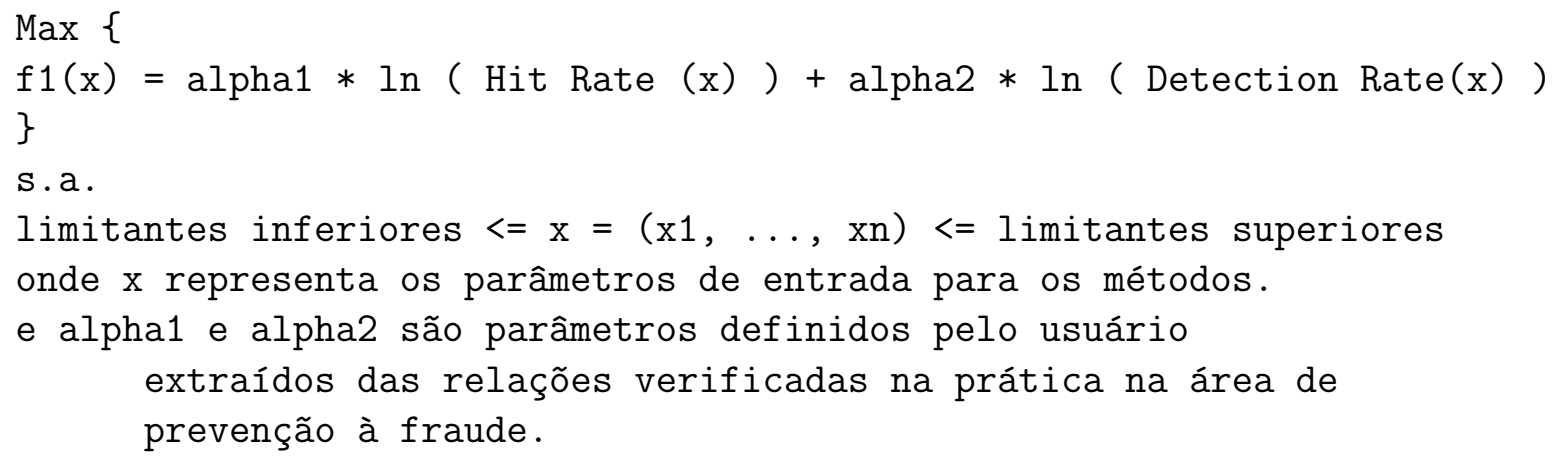

A versão 2 é a soma dos custos de perda de fraude:

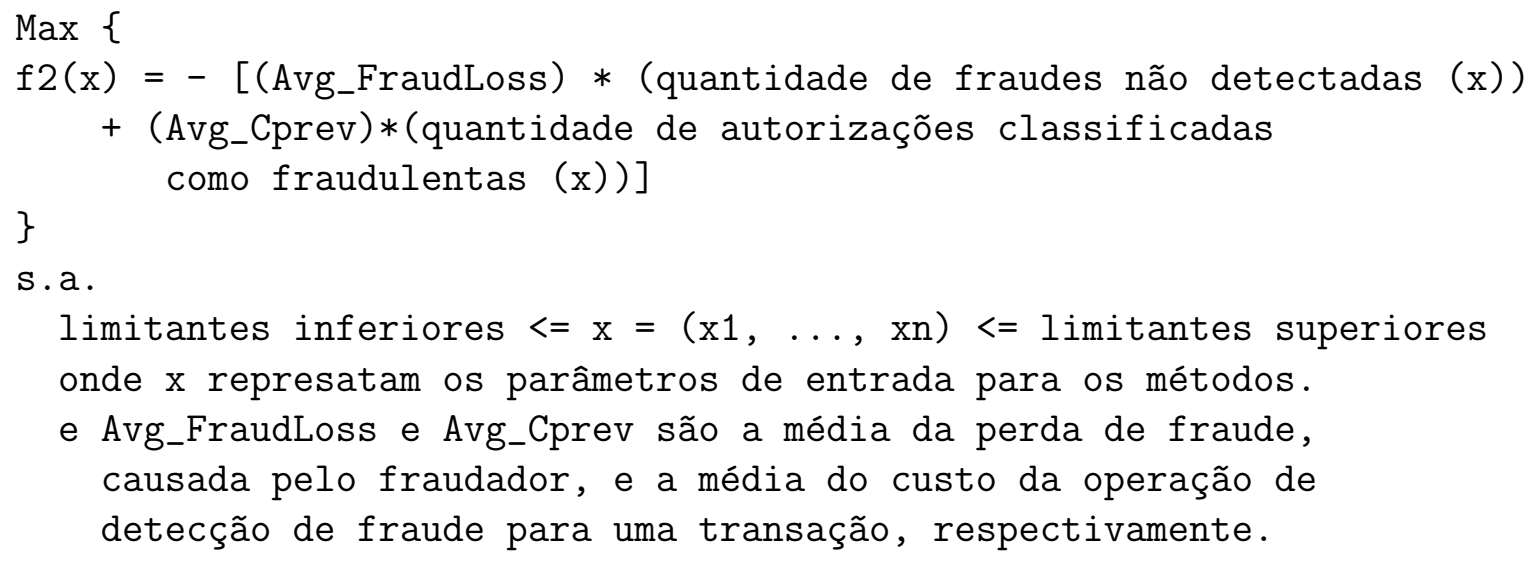

Repare que as duas funções foram propositadamente definidas com respostas nos reais negativos para manter a uniformidade dos programas e, assim, realizarem a maximização das funções.

\subsubsection{O custo ajustado}

Conforme fomos trabalhando com os dados e obtendo o primeiros resultados, nos deparamos com uma anomalia quando avaliamos a função objetivo versão 2. Obtivemos melhores resultados quando checamos 
todos os casos em vez de usar o modelo gerado pelos algoritmos, claro que esse fato é passível de ocorrer, mas não com tanta facilidade quanto estava ocorrendo. Para ilustrar esse fato vamos voltar à matriz de confusão mostrada anteriormente.

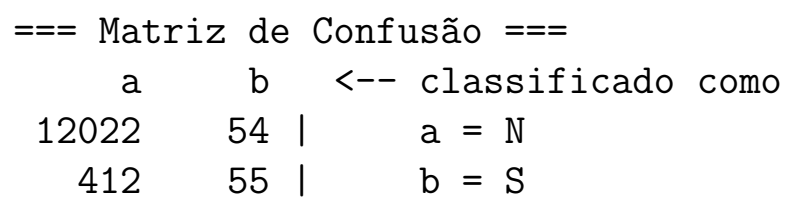

Para essa matriz, supondo Avg_FraudLoss $=\mathrm{R} \$ 100,00$ e Avg_Cprev $=\mathrm{R} \$ 1,00$ teremos

(a) $f 2(x)=-[100 * 412+1 * 109]=-41.309,00$

Porém, para o nosso problema existem duas outras possibilidades que poderíamos aplicar em vez de usarmos o modelo gerado anteriormente. A primeira é não usar uma área de prevenção à fraude, permitindo que qualquer fraudador obtenha sucesso em sua fraude. Assim, o total de autorizações fraudulentas evitadas seria zero, isso nos levaria a seguinte matriz.

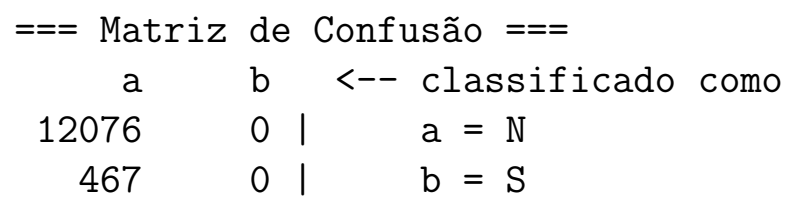

E então, teríamos o seguinte custo:

(b) $f 2(x)=-[100 * 467]=-46.700,00$

A segunda possibilidade seria a de checar todos os casos, isso nos levaria a seguinte matriz.

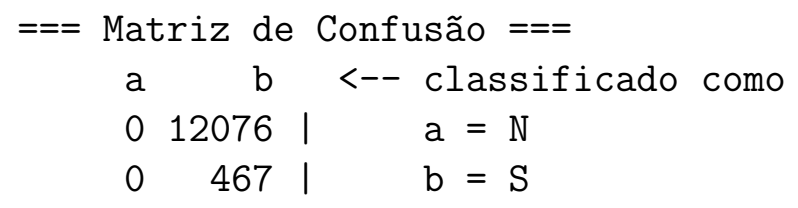


E então, teríamos o seguinte custo:

(c) $f 2(x)=-[1 * 12543]=-12.543,00$

Aqui nasce a anomalia, pois obtivemos menor custo dispensando o modelo e executando a checagem para todos as transações. Esse fato ocorreu, pois não nos atentamos ao fato da base ter sido artificialmente alterada quando da amostra estratificada. Para tentar minimizar esse fato, propusemos ajustar a matriz, gerando por fim um custo ajustado, tentando voltar à proporção inicial entre as classes.

DESAJUSTADA

$===$ Matriz de Confusão ===

\begin{tabular}{rr|c}
$\mathrm{a}$ & $\mathrm{b}$ & $<-$ \\
12022 & 54 & $\mathrm{a}=\mathrm{N}$ \\
412 & 55 & $\mathrm{~b}=\mathrm{S}$
\end{tabular}

AJUSTADA (Multiplicando por 10 os casos de autorizações legitimas). $===$ Matriz de Confusão ===

\begin{tabular}{rr|c}
$\mathrm{a}$ & $\mathrm{b}$ & $<-$ \\
120220 & 540 & $\mathrm{a}=\mathrm{N}$ \\
412 & 55 & $\mathrm{~b}=\mathrm{S}$
\end{tabular}

Refazendo os cálculos para essa nova matriz, obtivemos:
(a) $f 2(x)=-[100 * 412+1 * 595]=-41.795,00$
(b) $f 2(x)=-[100 * 467 \quad]=-46.700,00$
(c) $f 2(x)=-[\quad 1 * 121227]=-121.227,00$

Dessa forma, a opção (a) torna-se a melhor opção, chegando mais próximo da realidade.

\subsection{Uma breve discução sobre os parâmetros}

Antes de apresentarmos os resultados obtidos e discuti-los, reservamos essa seção para uma breve descrição dos parâmetros envolvidos em cada 
método implementado no Weka. Essa explicação já se faria importante caso esse trabalho apenas usasse os métodos, mas a importância cresceu na medida em que uma das tarefas feitas nesse trabalho foi o ajuste desses parâmetros, para conseguir resultados por um lado melhores e por outro lado mais estáveis. Nesta seção descrevemos separadamente, para cada um dos métodos, o nome parâmetro e sua função, explicitamos o domínio do parâmetro. Nosso padrão foi utilizar-se de todo o domínio do parâmetro, porém para alguns parâmetros expressamente informados, decidimos restringir o domínio ou fixar seu valor, as razões para isso são informadas na descrição do parâmetro, mas adiantamos que o principal motivo para restrição de domínio foi o tamanho do espaço de busca muito grande, caso observado no parâmetro E para NN.

\subsection{1 Árvore de Decisão}

A $\underline{\text { DT }}$ possui dois parâmetros -C e -M:

- A opção -C define a melhora da confiança, ou seja, se usamos o valor $0.3(30 \%)$ e, se em nossa base temos $96 \%$ de transações legítimas e $4 \%$ de transações fraudulentas, o algoritmo precisará de mais de $98 \%$ de registros de uma determinada classe para classificá-lo como dessa classe.

- A opção -M define o suporte, que corresponde ao número mínimo de elementos permitidos em um determinado nó, seja ele um nóintermediário ou terminal.

Para mais detalhes, ver parte teórica sobre DT.

\subsubsection{Redes Neurais}

A $\underline{\mathbf{N N}}$ possui sete parâmetros (-L,-M,-N,-V,-S,-E,-H):

- -L é o parâmetro de Taxa de Aprendizado (Learning Rate), esse parâmetro varia entre 0.00 e 1.00, quanto mais próximo de zero menor o impacto (ou influência) que uma nova observação terá 
sob a rede e quanto mais próximo de um maior esse impacto (ou influência).

- -M é o parâmetro de Taxa de Momentum (Momentum), esse parâmetro varia entre 0.00 e 1.00, e sua inclusão (valores maiores que zero) tem por objetivo aumentar a velocidade de treinamento da rede neural e reduzir o perigo de instabilidade (mínimos locais), esse parâmetro é geralmente interpretado como um pêndulo que faz com que a rede oscile de um lado para outro do ótimo local até encontrá-lo.

- -N corresponde ao número de épocas que a base de treinamento será submetida ao método, para nossos testes decidimos não variar esse parâmetro, usando o valor fixo de 500 épocas (valor default), pois em nossos testes iniciais mais submissões traziam alterações infimas na rede, já que a rede já havia convergido.

- -V corresponde ao tamanho do conjunto de validação interna do método, esse parâmetro varia entre $0 \%$ e 99,99\%, quando esse parâmetro é maior que zero prentede-se reduzir o overfitting na rede.

- -S é a semente para geração de números aleatórios, repetindo uma mesma semente somos capazes de repetir exatamente uma mesma execução, no nosso caso, como gostaríamos de ser possível reproduzir a posteriori todos os testes e eliminar fatores aleatórios não possíveis de comparar, decidimos não variar esse parâmetro e sim usá-lo sempre igual a zero.

- -E corresponde ao parâmetro de ponto de corte na validação (Validation Threshold), esse parâmetro no Weka é qualquer inteiro entre 1 e 100. Em conjunto com o parâmetro -N, formam as condições de parada do algoritmo, caso tenha sido atribuído 0 (zero) ao parâmetro - $\mathrm{V}$ este parâmetro passa a não ter qualquer efeito sobre o resultado final, restando apenas o parâmetro -N como condição de parada para o algoritmo.

- -H corresponde a uma string de números separados por vírgula. Cada um desses números representa o número de nós (Layers) que pertencerão a uma dada camada, e a quantidade de números representarão a quantidade de camadas intermediária ${ }^{18}$. Além

\footnotetext{
${ }^{18} \mathrm{Com}$ apenas um número, já se obtém uma camada intermediária, o que pretende
} 
da opção numérica, existem alguns curingas que podem ser utilizados: $a=$ (número de atributos + números de classes) $/ 2 ; i$ $=$ número de atributos, $o=$ números de classes; e $t=$ número de atributos + números de classes. Para nosso exemplo temos 17 atributos e 2 classes portanto. Devido à quantidade exponencial de parâmetros que teríamos que explorar caso variássemos a quantidade de números, por sua vez a quantidade de camadas escondidas, resolvemos fixar a quantidade de camadas escondidas igual a um e variamos apenas o número de nós nessa camada entre 0 e 20 , onde 19 representa o curinga t.

Para mais detalhes, ver parte teórica sobre NN.

\subsubsection{Naive Bayes}

A NB não possui qualquer parâmetro. Para mais detalhes, ver parte teórica sobre de NB dentro da seção teórica sobre BN.

\subsubsection{Redes Bayesianas}

A $\underline{\mathrm{BN}}$ possui quatro parâmetros (-D, -Q, -S, -E):

- -D define se o algoritmo não deve ou deve usar uma estrutura de árvore chamada de ADTree para economizar tempo de execução, evitando execuções repetidas. Se -D for explicitado o algoritmo não usa a estrutura, caso ele seja omitido então a estrutura é usada.

- -Q é usado para definir o tipo de algoritmo utilizado para buscar a topologia da rede, no Weka os algoritmos disponíveis são: GeneticSearch, HillClimber, K2, LocalScoreSearchAlgorithm, RepeatedHillClimber, SimulatedAnnealing, TabuSearch e TAN ${ }^{19}$, os

resolver o problema de funções não linearmente separáveis.

${ }^{19}$ Confessamos que estudamos apenas alguns desses algoritmos, e decidimos não explicálos aqui, pois cremos que essa explicação fugiria do escopo do trabalho, já que alguns dos algoritmos possuem adaptações para torná-los de algoritmo de busca em método de classicação, e poderíamos tê-los comparados com os cinco métodos escolhidos.Além disso, existem outros algoritmos que podem ser usados para buscar essa topologia e não estão 
algoritmos de busca possuem dois parâmetros -P e -S definidos logo abaixo.

- -P Define o número máximo de nós pais permitido na topologia.

- -S Define o tipo de pontuação a ser utilizada para montar a tabela de probabilidades condicionais, estão disponíveis no Weka: BAYES, BDeu, MDL, ENTROPY e AIC ${ }^{20}$.

- -E Define o estimador. Um estimador é um algoritmo para encontrar as tabelas de probabilidade condicional de Bayes. Os estimadores disponíveis no Weka são: BayesNetEstimator, BMAEstimator, MultiNomialBMAEstimator e SimpleEstimator ${ }^{21}$, esses estimadores possuem um parâmetros A, chamado de alpha, que varia entre $0 \%$ e $100 \%$, correspondendo a um chute inicial para a probabilidade condicional.

\subsubsection{Sistemas Imunolóligicos Artificiais}

O $\underline{\text { AIS }}$ possui 10 parâmetros $(-\mathrm{S},-\mathrm{F},-\mathrm{C},-\mathrm{H},-\mathrm{M},-\mathrm{R},-\mathrm{V},-\mathrm{A},-\mathrm{E},-\mathrm{K})^{22}$ :

- -S Semente (seed) usada para geração dos números aleatórios no algoritmo. Decidimos não variar esse parâmetro e sim usá-lo sempre igual a um, mas como será visto mais a frente, tivemos algumas poucas vezes que alterar esse parâmetro para melhorar a convergência do algoritmo.

- -F Percentual mínimo de falta de afinidade (affinity threshold), na implementação atual esse parâmetro corresponde a máxima

disponíveis no Weka, basicamente qualquer método de busca que não dependa de derivada (Free Derivate Search Methods). Para mais detalhes sobre os algoritmos disponíveis no Weka ver [WF05].

${ }^{20}$ Para mais detalhes sobre essas pontuações ver [WF05].

${ }^{21}$ Para mais detalhes sobre esses estimadores ver [WF05].

${ }^{22} \mathrm{~A}$ implementação do AIS utilizada em nosso trabalho corresponde a versão 1.6 de Março de 2006 de Jason Brownlee em [Bro05]. Jason Brownlee é um dotorando da Swinburne University of Technology, Melbourne, Australia. O plug-in WEKA Classification Algorithms pode ser encontrado em seu site pessoal [http://www.ict.swin.edu.au/personal/jbrownlee/], visitado por nós pela última vez em 26 de janeiro de 2008, ou direto no sorceforge [http://wekaclassalgos.sourceforge.net/], e segundo Brownlee sua implementação se baseou no algoritmo descrito em [WTB04]. 
distância permitida entre um anti-corpo e o antigêno; Está distância é calculada através da distância Euclidiana, quanto menor esse parâmetro mais próximo estarão o anti-corpo e o antígeno, ver [WTB04] na página 6 para mais detalhes.

- -C Valor de Clonagem (Clonal Rate) é um inteiro que determina a quantidade de clones permitida que uma B-Cell ${ }^{23}$ poderá tentar produzir, nessa implementação, esse parâmetro também é utilizado para o cálculo da quantidade de recursos necessários para uma B-Cell, o número de clones corresponderá a (clonal rate * stimulation value ${ }^{24,25}$ ).

- -H Percentual de hiper-mutação (hyper-mutation rate) é um inteiro, que varia entre 0 e 100, que determina a quantidade de clones (do item anterior) que sofrerão alguma mutação.

- -M Percentual de mutação (mutation rate) é um número entre 0 e 1 que corresponde a probabilidade de uma dada característica qualquer do vetor de características (feature vector) sofrer mutação, esse parâmetro só surte efeito (causando a mutação) sobre os clones selecionados para mutação através do parâmetro anterior. Na implementação atual são injetados pelo menos (hyper-mutation rate $*$ clonal rate $*$ stimulation value) clones com alguma mutação na população.

- - $\mathrm{R}$ Total de recursos $\mathrm{R}$ (total resources) é um número inteiro que representa o número máximo de B-Cell permitido em todo o sistema, se em uma dada interação atingimos um número de B-Cells maior que $R$, então mantem-se para a próxima interação as $R$ B-Cells mais estimuladas.

- -V Corte de estimulação (stimulation threshold), ou corte de afinidade, é um número entre 0 e 1 usado como critério de parada do treinamento de um dado antígeno. Nesta implementação, somente quando a estimulação média de todas as B-Cells de cada classe estiver

\footnotetext{
${ }^{23}$ No texto a B-Cell é chamada de ARB (Artificial Recognition Ball)

${ }^{24}$ Stimulation Value é o valor retornado pela Stimulation Function.

${ }^{25}$ Stimulation Function é a função usada para medir a resposta de um ARB em relação a um antígeno ou outro ARB. Nesta implementação este valor varia entre 0 e 1 . Para a implementação do AIRS apresentado essa função corresponde ao inverso da função distância Euclidiana.
} 
acima do corte de estimulação a reação de reconhecimento do particular antígeno é interrompida.

- -A Number of affinity threshold instances: Esse parâmetro não recebe qualquer explicação no texto [Bro05], e não recebeu qualquer variação nos exemplos do texto, recebendo sempre o valor -1 . Executamos testes simples e não notamos variação significante na assertividade quando variamos esse parâmetro, por esses motivos, decidimos manter esse parâmetro com seu valor default igual a -1.

- -E Define o número de instâncias aleatoriamente escolhidas para inicializar o pool de memória (Number of Initialisation Instances). Esse parâmetro pode variar entre 0 e o número de instâncias, como esperamos que esse parâmetro apenas altere a velocidade de convergência e não altere muito o custo, decidimos variá-lo entre 0 e 10 .

- -K é usado durante a parte dita somente-leitura do algoritmo ou aplicação do modelo ${ }^{26}$, ele determina a quantidade de células de memória mais próxima $(\mathrm{kNN})$ que serão usadas para a votação dos casos desconhecidos. Exemplo: Suponhamos que esse parâmetro seja 3, e para um dado antígeno as três células de memória mais próximas sejam: BCell-12(fraude), BCell-25(não fraude) e BCell140(fraude); dessa forma temos que a célula 12, a célula 25 e a célula 140 são as que mais se aproximam do antígeno, e então esse antígeno será classificado como fraude, pois recebeu dois votos para fraude contra um voto para não fraude.

\footnotetext{
${ }^{26} \mathrm{Em}$ nosso caso este passo corresponde ao teste nas bases de validação.
} 


\section{Capítulo 6}

\section{Relatório dos resultados obtidos e Análise}

Em nossos testes executamos o GA para descobrir quais os melhores parâmetros para reduzir o custo de fraude. Esse custo levou em consideração tanto a perda de fraude (gerada pelo fraudador) quanto o custo da operação de prevenção à fraude, que, para simplificar a compreensão podemos considerar como sendo unicamente o custo do contato telefônico com o cliente. Para a modelagem foram usadas duas estratégias: uma não levando o custo em consideração na modelagem e a outra, levando-o sim em consideração, os quais chamaremos de execução padrão e execução sensível ao custo, respectivamente.

Resolvemos testar os parâmetros default (do Weka), em uma tentativa de observar qual o método mais robusto e apropriado para os dados de prevenção à fraude no advento de um usuário sem experiência ou sem tempo de ajustar ou adequar melhor os parâmetro para um dado método.

Neste capítulo descrevemos os resultados obtidos em nosso trabalho, começando pelos resultados provenientes de execuções dos parâmetros default. Nas seções seguintes, discorreremos sobre os resultados do GA execução padrão e sensível ao custo e sobre os resultados da busca pelo conjunto de parâmetros ótimos estáveis ${ }^{1}$ para execução padrão e

\footnotetext{
${ }^{1}$ Parâmetros ótimos estáveis são o conjunto de parâmetros cujos custos estejam entre os melhores em todas nossas execuções.
} 
sensível ao custo.

Devido ao fato de estarmos lidando com um relatório de execuções e análises, esse capítulo tornou-se extenso. Reservamos, por isso, a seção 6.5 para trazer um resumo, retomando os resultados mais importantes, de uma forma mais direta e unificada.

\subsection{Resultados parâmetros default}

Abaixo apresentamos os resultados obtidos para os testes usando os parâmetros default do Weka, e utilizando a execução padrão do Weka (sem custo) e a meta heurística sensível ao custo.

\subsubsection{Parâmetros default - Execução padrão}

A figura 6.1 mostra o resultado da execução padrão com parâmetros default para os 5 métodos testados: DT, NN, BN, NB e AIS. Nessa figura, os valores em negativo representam o custo total da perda fraude a ser desembolsado pela empresa ${ }^{2}$ para a base de validação (30\% do total), por exemplo, se escolhermos olhar a base 1 e o método DT, temos um custo $\mathrm{R} \$ 34.728,00$; isso significa que uma parte desse custo seria originado por ato do fraudador (nesse caso seria $\mathrm{R} \$ 33.700,00$ ) e a outra parte teria origem no custo do tratamento dos casos analisado na área de detecção de fraude (nesse caso seria $\mathrm{R} \$ 1.028,00$ ). Além disso, a figura mostra o resultado obtido para cada uma das 9 bases de nossos testes. Na parte inferior, temos três tabelas, uma com a média dos resultados obtidos nas 9 bases, outra com o desvio padrão total e a última com o desvio padrão percentual da média.

E possível observar na figura 6.1 que, em todas as 9 bases, a Rede Bayesiana obteve melhor resultado, esse resultado vem seguido da Naive Bayes, Árvores de Decisão, Sistemas Imunológicos e por último as Redes Neurais. Acrescido a isso, temos que a variabilidade na Rede Bayesiana foi baixa, enquanto ela foi quase o dobro na Rede Neural.

\footnotetext{
${ }^{2}$ Custo total de perda fraude corresponde a soma dos valores subtraídos da empresa pelo fraudador somado ao custo gerado pelos casos analisados pela área de detecção de fraude.
} 


\begin{tabular}{|c|c|c|c|}
\hline \multicolumn{4}{|c|}{ Resultado Execuções dos métodos com parâmetros fixos. } \\
\hline \multicolumn{4}{|c|}{ Execuções baseadas nos parâmetros default usados pelo Weka. } \\
\hline & c & & $\mathrm{c}$ \\
\hline BASE 1 & Parâmetros Default & BASE 6 & Parâmetros Default \\
\hline Árvore de Decisão & $-\mathrm{R} \$ 34.728,00$ & Árvore de Decisão & $-\mathrm{R} \$ 31.380,00$ \\
\hline Rede Neural & $-\mathrm{R} \$ 37.986,00$ & Rede Neural & $-\mathrm{R} \$ 37.259,00$ \\
\hline Naive Bayes & $-\mathrm{R} \$ 31.217,00$ & Naive Bayes & $-\mathrm{R} \$ 30.325,00$ \\
\hline Redes Bayesianas & $-\mathrm{R} \$ 29.868,00$ & Redes Bayesianas & $-\mathrm{R} \$ 28.712,00$ \\
\hline AIS & $-\mathrm{R} \$ 37.276,00$ & AIS & $-\mathrm{R} \$ 34.400,00$ \\
\hline BASE 2 & Parâmetros Default & BASE 7 & Parâmetros Default \\
\hline Árvore de Decisão & $-\mathrm{R} \$ 33.762,00$ & Árvore de Decisão & $-\mathrm{R} \$ 33.325,00$ \\
\hline Rede Neural & $-R \$ 39.559,00$ & Rede Neural & $-R \$ 35.112,00$ \\
\hline Naive Bayes & $-\mathrm{R} \$ 30.787,00$ & Naive Bayes & $-R \$ 31.678,00$ \\
\hline Redes Bayesianas & $-\mathrm{R} \$ 28.375,00$ & Redes Bayesianas & $-\mathrm{R} \$ 29.357,00$ \\
\hline AIS & $-\mathrm{R} \$ 36.349,00$ & AIS & $-\mathrm{R} \$ 35.889,00$ \\
\hline BASE 3 & Parâmetros Default & BASE 8 & Parâmetros Default \\
\hline Árvore de Decisão & $-R \$ 34.273,00$ & Árvore de Decisão & $-R \$ 32.867,00$ \\
\hline Rede Neural & $-R \$ 36.480,00$ & Rede Neural & $-R \$ 41.028,00$ \\
\hline Naive Bayes & $-\mathrm{R} \$ 30.227,00$ & Naive Bayes & $-R \$ 29.946,00$ \\
\hline Redes Bayesianas & $-\mathrm{R} \$ 28.607,00$ & Redes Bayesianas & $-R \$ 28.102,00$ \\
\hline AIS & $-\mathrm{R} \$ 34.416,00$ & AIS & $-\mathrm{R} \$ 36.018,00$ \\
\hline BASE 4 & Parâmetros Default & BASE 9 & Parâmetros Default \\
\hline Árvore de Decisão & $-\mathrm{R} \$ 36.333,00$ & Árvore de Decisão & $-\mathrm{R} \$ 30.684,00$ \\
\hline Rede Neural & $-\mathrm{R} \$ 39.725,00$ & Rede Neural & $-\mathrm{R} \$ 38.283,00$ \\
\hline Naive Bayes & $-R \$ 30.961,00$ & Naive Bayes & $-R \$ 30.155,00$ \\
\hline Redes Bayesianas & $-\mathrm{R} \$ 30.880,00$ & Redes Bayesianas & $-\mathrm{R} \$ 28.765,00$ \\
\hline AIS & $-\mathrm{R} \$ 37.548,00$ & AIS & $-\mathrm{R} \$ 33.680,00$ \\
\hline BASE 5 & Parâmetros Default & & \\
\hline Árvore de Decisão & $-\mathrm{R} \$ 33.328,00$ & & \\
\hline Rede Neural & $-\mathrm{R} \$ 39.624,00$ & & \\
\hline Naive Bayes & $-R \$ 30.493,00$ & & \\
\hline Redes Bayesianas & $-R \$ 28.976,00$ & & \\
\hline AIS & $-\mathrm{R} \$ 34.801,00$ & & \\
\hline Média & Parâmetros Default & Desvio Padrão & Parâmetros Default \\
\hline Árvore de Decisão & $-\mathrm{R} \$ 33.408,89$ & Árvore de Decisão & 1612 \\
\hline Rede Neural & $-R \$ 38.339,56$ & Rede Neural & 1794 \\
\hline Naive Bayes & $-\mathrm{R} \$ 30.643,22$ & Naive Bayes & 516 \\
\hline Redes Bayesianas & $-\mathrm{R} \$ 29.071,33$ & Redes Bayesianas & 770 \\
\hline AIS & $-\mathrm{R} \$ 35.597,44$ & AIS & 1144 \\
\hline \multirow[t]{7}{*}{ Melhor } & $-\mathrm{R} \$ 29.071,33$ & & \\
\hline & & Desvio Padrão (\%) & Parâmetros Default \\
\hline & & Árvore de Decisão & $4,8 \%$ \\
\hline & & Rede Neural & $4,7 \%$ \\
\hline & & Naive Bayes & $1,7 \%$ \\
\hline & & Redes Bayesianas & $2,6 \%$ \\
\hline & & AIS & $3,2 \%$ \\
\hline
\end{tabular}

Figura 6.1: Resultados - parâmetros default - execução padrão 
Esse resultado por si já é bastante relevante, pois as Redes Neurais são as mais aplicadas na detecção de fraude hoje em dia ${ }^{3}$, e esse resultado mostra que NN não pode ser aplicada sem um conhecimento mínimo dos parâmetros. Tal análise confirma o resultado obtido por Maes em sua dissertação [MTV00] onde ele aborda em detalhes os métodos de Redes Bayesianas e Redes Neurais, e mostra que nos testes aplicados, as primeiras desempenharam uma classificação significativamente melhor que as últimas.

\begin{tabular}{|c|c|}
\hline$\overline{\mathrm{DTT}}$ & $-\mathrm{C} 0.25-\mathrm{M} 2$ \\
\hline NN & -L $0.3-\mathrm{M} 0.2-\mathrm{N} 500-\mathrm{V} 0-\mathrm{S} 0-\mathrm{E} 20-\mathrm{H}$ a \\
\hline NB & $\mathrm{n} / \mathrm{a}$ \\
\hline $\mathrm{BN}$ & -D -Q weka.classifiers.bayes.net.search.local.K2 - -P 1 -S BAYES -E \\
\hline AIS & -S 1 -F 0.2 -C 10.0 -H 2.0 -M 0.1 -R 150.0 -V 0.9 -A -1 -B 1 -E 1 -K 3 \\
\hline
\end{tabular}

Tabela 6.1: Tabela de parâmetros default

A tabela $6.1^{4}$ descreve quais os parâmetros default para os métodos em questão no Weka.

Por fim, temos a seguinte ordem dos métodos, do melhor para o pior, para o caso de base desbalanceada nas implementações e parâmetros default disponíveis no Weka e usando a execução padrão disponível ao iniciá-lo:

$\operatorname{Padrao}^{D E F}(B N)^{5}<\operatorname{Padrao}^{D E F}(N B)<\operatorname{Padrao}^{D E F}(D T)<\operatorname{Padrao}^{D E F}(A I S)<$ $\operatorname{Padrao}^{D E F}(N N)$

É possível ver também através da figura 6.1 que essa ordem se repete com uma única inversão entre AIS e NN na base 7, com NN passando para penúltima posição e AIS para última.

\footnotetext{
${ }^{3}$ Alguns exemplos de ferramentas comerciais de detecção de fraude utilizando NN: Falcon da FairIsaac, Lynx da Universidade do Conhecimento e SUAF da Sigmenta.

${ }^{4} \mathrm{DT}=$ Árvore de Decisão; NN = Redes Neurais; NB = Naive Bayes; BN = Redes Bayesianas; AIS $=$ Sistemas Imunológicos Artificiais.

${ }^{5}$ Lê-se Padrao ${ }^{D E F}(B N)$ como sendo o custo médio das execuções padrão para o conjunto de parâmetros default com o método BN.
} 


\subsubsection{Parâmetros default - Execução Sensível ao Custo}

Após termos comparado os métodos sem tomar o custo como entrada para a modelagem, repetimos os parâmetros default (tabela 6.1) para uma execução usando a meta heurística CostSensitiveClassifier, os resultados dessa execução podem ser vistos na figura 6.2.

O resultado para essa execução é bastante intrigante em relação às BN e NB, pois não houve melhora do resultado para esses métodos, pior que isso, para o caso de BN houve, em média, uma piora não desprezível de $10 \%$. Veremos mais à frente que isso se deve a restrição de número de nós pais na topologia da rede e que o resultado melhorou quando executamos um ajuste sensível ao custo. Porém, NB permaneceu com uma leve piora, e isso nos mostrou que nem todos os métodos se beneficiam do rebalanceamento das bases amostrais ${ }^{6}$ Para os demais algoritmos, tivemos melhoras substanciais: de $31 \%$ para NN, $12 \%$ para o AIS, e a melhor das reduções de custo ficou com DT com $33 \%^{7}$.

Outra mudança significativa foi a troca do melhor método para essa situação. A BN caiu de melhor método (ou método mais apropriado) para pior método (ou método menos apropriado), o que volta a pôr em discussão o risco do uso desavisado de um método para uma base de dados desbalanceada como o nosso caso.

Após obtermos esse resultado em relação a BN default-CostSensitive resolvemos investigar uma das possíveis razões para essa perda tão acentuada de previsibilidade quando comparado aos demais métodos. Descobrimos que um dos parâmetros default do Weka para BN (maxNrOfParents) limita o número de pais a um (1), o que permite que no máximo um nó (uma variável de nossa base de dados) tenha influência sobre outro nó. Em outras palavras, só é permitido aos nós que participam da topologia final da rede serem conectados ao nó classe. No nosso caso o nó Fraude (Sim ou Não) e para o caso de BN sensível ao custo observamos, em testes, que esse parâmetro faz bastante diferença.

Nessa execução, o melhor modelo obtido foi gerado pelo método DT com custo médio de -22378.56; e uma redução de $33 \%$ em relação

\footnotetext{
${ }^{6} \mathrm{Não}$ apresentamos aqui, mas esse resultado se repete para a meta heurística MetaCost. ${ }^{7} 33 \%=1-(-22378.56 /-33408.89)$.
} 


\begin{tabular}{|c|c|c|c|}
\hline \multicolumn{4}{|c|}{ Resultado Execuções dos métodos com parâmetros fixos. } \\
\hline \multicolumn{4}{|c|}{ Execuções baseadas nos parâmetros default usados pelo Weka. } \\
\hline & $\mathrm{b}$ & & $\mathrm{b}$ \\
\hline BASE 1 & Cost Sensitive-Defaults & BASE 6 & Cost Sensitive-Defaults \\
\hline Árvore de Decisão & $-\mathrm{R} \$ 20.373,00$ & Árvore de Decisão & $-\mathrm{R} \$ 21.543,00$ \\
\hline Rede Neural & $-R \$ 26.595,00$ & Rede Neural & $-\mathrm{R} \$ 25.881,00$ \\
\hline Naive Bayes & $-\mathrm{R} \$ 32.444,00$ & Naive Bayes & $-\mathrm{R} \$ 31.526,00$ \\
\hline Redes Bayesianas & $-\mathrm{R} \$ 32.026,00$ & Redes Bayesianas & $-\mathrm{R} \$ 32.219,00$ \\
\hline AIS & $-\mathrm{R} \$ 30.423,00$ & AIS & $-\mathrm{R} \$ 30.622,00$ \\
\hline BASE 2 & Cost Sensitive-Defaults & BASE 7 & Cost Sensitive-Defaults \\
\hline Árvore de Decisão & $-\mathrm{R} \$ 23.623,00$ & Árvore de Decisão & $-\mathrm{R} \$ 21.377,00$ \\
\hline Rede Neural & $-\mathrm{R} \$ 26.111,00$ & Rede Neural & $-R \$ 27.530,00$ \\
\hline Naive Bayes & $-\mathrm{R} \$ 30.786,00$ & Naive Bayes & $-\mathrm{R} \$ 32.141,00$ \\
\hline Redes Bayesianas & $-\mathrm{R} \$ 31.963,00$ & Redes Bayesianas & $-\mathrm{R} \$ 31.701,00$ \\
\hline AIS & $-\mathrm{R} \$ 29.598,00$ & AIS & $-\mathrm{R} \$ 31.900,00$ \\
\hline BASE 3 & Cost Sensitive-Defaults & BASE 8 & Cost Sensitive-Defaults \\
\hline Árvore de Decisão & $-\mathrm{R} \$ 21.491,00$ & Árvore de Decisão & $-\mathrm{R} \$ 22.730,00$ \\
\hline Rede Neural & $-R \$ 26.418,00$ & Rede Neural & $-\mathrm{R} \$ 25.123,00$ \\
\hline Naive Bayes & $-R \$ 29.869,00$ & Naive Bayes & $-R \$ 30.225,00$ \\
\hline Redes Bayesianas & $-\mathrm{R} \$ 31.620,00$ & Redes Bayesianas & $-R \$ 32.094,00$ \\
\hline AIS & $-\mathrm{R} \$ 31.896,00$ & AIS & $-\mathrm{R} \$ 31.278,00$ \\
\hline BASE 4 & Cost Sensitive-Defaults & BASE 9 & Cost Sensitive-Defaults \\
\hline Árvore de Decisão & $-\mathrm{R} \$ 23.762,00$ & Árvore de Decisão & $-\mathrm{R} \$ 22.179,00$ \\
\hline Rede Neural & $-\mathrm{R} \$ 24.857,00$ & Rede Neural & $-R \$ 25.554,00$ \\
\hline Naive Bayes & $-R \$ 31.031,00$ & Naive Bayes & $-R \$ 30.446,00$ \\
\hline Redes Bayesianas & $-\mathrm{R} \$ 32.841,00$ & Redes Bayesianas & $-\mathrm{R} \$ 31.143,00$ \\
\hline AIS & $-\mathrm{R} \$ 32.753,00$ & AIS & $-\mathrm{R} \$ 30.701,00$ \\
\hline BASE 5 & Cost Sensitive-Defaults & & \\
\hline Árvore de Decisão & $-\mathrm{R} \$ 24.329,00$ & & \\
\hline Rede Neural & $-\mathrm{R} \$ 29.354,00$ & & \\
\hline Naive Bayes & $-\mathrm{R} \$ 30.007,00$ & & \\
\hline Redes Bayesianas & $-\mathrm{R} \$ 31.743,00$ & & \\
\hline AIS & $-\mathrm{R} \$ 32.769,00$ & & \\
\hline Média & Cost Sensitive-Defaults & Desvio Padrão & Cost Sensitive-Defaults \\
\hline Árvore de Decisão & $-\mathrm{R} \$ 22.378,56$ & Árvore de Decisão & 1018 \\
\hline Rede Neural & $-R \$ 26.380,33$ & Rede Neural & 1369 \\
\hline Naive Bayes & $-\mathrm{R} \$ 30.941,67$ & Naive Bayes & 737 \\
\hline Redes Bayesianas & $-\mathrm{R} \$ 31.927,78$ & Redes Bayesianas & 466 \\
\hline AIS & $-\mathrm{R} \$ 31.326,67$ & AIS & 774 \\
\hline \multirow[t]{7}{*}{ Melhor } & $-\mathrm{R} \$ 22.378,56$ & & \\
\hline & & Desvio Padrão (\%) & Cost Sensitive-Defaults \\
\hline & & Árvore de Decisão & $4,6 \%$ \\
\hline & & Rede Neural & $5,2 \%$ \\
\hline & & Naive Bayes & $2,4 \%$ \\
\hline & & Redes Bayesianas & $1,5 \%$ \\
\hline & & AIS & $2,5 \%$ \\
\hline
\end{tabular}

Figura 6.2: Resultados - parâmetros default - CostSensitiveClassifier 
a DT execução padrão (não sensível ao custo), essa redução cai para aproximadamente $23 \%^{8}$ quando comparamos a melhora entre o mais apropriado nesta situação (DT) e o mais apropriado para a situação padrão $(\mathrm{BN})$.

Outro fator importante foi a pequena diferença entre os custos das BN e AIS, decidimos por considerar esses custos iguais.

Por fim, temos a seguinte ordem dos métodos, do melhor para o pior, para o caso de base desbalanceada nas implementações e parâmetros disponíveis no Weka usando a meta heurística CostSensitiveClassifier:

$\operatorname{Cost}^{D E F}(D T)^{9}<\operatorname{Cost}^{D E F}(N N)<\operatorname{Cost}^{D E F}(N B)<\operatorname{Cost}^{D E F}(A I S)=$ $\operatorname{Cost}^{D E F}(B N)$

É possivel ver através da figura 6.2 que essa ordem se repete sem inversão em todas as 9 bases de testes.

\subsection{Resultados da otimização dos parâmetros}

Após termos executado e explorado os parâmetros default fornecidos pelo Weka, passamos a execução de uma otimização (de um ajuste dos parâmetros) a fim de encontrarmos um conjunto de parâmetros para cada método que minimize o custo. E com esse resultado, dito ajustado, podermos comparar de maneira mais justa os diversos métodos.

Como pode ser visto na figura 6.3. Para o nosso caso, a maneira padrão e sensível ao custo, temos nas colunas GA - Execução Padrão e GA - Sensível ao Custo os resultados respectivos desses GAs.

\subsubsection{Resultados GA Execução Padrão}

A coluna GA - Execução Padrão da figura 6.3 mostra o resultado do algoritmo GA para encontrar o modelo que minimize o custo de fraude para cada um dos métodos, esse teste foi repetido independentemente para as nove bases. Vemos que partindo dos custos obtidos

${ }^{8} 23 \%=1(-22378.56 /-29071.33)$.

${ }^{9}$ Lê-se $\operatorname{Cost}^{D E F}(D T)$ como sendo o custo médio das execuções sensíveis ao custo para o conjunto de parâmetros default com o método DT. 


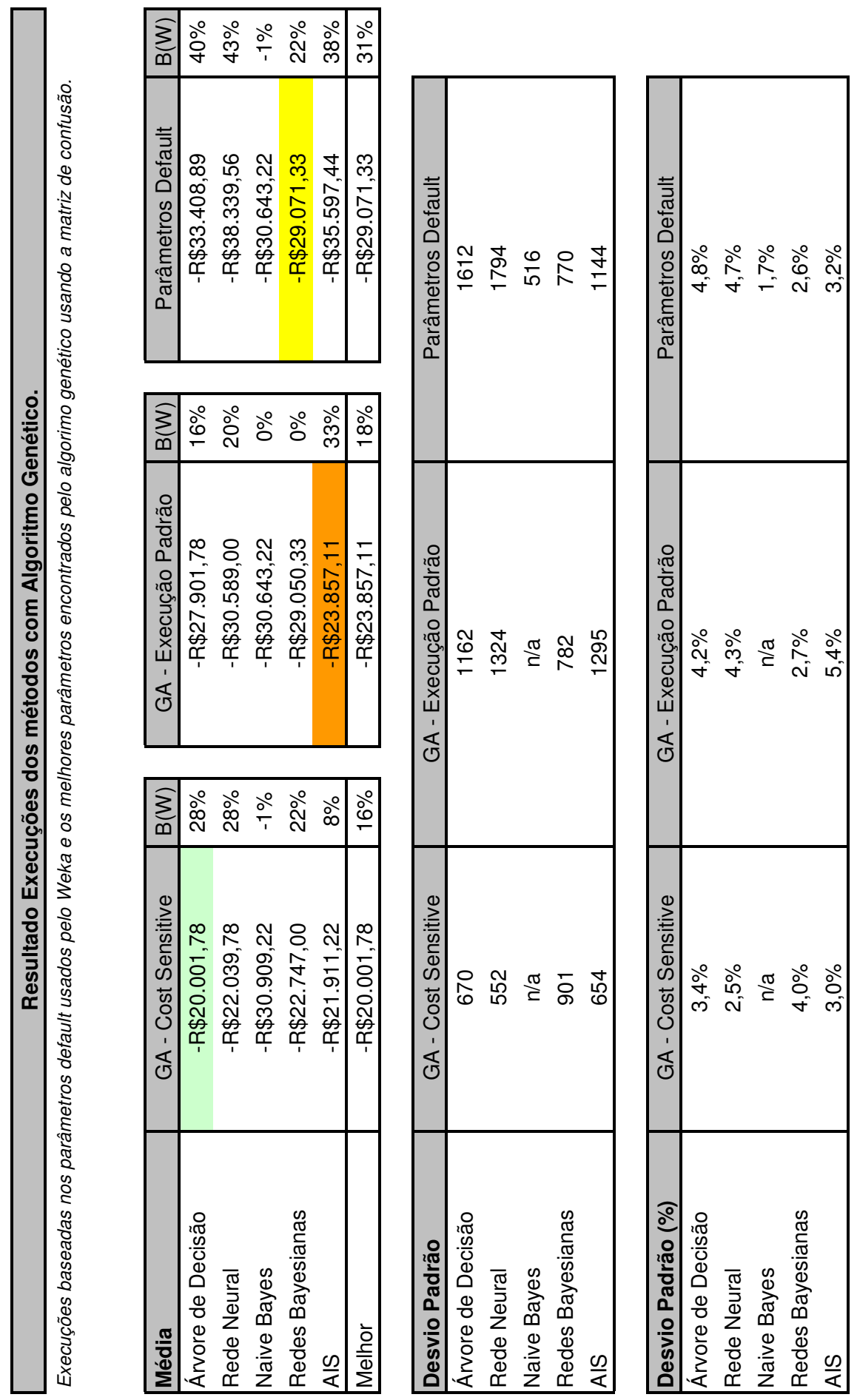

Figura 6.3: Resultados médio - Otimização de parâmetros GA 138 
na execução padrão com parâmetros default que o GA não melhorou em nada o resultado para $\mathrm{BN}$ e $\mathrm{NB}$, porém melhorou o resultado para os demais métodos. Para DT tivemos um redução média de $16 \%$ do custo, enquanto que para NN essa redução foi de $20 \%$, e por último, AIS obteve a maior redução 33\%. Essa redução elevada de custo levou o AIS a ser o melhor entre todos os cinco métodos nessa etapa de testes.

Esses resultados nos levam à seguinte ordem dos métodos, do melhor para o pior, para o caso de uma base desbalanceada, usando as implementações dos métodos disponíveis no Weka, encontrando os melhores ajustes paramétricos para cada conjunto de base de desenvolvimento e validação, e usando a execução padrão do Weka:

$\operatorname{Padrao}^{G A}(A I S)^{10}<\operatorname{Padrao}^{G A}(D T)<\operatorname{Padrao}^{G A}(B N)<\operatorname{Padrao}^{G A}(N B)=$ Padrao ${ }^{G A}(N N)$

A figura 6.4 mostra que o resultado acima se repete, com inversão apenas entre NN e AIS.

Problema de convergência na execução padrão do método AIS:

Nessa seção vale informar um problema bastante relevante que enfrentamos no que diz respeito ao parâmetro de semente de números aleatórios (-S) do método AIS. Seguindo o exemplo do que fizemos para NN, mantivemos S fixo para todas as execuções, e isso não gerou qualquer problema ou dúvida em relação à convergência de uma dada execução de GA para NN. Entretanto, para AIS, durante as execuções do GA, percebemos que esse método por vezes gerava ótimos com custos elevados, não condizentes com os ótimos obtido nas primeiras bases que executamos $^{11}$. Passamos a desconfiar que esse método pudesse ter algum problema de convergência, esse fato foi verificado quando executamos o GA para AIS permitindo que a semente de números aleatórios pudesse ser alterada, e como confirmação conseguimos que o método achasse uma solução ótima razoável e condizente com as soluções encontradas em outras bases.

\footnotetext{
${ }^{10}$ Lê-se $\operatorname{Padrao}^{G A}(A I S)$ como sendo o custo médio das execuções padrão para o conjunto de parâmetros ótimo ajustado através do GA para cada uma das bases com o método AIS.

${ }^{11}$ Para ser mais exato as bases 6 e 7 não covergiram com $-\mathrm{S}=1$. As bases 2,3 e 4 possuem -S diferente de 1, pois essas usaram o algoritmo que modifica o -S, não tendo sido testado o GA com -S fixo igual a 1.
} 


\begin{tabular}{|c|c|c|c|c|c|c|}
\hline \multicolumn{7}{|c|}{ Resultado Execuções dos métodos com Algoritmo Genético. } \\
\hline \multicolumn{7}{|c|}{ Execuções baseadas nos parâmetros default usados pelo Weka e os melhores parâmetros encontrados pelo algorimo genético usando a matriz de confusão. } \\
\hline & $\mathrm{a}$ & $a<b$ & $\mathrm{~b}$ & $b<c$ & $\mathrm{c}$ & $a<c$ \\
\hline BASE 1 & GA - Cost Sensitive & $\mathrm{B}(\mathrm{W})$ & GA - Execução Padrão & $B(W)$ & Parâmetros Default & $\mathrm{B}(\mathrm{W})$ \\
\hline Árvore de Decisão & $-\mathrm{R} \$ 18.761,00$ & $36 \%$ & $-\mathrm{R} \$ 29.127,00$ & $16 \%$ & $-\mathrm{R} \$ 34.728,00$ & $46 \%$ \\
\hline Rede Neural & $-R \$ 22.517,00$ & $26 \%$ & $-R \$ 30.544,00$ & $20 \%$ & $-R \$ 37.986,00$ & $41 \%$ \\
\hline Naive Bayes & $-R \$ 30.786,00$ & $1 \%$ & $-R \$ 31.217,00$ & $0 \%$ & $-R \$ 31.217,00$ & $1 \%$ \\
\hline Redes Bayesianas & $-R \$ 21.978,00$ & $26 \%$ & $-R \$ 29.858,00$ & $0 \%$ & $-R \$ 29.868,00$ & $26 \%$ \\
\hline AIS & $-\mathrm{R} \$ 21.772,00$ & & $-\mathrm{R} \$ 24.580,00$ & $34 \%$ & $-\mathrm{R} \$ 37.276,00$ & \\
\hline BASE 2 & GA - Cost Sensitive & $B(W)$ & GA - Execução Padrão & $B(W)$ & Parâmetros Default & $\mathrm{B}(\mathrm{W})$ \\
\hline Árvore de Decisão & $-R \$ 20.377,00$ & $25 \%$ & $-R \$ 27.133,00$ & $20 \%$ & $-\mathrm{R} \$ 33.762,00$ & $40 \%$ \\
\hline Rede Neural & $-R \$ 22.069,00$ & $28 \%$ & $-R \$ 30.657,00$ & $23 \%$ & $-R \$ 39.559,00$ & $44 \%$ \\
\hline Naive Bayes & $-R \$ 29.966,00$ & $3 \%$ & $-R \$ 30.787,00$ & $0 \%$ & $-R \$ 30.787,00$ & $3 \%$ \\
\hline Redes Bayesianas & $-R \$ 24.018,00$ & $15 \%$ & $-R \$ 28.375,00$ & $0 \%$ & $-R \$ 28.375,00$ & $15 \%$ \\
\hline AIS & $-R \$ 21.755,00$ & & $-\mathrm{R} \$ 22.531,00$ & $38 \%$ & $-\mathrm{R} \$ 36.349,00$ & \\
\hline BASE 3 & GA - Cost Sensitive & $\mathrm{B}(\mathrm{W})$ & GA - Execução Padrão & $B(W)$ & Parâmetros Default & $\mathrm{B}(\mathrm{W})$ \\
\hline Árvore de Decisão & $-R \$ 19.346,00$ & $30 \%$ & $-\mathrm{R} \$ 27.467,00$ & $20 \%$ & $-R \$ 34.273,00$ & $44 \%$ \\
\hline Rede Neural & $-R \$ 21.181,00$ & $31 \%$ & $-R \$ 30.663,00$ & $16 \%$ & $-R \$ 36.480,00$ & $42 \%$ \\
\hline Naive Bayes & $-R \$ 31.031,00$ & $-3 \%$ & $-R \$ 30.227,00$ & $0 \%$ & $-R \$ 30.227,00$ & $-3 \%$ \\
\hline Redes Bayesianas & $-R \$ 22.475,00$ & $21 \%$ & $-R \$ 28.478,00$ & $0 \%$ & $-R \$ 28.607,00$ & $21 \%$ \\
\hline AIS & $-R \$ 22.188,00$ & & $-\mathrm{R} \$ 22.518,00$ & $35 \%$ & $-R \$ 34.416,00$ & \\
\hline BASE 4 & GA - Cost Sensitive & \begin{tabular}{|l|}
$B(W)$ \\
\end{tabular} & GA - Execução Padrão & $B(W)$ & Parâmetros Default & $B(W)$ \\
\hline Árvore de Decisão & $-\mathrm{R} \$ 21.197,00$ & $30 \%$ & $-R \$ 30.308,00$ & $17 \%$ & $-R \$ 36.333,00$ & $42 \%$ \\
\hline Rede Neural & $-R \$ 22.639,00$ & $31 \%$ & $-R \$ 32.692,00$ & $18 \%$ & $-R \$ 39.725,00$ & $43 \%$ \\
\hline Naive Bayes & $-R \$ 29.618,00$ & $4 \%$ & $-R \$ 30.961,00$ & $0 \%$ & $-R \$ 30.961,00$ & $4 \%$ \\
\hline Redes Bayesianas & $-R \$ 23.958,00$ & $22 \%$ & $-R \$ 30.880,00$ & $0 \%$ & $-R \$ 30.880,00$ & $22 \%$ \\
\hline AIS & $-R \$ 23.297,00$ & & $-\mathrm{R} \$ 25.856,00$ & $31 \%$ & $-\mathrm{R} \$ 37.548,00$ & \\
\hline BASE 5 & GA - Cost Sensitive & $\mathrm{B}(\mathrm{W})$ & GA - Execução Padrão & $B(W)$ & Parâmetros Default & $\mathrm{B}(\mathrm{W})$ \\
\hline Árvore de Decisão & $-R \$ 20.677,00$ & $29 \%$ & $-\mathrm{R} \$ 28.996,00$ & $13 \%$ & $-\mathrm{R} \$ 33.328,00$ & $38 \%$ \\
\hline Rede Neural & $-R \$ 21.938,00$ & $32 \%$ & $-R \$ 32.430,00$ & $18 \%$ & $-R \$ 39.624,00$ & $45 \%$ \\
\hline Naive Bayes & $-R \$ 31.526,00$ & $-3 \%$ & $-R \$ 30.493,00$ & $0 \%$ & $-R \$ 30.493,00$ & $-3 \%$ \\
\hline Redes Bayesianas & $-R \$ 23.787,00$ & $18 \%$ & $-R \$ 28.946,00$ & $0 \%$ & $-R \$ 28.976,00$ & $18 \%$ \\
\hline \multirow[t]{2}{*}{ AIS } & $-R \$ 22.467,00$ & & $-\mathrm{R} \$ 24.017,00$ & $31 \%$ & $-R \$ 34.801,00$ & \\
\hline & $\mathrm{a}$ & $a<b$ & $\mathrm{~b}$ & $b<c$ & $\mathrm{c}$ & $a<c$ \\
\hline BASE 6 & GA - Cost Sensitive & $\mathrm{B}(\mathrm{W})$ & GA - Execução Padrão & $B(W)$ & Parâmetros Default & $\mathrm{B}(\mathrm{W})$ \\
\hline Árvore de Decisão & $-R \$ 20.583,00$ & $25 \%$ & $-\mathrm{R} \$ 27.286,00$ & $13 \%$ & $-R \$ 31.380,00$ & $34 \%$ \\
\hline Rede Neural & $-R \$ 21.442,00$ & $28 \%$ & $-R \$ 29.734,00$ & $20 \%$ & $-R \$ 37.259,00$ & $42 \%$ \\
\hline Naive Bayes & $-R \$ 32.141,00$ & $-6 \%$ & $-R \$ 30.325,00$ & $0 \%$ & $-R \$ 30.325,00$ & $-6 \%$ \\
\hline Redes Bayesianas & $-R \$ 22.089,00$ & $23 \%$ & $-R \$ 28.712,00$ & $0 \%$ & $-R \$ 28.712,00$ & $23 \%$ \\
\hline AIS & $-R \$ 21.438,00$ & & $-\mathrm{R} \$ 22.171,00$ & $36 \%$ & $-R \$ 34.400,00$ & \\
\hline BASE 7 & GA - Cost Sensitive & $B(W)$ & GA - Execução Padrão & $B(W)$ & Parâmetros Default & $B(W)$ \\
\hline Árvore de Decisão & $-R \$ 20.336,00$ & $23 \%$ & $-R \$ 26.403,00$ & $21 \%$ & $-R \$ 33.325,00$ & $39 \%$ \\
\hline Rede Neural & $-R \$ 22.880,00$ & $22 \%$ & $-R \$ 29.195,00$ & $17 \%$ & $-R \$ 35.112,00$ & $35 \%$ \\
\hline Naive Bayes & $-R \$ 30.225,00$ & $5 \%$ & $-R \$ 31.678,00$ & $0 \%$ & $-R \$ 31.678,00$ & $5 \%$ \\
\hline Redes Bayesianas & $-R \$ 21.659,00$ & $26 \%$ & $-R \$ 29.357,00$ & $0 \%$ & $-R \$ 29.357,00$ & $26 \%$ \\
\hline AIS & $-R \$ 21.385,00$ & & $-R \$ 22.723,00$ & $37 \%$ & $-R \$ 35.889,00$ & \\
\hline BASE 8 & GA - Cost Sensitive & $\mathrm{B}(\mathrm{W})$ & GA - Execução Padrão & $B(W)$ & Parâmetros Default & $B(W)$ \\
\hline Árvore de Decisão & $-\mathrm{R} \$ 19.119,00$ & $29 \%$ & $-\mathrm{R} \$ 27.063,00$ & $18 \%$ & $-R \$ 32.867,00$ & $42 \%$ \\
\hline Rede Neural & $-R \$ 21.508,00$ & $30 \%$ & $-R \$ 30.674,00$ & $25 \%$ & $-R \$ 41.028,00$ & $48 \%$ \\
\hline Naive Bayes & $-R \$ 30.446,00$ & $-2 \%$ & $-R \$ 29.946,00$ & $0 \%$ & $-R \$ 29.946,00$ & $-2 \%$ \\
\hline Redes Bayesianas & $-R \$ 21.907,00$ & $22 \%$ & $-R \$ 28.092,00$ & $0 \%$ & $-R \$ 28.102,00$ & $22 \%$ \\
\hline AIS & $-R \$ 21.160,00$ & & $-R \$ 24.908,00$ & $31 \%$ & $-R \$ 36.018,00$ & \\
\hline BASE 9 & GA - Cost Sensitive & $B(W)$ & GA - Execução Padrão & $B(W)$ & Parâmetros Default & $\mathrm{B}(\mathrm{W})$ \\
\hline Árvore de Decisão & $-R \$ 19.620,00$ & $28 \%$ & $-R \$ 27.333,00$ & $11 \%$ & $-R \$ 30.684,00$ & $36 \%$ \\
\hline Rede Neural & $-R \$ 22.184,00$ & $23 \%$ & $-R \$ 28.712,00$ & $25 \%$ & $-R \$ 38.283,00$ & $42 \%$ \\
\hline Naive Bayes & $-R \$ 32.444,00$ & $-8 \%$ & $-R \$ 30.155,00$ & $0 \%$ & $-R \$ 30.155,00$ & $-8 \%$ \\
\hline Redes Bayesianas & $-R \$ 22.852,00$ & $21 \%$ & $-R \$ 28.755,00$ & $0 \%$ & $-R \$ 28.765,00$ & $21 \%$ \\
\hline AIS & $-\mathrm{R} \$ 21.739,00$ & & $-\mathrm{R} \$ 25.410,00$ & $25 \%$ & $-\mathrm{R} \$ 33.680,00$ & \\
\hline
\end{tabular}

Figura 6.4: Resultados 9 bases - Otimização de parâmetros GA 
Por isso, criamos uma segunda versão do GA para AIS que incia S $=1$ e caso não melhore a solução atual por três gerações do GA, ele altera o parâmetro $\mathrm{S}$ para um número inteiro e aleatório entre 0 e 20, e continua os passos do GA. Esse novo algoritmo usou essa nova estratégia efetivamente para as bases 3, 4, 5, 6 e 7 como pode ser visto nas tabelas 9.6, 9.7, 9.8, 9.9 e 9.10 em anexo na seção 9.2.

Avaliação do melhores GA Execução Padrão usando avaliação sensível ao custo:

Após encontrarmos os pontos ótimos através do GA Execução Padrão surgiu uma dúvida: gostaríamos de saber se haveria melhora, e principalmente inversões, caso aplicássemos a meta heurística CostSensitiveClassifier a esses parâmetros encontrados. Então, selecionamos o parâmetros ótimos para cada método e para cada base gerados pelo GA execução padrão; e os utilizamos para avaliação da meta heurística CostSensitiveClassifier. Os resultados dessas execuções podem ser visto na figura 6.5 .

É muito interessante notar que a aplicação da meta heurística CostSensitiveClassifier melhorou na média: $20 \%$ o resultado para DT, $16 \%$ o resultado para NN e apenas $5 \%$ o resultado para AIS. Isso fez com que DT alcançasse AIS na primeira posição. Chegando a seguinte ordem dos métodos:

$\operatorname{Cost}\left(\operatorname{Padrao}^{G A}\right)(D T)^{12}=\operatorname{Cost}\left(\operatorname{Padrao}^{G A}\right)(A I S)<\operatorname{Cost}\left(\operatorname{Padrao}^{G A}\right)(N N)<$ $\operatorname{Cost}\left(\operatorname{Padrao}^{G A}\right)(N B)<\operatorname{Cost}\left(\right.$ Padrao $\left.^{G A}\right)(B N)$

\subsubsection{Resultados GA sensível ao custo}

Como informado em seções anteriores, nosso trabalho se baseou na aplicação de duas estratégias, uma chamada de execução padrão que não leva o custo em consideração no momento do treinamento do modelo, e outra que leva o custo em consideração usando a meta heurística chamada CostSensitiveClassifier, disponível na distribuição 3-4-11 do Weka.

\footnotetext{
${ }^{12}$ Lê-se $\operatorname{Cost}\left(\operatorname{Padrao}^{G A}\right)(D T)$ como sendo o custo médio da avaliação utlizando execução sensível ao csuto para o conjunto de parâmetros ótimo ajustado através do GA execução padrão para cada uma das bases com o método DT.
} 
Resultado Execuções dos métodos com parâmetros fixos.

Execuções do CostSensitiveClassifier para os melhores parâmetros encontrados pelo GA não sensível ao custo.

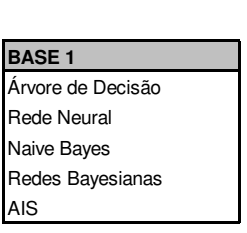

BASE 2

Árvore de Decisão

Rede Neural

Naive Bayes

Redes Bayesianas

AIS

\begin{tabular}{|l|}
\hline BASE 3 \\
\hline Árvore de Decisão \\
Rede Neural \\
Naive Bayes \\
Redes Bayesianas \\
AIS \\
\hline
\end{tabular}

BASE 4

Árvore de Decisão

Rede Neural

Naive Bayes

Redes Bayesianas

AIS

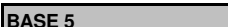

Árvore de Decisão

Rede Neural

Naive Bayes

Redes Bayesianas

AIS

$-\mathrm{R} \$ 22.325,00$

\begin{tabular}{|c|}
\hline Cost Sensitive-Otimos GA \\
\hline$-\mathrm{R} \$ 21.762,00$ \\
$-\mathrm{R} \$ 25.291,00$ \\
$-\mathrm{R} \$ 29.869,00$ \\
$-\mathrm{R} \$ 31.620,00$ \\
$-\mathrm{R} \$ 22.432,00$ \\
\hline
\end{tabular}

\begin{tabular}{|c|}
\hline Cost Sensitive-Otimos GA \\
\hline$-\mathrm{R} \$ 23.280,00$ \\
$-\mathrm{R} \$ 25.971,00$ \\
$-\mathrm{R} \$ 31.031,00$ \\
$-\mathrm{R} \$ 32.841,00$ \\
$-\mathrm{R} \$ 24.159,00$ \\
\hline
\end{tabular}

Cost Sensitive-Otimos GA

$-\mathrm{R} \$ 24.999,00$

$-\mathrm{R} \$ 25.532,00$

$-\mathrm{R} \$ 30.007,00$

$-R \$ 31.743,00$

$-R \$ 23.920,00$

\begin{tabular}{|l|}
\hline BASE 6 \\
\hline Árvore de Decisão \\
Rede Neural \\
Naive Bayes \\
Redes Bayesianas \\
AIS \\
\hline
\end{tabular}

BASE 7

Árvore de Decisão

Rede Neural

Naive Bayes

Redes Bayesianas

AIS

BASE 8

Árvore de Decisão

Rede Neural

Naive Bayes

Redes Bayesianas

AIS

BASE 9

Árvore de Decisão

Rede Neural

Naive Bayes

Redes Bayesianas

AIS

\begin{tabular}{|c|}
\hline a \\
\hline Cost Sensitive-Otimos $\mathrm{GA}$ \\
\hline$-\mathrm{R} \$ 21.737,00$ \\
$-\mathrm{R} \$ 24.275,00$ \\
$-\mathrm{R} \$ 31.526,00$ \\
$-\mathrm{R} \$ 32.219,00$ \\
$-\mathrm{R} \$ 22.685,00$ \\
\hline
\end{tabular}

\begin{tabular}{|c|}
\hline Cost Sensitive-Otimos GA \\
\hline$-R \$ 21.838,00$ \\
$-R \$ 27.621,00$ \\
$-R \$ 32.141,00$ \\
$-R \$ 31.701,00$ \\
$-R \$ 22.064,00$ \\
\hline
\end{tabular}

\begin{tabular}{|c|}
\hline Cost Sensitive-Otimos GA \\
\hline$-R \$ 22.240,00$ \\
$-R \$ 25.274,00$ \\
$-R \$ 30.225,00$ \\
$-R \$ 32.094,00$ \\
$-R \$ 22.091,00$ \\
\hline
\end{tabular}

Cost Sensitive-Otimos GA $-\mathrm{R} \$ 22.145,00$ -R $\$ 25.195,00$ $-R \$ 30.446,00$ $-\mathrm{R} \$ 31.143,00$ $-\mathrm{R} \$ 22.708,00$

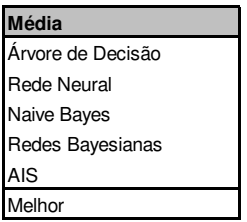

\begin{tabular}{|c|}
\hline Cost Sensitive-Otimos GA \\
\hline$-\mathrm{R} \$ 22.591,56$ \\
$-\mathrm{R} \$ 25.681,22$ \\
$-\mathrm{R} \$ 30.941,67$ \\
$-\mathrm{R} \$ 31.927,78$ \\
$-\mathrm{R} \$ 22.722,67$ \\
\hline$-\mathrm{R} \$ 22.591,56$ \\
\hline
\end{tabular}

Melho $-\mathrm{R} \$ 22.591,56$

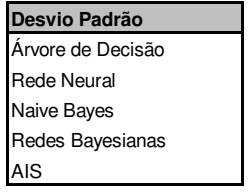

Desvio Padrão (\%)

Árvore de Decisão Rede Neural

Naive Bayes

Redes Bayesianas

AIS

Figura 6.5: Resultados - melhores GA sem custo - CostSensitiveClassifier 
Nesta seção, mostraremos os resultados obtidos e os problemas enfrentados quando aplicamos o algoritmo de GA para o método levando o custo em consideração na modelagem.

A figura 6.3 na coluna GA - Sensível ao Custo traz os resultados obtidos nessa busca. Vemos que, assim como no GA execução padrão, quando executamos a busca sensível ao custo, o resultado para NB não se reduz, pois esse método não possui parâmetro. Agora, para BN, diferentemente do GA execução padrão, conseguimos uma boa redução dos custos, fato principalmente gerado pela variação do parâmetro de quantidade de pais, que tem poder restritivo na topologia da rede, e por sua vez, impacta diretamente sobre a probabilidade estimada do evento, que para o caso sensível ao custo é suficiente para alterar a classe predita de uma instância.

Para NN, observamos sensível redução em relação a todos os testes anteriores, em especial podemos ver uma redução média de $27 \%$ de custo comparando o melhor modelo usando GA - Sensível ao Custo em relação ao melhor modelo usando GA - Execução Padrão. Em oposição, para AIS, observamos uma redução de apenas 8\% do melhor modelo usando GA - Sensível ao Custo em relação ao melhor modelo usando GA - Execução Padrão, isso levou AIS e NN a um empate técnico na segunda posição dessa execução.

Para DT tivemos uma surpresa: o resultado da otimização sensível ao custo reduziu 29\% em relação à otimização da execução padrão. Esta já havia reduzido o custo em $16 \%$ em relação aos parâmetros default e execução padrão, isso fez com que o melhor dos modelos para DT fosse na média de 40\% melhor que o modelo com parâmetros default e execução padrão no Weka. Com toda essa redução, as árvores de decisão obtiveram o melhor resultado em nossa modelagem.

Na próxima seção, mostraremos uma análise para os parâmetros encontrados que minimizam o custo. Será visto que tanto para AIS, quanto para NN, não é facilmente identificável um conjunto de parâmetros que sirva para todas as nossas 9 bases, o que nos levou a executar busca por parâmetros mais estáveis tanto para AIS quanto para NN.

$\underline{\text { Resultado: }}$

Por fim, temos a seguinte ordem dos métodos, do melhor para o pior, para o caso de uma base desbalanceada, usando implementações dos 
métodos disponíveis no Weka, encontrando os melhores ajustes de parâmetros para cada conjunto de base desenvolvimento e validação, e usando a meta heurística CostSensitiveClassifier:

$\operatorname{Cost}^{G A}(D T)^{13}<\operatorname{Cost}^{G A}(A I S)=\operatorname{Cost}^{G A}(N N)<\operatorname{Cost}^{G A}(B N)<$ $\operatorname{Cost}^{G A}(N B)$

A figura 6.4 mostra que o resultado acima se repete, com variação de ordem apenas para AIS e NN.

\subsection{Discussão sobre os parâmetros ótimos - Execução Padrão}

A tabela 6.2 mostra os parâmetros que minimizam o custo da operação de fraude para os métodos DT, NB e BN na execução padrão. NB não possui parâmetros, não havendo necessidade de elencar qualquer parâmetro ótimo. Para o caso de BN, os parâmetros ótimos coincidem com os parâmetros default. Dos três métodos dessa tabela, o único que possui uma pequena variação nos parâmetros é DT. Ainda assim permanece claro que os parâmetros mais recomendados são $\mathrm{C}=0.49 \mathrm{e}$ $\mathrm{M}=1$.

Os outros dois casos, NN e AIS, separamos em duas tabelas distintas, pois a identificação de um conjunto de parâmetros estável não foi possível em primeira análise.

NN: Através da tabela 6.3 é possível notar que todos parâmetros tiveram variação, exceto $\mathrm{N}$ e S que não foram testados. Em especial os parâmetros L, -M e E tiveram uma variação bastante relevante, variação essa que nos levou a fazer uma análise um pouco mais aprofundada de todos os parâmetros envolvidos na execução padrão da NN. As tabelas 9.1, 9.2, 9.3, 9.4 e 9.5, constituintes em anexo na seção 9.2, mostram os melhores 20 resultados obtidos pela execução do GA execução padrão para NN, e através destes resultados fomos capazes de compreender de

\footnotetext{
${ }^{13}$ Lê-se $\operatorname{Cost}^{G A}(D T)$ como sendo o custo médio das execuções sensíveis ao custo para o conjunto de parâmetros ótimo ajustado através do GA para cada uma das bases com o método DT.
} 


\begin{tabular}{|c|c|c|c|}
\hline Base & DT & NB & $\mathrm{BN}$ \\
\hline $\bar{~} 1$ & 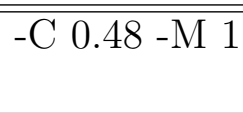 & $\overline{\mathrm{n} / \mathrm{a}}$ & $\begin{array}{l}\text {-D -Q weka.classifiers.bayes.net.search.local.K2 } \\
\text { - -P } 1 \text {-S BAYES -E weka...SimpleEstimator - -A } 0.5\end{array}$ \\
\hline 2 & -C $0.49-\mathrm{M} 1$ & $\mathrm{n} / \mathrm{a}$ & $\begin{array}{l}\text {-D -Q weka.classifiers.bayes.net.search.local.K2 } \\
\text { - -P } 1 \text {-S BAYES -E weka...SimpleEstimator - -A } 0.5\end{array}$ \\
\hline 3 & -C $0.49-\mathrm{M} 1$ & $\mathrm{n} / \mathrm{a}$ & $\begin{array}{l}\text {-D -Q weka.classifiers.bayes.net.search.local.K2 } \\
\text { - -P } 1 \text {-S BAYES -E weka...SimpleEstimator - -A } 0.5\end{array}$ \\
\hline 4 & -C $0.49-\mathrm{M} 1$ & $\mathrm{n} / \mathrm{a}$ & $\begin{array}{l}\text {-D -Q weka.classifiers.bayes.net.search.local.K2 } \\
\text { - -P } 1 \text {-S BAYES -E weka...SimpleEstimator - -A } 0.5\end{array}$ \\
\hline 5 & -C 0.49 -M 1 & $\mathrm{n} / \mathrm{a}$ & $\begin{array}{l}\text {-D -Q weka.classifiers.bayes.net.search.local.K2 } \\
- \text {-P } 1 \text {-S BAYES -E weka...SimpleEstimator - -A } 0.5\end{array}$ \\
\hline 6 & -C $0.48-\mathrm{M} 1$ & $\mathrm{n} / \mathrm{a}$ & $\begin{array}{l}\text {-D -Q weka.classifiers.bayes.net.search.local.K2 } \\
\text { - -P } 1 \text {-S BAYES -E weka...SimpleEstimator - -A } 0.5\end{array}$ \\
\hline 7 & -C $0.49-\mathrm{M} 1$ & $\mathrm{n} / \mathrm{a}$ & $\begin{array}{l}\text {-D -Q weka.classifiers.bayes.net.search.local.K2 } \\
- \text {-P } 1 \text {-S BAYES -E weka...SimpleEstimator - -A } 0.5\end{array}$ \\
\hline 8 & -C 0.49 -M 1 & $\mathrm{n} / \mathrm{a}$ & $\begin{array}{l}\text {-D -Q weka.classifiers.bayes.net.search.local.K2 } \\
\text { - -P } 1 \text {-S BAYES -E weka...SimpleEstimator - -A } 0.5\end{array}$ \\
\hline 9 & -C $0.49-\mathrm{M} 1$ & $\mathrm{n} / \mathrm{a}$ & $\begin{array}{l}\text {-D -Q weka.classifiers.bayes.net.search.local.K2 } \\
\text { - -P } 1 \text {-S BAYES -E weka...SimpleEstimator - -A } 0.5\end{array}$ \\
\hline
\end{tabular}

Tabela 6.2: Tabela de parâmetros ótimos - GA Exec. Padrão - DT, NB e BN

\begin{tabular}{llllllll} 
base & $-\mathrm{L}$ & $-\mathrm{M}$ & $-\mathrm{N}$ & $-\mathrm{V}$ & $-\mathrm{S}$ & $-\mathrm{E}$ & $-\mathrm{H}$ \\
\hline \hline 1 & 0.19 & 0.46 & 500 & 0 & 0 & 1 & 20 \\
\hline 2 & 0.14 & 0.18 & 500 & 0 & 0 & 31 & 20 \\
\hline 3 & 0.5 & 0.26 & 500 & 22 & 0 & 44 & 18 \\
\hline 4 & 0.13 & 0.05 & 500 & 0 & 0 & 1 & 17 \\
\hline 5 & 0.2 & 0 & 500 & 0 & 0 & 7 & 20 \\
\hline 6 & 0.21 & 0.06 & 500 & 0 & 0 & 9 & 18 \\
\hline 7 & 0.79 & 0 & 500 & 2 & 0 & 30 & 20 \\
\hline 8 & 0.71 & 0 & 500 & 21 & 0 & 46 & 18 \\
\hline 9 & 0.56 & 0 & 500 & 0 & 0 & 19 & 19 \\
\hline \hline
\end{tabular}

Tabela 6.3: Tabela de parâmetros ótimos - GA Exec. Padrão - NN 
maneira mais acertada o funcionamento de cada um dos parâmetros, porém como será visto em breve, com apenas esses resultados ainda não fomos capazes de concluir quais os melhores parâmetros, que depois viemos chamá-los de parâmetros estáveis.

Olhando atentamente as tabelas $(9.1,9.2,9.3,9.4$ e 9.5) em anexo na seção 9.2 , concluímos que o parâmetro $-\mathrm{H}$ poderia ser fixado em 20 sem grandes perdas. Também foi possível concluir que a melhor opção para o parâmetro $V$ era 0 , o que significa dizer que não teríamos mais uma amostra de validação interna ao método NN. Isso reforça ainda mais a desconfiança que tínhamos de que bases com grande desbalanceamento necessitam de algum nível de overfitting. Posto $V$ igual a 0, o parâmetro $E$ fez-se desnecessário, pois não mais haveria a necessidade da definição de um ponto de corte para a base de validação, quando essa possuir tamanho zero ${ }^{14}$. Todavia, em relação a $L$ e $M$, sentimos que naquele momento não tínhamos dados suficientes para definir quais eram os valores mais apropriados para esses parâmetros, resolvemos então usar dos resultados que possuíamos para extrair um intervalo reduzido para $L$ e $M$, e executar uma nova busca. Executamos a busca com $L$ variando entre 0.01 e 0.94 , e $M$ variando entre 0.01 e 0.56. Mostraremos mais detalhes sobre essa execução na seção Busca Semi-Exaustiva por parâmetros estáveis - NN Execução Padrão.

Observação: Quando os testes foram realizados, usamos as informações a respeito dos parâmetros contidas na documentação do software do Weka [WF08]. A respeito do parâmetro H, há a seguinte informação:

" There are also some wildcards. These are 'a' $=$ (number of attributes + number of classes) / 2 , 'i' $=$ number of attributes, 'o' $=$ number of classes, and 't' = number of attributes + number of classes".

Com essa definição em mãos, interpretamos $t$ como sendo 20 em nossa base de dados, pois são 17 variáveis independentes, 1 dependente, e 2 classes possíveis para a variável dependente (flag_fraude) em nossa base e uma delas, a variável flag_fraude, continha duas categorias. Depois de tudo executado e analisado; em fase final da escrita, ocorreu nos

\footnotetext{
${ }^{14}$ Este fenômeno foi observado na prática, executamos diversas bases fixando todos os demais parâmetros, em especial fixando $V$ igual 0 e verificamos que o valor do parâmetro $E$ não surtia qualquer efeito no valor do custo final da execução.
} 
verificar se a interpretação era correta e constatamos que o programa comportava-se como se $t$ fosse 19. Procuramos então a definição de atributo na documentação e não encontramos. Na seção 2.3 do livro do Weka [WF05],um atributo é definido como sendo:

"Each individual, independent instance that provides the input to machine learning..."

Realizando-se uma nova análise das tabelas (9.1, 9.2, 9.3, 9.4 e 9.5), somos levados agora a concluir que seria mais recomendável uma busca semi-exaustiva variando-se também o parâmetro $\mathrm{H}$ de $i(17)$ até $t+1(20)$.

Ainda que se tenha executado o parâmetro fixando-se H 20, temos fortes indícios de que a novas execuções não encontrariam custos substancialmente melhores, pois esse parâmetro aparece com freqüência entre os melhores de todas as bases. Ademais, seria necessária uma grande alteração no custo final para que a ordem obtida entre os métodos fosse alterada. Os dados preliminares das tabelas 9.16 e 9.17 em anexo, recentemente executado alterando-se o parâmetro $\mathrm{H}$ das melhores execuções para 20, confirmam esta hipótese. Este procedimento sugere também uma melhoria na fase de busca local realizada nos procedimentos genéticos, quando se usam os wildcards. De toda forma, uma segurança maior a este respeito recomenda que este procedimento seja no futuro refeito.

\begin{tabular}{llllllllll} 
base & $-\mathrm{S}$ & $-\mathrm{F}$ & $-\mathrm{C}$ & $-\mathrm{H}$ & $-\mathrm{R}$ & $-\mathrm{V}$ & $-\mathrm{A}$ & $-\mathrm{E}$ & $-\mathrm{K}$ \\
\hline \hline 1 & 1 & 0 & 23 & 10 & 105 & 1 & -1 & 6 & 1 \\
\hline 2 & 15 & 0.02 & 50 & 10 & 200 & 1 & -1 & 0 & 1 \\
\hline 3 & 15 & 0 & 50 & 10 & 144 & 1 & -1 & 10 & 1 \\
\hline 4 & 12 & 0 & 38 & 10 & 131 & 1 & -1 & 10 & 1 \\
\hline 5 & 1 & 0 & 49 & 10 & 132 & 1 & -1 & 9 & 1 \\
\hline 6 & 7 & 0.1 & 28 & 10 & 191 & 1 & -1 & 10 & 1 \\
\hline 7 & 12 & 0 & 24 & 10 & 131 & 1 & -1 & 0 & 1 \\
\hline 8 & 1 & 0 & 21 & 1 & 90 & 1 & -1 & 3 & 1 \\
\hline 9 & 1 & 0.11 & 41 & 10 & 48 & 1 & -1 & 0 & 1
\end{tabular}

Tabela 6.4: Tabela de parâmetros ótimos - GA Exec. Padrão - AIS 
AIS: Da mesma forma que fizemos anteriormente para NN execução padrão, também fizemos para AIS execução padrão e analisamos a tabela 6.4 na busca de identificar parâmetros estáveis entre os melhores ou restringir a um intervalo para realizar uma nova busca. Para esse trabalho de restrição usamos também as tabelas 9.6, 9.7, 9.8, 9.9 e 9.10 em anexo na seção 9.2, e fomos capazes de fixar -S igual a 1 (por ser a semente para números aleatórios), -F igual $0,-\mathrm{H}$ igual a $10,-\mathrm{V}$ igual a 1, -A igual a -1 e $-\mathrm{K}$ igual a 1 , restando os parâmetros $-\mathrm{C},-\mathrm{R}$ e -E para encontrarmos valores estáveis. Executamos a busca com $C$ variando entre 20 e 50, $R$ variando entre 131 e 200, e $E$ variando entre 0 e 10. Mostraremos mais detalhes sobre essa execução na seção - Busca Semi-Exaustiva por parâmetros estáveis - AIS Execução Padrão.

\subsubsection{Busca Semi-Exaustiva por parâmetros estáveis - NN Execução Padrão.}

Como visto na seção anterior, em uma primeira análise não foi possível identificar para NN execução padrão um conjunto de parâmetros ótimos, de modo que naquele momento fomos capazes apenas de identificar padrões para alguns dos parâmetros, restando dois parâmetros $L$ e $M$ que tivemos que executar uma nova busca para encontrar boas indicações de valores para eles. Essa nova busca nos parâmetros $L$ e $M$ teve um domínio reduzido, com $L$ variando entre 0.01 e 0.94 , e $M$ variando entre 0.01 e 0.56 , devido à análise realizada através dos 20 melhores resultados obtidos por GA execução padrão, resultados que podem ser vistos nas tabelas 9.1, 9.2, 9.3, 9.4 e 9.5.

Iniciamos a busca por parâmetros ótimos estáveis através de uma busca local simultânea em todas as bases. Na primeira execução exigimos que o custo diminuísse em todas as bases para se alterar o ótimo estável atual, na segunda tentativa, permitimos que uma das bases não diminuísse o custo. Porém, mesmo com essa estratégia, não tínhamos um controle muito bom sobre o que acontecia nessa busca, em especial não conseguimos em nenhuma delas um ponto estável que realmente podíamos confiar que era próximo do ótimo. De modo que resolvemos mudar nossa estratégia para uma busca semi-exautiva, onde teríamos um maior controle. Entendemos por busca semi-exaustiva, uma busca esparsa em todo o subdomínio que se deseja explorar. Para essa nova 

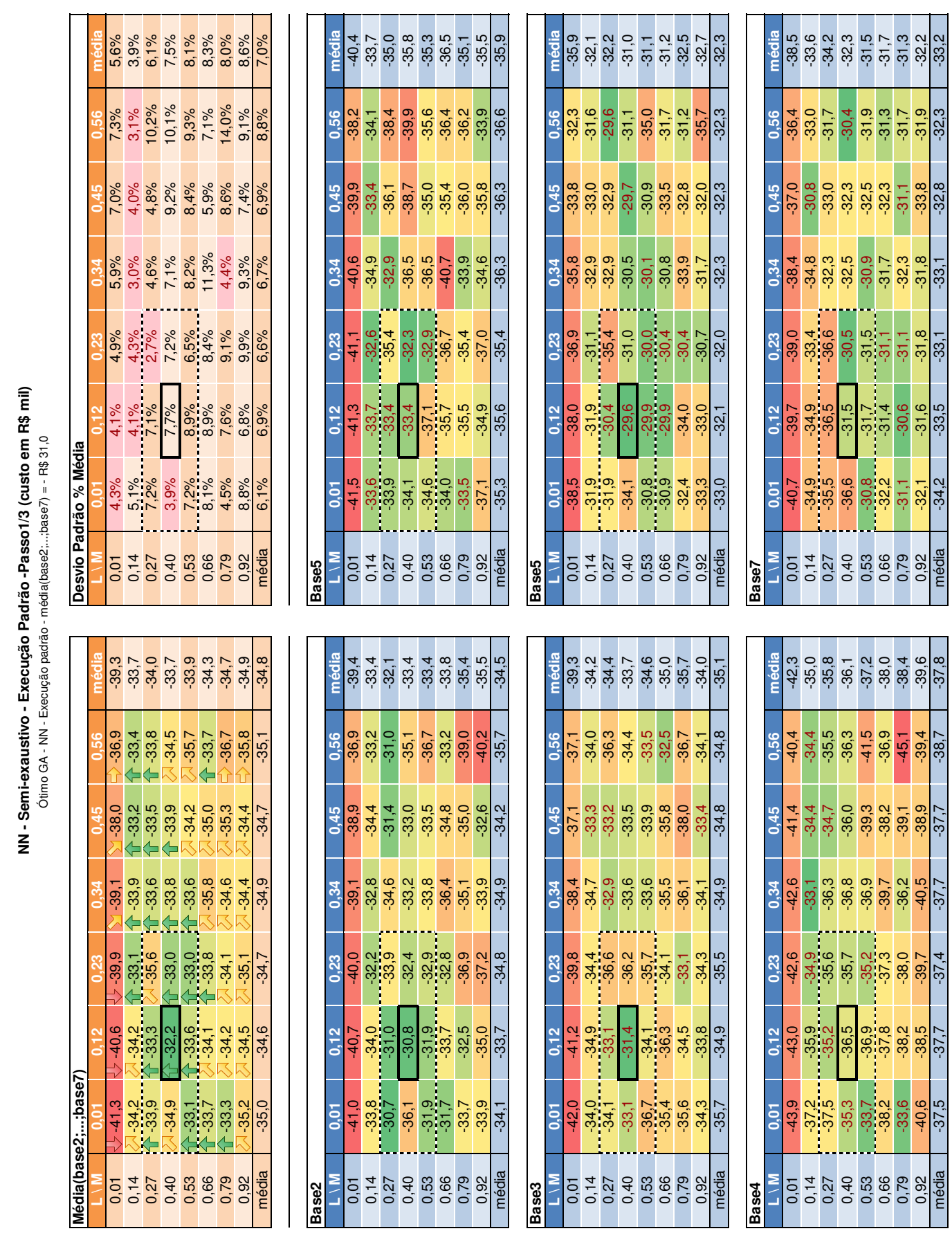

Figura 6.6: NN - Semi-exaustivo execução padrão - 1/3 
busca tínhamos 94 possibilidades para $L$ e 56 possibilidades para $M$ e nove bases para repetir os testes, teríamos que repetir 48.384 vezes as execuções de NN para uma busca exaustiva, e como cada NN levava em torno de 20 minutos para ser executado e dispúnhamos de 4 máquinas, levaríamos 168 dias para executar tais testes, logo desistimos dessa estratégia e fizemos uma busca semi-exaustiva, quebrando o parâmetro $L$ em 8 valores $(0,01 ; 0,14 ; 0,27 ; 0,40 ; 0,53 ; 0,66 ; 0,79 ; 0,92)$ e o parâmetro $M$ em 6 valores ( 0,$01 ; 0,12 ; 0,23 ; 0,34 ; 0,45 ; 0,56)$ como pode ser visto na figura 6.6, em adição a isto, elegemos 6 conjuntos de bases (desenvolvimento e validação) para executar a busca, bases 2 , $3,4,5,6$ e 7; e 3 outros conjuntos para a avaliação da qualidade do conjunto paramétrico encontrado, bases 8, 9 e 1 .

Repetimos esse processo de busca por três níveis de refinamento, executando duas buscas semi-exaustivas com diferentes resoluções e uma busca exaustiva, como pode ser visto nas figuras 6.6, 6.7 e 6.8 respectivamente, a cada passo elegemos um ponto central que minimizasse o custo médio nessas 6 bases e ao mesmo tempo se mantivesse no primeiro tercil de custo em pelo menos 5 das 6 bases; em seguida fizemos uma outra busca em torno desse ponto central e os pontos ao redor. Abaixo enumeramos as etapas executadas:

(a) Na primeira etapa, figura 6.6, elegemos $L$ igual a 0.4 e $M$ igual a 0.12 como ponto central, e os intervalos com $L$ variando entre 0.27 e 0.53 e $M$ variando entre 0.01 e 0.23 para uma nova busca.

(b) Na segunda etapa, figura 6.7, elegemos $L$ igual a 0.4 e $M$ igual a 0.13 como ponto central, e os intervalos com $L$ variando entre 0.37 e 0.33 e $M$ variando entre 0.10 e 0.16 para uma última busca, dessa vez exaustiva.

(c) $\mathrm{Na}$ terceira e última etapa, figura 6.8, chegamos a conclusão que o ponto $L$ igual a 0.4 e $M$ igual a 0.12 corresponde aos melhores ajustes para os testes executados.

Após essas etapas, pudemos concluir que o conjunto de parâmetros mais apropriado para NN execução padrão em nossas bases foi:

$$
\text { -L } 0.40 \text {-M } 0.12 \text {-N } 500 \text {-V } 0 \text {-S } 0 \text {-E } 0 \text {-H } 20
$$

Com esse conjunto de parâmetros conseguimos um custo médio de $\mathrm{R} \$ 32.188,67$ no conjunto de bases usadas no desenvolvimento e de - 
NN - Semi-exaustivo - Execução Padrão - Passo 2/3 (custo em R\$ mil)

Ótimo GA - NN - Execução padrão - média(base2; ;.;base7) = - R\$ 31,0

\begin{tabular}{|c|c|c|c|c|c|c|c|c|}
\hline Média & M & & & & & & & \\
\hline L & 0,01 & 0,04 & 0,07 & 0,1 & 0,13 & 0,16 & 0,19 & Geral \\
\hline 0,28 & $-34,1$ & $-34,2$ & $-33,6$ & 33,8 & $\sum-33,3$ & $\sum_{-33,1}$ & $-34,6$ & $-33,8$ \\
\hline 0,31 & $-34,3$ & $-33,4$ & $-33,6$ & 34,7 & 33,4 & - 32,5 & $\sum-33,1$ & $-33,6$ \\
\hline 0,34 & S-34,8 & $-33,5$ & $\sum-33,2$ & 32,7 & $1-32,6$ & $-33,4$ & 33,5 & $-33,4$ \\
\hline 0,37 & $\Rightarrow-33,4$ & - $-32,4$ & $-33,8$ & 33,9 & 34,9 & 2, & $-33,6$ & $-33,5$ \\
\hline 0,4 & ת-34,9 & $\sum-33,0$ & $-33,6$ & $-32,9$ & पि-32,4 & $-34,4$ & $-34,5$ & $-33,7$ \\
\hline 0,43 & $\Rightarrow-33,9$ & $-32,5$ & $\sum-33,0$ & $-33,5$ & $-34,1$ & $-34,8$ & $-32,6$ & $-33,5$ \\
\hline 0,46 & $\Rightarrow-33,6$ & $-34,4$ & $-34,1$ & 34,5 & $-33,6$ & $-32,5$ & $\sum-33,0$ & $-33,7$ \\
\hline 0,49 & Љ-34,5 & $-34,3$ & $\sum-33,2$ & 1-32,3 & $-33,9$ & $-33,5$ & $-33,7$ & $-33,6$ \\
\hline Geral & $-34,2$ & $-33,5$ & $-33,5$ & $-33,5$ & $-33,5$ & $-33,4$ & $-33,6$ & $-33,6$ \\
\hline
\end{tabular}

\begin{tabular}{|c|c|c|c|c|c|c|c|c|}
\hline Média & M & & & & & & & \\
\hline L & 0,01 & 0,04 & 0,07 & 0,1 & 0,13 & 0,16 & 0,19 & Geral \\
\hline 0,28 & $5 \%$ & $5 \%$ & $2 \%$ & $5 \%$ & $5 \%$ & $5 \%$ & $3 \%$ & $5 \%$ \\
\hline 0,31 & $6 \%$ & $6 \%$ & $5 \%$ & $6 \%$ & $5 \%$ & $5 \%$ & $6 \%$ & $6 \%$ \\
\hline 0,34 & $7 \%$ & $7 \%$ & $5 \%$ & $7 \%$ & $5 \%$ & $6 \%$ & $4 \%$ & $6 \%$ \\
\hline 0,37 & $8 \%$ & $5 \%$ & $12 \%$ & $5 \%$ & $5 \%$ & $7 \%$ & $10 \%$ & $7 \%$ \\
\hline 0,4 & $4 \%$ & $4 \%$ & $6 \%$ & $5 \%$ & $7 \%$ & $8 \%$ & $12 \%$ & $7 \%$ \\
\hline 0,43 & $7 \%$ & $6 \%$ & $9 \%$ & $9 \%$ & $11 \%$ & $10 \%$ & $5 \%$ & $8 \%$ \\
\hline 0,46 & $8 \%$ & $7 \%$ & $11 \%$ & $10 \%$ & $9 \%$ & $6 \%$ & $6 \%$ & $8 \%$ \\
\hline 0,49 & $12 \%$ & $10 \%$ & $8 \%$ & $5 \%$ & $8 \%$ & $6 \%$ & $10 \%$ & $9 \%$ \\
\hline Geral & $7 \%$ & $6 \%$ & $7 \%$ & $7 \%$ & $7 \%$ & $7 \%$ & $7 \%$ & $7 \%$ \\
\hline
\end{tabular}

\begin{tabular}{ccccccccc}
\hline Média & $\mathrm{M}$ & & & & & & & \\
$\mathrm{L}$ & 0,01 & 0,04 & 0,07 & 0,1 & 0,13 & 0,16 & 0,19 & Geral \\
\hline 0,28 & $-32,1$ & $-32,4$ & $-33,2$ & $-36,6$ & $-32,2$ & $-34,0$ & $-35,0$ & $-33,6$ \\
0,31 & $-31,9$ & $-34,8$ & $-32,8$ & $-33,8$ & $-32,9$ & $-31,1$ & $-30,4$ & $-32,5$ \\
0,34 & $-33,0$ & $-33,3$ & $-35,3$ & $-35,6$ & $-32,3$ & $-35,3$ & $-33,4$ & $-34,0$ \\
0,37 & $-31,3$ & $-31,9$ & $-32,8$ & $-33,7$ & $-33,6$ & $-31,7$ & $-30,6$ & $-32,2$ \\
0,4 & $-36,1$ & $-32,8$ & $-32,5$ & $-31,6$ & $-31,0$ & $-34,1$ & $-32,6$ & $-32,9$ \\
0,43 & $-31,3$ & $-32,3$ & $-31,5$ & $-31,9$ & $-30,3$ & $-31,8$ & $-31,8$ & $-31,6$ \\
0,46 & $-31,6$ & $-32,2$ & $-32,8$ & $-33,3$ & $-31,3$ & $-32,1$ & $-32,2$ & $-32,2$ \\
0,49 & $-31,9$ & $-31,0$ & $-31,2$ & $-31,3$ & $-32,4$ & $-32,6$ & $-31,3$ & $-31,7$ \\
\hline Geral & $-\mathbf{3 2 , 4}$ & $-\mathbf{3 2 , 6}$ & $-\mathbf{- 3 2 , 8}$ & $\mathbf{- 3 3 , 5}$ & $\mathbf{- 3 2 , 0}$ & $-\mathbf{3 2 , 9}$ & $\mathbf{- 3 2 , 1}$ & $\mathbf{- 3 2 , 6}$ \\
\hline
\end{tabular}

\begin{tabular}{|c|c|c|c|c|c|c|c|c|}
\hline Média & M & & & & & & & \\
\hline L & 0,01 & 0,04 & 0,07 & 0,1 & 0,13 & 0,16 & 0,19 & Geral \\
\hline 0,28 & $-32,7$ & $-34,3$ & $-33,6$ & $-34,1$ & $-35,1$ & $-34,3$ & $-35,4$ & $-34,2$ \\
\hline 0,31 & $-35,1$ & $-32,9$ & $-33,9$ & $-35,1$ & $-35,2$ & $-34,7$ & $-34,8$ & $-34,6$ \\
\hline 0,34 & $-34,3$ & $-34,2$ & $-33,6$ & $-33,0$ & $-33,2$ & $-34,8$ & $-33,9$ & $-33,8$ \\
\hline 0,37 & $-34,4$ & $-31,6$ & $-33,5$ & $-32,6$ & $-35,7$ & $-35,7$ & $-35,0$ & $-34,1$ \\
\hline 0,4 & $-34,1$ & $-33,9$ & $-34,6$ & $-33,9$ & $-34,4$ & $-34,6$ & $-35,5$ & $-34,4$ \\
\hline 0,43 & $-35,0$ & $-32,4$ & $-33,5$ & $-34,9$ & $-34,1$ & $-37,1$ & $-34,8$ & $-34,6$ \\
\hline 0,46 & $-34,7$ & $-35,3$ & $-32,9$ & $-35,0$ & $-38,1$ & $-33,3$ & $-35,2$ & $-34,9$ \\
\hline 0,49 & $-35,1$ & $-36,0$ & $-35,6$ & $-32,6$ & $-34,2$ & $-32,6$ & $-38,1$ & $-34,9$ \\
\hline Geral & $-34,4$ & $-33,8$ & $-33,9$ & $-33,9$ & $-35,0$ & $-34,6$ & $-35,3$ & $-34,4$ \\
\hline
\end{tabular}

\begin{tabular}{ccccccccc}
\hline Média & $\mathrm{M}$ & & & & & & & \\
$\mathrm{L}$ & 0,01 & 0,04 & 0,07 & 0,1 & 0,13 & 0,16 & 0,19 & Geral \\
\hline 0,28 & $-34,5$ & $-34,4$ & $-32,9$ & $-34,7$ & $-32,6$ & $-33,2$ & $-32,6$ & $-33,6$ \\
0,31 & $-35,3$ & $-33,5$ & $-34,1$ & $-34,1$ & $-33,5$ & $-32,3$ & $-33,9$ & $-33,8$ \\
0,34 & $-35,9$ & $-32,9$ & $-33,3$ & $-33,1$ & $-33,0$ & $-31,6$ & $-32,5$ & $-33,2$ \\
0,37 & $-33,1$ & $-32,3$ & $-32,4$ & $-32,3$ & $-34,8$ & $-31,7$ & $-32,7$ & $-32,8$ \\
0,4 & $-33,1$ & $-32,1$ & $-31,4$ & $-33,4$ & $-31,1$ & $-34,4$ & $-33,8$ & $-32,8$ \\
0,43 & $-34,1$ & $-34,2$ & $-32,5$ & $-32,7$ & $-34,7$ & $-36,8$ & $-33,6$ & $-34,1$ \\
0,46 & $-30,9$ & $-34,3$ & $-34,2$ & $-33,8$ & $-35,3$ & $-35,8$ & $-32,4$ & $-33,8$ \\
0,49 & $-37,6$ & $-34,7$ & $-36,3$ & $-33,2$ & $-33,2$ & $-34,9$ & $-34,3$ & $-34,9$ \\
\hline Geral & $\mathbf{- 3 4 , 3}$ & $\mathbf{- 3 3 , 6}$ & $\mathbf{- 3 3 , 4}$ & $\mathbf{- 3 3 , 4}$ & $\mathbf{- 3 3 , 5}$ & $\mathbf{- 3 3 , 8}$ & $\mathbf{- 3 3 , 2}$ & $\mathbf{- 3 3 , 6}$ \\
\hline
\end{tabular}

\begin{tabular}{|c|c|c|c|c|c|c|c|c|}
\hline Média & M & & & & & & & \\
\hline L & 0,01 & 0,04 & 0,07 & 0,1 & 0,13 & 0,16 & 0,19 & Geral \\
\hline 0,28 & $-33,2$ & $-31,7$ & $-33,7$ & $-31,3$ & $-30,6$ & $-30,8$ & $-35,0$ & $-32,3$ \\
\hline 0,31 & $-31,8$ & $-29,4$ & $-30,6$ & $-31,7$ & $-30,9$ & $-30,9$ & $-33,5$ & $-31,3$ \\
\hline 0,34 & $-31,5$ & $-29,4$ & $-29,9$ & $-28,8$ & $-30,1$ & $-30,9$ & $-31,8$ & $-30,4$ \\
\hline 0,37 & $-29,6$ & $-30,8$ & $-29,3$ & $-33,4$ & $-32,5$ & $-32,1$ & $-29,2$ & $-31,0$ \\
\hline 0,4 & $-34,1$ & $-31,2$ & $-31,3$ & $-31,5$ & $-30,7$ & $-29,3$ & $-31,7$ & $-31,4$ \\
\hline 0,43 & $-31,2$ & $-30,4$ & $-29,6$ & $-29,0$. & $-32,9$ & $-30,7$ & $-30,9$ & $-30,6$ \\
\hline 0,46 & $-30,9$ & $-30,8$ & $-30,3$ & $-32,0$ & $-31,7$ & $-30,1$ & $-31,0$ & $-31,0$ \\
\hline 0,49 & $-31,0$ & $-31,9$ & $-30,5$ & $-30,5$ & $-30,1$ & $-30,1$ & $-30,4$ & $-30,7$ \\
\hline Geral & $-31,7$ & $-30,7$ & $-30,7$ & $-31,0$ & $-31,2$ & $-30,6$ & $-31,7$ & $-31,1$ \\
\hline
\end{tabular}

\begin{tabular}{ccccccccc}
\hline Média & $\mathrm{M}$ & & & & & & & \\
\hline $\mathrm{L}$ & 0,01 & 0,04 & 0,07 & 0,1 & 0,13 & 0,16 & 0,19 & Geral \\
\hline 0,28 & $-35,9$ & $-36,4$ & $-33,7$ & $-33,9$ & $-34,0$ & $-35,0$ & $-33,9$ & $-34,7$ \\
0,31 & $-36,4$ & $-34,5$ & $-34,4$ & $-37,3$ & $-35,5$ & $-34,1$ & $-34,7$ & $-35,3$ \\
0,34 & $-37,9$ & $-35,7$ & $-34,1$ & $-34,4$ & $-34,7$ & $-35,7$ & $-36,1$ & $-35,5$ \\
0,37 & $-34,3$ & $-35,8$ & $-41,4$ & $-34,3$ & $-35,8$ & $-35,2$ & $-37,4$ & $-36,3$ \\
0,4 & $-35,3$ & $-35,3$ & $-35,8$ & $-35,7$ & $-36,1$ & $-38,1$ & $-42,0$ & $-36,9$ \\
0,43 & $-34,7$ & $-34,9$ & $-38,1$ & $-37,6$ & $-40,9$ & $-39,9$ & $-33,6$ & $-37,1$ \\
0,46 & $-37,1$ & $-36,8$ & $-41,0$ & $-41,4$ & $-35,1$ & $-32,8$ & $-35,9$ & $-37,2$ \\
0,49 & $-40,8$ & $-40,3$ & $-34,7$ & $-35,2$ & $-35,8$ & $-35,3$ & $-37,4$ & $-37,1$ \\
\hline Geral & $\mathbf{- 3 6 , 5}$ & $\mathbf{- 3 6 , 2}$ & $\mathbf{- 3 6 , 6}$ & $\mathbf{- 3 6 , 2}$ & $\mathbf{- 3 6 , 0}$ & $\mathbf{- 3 5 , 8}$ & $\mathbf{- 3 6 , 4}$ & $\mathbf{- 3 6 , 3}$ \\
\hline
\end{tabular}

\begin{tabular}{ccccccccc}
\hline Média & $\mathrm{M}$ & & & & & & & \\
\hline $\mathrm{L}$ & 0,01 & 0,04 & 0,07 & 0,1 & 0,13 & 0,16 & 0,19 & Geral \\
\hline 0,28 & $-36,3$ & $-35,8$ & $-34,7$ & $-32,4$ & $-35,4$ & $-31,3$ & $-35,5$ & $-34,5$ \\
0,31 & $-35,3$ & $-35,0$ & $-35,9$ & $-35,9$ & $-32,5$ & $-31,8$ & $-31,2$ & $-33,9$ \\
0,34 & $-36,1$ & $-35,6$ & $-32,7$ & $-31,3$ & $-32,1$ & $-31,9$ & $-33,2$ & $-33,3$ \\
0,37 & $-37,4$ & $-32,1$ & $-33,4$ & $-36,8$ & $-37,2$ & $-29,9$ & $-36,6$ & $-34,8$ \\
0,4 & $-36,6$ & $-32,8$ & $-36,0$ & $-31,3$ & $-31,0$ & $-36,0$ & $-31,2$ & $-33,6$ \\
0,43 & $-36,9$ & $-30,6$ & $-32,5$ & $-34,6$ & $-31,5$ & $-32,8$ & $-30,8$ & $-32,8$ \\
0,46 & $-36,3$ & $-36,9$ & $-33,6$ & $-31,6$ & $-29,9$ & $-30,8$ & $-31,7$ & $-33,0$ \\
0,49 & $-30,6$ & $-31,8$ & $-30,9$ & $-31,0$ & $-37,6$ & $-35,7$ & $-30,9$ & $-32,7$ \\
\hline Geral & $-\mathbf{3 5 , 7}$ & $\mathbf{- 3 3 , 8}$ & $\mathbf{- 3 3 , 7}$ & $\mathbf{- 3 3 , 1}$ & $\mathbf{- 3 3 , 4}$ & $\mathbf{- 3 2 , 5}$ & $\mathbf{- 3 2 , 6}$ & $\mathbf{- 3 3 , 6}$ \\
\hline
\end{tabular}

Figura 6.7: NN - Semi-exaustivo execução padrão - 2/3 
$\mathrm{R} \$ 36.332,33$ no conjunto de bases usadas na avaliação.

\subsubsection{Busca Semi-Exaustiva por parâmetros estáveis - AIS Execução Padrão.}

Para AIS execução padrão, também não foi possível em primeira análise encontrarmos um conjunto de parâmetros ótimos estável, e após a análise das tabelas 9.6, 9.7, 9.8, 9.9 e 9.10 em anexo na seção 9.2, fomos capazes de fixar os seguintes parâmetros $\mathrm{S}=1$ (por ser a semente para números aleatórios), $\mathrm{F}=0, \mathrm{H}=10, \mathrm{~V}=1, \mathrm{~A}=-1$ e $\mathrm{K}$ $=1$, restando três parâmetros $-\mathrm{C}$, $-\mathrm{R}$ e $-\mathrm{E}$ para encontrarmos valores estáveis.

Executamos então a busca semi-exaustiva com $C$ variando entre 20 e $50, R$ variando entre 131 e 200, e $E$ variando entre 0 e 10 conforme mostra a figura 6.9. Analisando essa mesma figura, elegemos $C$ igual a $30, R$ igual a 177 e $E$ igual a 5 como ponto central para uma busca exaustiva, entretanto como esse ponto possuía custo de $\mathrm{R} \$ 23,36$ mil contra $\mathrm{R} \$ 23,30$ mil dos pontos ótimos ajustados para cada base, decidimos que não seria necessário executar uma nova busca semi-exaustiva e nem mesmo executar uma busca exaustiva, poderíamos sim executar uma busca nas três direções independentemente somente para garantir que não existiria uma direção que pudéssemos nos mover e encontrarmos melhores parâmetros, o resultado dessa execução pode ser visto na figura 6.10 .

Após termos confirmado o ponto $(\mathrm{C}, \mathrm{R}, \mathrm{E})=(30,177,5)$ como melhor através da figura 6.10, pudemos concluir que o conjunto de parâmetros mais apropriado para AIS execução padrão em nossas bases foi:

$$
\text { -S } 1 \text {-F } 0 \text {-C } 30 \text {-H } 10 \text {-R } 177 \text {-V } 1 \text {-A -1 -E } 5 \text {-K } 1
$$

Com esse conjunto de parâmetros conseguimos um custo de - $\mathrm{R} \$ 23.355,16$ no conjunto usado no desenvolvimento e $-\mathrm{R} \$ 23.303,00$ no conjunto de bases de avaliação. 


\begin{tabular}{|c|}
\hline NN - Semi-exaustivo - Execução Padrão - Passo 3/3 (custo em R\$ mil) \\
\hline Ótimo GA - NN - Execução padrão - média(base2;...;base7) = - R\$ 31,0 \\
\hline Conjunto de parâmetros ótimos eleito: -L 0.40 -M 0.12 -N 500 -V 0 -S 0 -E 0 -H 20 \\
\hline
\end{tabular}

\begin{tabular}{|c|c|c|c|c|c|c|c|}
\hline Média & $M$ & & & & & & \\
\hline L & 0,10 & 0,11 & 0,12 & 0,13 & 0,14 & 0,15 & Geral \\
\hline 0,37 & $>-33,9$ & $\sum_{-32,8}$ & $-33,6$ & $\int-34,9$ & $-33,8$ & $\lambda_{-33,0}$ & $-33,7$ \\
\hline 0,38 & $\Rightarrow-33,7$ & $\sum_{-33,3}$ & $\Rightarrow-33,8$ & $-33,6$ & $\Rightarrow-33,7$ & $\nabla_{-33,3}$ & $-33,6$ \\
\hline 0,39 & $\Rightarrow-33,9$ & $\Rightarrow-33,9$ & $\Rightarrow-33,6$ & $-32,5$ & $2-33,1$ & - $-32,5$ & $-33,2$ \\
\hline 0,40 & $-32,9$ & $\sum-33,1$ & $-32,2$ & $-32,4$ & $-33,6$ & $\Rightarrow-33,4$ & $-32,9$ \\
\hline 0,41 & $\Rightarrow-33,4$ & 1-32,7 & $-34,4$ & $\Rightarrow-33,5$ & $-34,0$ & Z $-34,7$ & $-33,8$ \\
\hline 0,42 & $\Rightarrow-33,5$ & $\sum-33,1$ & Z $-34,6$ & Z $-35,1$ & $5-33,6$ & $\Rightarrow-33,9$ & $-34,0$ \\
\hline Geral & $-33,6$ & $-33,2$ & $-33,7$ & $-33,7$ & $-33,6$ & $-33,5$ & $-33,5$ \\
\hline
\end{tabular}

\begin{tabular}{|c|c|c|c|c|c|c|c|}
\hline DesPad & M & & & & & & \\
\hline $\mathrm{L}$ & 0,10 & 0,11 & 0,12 & 0,13 & 0,14 & 0,15 & Geral \\
\hline 0,37 & $4,8 \%$ & $3,5 \%$ & $6,1 \%$ & $4,8 \%$ & $5,1 \%$ & $4,9 \%$ & $4,9 \%$ \\
\hline 0,38 & $6,9 \%$ & $5,3 \%$ & $5,3 \%$ & $5,5 \%$ & $8,2 \%$ & $6,5 \%$ & $6,3 \%$ \\
\hline 0,39 & $6,3 \%$ & $7,8 \%$ & $6,4 \%$ & $6,0 \%$ & $8,8 \%$ & $8,2 \%$ & $7,2 \%$ \\
\hline 0,40 & $5,3 \%$ & $4,7 \%$ & $7,7 \%$ & $7,1 \%$ & $6,1 \%$ & $5,5 \%$ & $6,1 \%$ \\
\hline 0,41 & $8,5 \%$ & $7,9 \%$ & $7,5 \%$ & $9,7 \%$ & $8,9 \%$ & $12,8 \%$ & $9,2 \%$ \\
\hline 0,42 & $5,3 \%$ & $8,1 \%$ & $6,9 \%$ & $10,2 \%$ & $11,9 \%$ & $11,6 \%$ & $9,0 \%$ \\
\hline Geral & $6,2 \%$ & $6,2 \%$ & $6,7 \%$ & $7,2 \%$ & $8,2 \%$ & $8,3 \%$ & $7,1 \%$ \\
\hline Base 05 & $M$ & & & & & & \\
\hline $\mathrm{L}$ & 0,10 & 0,11 & 0,12 & 0,13 & 0,14 & 0,15 & Geral \\
\hline 0,37 & $-32,6$ & $-33,5$ & $-33,1$ & $-35,7$ & $-35,6$ & $-35,4$ & $-34,3$ \\
\hline 0,38 & $-34,0$ & $-34,4$ & $-35,3$ & $-33,7$ & $-36,9$ & $-35,7$ & $-35,0$ \\
\hline 0,39 & $-35,4$ & $-36,0$ & $-36,1$ & $-33,7$ & $-36,1$ & $-36,6$ & $-35,7$ \\
\hline 0,40 & $-33,9$ & $-34,4$ & $-33,4$ & $-34,4$ & $-35,6$ & $-35,3$ & $-34,5$ \\
\hline 0,41 & $-36,1$ & $-32,0$ & $-35,5$ & $-38,3$ & $-34,5$ & $-36,0$ & $\mid-35,4$ \\
\hline 0,42 & $-34,6$ & $-35,3$ & $-35,2$ & $-37,0$ & $-33,8$ & $-34,8$ & $-35,1$ \\
\hline Geral & $-34,4$ & $-34,3$ & $-34,8$ & $-35,5$ & $-35,4$ & $-35,6$ & $-35,0$ \\
\hline
\end{tabular}

\begin{tabular}{|c|cccccc|c|}
\hline \multicolumn{1}{|l|}{ Base 03 } & \multicolumn{1}{|l}{$\mathrm{M}$} \\
\hline $\mathrm{L}$ & 0,10 & 0,11 & 0,12 & 0,13 & 0,14 & 0,15 & Geral \\
\hline 0,37 & $-32,3$ & $-32,6$ & $-33,2$ & $-34,8$ & $-35,1$ & $-33,9$ & $-33,6$ \\
0,38 & $-32,1$ & $-33,5$ & $-33,2$ & $-35,2$ & $-32,9$ & $-33,4$ & $-33,4$ \\
0,39 & $-33,9$ & $-32,4$ & $-33,1$ & $-33,0$ & $-32,0$ & $-31,5$ & $-32,7$ \\
0,40 & $-33,4$ & $-33,6$ & $-31,4$ & $-31,1$ & $-33,3$ & $-32,9$ & $-32,6$ \\
0,41 & $-33,9$ & $-35,3$ & $-34,2$ & $-33,6$ & $-34,6$ & $-34,7$ & $-34,4$ \\
0,42 & $-33,7$ & $-32,7$ & $-36,0$ & $-35,2$ & $-33,0$ & $-34,4$ & $-34,2$ \\
\hline Geral & $-33,2$ & $-33,4$ & $-33,5$ & $-33,8$ & $-33,5$ & $-33,5$ & $-33,5$ \\
\hline
\end{tabular}

\begin{tabular}{|l|cccccc|c|}
\hline Base 06 & \multicolumn{1}{|l|}{$M$} \\
\hline $\mathrm{L}$ & 0,10 & 0,11 & 0,12 & 0,13 & 0,14 & 0,15 & Geral \\
\hline 0,37 & $-33,4$ & $-31,0$ & $-32,0$ & $-32,5$ & $-31,6$ & $-32,2$ & $-32,1$ \\
0,38 & $-32,7$ & $-31,4$ & $-31,9$ & $-33,0$ & $-32,2$ & $-30,7$ & $-32,0$ \\
0,39 & $-30,9$ & $-30,4$ & $-31,6$ & $-30,1$ & $-30,3$ & $-30,8$ & $-30,7$ \\
0,40 & $-31,5$ & $-32,8$ & $-29,6$ & $-30,7$ & $-30,8$ & $-31,5$ & $-31,1$ \\
0,41 & $-29,6$ & $-30,1$ & $-30,5$ & $-32,7$ & $-29,3$ & $-32,2$ & $-30,7$ \\
0,42 & $-31,2$ & $-30,5$ & $-31,0$ & $-33,5$ & $-30,8$ & $-31,6$ & $-31,4$ \\
\hline Geral & $-31,6$ & $-31,0$ & $-31,1$ & $-32,1$ & $-30,8$ & $-31,5$ & $-31,3$ \\
\hline
\end{tabular}

\begin{tabular}{|c|cccccc|c|}
\hline \multicolumn{2}{|l|}{ Base 04 } & \multicolumn{1}{l}{$\mathrm{M}$} \\
\hline $\mathrm{L}$ & 0,10 & 0,11 & 0,12 & 0,13 & 0,14 & 0,15 & Geral \\
\hline 0,37 & $-34,3$ & $-34,0$ & $-34,2$ & $-35,8$ & $-33,3$ & $-33,8$ & $-34,2$ \\
0,38 & $-34,0$ & $-34,9$ & $-34,7$ & $-34,0$ & $-37,4$ & $-35,9$ & $-35,2$ \\
0,39 & $-35,6$ & $-35,0$ & $-36,3$ & $-35,4$ & $-37,1$ & $-35,0$ & $-35,8$ \\
0,40 & $-35,7$ & $-34,9$ & $-36,5$ & $-36,1$ & $-35,1$ & $-35,9$ & $-35,7$ \\
0,41 & $-37,2$ & $-36,6$ & $-36,9$ & $-36,1$ & $-37,7$ & $-42,9$ & $-37,9$ \\
0,42 & $-35,7$ & $-37,4$ & $-37,0$ & $-41,3$ & $-41,4$ & $-41,1$ & $-39,0$ \\
\hline Geral & $-35,4$ & $-35,5$ & $-36,0$ & $-36,5$ & $-37,0$ & $-37,4$ & $-36,3$ \\
\hline
\end{tabular}

\begin{tabular}{|l|cccccc|c|}
\hline Base 07 & \multicolumn{1}{|l|}{$M$} \\
\hline $\mathrm{L}$ & 0,10 & 0,11 & 0,12 & 0,13 & 0,14 & 0,15 & Geral \\
\hline 0,37 & $-36,8$ & $-31,9$ & $-37,3$ & $-37,2$ & $-35,2$ & $-31,1$ & $-34,9$ \\
0,38 & $-37,9$ & $-34,6$ & $-35,9$ & $-35,5$ & $-30,8$ & $-31,3$ & $-34,3$ \\
0,39 & $-35,8$ & $-37,3$ & $-31,4$ & $-31,2$ & $-32,7$ & $-29,8$ & $-33,0$ \\
0,40 & $-31,3$ & $-30,5$ & $-31,5$ & $-31,0$ & $-35,4$ & $-33,0$ & $-32,1$ \\
0,41 & $-32,4$ & $-31,7$ & $-36,8$ & $-30,1$ & $-36,0$ & $-30,5$ & $-32,9$ \\
0,42 & $-34,3$ & $-31,7$ & $-36,0$ & $-32,0$ & $-31,3$ & $-30,4$ & $-32,6$ \\
\hline Geral & $-34,8$ & $-32,9$ & $-34,8$ & $-32,8$ & $-33,6$ & $-31,0$ & $-33,3$ \\
\hline
\end{tabular}

Figura 6.8: NN - Semi-exaustivo execução padrão - 3/3 


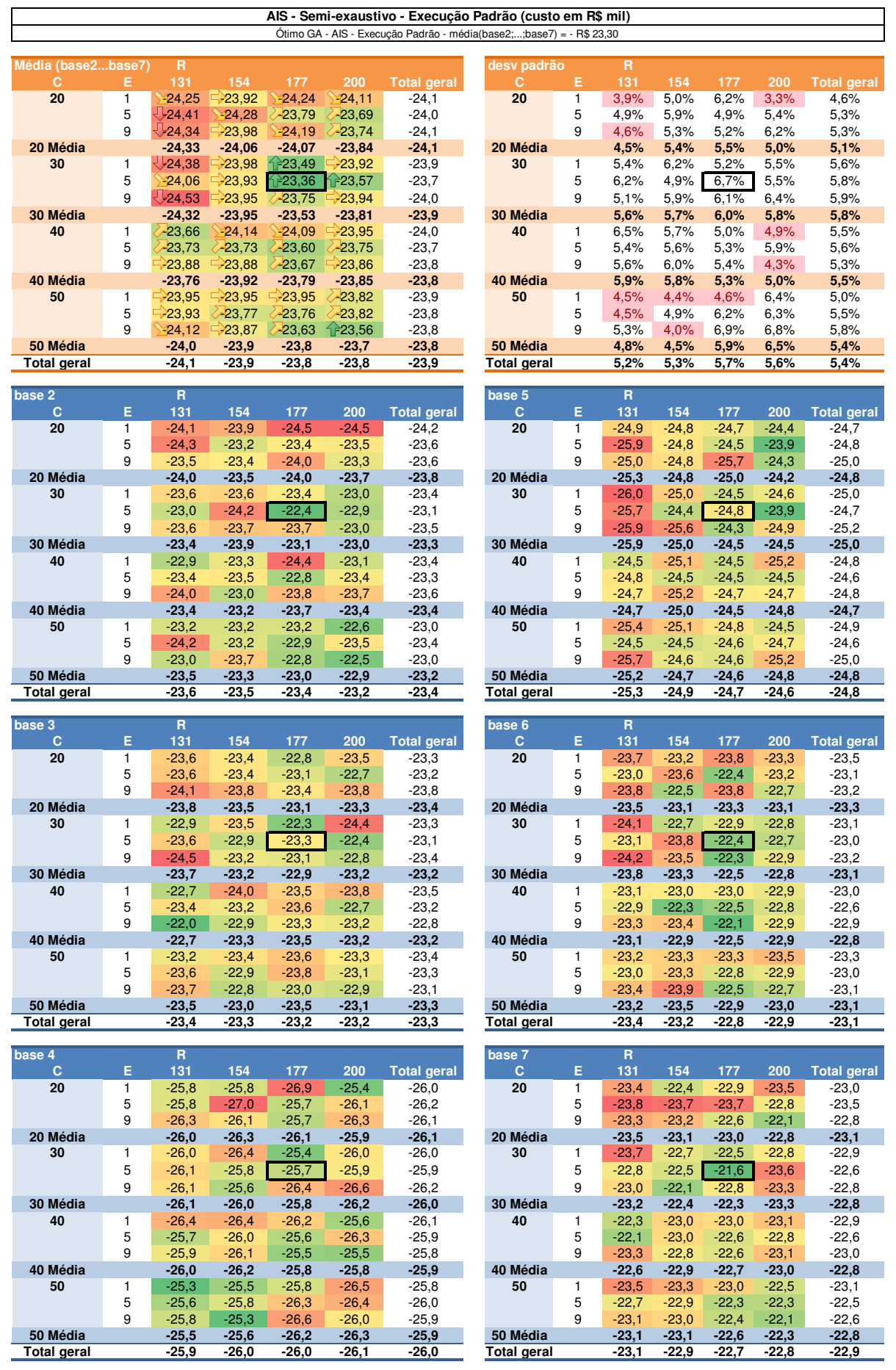

Figura 6.9: AIS - Semi-exaustivo execução padrão - 1/2 


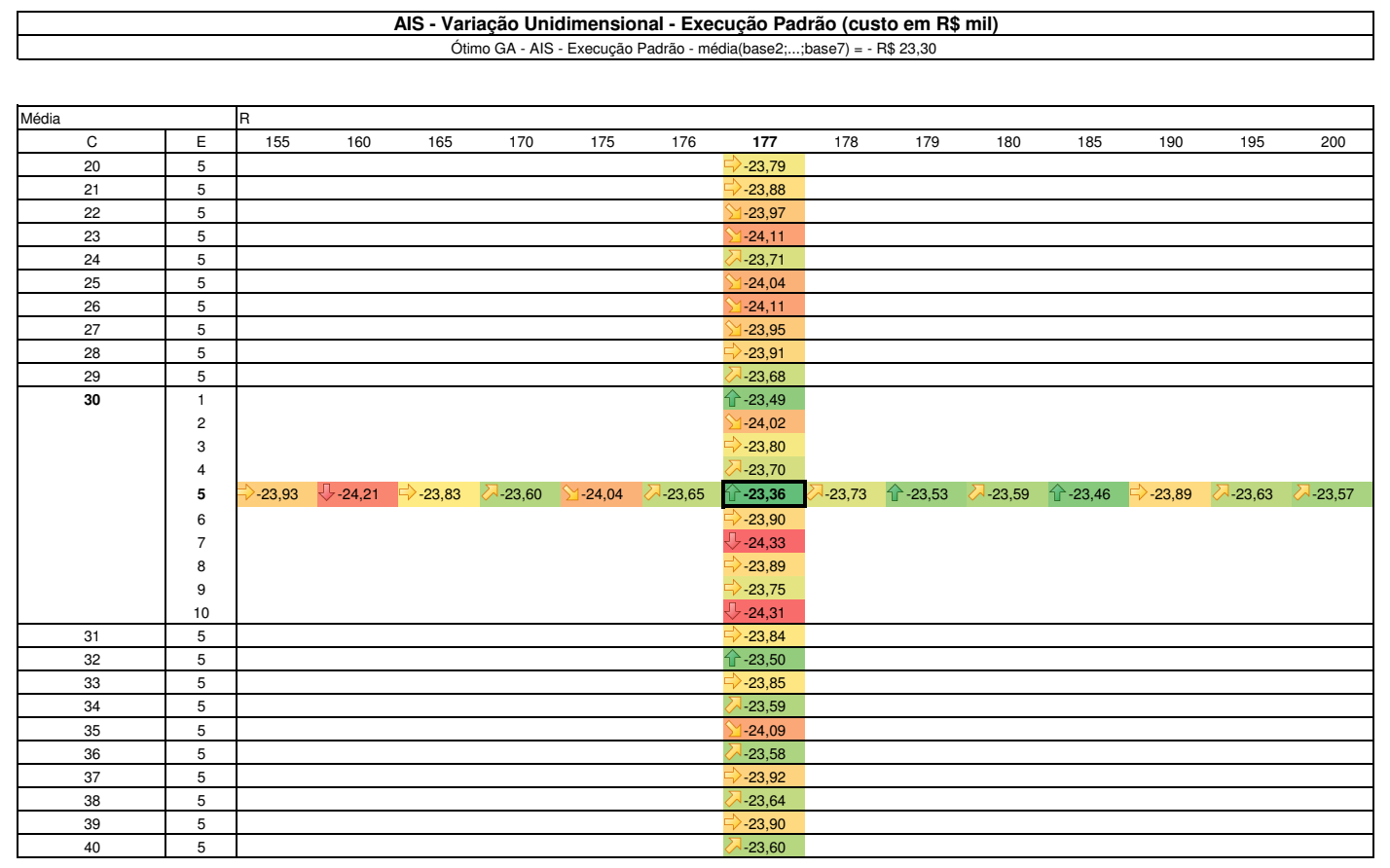

Figura 6.10: AIS - Local Search - execução padrão - 2/2

\subsection{Discussão sobre os parâmetros ótimos - Sensível ao custo}

Quando falamos de parâmetros estáveis para o GA sensível ao custo, notamos uma variação um pouco maior dos parâmetros ótimos para DT e BN, o conjunto de parâmetros ótimos para NN obteve menor variação, mas ainda assim houve a necessidade de uma busca semi-exaustiva em três etapas. Para AIS, decidimos que não haveria necessidade de executar uma busca por parâmetros ótimos e estáveis, porque o conjunto de parâmetros ótimos e estáveis do GA execução padrão já colocou AIS como o segundo melhor método atrás apenas de DT, e acrescido disso, temos o fato do resultado do GA sensível ao custo para o AIS ter ficado atrás do DT estável como será visto mais a frente, fato que mostra que é improvável que AIS tenha um conjunto de parâmetros que supere DT, isso só ocorreria se nosso GA não tivesse convergido.

Analisando a tabela 6.5 vemos que podemos eleger os parâmetros $C$ 
igual a 0.01 e $M$ igual a 1 para DT sem que haja muita perda, agora para BN, essa tabela não nos ofereceu informação suficiente para decidirmos qual o melhor conjunto de parâmetros ótimos estáveis, de modo que realizamos para $\mathrm{BN}$ uma busca exaustiva para todos os parâmetros disponíveis no Weka, esse resultado pode ser visto na tabela 9.15, em anexo na seção 9.2, a tabela apresenta o conjunto de parâmetros e as médias nas bases de 2 a 7 e 8, 9 e 1 para os 20 melhores custos obtidos nessa busca. Munidos dessa informação elegemos como melhor o seguinte conjunto de parâmetros:

$-D-Q$ weka.classifiers.bayes.net.search.local.K2 - - $-P 10-S$ AIC

$-E$ weka.classifiers.bayes.net.estimate.SimpleEstimator $---A 1.0$

\begin{tabular}{|c|c|c|c|}
\hline Base & $\mathrm{DT}$ & $\mathrm{NB}$ & $\mathrm{BN}$ \\
\hline $\bar{~} 1$ & - $-\mathrm{C} 0.02-\mathrm{M} 1$ & $\mathrm{n} / \mathrm{a}$ & $\begin{array}{l}\text {-D -Q weka.classifiers.bayes.net.search.local.K2 } \\
\text { - -P } 8 \text {-S ENTROPY -E weka...SimpleEstimator - -A } 1.0\end{array}$ \\
\hline 2 & -C $0.01-\mathrm{M} 3$ & $\mathrm{n} / \mathrm{a}$ & $\begin{array}{l}\text {-D -Q weka.classifiers.bayes.net.search.local.K2 } \\
\text { - -P } 7 \text {-S ENTROPY -E weka...SimpleEstimator - -A } 1.0\end{array}$ \\
\hline 3 & -C $0.02-\mathrm{M} 1$ & $\mathrm{n} / \mathrm{a}$ & $\begin{array}{l}\text {-D -Q weka.classifiers.bayes.net.search.local.K2 } \\
- \text {-P } 8 \text {-S BDeu -E weka...SimpleEstimator - -A } 1.0\end{array}$ \\
\hline 4 & -C $0.01-\mathrm{M} 1$ & $\mathrm{n} / \mathrm{a}$ & $\begin{array}{l}\text {-D -Q weka.classifiers.bayes.net.search.local.K2 } \\
- \text {-P } 6 \text {-S BDeu -E weka...SimpleEstimator - -A } 1.0\end{array}$ \\
\hline 5 & -C $0.01-\mathrm{M} 1$ & $\mathrm{n} / \mathrm{a}$ & $\begin{array}{l}\text {-D -Q weka.classifiers.bayes.net.search.local.K2 } \\
- \text {-P } 8 \text {-S BDeu -E weka...SimpleEstimator - -A } 1.0\end{array}$ \\
\hline 6 & $-\mathrm{C} 0.06-\mathrm{M} 1$ & $\mathrm{n} / \mathrm{a}$ & $\begin{array}{l}\text {-D -Q weka.classifiers.bayes.net.search.local.K2 } \\
- \text {-P } 9 \text {-S BDeu -E weka...SimpleEstimator - -A } 1.0\end{array}$ \\
\hline 7 & -C $0.02-\mathrm{M} 1$ & $\mathrm{n} / \mathrm{a}$ & $\begin{array}{l}\text {-D -Q weka.classifiers.bayes.net.search.local.K2 } \\
\text { - -P } 8 \text {-S ENTROPY -E weka...SimpleEstimator - -A } 1.0\end{array}$ \\
\hline 8 & -C $0.01-\mathrm{M} 2$ & $\mathrm{n} / \mathrm{a}$ & $\begin{array}{l}\text {-D -Q weka.classifiers.bayes.net.search.local.K2 } \\
- \text {-P } 7 \text {-S ENTROPY -E weka...SimpleEstimator - -A } 1.0\end{array}$ \\
\hline 9 & $-\mathrm{C} 0.02-\mathrm{M} 1$ & $\mathrm{n} / \mathrm{a}$ & $\begin{array}{l}\text {-D -Q weka.classifiers.bayes.net.search.local.K2 } \\
- \text {-P } 6 \text {-S ENTROPY -E weka...SimpleEstimator - -A } 1.0\end{array}$ \\
\hline
\end{tabular}

Tabela 6.5: Tabela de parâmetros ótimos - GA sensível ao custo - DT, NB e $\mathrm{BN}$

Quando tratamos de NN sensível ao custo, verificamos fenômeno parecido com o resultado obtido para NN execução padrão, analisando a 


\begin{tabular}{llllllll} 
base & $-\mathrm{L}$ & $-\mathrm{M}$ & $-\mathrm{N}$ & $-\mathrm{V}$ & $-\mathrm{S}$ & $-\mathrm{E}$ & $-\mathrm{H}$ \\
\hline \hline 1 & 0.01 & 0.46 & 500 & 0 & 0 & 31 & 18 \\
\hline 2 & 0.05 & 0.12 & 500 & 0 & 0 & 13 & 19 \\
\hline 3 & 0.07 & 0.1 & 500 & 5 & 0 & 63 & 18 \\
\hline 4 & 0.09 & 0 & 500 & 0 & 0 & 61 & 20 \\
\hline 5 & 0.09 & 0.26 & 500 & 4 & 0 & 32 & 18 \\
\hline 6 & 0.13 & 0.07 & 500 & 0 & 0 & 9 & 20 \\
\hline 7 & 0.01 & 0 & 500 & 0 & 0 & 51 & 20 \\
\hline 8 & 0.01 & 0 & 500 & 0 & 0 & 37 & 20 \\
\hline 9 & 0.01 & 0.11 & 500 & 0 & 0 & 9 & 20 \\
\hline \hline
\end{tabular}

Tabela 6.6: Tabela de parâmetros ótimos - GA sensível ao custo - NN

tabela 6.6 e as tabelas $(9.11,9.12,9.2,9.13$ e 9.14), em anexo na seção 9.2, pudemos não mais que decidir por alguns dos parâmetros e restringir o espaço de busca para os parâmetros $L$ e $M$, e de maneira análoga a execução padrão, executamos um busca semi-exaustiva para encontrarmos bons valores para esse parâmetro como será visto na seção seguinte. Em resumo, fixamos $N$ igual a $500, V$ igual a $0, S$ igual a 0 , $E$ igual a 0 e $H$ igual a 20, e executamos a busca com $L$ variando entre 0.01 e 0.25 , e $M$ variando entre 0.01 e 0.55 .

\subsubsection{Busca Semi-Exaustiva por parâmetros estáveis - NN sensível ao custo.}

A busca por parâmetros estáveis ótimos para NN sensível ao custo foi executada em duas etapas semi-exaustiva e uma exaustiva, abaixo enumeramos os resultados obtidos em cada uma dessas etapas.

(a) A primeira etapa constou de uma busca semi-exaustiva nos parâmetros $L$ e $M$, com $L$ variando entre 0.01 e 0.25 , e $M$ variando entre 0.01 e 0.55 conforme pode ser visto na figura 6.11 ; nesta execução elegemos dois pontos centrais para uma nova busca semi-exautiva, foram eles: $(L, M)=(0.01,0.19)$ e $(0.01,0.59)$, com intervalos de $L$ variando entre 0.01 e 0.07 , e $M$ variando na união de dois intervalos 0.01 e 0.28 , e 0.52 e 0.56 . 


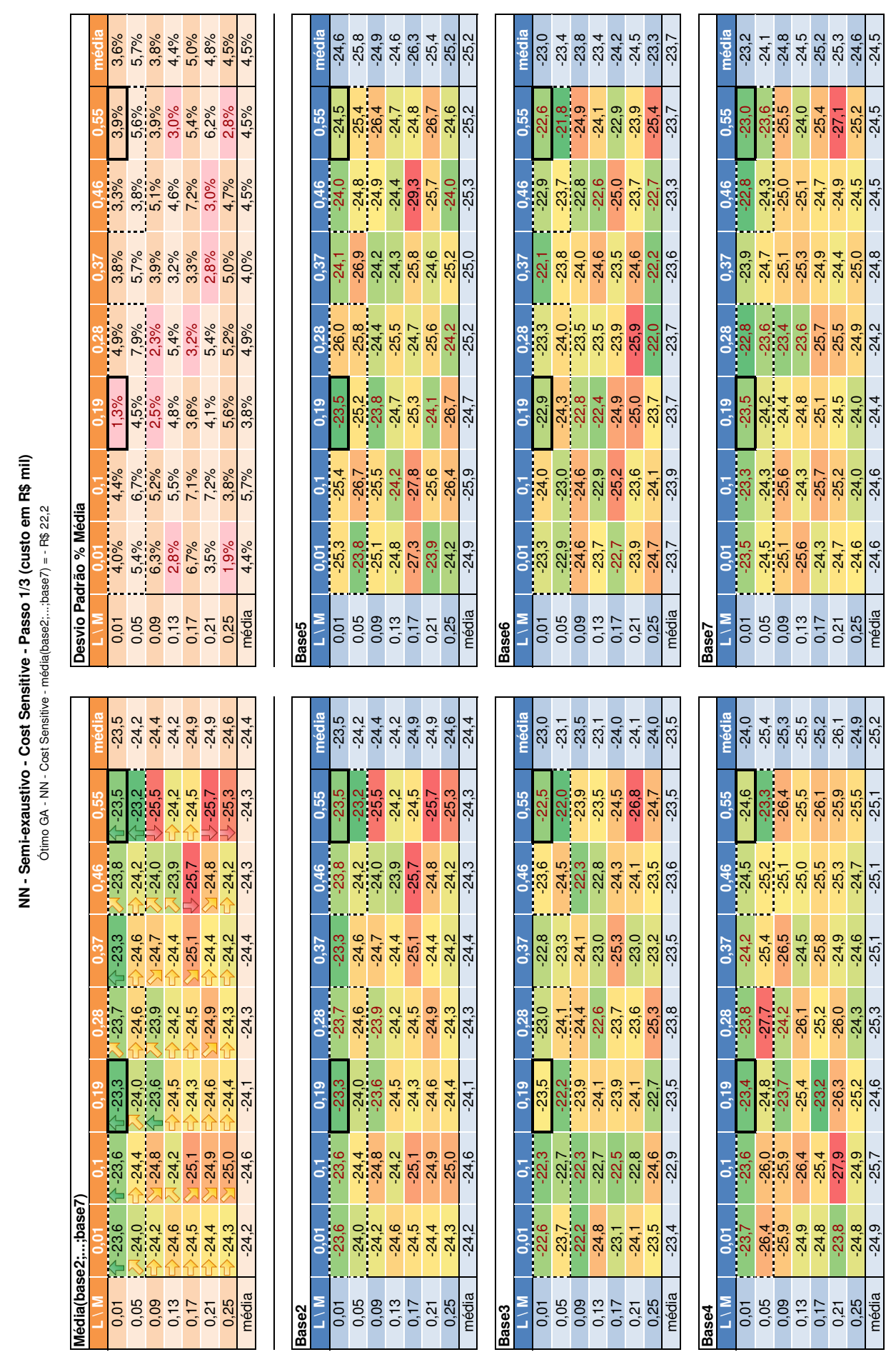

Figura 6.11: NN - Semi-exaustivo sensível ao custo - 1/2 
(b) Os resultados da segunda etapa, conforme pode ser visto na parte superior da figura 6.12, nos levou a elegermos $L$ igual a 0.01 e $M$ igual a 0.13 como ponto central e o intervalo com $L$ variando entre 0.01 e 0.03 , e $M$ variando entre 0.07 e 0.19 para uma busca final exaustiva.

(c) Na terceira e última etapa, conforme pode ser visto na parte inferior da figura 6.12, chegamos a conclusão que o ponto $L$ igual a $0.01 \mathrm{e}$ $M$ igual a 0.08 corresponde aos melhores ajustes para nossos testes.

Após essas etapas, pudemos concluir que o conjunto de parâmetros mais apropriado para NN sensível ao custo em nossas bases foi:

$$
\text { -L } 0.01 \text {-M } 0.08 \text {-N } 500 \text {-V } 0 \text {-S } 0 \text {-E } 0 \text {-H } 20
$$

Com esse conjunto de parâmetros conseguimos um custo de - $\mathrm{R} \$ 23.080,66$ no conjunto da bases usadas no desenvolvimento e - $\mathrm{R} \$ 23.340,33$ no conjunto de bases usadas na avaliação.

\subsubsection{Busca Semi-Exaustiva por parâmetros estáveis - AIS sensível ao custo.}

Durante o andamento do trabalho, mais especificamente nas execuções dos testes, havíamos abandonado a idéia de executar as estratégia $\operatorname{Cost}^{G A}\left(A I S\right.$ e $\operatorname{Cost}^{S T A}(A I S$. Os principais fatores que nos levaram a essa decisão naquele momento foram: o tempo de computação e outros testes que deviam ser feito; mas no final de nosso trabalho, seduzidos pelos resultados alcançados tanto para $\operatorname{Padrao}^{G A}$ (AIS quanto para $\operatorname{Padrao}^{S T A}(A I S$, resolvemos aplicar todo poder computacional que dispúnhamos, e mais outros que viemos a conseguir ${ }^{15}$, para executar esses testes. Como o prazo foi pequeno para nossos testes executamos por completo apenas a estratégia $\operatorname{Cost}^{G A}(A I S$, sendo que os parâmetros encontrados para $\operatorname{Cost}^{S T A}(A I S$ foi um sub-ótimo extraído das execuções da busca pelo $\operatorname{Cost}^{G A}(A I S$ (completando-se com execuções em todas as bases para o conjunto de melhores parâmetros de cada base individualmente).

\footnotetext{
${ }^{15}$ A máquina pessoal do Yoshi e a máquina Malária cedida pelo JEF.
} 


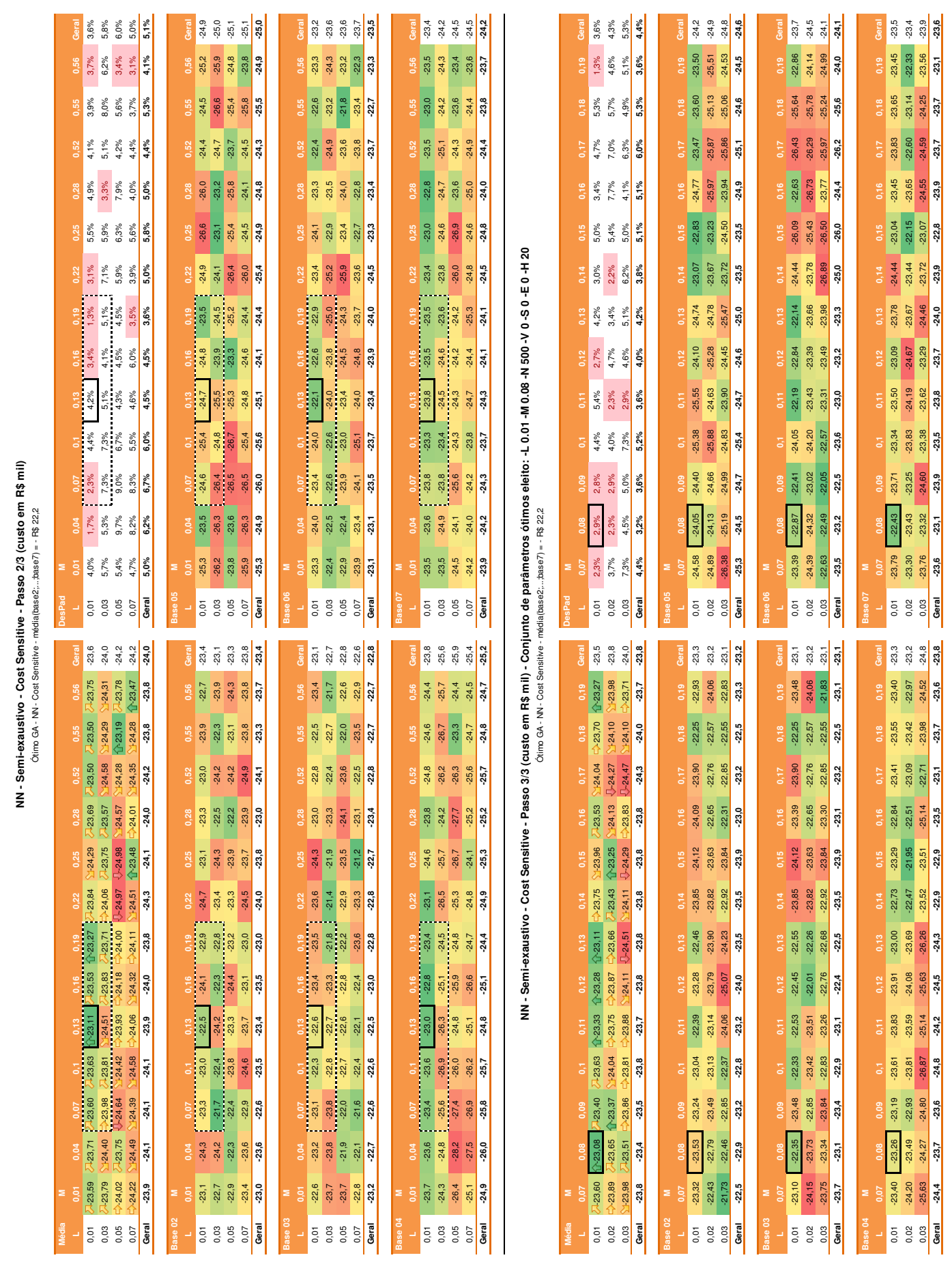

Figura 6.12: NN - Semi-exaustivo sensível ao custo - 2/2 


\subsection{Sumário dos resultados.}

Essa seção traz de uma maneira suscinta os principais resultados atingidos em nossas execuções.

Lembramos que os métodos comparados foram:

- Naive Bayes (NB);

- Redes Neurais (NN);

- Bayesian Networks (BN);

- Sistemas Imunológicos Artificiais (AIS);

- Árvores de Decisão (DT).

E que as estratégias de execução, para um dado método $M$ do nosso conjunto de métodos, foram:

- $\operatorname{Padrao}{ }^{D E F}(M)^{16}$;

- $\operatorname{Cost}^{D E F}(M)$;

- $\operatorname{Padrao}{ }^{G A}(M)$;

- $\operatorname{Cost}^{G A}(M)$;

- $\operatorname{Padrao} o^{S T A}(M)$;

- $\operatorname{Cost}^{S T A}(M)$.

Análise por método: A figura 6.13 nos mostra de maneira bem condensada como cada método se comportou a cada diferente estratégia que utilizamos. Escolhemos mostrar aqui apenas os resultados com as 3 bases de avaliação. Com essa figura podemos ver que:

- O método NB, como não há um conjunto de parâmetros a serem variados todas as execuções se resumem a duas, execução padrão e sensível ao custo, e não nos interessamos em descobrir por que a meta heurística piora esse método ligeiramente;

\footnotetext{
${ }^{16}$ Padrao deve ser interpretado como a execução padrão do Weka (sem qualquer meta heurística); Cost deve ser interpretado como a execução utilizando a meta heurística CostSensitiveClassifier do Weka; ${ }^{D E F}$ deve ser interpretado como o uso dos parâmetros default do Weka; ${ }^{G A}$ deve ser interpretado como sendo usado um conjunto de parâmetros otimizados por algoritmo genético para cada base; e ${ }^{S T A}$ deve ser interpretado como sendo usado um conjunto de parâmetros estável otimizado (por busca semi-exaustiva por NN e AIS) sobre 6 das 9 bases.
} 


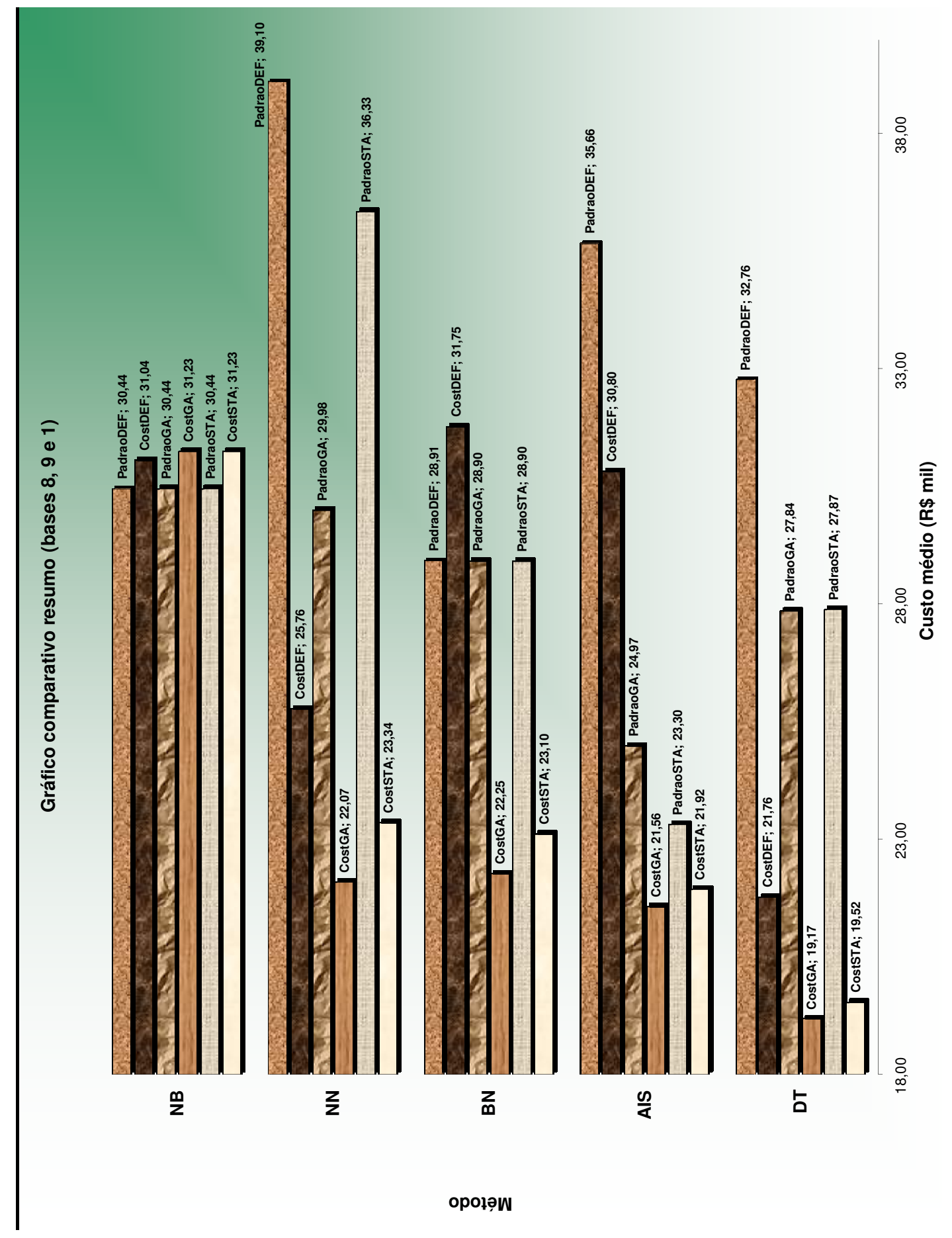

Figura 6.13: Resumo dos resultados visão método. 162 
- $\mathrm{NN}$ conseguiu uma queda de $23,33 \%^{17}$ e $14,32 \% \%{ }^{18}$ no custo quando aplicamos o GA em relação as execuções com parâmetros default. Essa queda foi ainda maior todas as vezes que optamos por utilizar a estratégia sensível ao custo: $34,12 \%^{19}, 26,38 \%^{20}$ e $35,76 \%^{21}$. Por último, vemos que NN teve piora de $5,80 \%^{22}$ e $21,20 \%{ }^{23}$ no custo quando buscamos por parâmetros ótimos estáveis em relação as execuções com o GA, isso se deu, provavelmente, por NN ser mais suscetível a overfitting;

- Para BN o parâmetro número máximo de nós pais foi importante apenas nas execuções sensíveis ao custo. Verificamos, por isso, que o custo não melhorou em qualquer uma das execuções usando a execução padrão, chegando até mesmo a piorar um pouco para $\operatorname{Cost}^{D E F}(B N)^{24}$. As execuções sensíveis ao custo $\operatorname{Cost}^{G A}(B N) \mathrm{e}$ $\operatorname{Cost}^{S T A}(B N)$ melhoram $23,03 \%^{25}$ e $20,07 \%^{26}$ em relação às execuções $\operatorname{Padrao}^{G A}(B N)$ e $\operatorname{Padrao}^{S T A}(B N)$ respectivamente;

- Com AIS conseguimos um resultado bastante interessante. Diferente dos demais métodos, para AIS, a parte mais importante da estratégia foi a otimização parâmétrica com uso do GA, com reduções de $29,98 \%^{27}$ e $30,01 \%^{28}$, enquanto que as reduções obtidas pelo uso da execução sensível ao custo foram de $13,62 \%{ }^{29}$, $13,65 \%^{30}$ e $5,93 \%^{31}$

- Em contrapartida para DT o resultado foi contrário ao do AIS, as

\footnotetext{
${ }^{17} 23,33 \%=1-\mathrm{R} \$ 29,98 \mathrm{mil} / \mathrm{R} \$ 39,10 \mathrm{mil}=1-\operatorname{Padrao}^{G A}(N N) / \operatorname{Padrao}^{D E F}(N N)$

$1814,32 \%=1-\mathrm{R} \$ 22,07 \mathrm{mil} / \mathrm{R} \$ 25,76 \mathrm{mil}=1-\operatorname{Cost}^{G A}(N N) / \operatorname{Cost}^{D E F}(N N)$

${ }^{19} 34,12 \%=1-\mathrm{R} \$ 25,76 \mathrm{mil} / \mathrm{R} \$ 39,10 \mathrm{mil}=1-\operatorname{Cost}^{D E F}(N N) / \operatorname{Padrao}^{D E F}(N N)$

${ }^{20} 26,38 \%=1-\mathrm{R} \$ 22,07 \mathrm{mil} / \mathrm{R} \$ 29,98 \mathrm{mil}=1-\operatorname{Cost}^{G A}(N N) / \operatorname{Padrao}^{G A}(N N)$

${ }^{21} 35,76 \%=1-\mathrm{R} \$ 23,34 \mathrm{mil} / \mathrm{R} \$ 36,33 \mathrm{mil}=1-\operatorname{Cost}^{S T A}(N N) / \operatorname{Padrao}^{S T A}(N N)$

${ }^{22} 5,80 \%=1-\mathrm{R} \$ 23,34 \mathrm{mil} / \mathrm{R} \$ 27,07 \mathrm{mil}=1-\operatorname{Cost}^{S T A}(N N) / \operatorname{Cost}^{G A}(N N)$

${ }^{23} 21,20 \%=1-\mathrm{R} \$ 36,33 \mathrm{mil} / \mathrm{R} \$ 29,98 \mathrm{mil}=1-\operatorname{Padrao}^{S T A}(N N) / \operatorname{Padrao}^{G A}(N N)$

${ }^{24} \operatorname{Cost}^{D E F}(B N)$ não melhorou pois, o número máximo de nós pais é fixo em 1 para os parâmetros default do Weka.

${ }^{25} 23,03 \%=1-\mathrm{R} \$ 22,25 \mathrm{mil} / \mathrm{R} \$ 28,90 \mathrm{mil}=1-\operatorname{Cost}^{G A}(B N) / \operatorname{Padrao}^{G A}(B N)$

${ }^{26} 20,07 \%=1-\mathrm{R} \$ 23,10 \mathrm{mil} / \mathrm{R} \$ 28,90 \mathrm{mil}=1-\operatorname{Cost}^{S T A}(B N) / \operatorname{Padrao}^{S T A}(B N)$

${ }^{27} 29,98 \%=1-\mathrm{R} \$ 24,97 \mathrm{mil} / \mathrm{R} \$ 35,66 \mathrm{mil}=1-\operatorname{Padrao}^{G A}(A I S) / \operatorname{Padrao}^{D E F}(A I S)$

${ }^{28} 30,01 \%=1-\mathrm{R} \$ 21,56 \mathrm{mil} / \mathrm{R} \$ 30,80 \mathrm{mil}=1-\operatorname{Cost}^{G A}(A I S) / \operatorname{Cost}^{D E F}(A I S)$

${ }^{29} 13,62 \%=1-\mathrm{R} \$ 30,80 \mathrm{mil} / \mathrm{R} \$ 35,66 \mathrm{mil}=1-\operatorname{Cost}^{D E F}(A I S) / \operatorname{Padrao}^{D E F}(A I S)$

${ }^{30} 13,65 \%=1-\mathrm{R} \$ 21,56 \mathrm{mil} / \mathrm{R} \$ 24,97 \mathrm{mil}=1-\operatorname{Cost}^{G A}(A I S) / \operatorname{Padrao}^{G A}(A I S)$

${ }^{31} 5,93 \%=1-\mathrm{R} \$ 21,92 \mathrm{mil} / \mathrm{R} \$ 23,30 \mathrm{mil}=1-\operatorname{Cost}^{S T A}(A I S) / \operatorname{Padrao}^{S T A}(A I S)$
} 
execuções de GA reduziram 15,01\% ${ }^{32}$ e 11,92\% ${ }^{33}$, enquanto que as aplicações da execução sensível ao custo tiveram sucesso maior nas reduções, $33,57 \%^{34}, 31,16 \%^{35}, 29,95 \%^{36}$.

Excluindo-se NB, vemos que, em geral, conseguimos reduções consideráveis utilizando o algoritmo genético para realização da busca paraétrica e a execução sensível ao custo separadamente. Em especial, a utilização conjunta das duas estratégias atingiu resultados ainda melhores.

Análise por estratégia: Utilizamos outra maneira para compararmos as estratégias. A figura 6.14 mostra uma visão diferente dos resultados, que nos facilita estabelecer relações de ordem entre os métodos e, em especial, identificar qual o melhor método para cada tipo de estratégia. Escolhemos a disposição: Padrao ${ }^{D E F}(M), \operatorname{Cost}^{D E F}(M)$, $\operatorname{Padrao}^{G A}(M), \operatorname{Cost}^{G A}(M), \operatorname{Padrao}^{S T A}(M)$ e $\operatorname{Cost}^{S T A}(M)$, por essa ter sido a ordem de nossas execuções. Com essa figura podemos ver que:

- Na estratégia Padrao ${ }^{D E F}(M)$, BN teve obteve resultado incontestavelmente melhor, AIS e NN chegaram a resultados muito ruíns em relação aos outros métodos, em especial NN melhorou apenas $15,4 \%{ }^{37}$ em relação a uma estratégia que considerasse todas como legítimas;

- Na estratégia seguinte, $\operatorname{Cost}^{D E F}(M)$, vemos redução do custo em relação a $\operatorname{Padrao}{ }^{D E F}(M)$ para quase todos os métodos, e em particular, podemos apontar as reduções de DT e NN, que os colocou em primeira e segunda posição.

- Padrao ${ }^{G A}(M)$, de modo análogo ao anterior, verificamos que quase todos os métodos obtiveram redução em relação a $\operatorname{Padrao}^{D E F}(M)$, porém dessa vez, o método a reduzir mais seu custo e assumir a primeira colocação foi o AIS;

\footnotetext{
${ }^{32} 15,01 \%=1-\mathrm{R} \$ 27,84 \mathrm{mil} / \mathrm{R} \$ 32,76 \mathrm{mil}=1-\operatorname{Padrao}^{G A}(D T) / \operatorname{Padrao}^{D E F}(D T)$

${ }^{33} 15,01 \%=1-\mathrm{R} \$ 19,17 \mathrm{mil} / \mathrm{R} \$ 21,76 \mathrm{mil}=1-\operatorname{Cost}^{G A}(D T) / \operatorname{Cost}^{D E F}(D T)$

${ }^{34} 33,57 \%=1-\mathrm{R} \$ 21,76 \mathrm{mil} / \mathrm{R} \$ 32,76 \mathrm{mil}=1-\operatorname{Cost}^{D E F}(D T) / \operatorname{Padrao}^{D E F}(D T)$

${ }^{35} 31,16 \%=1-\mathrm{R} \$ 19,17 \mathrm{mil} / \mathrm{R} \$ 27,84 \mathrm{mil}=1-\operatorname{Cost}^{G A}(D T) / \operatorname{Padrao}^{G A}(D T)$

${ }^{36} 29,95 \%=1-\mathrm{R} \$ 19,52 \mathrm{mil} / \mathrm{R} \$ 27,87 \mathrm{mil}=1-\operatorname{Cost}^{S T A}(D T) / \operatorname{Padrao}^{S T A}(D T)$

${ }^{37} 15,4 \%=-\mathrm{R} \$ 39,1 \mathrm{mil} /-\mathrm{R} \$ 46,2$ mil, onde - $\mathrm{R} \$ 46,2$ mil corresponde ao custo médio das bases 8,9 e 1 quando resolve-se não criar uma área de detecção de fraude.
} 


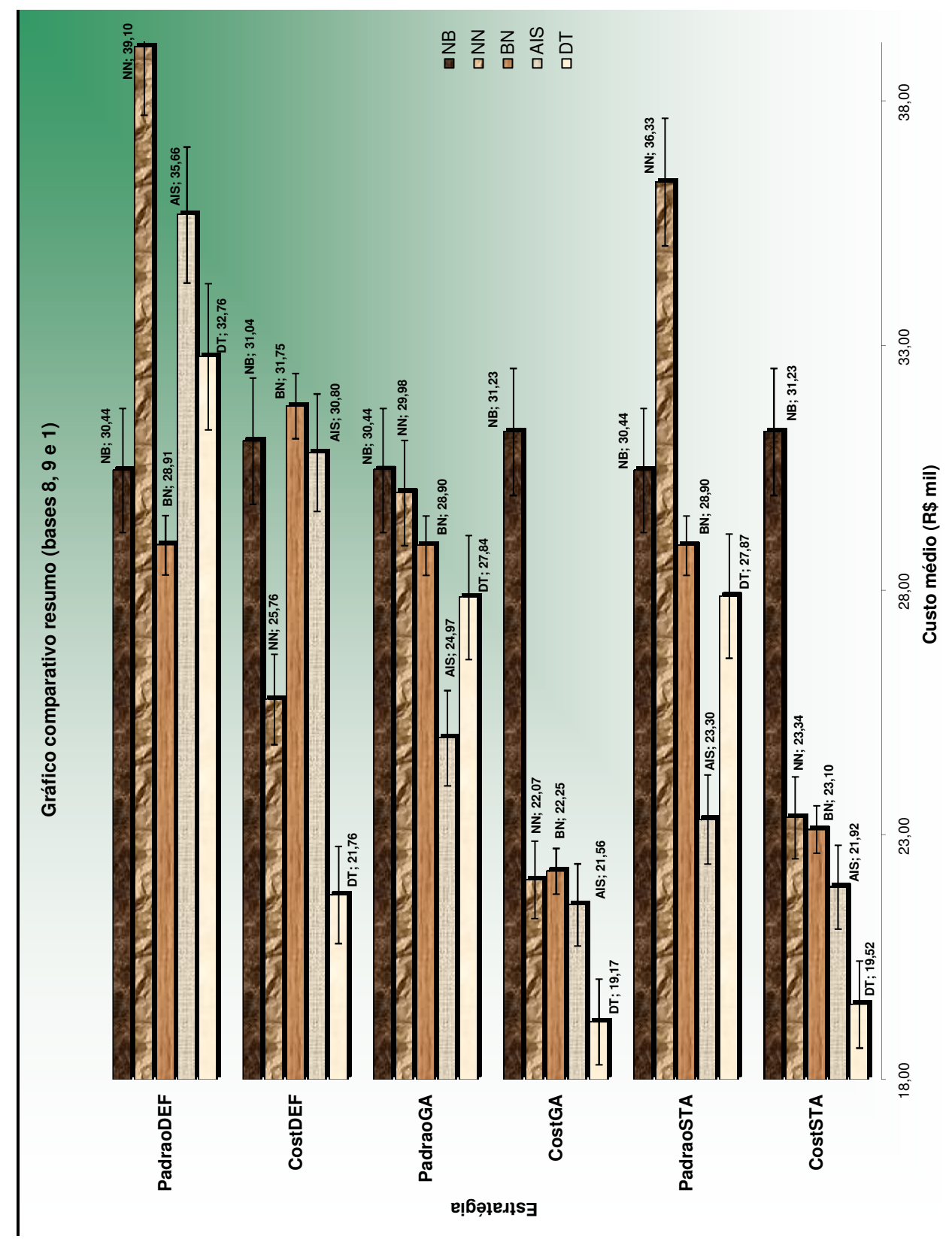

Figura 6.14: Resumo dos resultados visão estratégia.

Por limitação técnica da planilha utilizada, fixado o método, a barra de erros presente nas seis estratégias mostradas na figura precisa ser a mesma. Adotamos o máximo entre os seis desvios-padrão. 
- A próxima estratégia, $\operatorname{Cost}^{G A}(M)$, mostra como a junção das duas estratégias anteriores pode reduzir a níveis muito interessantes os custos obtidos. E em especial, excluindo-se NB, para todos os métodos essa foi a estratégia onde obtivemos os melhores modelos. Em uma análise mais refinada, atenta aos desvios padrão, vemos que $\operatorname{Cost}^{G A}(D T)$ foi o melhor método, seguido pelos três métodos, $\operatorname{Cost}^{G A}(A I S), \operatorname{Cost}^{G A}(N N)$ e $\operatorname{Cost}^{G A}(B N)$ com custo iguais, mas com uma ligeira vantagem para AIS, e com $\operatorname{Cost}^{G A}(N B)$ como último colocado;

- Quando analisamos a execução $\operatorname{Padrao}^{S T A}(M)$, vemos dois fatos importantes: o primeiro foi um aumento brusco do custo de $\operatorname{Padrao}^{S T A}(N N)$ em relação a $\operatorname{Padrao}^{G A}(N N)$, que mostra a tendência a overfitting do método NN com parâmetros otimizados, isso pode ser verificado na tabela 6.15. O segundo foi a redução do custo de $\operatorname{Padrao}^{S T A}(A I S)$ em relação a $\operatorname{Padrao}^{G A}(A I S)$. Supomos que isso se deva ao fato do método AIS ser aquele com mais parâmetros, tendo, portanto o mais amplo espaço paramétrico de busca e provavelmente destacamos, ter uma otimização por GA mais ineficiente. De modo que quando o espaço paramétrico é reduzido, após o congelamento de alguns dos parâmetros, durante o processo de estabilização dos parâmetros, pode-se observar uma otimização mais eficiente. Este fenômeno é muitas vezes mencionado como sendo "Maldição da Dimensionalidade";

- Temos como última estratégia, $\operatorname{Cost}^{S T A}(M)$. Aqui fica clara a superioridade de DT sobre os demais métodos, AIS passa a ocupar uma segunda colocação com folga, NN e BN se igualam na terceira posição, e verificamos que NB se apresentou como sendo o pior método.

Por fim, destacamos que Naive Bayes se comportou como pior dentre os métodos comparados, Redes Neurais perdem bastante desempenho quando se exige um conjunto de parâmetros estáveis, e Árvore de Decisão e Sistema Imunológicos Artificiais se apresentaram como os melhores métodos.

Análise do conjunto de parâmetros ótimos estáveis: Como um complemento ao sumário (parte anterior dessa seção), trazemos a figura 
6.15 que sintetiza os resultados das execuções de busca por parâmetros estáveis ótimos para as 9 bases, os 5 métodos e as duas estratégias, Padrao e Cost. Além disso, também apresentamos nesta seção a tabela 6.7. Essa tabela contem o conjunto parâmetros para cada método para cada uma das estratégias de execução, Padrao e Cost.

\begin{tabular}{lll}
\hline \hline Método & $\begin{array}{l}\text { Custo médio } \\
\text { na avaliação }\end{array}$ & Parâmetros ótimos estáveis \\
\hline \hline & & Execução Padrão \\
\hline DT & $-\mathrm{R} \$ 27.870,66$ & -C 0.49 -M 1 \\
NN & $-\mathrm{R} \$ 36.332,33$ & -L 0.40 -M 0.12 -N 500 -V 0 -S 0 -E 0 -H 20 \\
NB & $-\mathrm{R} \$ 30.439,33$ & n/a \\
BN & $-\mathrm{R} \$ 28.901,66$ & -D -Q weka.classifiers.bayes.net.search.local.K2 - -P 1 -S BAYES \\
& & -E weka.classifiers.bayes.net.estimate.SimpleEstimator - -A 0.5 \\
AIS & $-\mathrm{R} \$ 23.303,00$ & -S 1 -F 0 -C 30 -H 10 -R 177 -V 1 -A -1 -E 5 -K 1 \\
\hline \hline & & Sensível ao Custo \\
\hline DT & $-\mathrm{R} \$ 19.523,66$ & -C 0.01 -M 1 \\
NN & $-\mathrm{R} \$ 23.340,33$ & -L 0.01 -M 0.08 -N 500 -V 0 -S 0 -E 0 -H 20 \\
NB & $-\mathrm{R} \$ 31.225,33$ & n/a \\
BN & $-\mathrm{R} \$ 23.101,33$ & -D -Q weka.classifiers.bayes.net.search.local.K2 - -P 8 -S BDeu \\
& -E weka.classifiers.bayes.net.estimate.SimpleEstimator - -A 1.0 \\
AIS & $-\mathrm{R} \$-22.307,80$ & -S 1 -F 0 -C 16 -H 10 -R 87 -V 1 -A -1 -E 10 -K 4 \\
\hline \hline
\end{tabular}

Tabela 6.7: Tabela resumo de parâmetros ótimos estáveis

Em uma primeira análise desatenta, podemos afirmar que para DT temos uma árvore com poda mínima segundo o parâmetro M, e que variamos de uma poda máxima para uma poda mínima quando mudamos de execução padrão para sensível ao custo. No caso de NN, vemos que os únicos parâmetros que diferem entre execução padrão e sensível ao custo são L e M, sendo que no caso da execução sensível ao custo, tanto a força da amostra nova (L - Learning Rate) quanto o momento (M Momentum) apresentam menor valor, nos arriscamos a traçar um paralelo com DT, e entender que para NN também houve um passo para maior liberalismo quando mudamos de estratégia. Para $\mathrm{BN}$, a grande diferença acontece no parâmetro número de nós pais, na execução sensível ao custo esse parâmetro passa a apresentar força suficiente para mudar a classe predita para uma instância. Por fim, para AIS, como não conseguimos executar uma busca semi-exaustiva por parâmetros ótimos estáveis, preferimos não expressar qualquer comparação entre os parâmetros. 


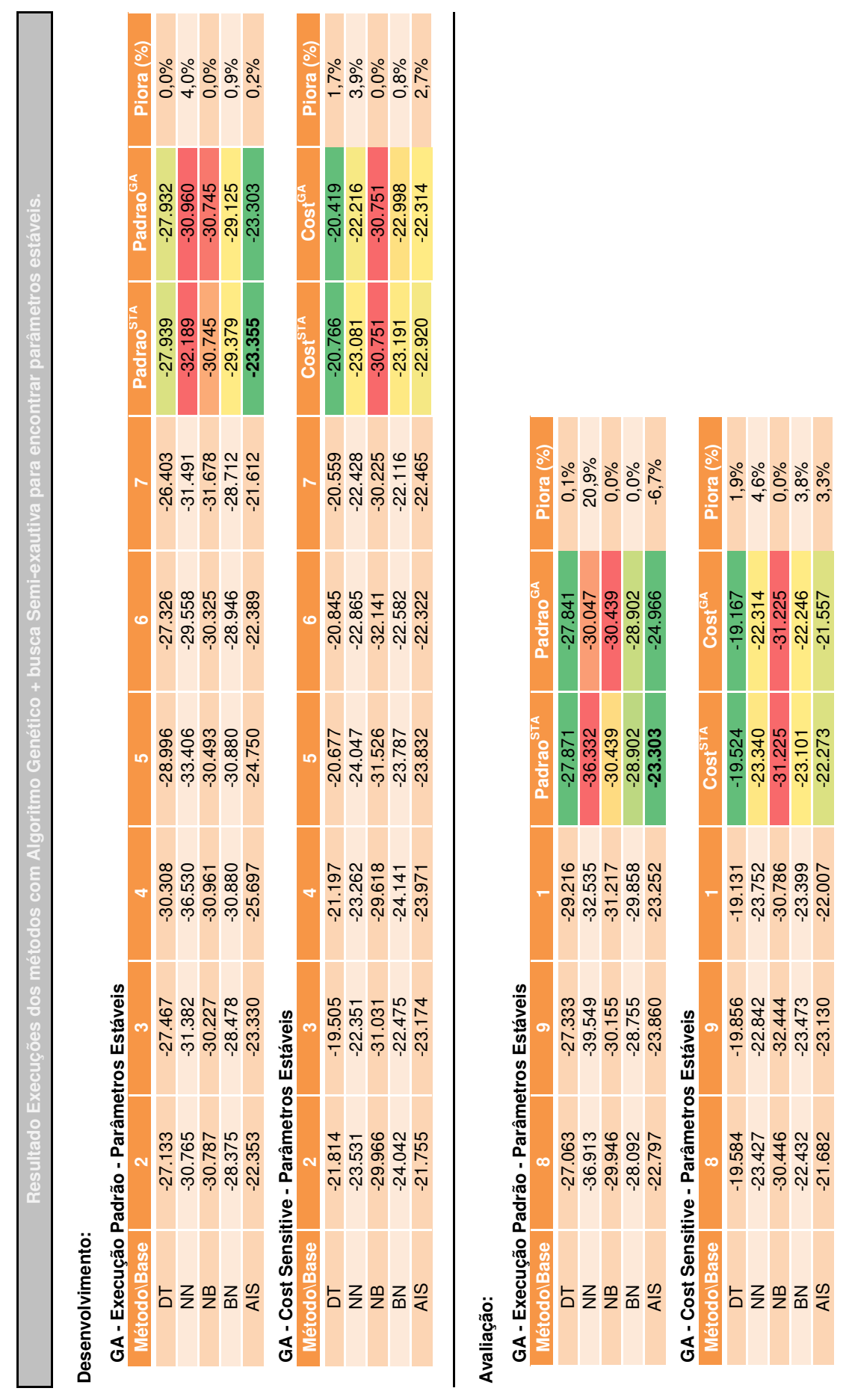

Figura 6.15: Resultado busca por parâmetros estáveis. 


\section{Capítulo 7}

\section{Conclusões}

Nosso trabalho constou em apresentar uma comparação de cinco métodos de classificação aplicados ao problema de detecção de fraude em Cartões de Crédito. Árvores de Decisão, Redes Neurais, Redes Bayesianas, Naive Bayes e Sistemas Imunológicos Artificiais foram os métodos testados. Todas as implementações usadas foram provenientes do pacote básico do Weka-3-4-11, exceto AIS cuja implementação foi retirada de [Bro05]. Através da análise dos resultados dos testes que realizamos, pudemos chegar a algumas conclusões.

DT, talvez por ser um método de classificação já bastante clássico, tem sido esquecido dos trabalhos mais recentes, porém ainda se mostra um dos melhores métodos, com resultados bastante competitivos.

A definição da função objetivo a ser otimizada e o uso dos diferentes custos dos tipos de erros (falso positivo e falso negativo) tem impacto fundamental na qualidade do modelo gerado. O uso da diferenciação dos custos é importante tanto na avaliação do desempenho de um modelo quanto no desenvolvimento desse modelo para obterem-se modelos com melhor precisão. Em nossa experiência de mercado observamos pouco interesse em investir tempo em definir boas funções objetivo, e além disso, quase nenhuma utilização da distinção de custos dos diferentes tipos de erros no desenvolvimento dos modelos. Os própros fornecedores de serviço de desenvolvimento dos classificadores não solicitam estas informações.

Em todas as nossas execuções, exceto para NB que não possui parâmetros, 
verificamos que os melhores resultados não foram atingidos com os parâmetros default, em particular para os métodos NN e AIS (observase que os resultados obtidos por esses métodos em seus parâmetros default são pífios, quando comparados aos obtidos após um ajuste paramétrico e desenvolvimento sensível ao custo). Podemos até ousar dizer, munidos dos resultados por nós alcançados, que é praticamente possível gerar qualquer ordem entre os cinco métodos através de uma escolha apropriada de parâmetros para cada um deles.

Nossos testes reproduziram os resultados do Maes em [MTV00] ao analisar que BN é melhor que $\mathrm{NN}$, isso ocorreu em praticamente todos os casos avaliados, tendo como única exceção a execução da otimização GA sensível ao custo onde NN superou um pouco BN.

Algo que se observa no mercado é que NN é surpreendentemente o método mais utilizado. No entanto se mostrou, em nossos testes, quase sempre estar entre os piores, seja com parâmetros default, otimização com GA execução padrão ou GA sensível ao custo.

AIS obteve um bom desempenho mesmo não usando a informação de custos distintos entre os diferentes tipos de erros, e quando usou-se tal informação, o AIS melhorou ainda mais seu desempenho. Porém foi superado unicamente por DT, desenvolvido, também, levando-se em consideração a diferença dos custo no processamento do modelo. Dada a pouca melhoria do método AIS com a introdução da meta heurística sensível ao custo, há que se perguntar se os próprios sistemas imunológicos naturais não levam em consideração estes "custos", e se não terá havido portanto uma simplificação na elaboração do modelo presente nos sistemas imunológicos artificiais. A própria "danger theory" [AC02] pode apontar neste sentido. Infelizmente, tal melhoria no modelo certamente introduziria um novo parâmetro e, portanto, aumentaria as dificuldades de um bom ajuste paramétrico por decorrência do aumento da dimensionalidade.

Em adição à confirmação dos premiados resultados obtidos por Maes,que apontam BN como um melhor método para detecção de fraude que NN, conclui-se que independente do uso ou não dos custos na modelagem, os métodos DT e AIS obtiveram melhor desempenho que os demais. Sem informação de custo na etapa de modelagem AIS obteve melhor resultado que DT, enquanto que DT superou AIS quando incorpora-se 
o custo na modelagem. 


\section{Capítulo 8}

\section{Trabalhos Futuros}

Pretendemos executar uma nova busca por parâmetros ótimos estáveis para NN, tanto Padrao ${ }^{S T A}(N N)$ quanto $\operatorname{Cost}^{S T A}(N N)$. Essa busca semi-exaustiva variaria o parâmetro $\mathrm{H}$, de $i(17)$ até $t+1(20)$, juntamente com os outros dois, L e M. Nessa mesma linha, pretendemos executar a busca pelo $\operatorname{Cost}^{S T A}(A I S)$ seguindo o mesmo princípio adotado para os outros métodos, a busca semi-exaustiva. A fim de avaliar com menor grau de liberdade o desvio padrão, pretendemos gerar número N grande de amostras, nos mesmos padrões dos conjuntos de 9 bases desenvolvimento e validação, e aplicarmos a essas $\mathrm{N}$ bases os parâmetros encontrados para cada estratégia e método.

Em futuro próximo, pretendemos analisar os parâmetros ótimos encontrados, tentando interpretar relações entre o valor do parâmetro e o problema de dados desbalanceados ou dados de fraude.

Pretendemos comparar os cinco métodos de classificação quanto à persistência do modelo gerado. Como a fraude é muito volátil é muito comum que um modelo perca sua força de predição ao longo dos próximos meses após sua implantação, esse fato se deve principalmente ao motivo dos fraudadores procurarem maneiras de fraudar que não estejam sendo monitoradas pelos modelos. Então é muito importante além de saber qual o método que gera o melhor modelo, qual o método que gera o modelo que permanece assertivo por mais tempo.

No início dos trabalhos pretendíamos comparar também o método Support Vector Machine (SVM). De fato, iniciamos os experimentos com 
ele. Desistimos do método à medida que ele não mostrou um bom desempenho de custo nos experimentos iniciais, mas principalmente porque a implementação de SVM disponível no Weka (chamada de SMO) é bastante instável para dados desbalanceados. Em nossos testes ela entrou em loop infinito diversas vezes, com diferentes conjuntos de parâmetros e bases. Isso nos traz o desejo de buscar uma implementação mais estável de SVM para o Weka, e gerar todas as análises necessárias para compará-la com o conjunto dos cinco métodos analisados.

Por fim, assim como a inclusão do SVM no pool de testes, pretendemos também agregar ensaios de construção de métodos de classificação usando combinação de métodos, conhecido por vezes como esemble de estratégias.

ps. Alguns dos trabalhos futuros apresentados aqui nesta seção já foram executados e publicados na conferência ICARIS 2008 [GWdL08]. 


\section{Referências Bibliográficas}

[Abe] Site da associação brasileira das empresas de cartões de credito e serviços - http://www.abecs.org.br - consultado em ago/2007.

[AC02] U. Aickelin and S. Cayzer. The danger theory and its application to artificial immune systems, 2002.

[Amo08] Janduí Amorim. Aulas de biologia, 2008. url:http://www.passeiweb.com/na_ponta_lingua/

sala_de_aula/biologia/biologia_animal/

sistema_nervoso/sist_nervoso consultado em 28/Feb/2008.

[AR05] Fábio J. Ayres and Rangaraj M. Rangayyan. Performance analysis of oriented feature detectors. In SIBGRAPI, pages 147-154, 2005.

[Ati01] Amir F. Atiya. Bankruptcy prediction for risk using neural networks: A survey and new results. In IEEE TRANSACTIONS ON NEURAL NETWORKS, volume 12, pages 929-935, 2001.

[BH02] Richard J. Bolton and David J. Hand. Statistical fraud detection: A review. In Statistical Science, volume 17, pages $235-255,2002$.

[Bit01] Guilherme Bittencourt. Inteligência Artificial - Ferramentas e Teorias. Editora da UFSC, 2001.

[BL97] Michael J. A. Berry and Gordon Linoff. Data Mining Techniques: For Marketing, Sales, and Customer Support. John Wiley Sons, Inc, USA, 1997.

[Bro05] Jason Brownlee. Artificial immune recognition system (airs) - a review and analysis. Technical report, Victoria, 
Australia: Centre for Intelligent Systems and Complex Processes (CISCP), Faculty of Information and Communication Technologies (ICT), Swinburne University of Technology, Jan 2005.

[Bt94] Roberto Battiti and Giampietro tecchiolli. The reactive tabu search. In Orsa journal on Computing, volume 6, pages 126 - 140, 1994.

[BUR98] CHRISTOPHER J.C. BURGES. A tutorial on support vector machines for pattern recognition. In Data Mining and Knowledge Discovery, volume 2, pages 121 - 167, 1998.

[CFPS99] P. Chan, W. Fan, A. Prodromidis, and S. Stolfo. Distributed data mining in credit card fraud detection, 1999.

[Cha91] Eugene Charniak. Bayesians networks without tears. AI Magazine, 1991.

[CLR67] Chakravarti, Laha, and Roy. The kolmogorov-smirnov test of goodness of fit. Handbook of Methods of Applied Statistics, Volume I:pp. 392-394, 1967. John Wiley and Sons.

[CP00] Gert Cauwenberghs and Tomaso Poggio. Incremental and decremental support vector machine learning. Technical report, MIT, 2000.

[dCT02a] Leandro Nunes de Castro and J. Timmis. Artificial Immune Systems: A New Computational Intelligence Approach. Springer, 2002.

[dCT02b] Leandro Nunes de Castro and J. Timmis. Artificial Immune Systems: A Novel Paradigm to Pattern Recognition. University of Paisley, 2002.

[dCZ] Leandro Nunes de Castro and Fernando José Von Zuben. Artificial immune systems: Part ii - a survey of applications. Technical report.

[dLFdC] André Ponce de Leon F. de Carvalho. Icme - usp.

[DMRT01] Srinivas Doddi, Achla Marathe, S. S. Ravi, and David C. Torney. Discovery of association rules in medical data. Technical report, Los Alamos National Laboratory, 2001. 
[FSZC99] Wei Fan, Salvatore J. Stolfo, Junxin Zhang, and Philip K. Chan. AdaCost: misclassification cost-sensitive boosting. In Proc. 16th International Conf. on Machine Learning, pages 97-105. Morgan Kaufmann, San Francisco, CA, 1999.

[Gin12] Corrado Gini. Variabilità e mutabilità, 1912. Reprinted in Memorie di metodologica statistica (Ed. Pizetti E, Salvemini, T). Rome: Libreria Eredi Virgilio Veschi (1955).

[GK02] Patrice Godefroid1 and Sarfraz Khurshid. Exploring very large state spaces using genetic algorithms. In $C P M{ }^{\prime} 01$ : Proceedings of the 12th Annual Symposium on Combinatorial Pattern Matching, pages 266-280, Massachusetts Institute of Technology, USA, 2002.

[Gou97] C. Goutte. Note on free lunches and cross-validation. In Neural Computation, volume 9, pages 1211 - 1215, 1997.

[Gun98] Steve R. Gunn. Support vector machines for classification and regression. Technical report, Faculty of Engineering, Science and Mathematics School of Electronics and Computer Science, 1998.

[GWdL08] Manoel Fernando Alonso Gadi, Xidi Wang, and Alair Pereira do Lago. Credit card fraud detection with artificial immune system, 7th international conference, icaris 2008, phuket, thailand, august 10-13, 2008, proceedings. In ICARIS, Lecture Notes in Computer Science. Springer, 2008.

[Hay99] Simon Haykin. Neural Networks: A Comprehensive Foundation, 2/E. Prentice Hall, Ontario, Canada, 1999.

[His] Site do banco central do brasil http://www.bcb.gov.br/?histcartao - consultado em jan/2008.

[HN91] R. Hecht-Nielsen. Neurocomputing. Addison-Wesley Publishing Company, Reading, MA,, 1991.

[Hol75] John Holland. Adaptation in Natural and Artificial Systems. 1st MIT press, 1975. 
[Hop82] J. J. Hopfield. Neural networks and physical systems with emergent collective computational abilities. In Proceedings of the National Academy of Science, volume 79, pages 2554-2558, 1982.

[Joa98] Thorsten Joachims. Text categorization with support vector machines: Learning with many relevant features. Technical report, Universitãt Dortmund, 1998.

[Kla02] Erica Klarreich. Inspired by immunity. Nature, (415):468-470, January 2002. doi:10.1038/415468a.

[Koh87] Teuvo Kohonen. Content-Addressable Memories. Springer-Verlag, New Jersey, USA, 1987.

[Kos91] Bart Kosko. Neural networks and fuzzy systems: a dynamical systems approach to machine intelligence. Prentice-Hall, Inc., Upper Saddle River, NJ, USA, 1991.

[LS02] David Lawrence and Arlene Solomon. Managing a Consumer Lending Business. Salomon Lawrence Parterns, New York, New York, USA, 2002.

[Mac05] Renato Bobsin Machado. Uma abordagem de deteç̧̃̃o de intrusão baseada em sistemas imunológicos artificiais e agentes móveis. Master's thesis, Universidade Federal de Santa Catarina, 2005.

[Mar] Roberto Ligeiro Marques. Redes bayesianas: o que são, para que servem, algoritmos e exemplos de aplicações. Coppe Sistemas UFRJ.

[MGdL01] Vittorio Maniezzo, Luca Maria Gambardella, and Fabio de Luigi. Ant colony optimization. In Future 83 Emerging Technologies unit of the European Commission through Project BISON, 2001.

[MkTVM01] Sam Maes, karl Tuyls, Bram Vanschoenwinkel, and Bernard Manderick. Credit card fraud detection using bayesian and neural networks. In Vrije Universiteir Brussel, 2001.

[MM] Alexandra Carniel Perdigao Maia and Roberto Michelan. Din - uem.

[MOK98] Sreeram K. Murthy, Enno Ohlebusch, and Stefan Kurtz. Automatic construction of decision trees from data: A 
multi-disciplinary survey. In Data Mining and Knowledge Discovery, volume 2, pages 345 - 389, USA, 1998. Kluwer Academic Publishers.

[Mon] Site monitor das fraudes - http://www.fraudes.org - consultado em ago/2007.

[Mon04] David A. Montague. Fraud Prevention Techniques For Credit Card Fraud. Trafford Plushing, Victoria, CANADA, 2004.

[MP69] Marvin Minsky and Seymour Papert. Perceptrons: An Introduction to Computational Geometry. MIT Press, Cambridge, Mass., 1969.

[MSrG97] Bertrand Mazure, Lakhdar Sais, and Éric Grégoire. Tabu search for sat. In American Association for Artificial Intelligence, 1997.

[MTV00] S. Maes, K. Tuyls, and B. Vanschoenwinkel. Machine learning techniques for fraud detection, 2000.

[Nob03] William Stafford Noble. Support vector machine applications in computational biology. Technical report, Department of Genome Sciences, 2003.

[Pea00] Judea Pearl. Causality: models, reasoning, and inference. Cambridge University Press, New York, NY, USA, 2000.

[PLF02] Rafael S. Parpinelli, Heitor S. Lopes, and Alex A. Freitas. Data mining with an ant colony optimization algorithm. In IEEE-TEC, 2002.

[PLSG05] Clifton Phua, Vincent Lee, Kate Smith, and Ross Gayler. A comprehensive survey of data mining-based fraud detection research. In Não informado, 2005.

[rDT05] Éric D. Taillard. Few guidelines for analyzing methods. In The Sixth Metaheuristics International Conference, pages 22 - 26, AUSTRIA, 2005.

[rDTGGP01] Éric D. Taillarda, Lucas M. Gambardellab, Michel Gendreauc, and Jean Yves Potvinc. Adaptive memory programming: A unified view of metaheuristics. In European Journal of Operational Research, volume 135, pages 1 16, 2001. 
[RHW86] D. E. Rumelhart, G. E. Hinton, and R. J. Williams. Learning internal representations by error propagation. In Parallel distributed processing: Explorations in the microstructure of cognition. Vol. 1. MIT Press, Cambridge, MA, 1986.

[Ros62] F. Rosenblatt. Principles of Neurodynamics. Spartan, New York, 1962.

$\left[\mathrm{SFL}^{+} 97\right] \quad$ S. Stolfo, W. Fan, W. Lee, A. Prodromidis, and P. Chan. Credit card fraud detection using meta-learning: Issues and initial results, 1997.

[Shi06] Tamio Shimizu. Decisão nas Organizações. Editora Atlas, 2006.

[SL91] S. Rasoul Safavian and David Landgrebe. A survey of decision tree classifier methodology. Technical report, Purdue University, 1991.

[Sob03] Ana Paula Barbosa Sobral. Previsão de carga horária Uma nova abordagem por Árvore de Decisão. PhD thesis, Pontifícia Universidade Católica do Rio de Janeiro, 2003.

[Spa89] Kent A. Spackman. Signal detection theory: valuable tools for evaluating inductive learning. In Proceedings of the sixth international workshop on Machine learning, pages 160-163, San Francisco, CA, USA, 1989. Morgan Kaufmann Publishers Inc.

[Sta88] CORPORATE SAS Institute Inc. Staff, editor. SASSTAT User's Guide: release 6.03 edition. SAS Institute Inc., Cary, NC, USA, 1988.

[TK00] Cassia Yuri Tatibana and Deisi Yuki Kaetsu. Uma introdução às redes neurais - site consultado em dez/07, 2000 .

[TK06] Sergios Theodoridis and Konstantinos Koutroumbas. Pattern Recognition, Third Edition. Academic Press, Inc., Orlando, FL, USA, 2006.

[vH05] Johan $\mathrm{H}$ van Heerden. Detecting fraud in cellular telephone networks. In Master Thesis, 2005. 
[WF05] Ian H. Witten and Eibe Franku. Data Mining: Practical Machine Learning Tools and Techniques (Second Edition). Elsevier, 2005.

[WF08] Ian H. Witten and Eibe Franku. Software documentation: Weka, $2008 . \quad$ file /Weka-3-4-11/doc/weka/classifiers/functions/ MultilayerPerceptron.html from Weka package.

[WTB04] Andrew Watkins, Jon Timmis, and Lois Boggess. Artificial immune recognition system (AIRS): An immuneinspired supervised machine learning algorithm. Genetic Programming and Evolvable Machines, 5(3):291317, September 2004. 


\section{Capítulo 9}

\section{Anexos}

Neste capítulo trazemos demonstrações, tabelas e figuras que foram importantes para o desenvolvimento da pesquisa, mas atraplhariam a fluídez da leitura caso permanecessem dentro do texto.

\subsection{Demonstrações}

Demonstração do teorema das Probabilidades Totais

Podemos verificar que B pode ser escrito como a união disjunta das intersecções de B com cada um dos Ai. Assim:

$$
P(B)=P(B \cap \Omega)=P\left(B \cap\left(\bigcup_{n \geq 1} A_{n}\right)=P\left(\bigcup_{n \geq 1}\left(B \cap A_{n}\right)\right)=\sum_{n \geq 1} p\left(B \cap A_{n}\right)=\sum_{n \geq 1} p\left(B \mid A_{n}\right) p\left(A_{n}\right)\right.
$$

O Teorema de Bayes resulta como conseqüência imediata do Teorema das Probabilidades Totais.

Demonstração do teorema de Bayes

Nas mesmas condições do teorema das Probabilidades Totais tem-se também:

$P\left(A_{i} \mid B\right)=\frac{P\left(B \mid A_{i}\right) P\left(A_{i}\right)}{\sum_{n \geq 1} P\left(B \mid A_{n}\right) P\left(A_{n}\right)}$, para todo o $\mathrm{i}=1,2, \ldots, \mathrm{n}$ desde que $\mathrm{p}(\mathrm{B})$ $\neq 0$. 
Reparemos que, de $P\left(A_{i} \mid B\right) P(B)=P\left(B \mid A_{i}\right) P\left(A_{i}\right)$, podemos concluir que:

$$
P\left(A_{i} \mid B\right)=\frac{P\left(B \mid A_{i}\right) P\left(A_{i}\right)}{P(B)}
$$

e aplicando o Teorema das Probabilidades Totais a $P(B)$ fica concluída a demonstração.

\subsection{Figuras e Tabelas}




\begin{tabular}{lllllllll} 
base & custo & $-\mathrm{L}$ & $-\mathrm{M}$ & $-\mathrm{N}$ & $-\mathrm{V}$ & $-\mathrm{S}$ & $-\mathrm{E}$ & $-\mathrm{H}$ \\
\hline \hline 1 & -34977 & 0.34 & 0.64 & 500 & 0 & 0 & 1 & $\mathrm{t}$ \\
1 & -34795 & 0.65 & 0.79 & 500 & 4 & 0 & 80 & $\mathrm{t}$ \\
1 & -34278 & 0.21 & 0.06 & 500 & 0 & 0 & 13 & $\mathrm{i}$ \\
1 & -33969 & 0.23 & 0.16 & 500 & 0 & 0 & 1 & 15 \\
1 & -33613 & 0.13 & 0.03 & 500 & 0 & 0 & 11 & 17 \\
1 & -33613 & 0.13 & 0.03 & 500 & 0 & 0 & 1 & $\mathrm{i}$ \\
1 & -33583 & 0.52 & 0 & 500 & 0 & 0 & 19 & 19 \\
1 & -33385 & 0.71 & 0 & 500 & 21 & 0 & 33 & $\mathrm{i}$ \\
1 & -33336 & 0.16 & 0 & 500 & 0 & 0 & 30 & $\mathrm{t}$ \\
1 & -33297 & 0.2 & 0 & 500 & 0 & 0 & 11 & $\mathrm{t}$ \\
1 & -33020 & 0.24 & 0 & 500 & 0 & 0 & 53 & $\mathrm{i}$ \\
1 & -32980 & 0.27 & 0 & 500 & 0 & 0 & 1 & $\mathrm{t}$ \\
1 & -32961 & 0.27 & 0 & 500 & 16 & 0 & 53 & $\mathrm{i}$ \\
1 & -32484 & 0.2 & 0.04 & 500 & 0 & 0 & 1 & $\mathrm{t}$ \\
1 & -32474 & 0.14 & 0.18 & 500 & 0 & 0 & 38 & 20 \\
1 & -32464 & 0.16 & 0.55 & 500 & 0 & 0 & 9 & $\mathrm{t}$ \\
1 & -31989 & 0.19 & 0 & 500 & 0 & 0 & 12 & $\mathrm{t}$ \\
1 & -31840 & 0.16 & 0.46 & 500 & 0 & 0 & 18 & $\mathrm{t}$ \\
1 & -31665 & 0.17 & 0.07 & 500 & 0 & 0 & 1 & 16 \\
1 & -30544 & 0.13 & 0.41 & 500 & 0 & 0 & 6 & 20 \\
\hline 2 & -34131 & 0.34 & 0.64 & 500 & 0 & 0 & 1 & $\mathrm{t}$ \\
2 & -34118 & 0.14 & 0.28 & 500 & 1 & 0 & 44 & 15 \\
2 & -34100 & 0.14 & 0.81 & 500 & 0 & 0 & 28 & 18 \\
2 & -33941 & 0.2 & 0 & 500 & 0 & 0 & 11 & $\mathrm{t}$ \\
2 & -33854 & 0.21 & 0.06 & 500 & 0 & 0 & 13 & 18 \\
2 & -33781 & 0.19 & 0 & 500 & 3 & 0 & 41 & 20 \\
2 & -33241 & 0.5 & 0.26 & 500 & 26 & 0 & 42 & $\mathrm{i}$ \\
2 & -33237 & 0.13 & 0.01 & 500 & 0 & 0 & 1 & 17 \\
2 & -33214 & 0.18 & 0.2 & 500 & 0 & 0 & 40 & $\mathrm{i}$ \\
2 & -33070 & 0.29 & 0 & 500 & 0 & 0 & 23 & 16 \\
2 & -33051 & 0.21 & 0 & 500 & 0 & 0 & 7 & 20 \\
2 & -32840 & 0.14 & 0 & 500 & 0 & 0 & 24 & 20 \\
2 & -32291 & 0.14 & 0.33 & 500 & 0 & 0 & 40 & 20 \\
2 & -32147 & 0.13 & 0.03 & 500 & 0 & 0 & 11 & 17 \\
2 & -32147 & 0.13 & 0.03 & 500 & 0 & 0 & 1 & 18 \\
2 & -32053 & 0.14 & 0.35 & 500 & 0 & 0 & 35 & 20 \\
2 & -32052 & 0.21 & 0 & 500 & 0 & 0 & 41 & $\mathrm{i}$ \\
2 & -31891 & 0.09 & 0.04 & 500 & 0 & 0 & 41 & 20 \\
2 & -31668 & 0.18 & 0.2 & 500 & 0 & 0 & 58 & 20 \\
2 & -30657 & 0.3 & 0.18 & 500 & 0 & 0 & 41 & 20 \\
\hline \hline & & & & & & & & \\
\hline
\end{tabular}

Tabela 9.1: Tab. de par. ótimos - GA Exec. Padrão - NN - Melhores 20 Bases 1 e 2 


\begin{tabular}{lllllllll} 
base & custo & $-\mathrm{L}$ & $-\mathrm{M}$ & $-\mathrm{N}$ & $-\mathrm{V}$ & $-\mathrm{S}$ & $-\mathrm{E}$ & $-\mathrm{H}$ \\
\hline \hline 3 & -33731 & 0.72 & 0.06 & 500 & 0 & 0 & 63 & 18 \\
3 & -33401 & 1 & 0.32 & 500 & 12 & 0 & 23 & $\mathrm{t}$ \\
3 & -33382 & 0.5 & 0 & 500 & 6 & 0 & 44 & 18 \\
3 & -33372 & 0.52 & 0.15 & 500 & 0 & 0 & 1 & $\mathrm{t}$ \\
3 & -33344 & 0.59 & 0 & 500 & 11 & 0 & 38 & $\mathrm{t}$ \\
3 & -33334 & 0.74 & 0 & 500 & 0 & 0 & 1 & $\mathrm{t}$ \\
3 & -33303 & 0.5 & 0.26 & 500 & 14 & 0 & 48 & 18 \\
3 & -33283 & 0.21 & 0 & 500 & 0 & 0 & 21 & 18 \\
3 & -33273 & 0.2 & 0 & 500 & 0 & 0 & 21 & 18 \\
3 & -32939 & 0.6 & 0.32 & 500 & 22 & 0 & 44 & 20 \\
3 & -32938 & 0.79 & 0 & 500 & 2 & 0 & 18 & $\mathrm{t}$ \\
3 & -32599 & 0.12 & 0 & 500 & 0 & 0 & 5 & $\mathrm{t}$ \\
3 & -32466 & 0.52 & 0.11 & 500 & 22 & 0 & 58 & 20 \\
3 & -32168 & 0.19 & 0.46 & 500 & 0 & 0 & 13 & $\mathrm{t}$ \\
3 & -32098 & 0.5 & 0.29 & 500 & 1 & 0 & 44 & 20 \\
3 & -32097 & 0.59 & 0 & 500 & 4 & 0 & 22 & $\mathrm{t}$ \\
3 & -31935 & 0.21 & 0.06 & 500 & 0 & 0 & 13 & 18 \\
3 & -31366 & 0.2 & 0.04 & 500 & 0 & 0 & 1 & $\mathrm{t}$ \\
3 & -31017 & 0.2 & 0 & 500 & 0 & 0 & 11 & $\mathrm{t}$ \\
3 & -30663 & 0.5 & 0.26 & 500 & 22 & 0 & 44 & $\mathrm{i}$ \\
\hline 4 & -37452 & 0.16 & 0.03 & 500 & 0 & 0 & 1 & $\mathrm{i}$ \\
4 & -37176 & 0.2 & 0 & 500 & 0 & 0 & 11 & $\mathrm{t}$ \\
4 & -37077 & 0.8 & 0.62 & 500 & 29 & 0 & 38 & $\mathrm{t}$ \\
4 & -36921 & 0.79 & 0 & 500 & 2 & 0 & 18 & $\mathrm{t}$ \\
4 & -36906 & 0.2 & 0.12 & 500 & 0 & 0 & 1 & $\mathrm{t}$ \\
4 & -36455 & 0.15 & 0.08 & 500 & 0 & 0 & 4 & 15 \\
4 & -36007 & 0.13 & 0.05 & 500 & 0 & 0 & 1 & 13 \\
4 & -35849 & 0.21 & 0.06 & 500 & 0 & 0 & 13 & $\mathrm{i}$ \\
4 & -35484 & 0.19 & 0.46 & 500 & 0 & 0 & 13 & $\mathrm{t}$ \\
4 & -35481 & 0.13 & 0.13 & 500 & 0 & 0 & 7 & 17 \\
4 & -35414 & 0.14 & 0.13 & 500 & 0 & 0 & 13 & 16 \\
4 & -35376 & 0.13 & 0 & 500 & 0 & 0 & 4 & 12 \\
4 & -35029 & 0.13 & 0.41 & 500 & 0 & 0 & 1 & 17 \\
4 & -34581 & 0.14 & 0.18 & 500 & 0 & 0 & 38 & 20 \\
4 & -34393 & 0.1 & 0.13 & 500 & 0 & 0 & 1 & $\mathrm{i}$ \\
4 & -34257 & 0.52 & 0 & 500 & 0 & 0 & 19 & 19 \\
4 & -34008 & 0.06 & 0 & 500 & 0 & 0 & 13 & $\mathrm{i}$ \\
4 & -33802 & 0.2 & 0.04 & 500 & 0 & 0 & 1 & $\mathrm{t}$ \\
4 & -33129 & 0.13 & 0.02 & 500 & 0 & 0 & 1 & 17 \\
4 & -32692 & 0.13 & 0.05 & 500 & 0 & 0 & 7 & 17 \\
\hline \hline & & & & & & & & \\
3 & & & & & 0
\end{tabular}

Tabela 9.2: Tab. de par. ótimos - GA Exec. Padrão - NN - Melhores 20 Bases 3 e 4 


\begin{tabular}{lllllllll} 
base & custo & $-\mathrm{L}$ & $-\mathrm{M}$ & $-\mathrm{N}$ & $-\mathrm{V}$ & $-\mathrm{S}$ & $-\mathrm{E}$ & $-\mathrm{H}$ \\
\hline \hline 5 & -36187 & 0.1 & 0.64 & 500 & 0 & 0 & 1 & $\mathrm{t}$ \\
5 & -36078 & 0.19 & 0 & 500 & 3 & 0 & 41 & $\mathrm{t}$ \\
5 & -36028 & 0.2 & 0.64 & 500 & 0 & 0 & 1 & $\mathrm{t}$ \\
5 & -35836 & 0.8 & 0.04 & 500 & 14 & 0 & 38 & $\mathrm{t}$ \\
5 & -35665 & 0.19 & 0.46 & 500 & 0 & 0 & 13 & $\mathrm{t}$ \\
5 & -35573 & 0.94 & 0.25 & 500 & 0 & 0 & 16 & $\mathrm{t}$ \\
5 & -35394 & 0.28 & 0 & 500 & 0 & 0 & 44 & $\mathrm{t}$ \\
5 & -35376 & 0.52 & 0 & 500 & 0 & 0 & 19 & 19 \\
5 & -35326 & 0.2 & 0.14 & 500 & 0 & 0 & 1 & $\mathrm{t}$ \\
5 & -35232 & 0.77 & 0 & 500 & 0 & 0 & 28 & 16 \\
5 & -35029 & 0.21 & 0.13 & 500 & 0 & 0 & 1 & $\mathrm{t}$ \\
5 & -34863 & 0.41 & 0.06 & 500 & 0 & 0 & 9 & $\mathrm{i}$ \\
5 & -34585 & 0.34 & 0 & 500 & 0 & 0 & 27 & $\mathrm{t}$ \\
5 & -34535 & 0.14 & 0.18 & 500 & 0 & 0 & 42 & $\mathrm{t}$ \\
5 & -34412 & 0.8 & 0 & 500 & 27 & 0 & 36 & $\mathrm{t}$ \\
5 & -34362 & 0.34 & 0.46 & 500 & 0 & 0 & 20 & $\mathrm{t}$ \\
5 & -33317 & 0.21 & 0.06 & 500 & 0 & 0 & 13 & $\mathrm{i}$ \\
5 & -32915 & 0.14 & 0.18 & 500 & 0 & 0 & 38 & 20 \\
5 & -32508 & 0.2 & 0 & 500 & 0 & 0 & 9 & $\mathrm{t}$ \\
5 & -32430 & 0.94 & 0.04 & 500 & 0 & 0 & 1 & $\mathrm{t}$ \\
\hline 6 & -32792 & 0.87 & 0.57 & 500 & 20 & 0 & 38 & $\mathrm{i}$ \\
6 & -32774 & 0.87 & 0 & 500 & 6 & 0 & 30 & $\mathrm{i}$ \\
6 & -32771 & 0.21 & 0.1 & 500 & 3 & 0 & 38 & $\mathrm{i}$ \\
6 & -32594 & 0.71 & 0 & 500 & 21 & 0 & 33 & $\mathrm{i}$ \\
6 & -32383 & 0.87 & 0 & 500 & 95 & 0 & 34 & 1 \\
6 & -32202 & 0.8 & 0.62 & 500 & 29 & 0 & 38 & $\mathrm{t}$ \\
6 & -32010 & 0.87 & 0.26 & 500 & 20 & 0 & 88 & $\mathrm{t}$ \\
6 & -31903 & 0.36 & 0.2 & 500 & 0 & 0 & 11 & $\mathrm{i}$ \\
6 & -31729 & 0.05 & 0.06 & 500 & 0 & 0 & 12 & $\mathrm{i}$ \\
6 & -31672 & 0.45 & 0.19 & 500 & 0 & 0 & 36 & $\mathrm{t}$ \\
6 & -31525 & 0.43 & 0 & 500 & 25 & 0 & 43 & $\mathrm{t}$ \\
6 & -31505 & 0.14 & 0.18 & 500 & 0 & 0 & 38 & 20 \\
6 & -31486 & 0.57 & 0.06 & 500 & 18 & 0 & 87 & $\mathrm{i}$ \\
6 & -31406 & 0.34 & 0.64 & 500 & 0 & 0 & 1 & $\mathrm{t}$ \\
6 & -31317 & 0.45 & 0 & 500 & 0 & 0 & 1 & $\mathrm{t}$ \\
6 & -30704 & 0.5 & 0 & 500 & 0 & 0 & 11 & $\mathrm{i}$ \\
6 & -30507 & 0.19 & 0.46 & 500 & 0 & 0 & 13 & $\mathrm{t}$ \\
6 & -30190 & 0.21 & 0.04 & 500 & 0 & 0 & 31 & $\mathrm{i}$ \\
6 & -30131 & 0.5 & 0.13 & 500 & 0 & 0 & 1 & $\mathrm{i}$ \\
6 & -29734 & 0.21 & 0.56 & 500 & 13 & 0 & 66 & $\mathrm{i}$ \\
\hline \hline & & & & & & & & \\
\hline
\end{tabular}

Tabela 9.3: Tab. de par. ótimos - GA Exec. Padrão - NN - Melhores 20 Bases 5 e 6 


\begin{tabular}{lllllllll} 
base & custo & $-\mathrm{L}$ & $-\mathrm{M}$ & $-\mathrm{N}$ & $-\mathrm{V}$ & $-\mathrm{S}$ & $-\mathrm{E}$ & $-\mathrm{H}$ \\
\hline \hline 7 & -32404 & 0.71 & 0 & 500 & 14 & 0 & 20 & 19 \\
7 & -32321 & 0.59 & 0.15 & 500 & 0 & 0 & 48 & $\mathrm{t}$ \\
7 & -32241 & 0.97 & 0.01 & 500 & 2 & 0 & 34 & $\mathrm{t}$ \\
7 & -32234 & 0.75 & 0 & 500 & 11 & 0 & 38 & $\mathrm{t}$ \\
7 & -32142 & 0.79 & 0.1 & 500 & 9 & 0 & 65 & $\mathrm{t}$ \\
7 & -31917 & 0.79 & 0.1 & 500 & 11 & 0 & 79 & $\mathrm{i}$ \\
7 & -31896 & 0.52 & 0.14 & 500 & 0 & 0 & 23 & $\mathrm{t}$ \\
7 & -31736 & 0.79 & 0 & 500 & 0 & 0 & 42 & $\mathrm{t}$ \\
7 & -31641 & 0.5 & 0.26 & 500 & 26 & 0 & 42 & $\mathrm{i}$ \\
7 & -31640 & 0.34 & 0.64 & 500 & 0 & 0 & 1 & $\mathrm{t}$ \\
7 & -31462 & 0.8 & 0 & 500 & 9 & 0 & 31 & $\mathrm{t}$ \\
7 & -31371 & 0.66 & 0 & 500 & 2 & 0 & 20 & $\mathrm{t}$ \\
7 & -31329 & 0.79 & 0 & 500 & 21 & 0 & 34 & $\mathrm{t}$ \\
7 & -31171 & 0.2 & 0.04 & 500 & 0 & 0 & 1 & $\mathrm{t}$ \\
7 & -30791 & 0.59 & 0.54 & 500 & 9 & 0 & 33 & $\mathrm{t}$ \\
7 & -30561 & 0.83 & 0 & 500 & 2 & 0 & 83 & $\mathrm{t}$ \\
7 & -30245 & 0.52 & 0 & 500 & 0 & 0 & 19 & 19 \\
7 & -30216 & 0.79 & 0.1 & 500 & 2 & 0 & 88 & $\mathrm{t}$ \\
7 & -30069 & 0.8 & 0 & 500 & 2 & 0 & 25 & $\mathrm{t}$ \\
7 & -29195 & 0.79 & 0 & 500 & 2 & 0 & 38 & $\mathrm{t}$ \\
\hline 8 & -34571 & 0.71 & 0.79 & 500 & 0 & 0 & 40 & 11 \\
8 & -34489 & 0.04 & 0.19 & 500 & 0 & 0 & 3 & 17 \\
8 & -34213 & 0.2 & 0 & 500 & 0 & 0 & 11 & $\mathrm{t}$ \\
8 & -33742 & 0.71 & 0 & 500 & 13 & 0 & 45 & 18 \\
8 & -33571 & 0.13 & 0.03 & 500 & 0 & 0 & 11 & 17 \\
8 & -33571 & 0.13 & 0.03 & 500 & 0 & 0 & 1 & $\mathrm{i}$ \\
8 & -33520 & 0.13 & 0.17 & 500 & 0 & 0 & 1 & $\mathrm{i}$ \\
8 & -33495 & 0.13 & 0 & 500 & 0 & 0 & 1 & 15 \\
8 & -33242 & 0.15 & 0.04 & 500 & 0 & 0 & 1 & $\mathrm{i}$ \\
8 & -33020 & 0.64 & 0 & 500 & 21 & 0 & 54 & $\mathrm{i}$ \\
8 & -32799 & 0.36 & 0 & 500 & 0 & 0 & 37 & $\mathrm{i}$ \\
8 & -32794 & 0.5 & 0.26 & 500 & 26 & 0 & 43 & $\mathrm{i}$ \\
8 & -32659 & 0.2 & 0.04 & 500 & 0 & 0 & 1 & $\mathrm{t}$ \\
8 & -32583 & 0.33 & 0 & 500 & 0 & 0 & 48 & $\mathrm{i}$ \\
8 & -32463 & 0.09 & 0.63 & 500 & 0 & 0 & 26 & $\mathrm{i}$ \\
8 & -32411 & 0.19 & 0.46 & 500 & 0 & 0 & 13 & $\mathrm{t}$ \\
8 & -32405 & 0.14 & 0.18 & 500 & 0 & 0 & 38 & 20 \\
8 & -31381 & 0.71 & 0.63 & 500 & 0 & 0 & 26 & $\mathrm{i}$ \\
8 & -31277 & 0.13 & 0.01 & 500 & 0 & 0 & 1 & 17 \\
8 & -30674 & 0.71 & 0 & 500 & 21 & 0 & 46 & $\mathrm{i}$ \\
\hline \hline & & & & & & & & \\
\hline & & & & & & & &
\end{tabular}

Tabela 9.4: Tab. de par. ótimos - GA Exec. Padrão - NN - Melhores 20 Bases 7 e 8 


\begin{tabular}{lllllllll} 
base & custo & $-\mathrm{L}$ & $-\mathrm{M}$ & $-\mathrm{N}$ & $-\mathrm{V}$ & $-\mathrm{S}$ & $-\mathrm{E}$ & $-\mathrm{H}$ \\
\hline \hline 9 & -35445 & 0.13 & 0.03 & 500 & 0 & 0 & 1 & $\mathrm{i}$ \\
9 & -35257 & 0.19 & 0.46 & 500 & 0 & 0 & 13 & $\mathrm{t}$ \\
9 & -35247 & 0.52 & 0 & 500 & 0 & 0 & 19 & 7 \\
9 & -35050 & 0.2 & 0.04 & 500 & 0 & 0 & 1 & $\mathrm{t}$ \\
9 & -35040 & 0.52 & 0.06 & 500 & 12 & 0 & 19 & $\mathrm{t}$ \\
9 & -34386 & 0.52 & 0.67 & 500 & 0 & 0 & 4 & 16 \\
9 & -34357 & 0.11 & 0 & 500 & 0 & 0 & 1 & $\mathrm{t}$ \\
9 & -33949 & 0.51 & 0 & 500 & 0 & 0 & 19 & $\mathrm{i}$ \\
9 & -33852 & 0.79 & 0 & 500 & 2 & 0 & 18 & $\mathrm{t}$ \\
9 & -33794 & 0.13 & 0 & 500 & 0 & 0 & 1 & 15 \\
9 & -32679 & 0.8 & 0.62 & 500 & 29 & 0 & 38 & $\mathrm{t}$ \\
9 & -32615 & 0.13 & 0.01 & 500 & 0 & 0 & 1 & 17 \\
9 & -32498 & 0.75 & 0.1 & 500 & 2 & 0 & 63 & 19 \\
9 & -32388 & 0.83 & 0.12 & 500 & 0 & 0 & 63 & 20 \\
9 & -32013 & 0.42 & 0.04 & 500 & 0 & 0 & 19 & $\mathrm{i}$ \\
9 & -30857 & 0.21 & 0.06 & 500 & 0 & 0 & 13 & $\mathrm{i}$ \\
9 & -30739 & 0.3 & 0 & 500 & 0 & 0 & 19 & 19 \\
9 & -30550 & 0.42 & 0.15 & 500 & 0 & 0 & 19 & 19 \\
9 & -30108 & 0.52 & 0 & 500 & 0 & 0 & 46 & 19 \\
9 & -29103 & 0.14 & 0.18 & 500 & 0 & 0 & 38 & 20 \\
9 & -28712 & 0.56 & 0 & 500 & 0 & 0 & 19 & 19 \\
\hline \hline
\end{tabular}

Tabela 9.5: Tab. de par. ótimos - GA Exec. Padrão - NN - Melhores 20 Base 9 


\begin{tabular}{|c|c|c|c|c|c|c|c|c|c|c|}
\hline base & custo & $-\mathrm{S}$ & $-F$ & $-\mathrm{C}$ & $-\mathrm{H}$ & $-R$ & $-\mathrm{V}$ & $-A$ & $-E$ & $-K$ \\
\hline 1 & -37146 & $\bar{~} 1$ & $\overline{0}$ & 24 & 5 & 92 & $\bar{~} 1$ & -1 & 0 & 5 \\
\hline 1 & -37104 & 1 & 0 & 4 & 5 & 32 & 0 & -1 & 10 & 1 \\
\hline 1 & -36856 & 1 & 0 & 19 & 5 & 11 & 0.38 & -1 & 10 & 5 \\
\hline 1 & -36786 & 1 & 0.13 & 11 & 10 & 114 & 0.72 & -1 & 0 & 1 \\
\hline 1 & -36294 & 1 & 0.05 & 21 & 10 & 20 & 0.85 & -1 & 10 & 1 \\
\hline 1 & -36290 & 1 & 0 & 5 & 5 & 70 & 1 & -1 & 2 & 3 \\
\hline 1 & -36192 & 1 & 0.06 & 19 & 5 & 84 & 0 & -1 & 0 & 1 \\
\hline 1 & -35933 & 1 & 0.27 & 5 & 10 & 19 & 0.38 & -1 & 0 & 6 \\
\hline 1 & -35747 & 1 & 0.05 & 39 & 10 & 74 & 0.85 & -1 & 0 & 1 \\
\hline 1 & -35728 & 1 & 0 & 19 & 10 & 84 & 0.38 & -1 & 0 & 1 \\
\hline 1 & -35421 & 1 & 0.13 & 22 & 10 & 118 & 0.72 & -1 & 8 & 1 \\
\hline 1 & -35313 & 1 & 0.05 & 24 & 10 & 40 & 0.15 & -1 & 2 & 1 \\
\hline 1 & -34652 & 1 & 0 & 34 & 10 & 84 & 0.38 & -1 & 0 & 1 \\
\hline 1 & -34300 & 1 & 0 & 13 & 10 & 118 & 0.72 & -1 & 3 & 1 \\
\hline 1 & -33719 & 1 & 0 & 2 & 10 & 15 & 1 & -1 & 1 & 1 \\
\hline 1 & -28237 & 1 & 0.17 & 32 & 10 & 51 & 1 & -1 & 0 & 1 \\
\hline 1 & -26759 & 1 & 0.17 & 42 & 10 & 51 & 1 & -1 & 0 & 1 \\
\hline 1 & -25797 & 1 & 0 & 4 & 10 & 43 & 1 & -1 & 10 & 1 \\
\hline 1 & -25404 & 1 & 0.13 & 43 & 10 & 54 & 1 & -1 & 10 & 1 \\
\hline 1 & -24580 & 1 & 0 & 23 & 10 & 105 & 1 & -1 & 6 & 1 \\
\hline 2 & -22531 & 15 & 0.02 & 50 & 10 & 200 & 1 & -1 & 0 & 1 \\
\hline 2 & -28886 & 5 & 0.26 & 28 & 10 & 127 & 1 & -1 & 10 & 1 \\
\hline 2 & -27293 & 4 & 0 & 25 & 10 & 37 & 1 & -1 & 10 & 1 \\
\hline 2 & -27037 & 3 & 0.07 & 32 & 5 & 125 & 0.98 & -1 & 0 & 1 \\
\hline 2 & -26852 & 13 & 0 & 29 & 10 & 34 & 1 & -1 & 10 & 1 \\
\hline 2 & -25853 & 16 & 0.18 & 50 & 5 & 127 & 1 & -1 & 0 & 1 \\
\hline 2 & -25690 & 4 & 0.04 & 33 & 10 & 64 & 1 & -1 & 5 & 1 \\
\hline 2 & -24543 & 0 & 0.17 & 47 & 10 & 200 & 1 & -1 & 10 & 1 \\
\hline 2 & -24542 & 6 & 0.04 & 50 & 10 & 112 & 1 & -1 & 0 & 1 \\
\hline 2 & -24413 & 2 & 0.07 & 32 & 10 & 64 & 1 & -1 & 10 & 1 \\
\hline 2 & -23680 & 16 & 0 & 21 & 10 & 125 & 1 & -1 & 10 & 1 \\
\hline 2 & -23632 & 0 & 0 & 16 & 10 & 112 & 1 & -1 & 5 & 1 \\
\hline 2 & -23611 & 0 & 0.07 & 45 & 10 & 125 & 1 & -1 & 7 & 1 \\
\hline 2 & -23602 & 14 & 0.08 & 43 & 10 & 111 & 1 & -1 & 0 & 1 \\
\hline 2 & -23561 & 13 & 0 & 11 & 10 & 123 & 1 & -1 & 0 & 1 \\
\hline 2 & -23422 & 6 & 0.02 & 50 & 10 & 200 & 1 & -1 & 0 & 1 \\
\hline 2 & -23363 & 11 & 0.06 & 16 & 10 & 110 & 1 & -1 & 10 & 1 \\
\hline 2 & -23285 & 2 & 0.11 & 50 & 10 & 189 & 1 & -1 & 0 & 1 \\
\hline 2 & -22789 & 3 & 0.02 & 11 & 10 & 189 & 1 & -1 & 10 & 1 \\
\hline 2 & -22611 & 11 & 0 & 11 & 10 & 157 & 1 & -1 & 10 & 1 \\
\hline 2 & -22531 & 15 & 0.02 & 50 & 10 & 200 & 1 & -1 & 0 & 1 \\
\hline
\end{tabular}

Tabela 9.6: Tab. de par. ótimos - GA Exec. Padrão - AIS - Melhores 20 Bases 1 e 2 


\begin{tabular}{|c|c|c|c|c|c|c|c|c|c|c|}
\hline base & custo & $-\mathrm{S}$ & $-F$ & $-\mathrm{C}$ & $-\mathrm{H}$ & $-\mathrm{R}$ & $-\mathrm{V}$ & $-\mathrm{A}$ & $-E$ & $-K$ \\
\hline 3 & -23252 & 12 & 0 & 50 & 10 & 144 & 1 & -1 & 6 & 1 \\
\hline 3 & -23251 & 16 & 0 & 50 & 6 & 144 & 1 & -1 & 10 & 1 \\
\hline 3 & -23250 & 9 & 0 & 50 & 2 & 168 & 1 & -1 & 10 & 1 \\
\hline 3 & -23221 & 1 & 0 & 40 & 10 & 144 & 1 & -1 & 10 & 1 \\
\hline 3 & -23221 & 2 & 0.03 & 50 & 10 & 144 & 1 & -1 & 10 & 1 \\
\hline 3 & -23200 & 15 & 0 & 50 & 8 & 144 & 1 & -1 & 10 & 1 \\
\hline 3 & -23141 & 12 & 0 & 50 & 10 & 144 & 1 & -1 & 10 & 1 \\
\hline 3 & -23112 & 17 & 0 & 50 & 10 & 155 & 1 & -1 & 10 & 1 \\
\hline 3 & -23063 & 5 & 0.07 & 50 & 10 & 114 & 1 & -1 & 6 & 1 \\
\hline 3 & -23044 & 10 & 0.1 & 50 & 10 & 144 & 1 & -1 & 10 & 1 \\
\hline 3 & -23043 & 15 & 0 & 50 & 10 & 154 & 1 & -1 & 10 & 1 \\
\hline 3 & -23041 & 15 & 0 & 50 & 10 & 168 & 1 & -1 & 10 & 1 \\
\hline 3 & -22914 & 9 & 0 & 50 & 10 & 144 & 1 & -1 & 10 & 1 \\
\hline 3 & -22836 & 6 & 0 & 50 & 10 & 144 & 1 & -1 & 10 & 1 \\
\hline 3 & -22825 & 1 & 0 & 48 & 10 & 144 & 1 & -1 & 10 & 1 \\
\hline 3 & -22785 & 4 & 0 & 50 & 10 & 168 & 1 & -1 & 10 & 1 \\
\hline 3 & -22687 & 9 & 0 & 46 & 10 & 144 & 1 & -1 & 10 & 1 \\
\hline 3 & -22647 & 14 & 0 & 50 & 10 & 114 & 1 & -1 & 10 & 1 \\
\hline 3 & -22626 & 10 & 0 & 50 & 10 & 144 & 1 & -1 & 10 & 1 \\
\hline 3 & -22518 & 15 & 0 & 50 & 10 & 144 & 1 & -1 & 10 & 1 \\
\hline 4 & -35113 & 10 & 0 & 50 & 10 & 71 & 0 & -1 & 0 & 1 \\
\hline 4 & -34827 & 17 & 0 & 47 & 10 & 65 & 0 & -1 & 0 & 1 \\
\hline 4 & -34827 & 17 & 0 & 47 & 10 & 78 & 0.8 & -1 & 0 & 1 \\
\hline 4 & -34638 & 5 & 0 & 47 & 10 & 1 & 0 & -1 & 0 & 1 \\
\hline 4 & -34411 & 1 & 0 & 50 & 10 & 95 & 0 & -1 & 0 & 1 \\
\hline 4 & -27717 & 13 & 0 & 43 & 10 & 76 & 1 & -1 & 0 & 1 \\
\hline 4 & -27624 & 7 & 0.15 & 27 & 7 & 112 & 1 & -1 & 4 & 1 \\
\hline 4 & -27045 & 16 & 0 & 27 & 10 & 57 & 1 & -1 & 0 & 1 \\
\hline 4 & -27017 & 18 & 0 & 47 & 10 & 78 & 1 & -1 & 0 & 1 \\
\hline 4 & -26936 & 16 & 0.1 & 38 & 10 & 131 & 1 & -1 & 10 & 1 \\
\hline 4 & -26877 & 5 & 0 & 47 & 10 & 71 & 1 & -1 & 0 & 1 \\
\hline 4 & -26768 & 7 & 0 & 37 & 10 & 66 & 1 & -1 & 0 & 1 \\
\hline 4 & -26699 & 16 & 0 & 38 & 10 & 131 & 1 & -1 & 10 & 1 \\
\hline 4 & -26629 & 3 & 0 & 38 & 10 & 110 & 1 & -1 & 0 & 1 \\
\hline 4 & -26369 & 1 & 0.16 & 27 & 7 & 131 & 1 & -1 & 0 & 1 \\
\hline 4 & -26334 & 9 & 0 & 47 & 10 & 56 & 1 & -1 & 2 & 1 \\
\hline 4 & -26244 & 7 & 0.11 & 27 & 7 & 131 & 1 & -1 & 0 & 1 \\
\hline 4 & -26035 & 3 & 0 & 48 & 10 & 131 & 1 & -1 & 10 & 1 \\
\hline 4 & -25886 & 5 & 0 & 30 & 10 & 156 & 1 & -1 & 10 & 1 \\
\hline 4 & -25856 & 12 & 0 & 38 & 10 & 131 & 1 & -1 & 10 & 1 \\
\hline
\end{tabular}

Tabela 9.7: Tab. de par. ótimos - GA Exec. Padrão - AIS - Melhores 20 Bases 3 e 4 


\begin{tabular}{|c|c|c|c|c|c|c|c|c|c|c|}
\hline base & custo & $-\mathrm{S}$ & $-F$ & $-\mathrm{C}$ & $-\mathrm{H}$ & $-\mathrm{R}$ & $-\mathrm{V}$ & $-\mathrm{A}$ & $-E$ & $-K$ \\
\hline 5 & $\begin{array}{l}-24911 \\
\end{array}$ & 11 & 0 & $\overline{49}$ & 10 & 114 & 1 & -1 & 7 & $\bar{~} 1$ \\
\hline 5 & -24909 & 1 & 0 & 23 & 10 & 132 & 1 & -1 & 8 & 1 \\
\hline 5 & -24909 & 2 & 0 & 43 & 10 & 132 & 1 & -1 & 9 & 1 \\
\hline 5 & -24908 & 13 & 0 & 50 & 10 & 96 & 1 & -1 & 10 & 1 \\
\hline 5 & -24851 & 18 & 0 & 49 & 10 & 138 & 1 & -1 & 9 & 1 \\
\hline 5 & -24819 & 17 & 0 & 50 & 4 & 143 & 1 & -1 & 10 & 1 \\
\hline 5 & -24808 & 12 & 0 & 49 & 10 & 96 & 1 & -1 & 10 & 1 \\
\hline 5 & -24802 & 19 & 0.06 & 49 & 10 & 132 & 1 & -1 & 9 & 1 \\
\hline 5 & -24792 & 13 & 0 & 49 & 10 & 132 & 1 & -1 & 9 & 1 \\
\hline 5 & -24772 & 15 & 0 & 50 & 10 & 96 & 1 & -1 & 10 & 1 \\
\hline 5 & -24770 & 11 & 0 & 49 & 10 & 132 & 1 & -1 & 9 & 1 \\
\hline 5 & -24661 & 1 & 0.03 & 49 & 10 & 168 & 1 & -1 & 0 & 1 \\
\hline 5 & -24632 & 16 & 0 & 49 & 10 & 96 & 1 & -1 & 10 & 1 \\
\hline 5 & -24573 & 1 & 0 & 49 & 4 & 132 & 1 & -1 & 9 & 1 \\
\hline 5 & -24555 & 5 & 0 & 49 & 3 & 95 & 1 & -1 & 10 & 1 \\
\hline 5 & -24365 & 8 & 0 & 50 & 10 & 130 & 1 & -1 & 10 & 1 \\
\hline 5 & -24335 & 14 & 0 & 49 & 10 & 165 & 1 & -1 & 10 & 1 \\
\hline 5 & -24316 & 6 & 0.05 & 25 & 9 & 130 & 1 & -1 & 10 & 1 \\
\hline 5 & -24245 & 9 & 0 & 49 & 10 & 106 & 1 & -1 & 10 & 1 \\
\hline 5 & -24017 & 1 & 0 & 49 & 10 & 132 & 1 & -1 & 9 & 1 \\
\hline 6 & -23471 & 4 & 0.14 & 37 & 10 & 174 & 1 & -1 & 0 & 1 \\
\hline 6 & -23321 & 10 & 0.07 & 37 & 10 & 174 & 1 & -1 & 10 & 1 \\
\hline 6 & -23320 & 13 & 0 & 42 & 10 & 145 & 1 & -1 & 0 & 1 \\
\hline 6 & -23182 & 1 & 0 & 28 & 10 & 169 & 1 & -1 & 3 & 1 \\
\hline 6 & -23182 & 2 & 0.12 & 5 & 10 & 174 & 1 & -1 & 0 & 1 \\
\hline 6 & -23162 & 15 & 0.01 & 6 & 8 & 191 & 1 & -1 & 10 & 1 \\
\hline 6 & -23113 & 17 & 0.1 & 42 & 10 & 174 & 1 & -1 & 10 & 1 \\
\hline 6 & -23082 & 3 & 0 & 28 & 10 & 183 & 1 & -1 & 1 & 1 \\
\hline 6 & -22994 & 4 & 0.1 & 26 & 10 & 174 & 1 & -1 & 0 & 1 \\
\hline 6 & -22992 & 1 & 0 & 17 & 8 & 191 & 1 & -1 & 1 & 1 \\
\hline 6 & -22973 & 13 & 0.1 & 28 & 10 & 99 & 1 & -1 & 0 & 1 \\
\hline 6 & -22954 & 8 & 0.01 & 38 & 10 & 191 & 1 & -1 & 10 & 1 \\
\hline 6 & -22924 & 13 & 0.1 & 22 & 10 & 174 & 1 & -1 & 0 & 1 \\
\hline 6 & -22854 & 0 & 0 & 21 & 10 & 191 & 1 & -1 & 0 & 1 \\
\hline 6 & -22776 & 5 & 0 & 37 & 10 & 172 & 1 & -1 & 0 & 1 \\
\hline 6 & -22746 & 19 & 0 & 28 & 10 & 174 & 1 & -1 & 10 & 1 \\
\hline 6 & -22666 & 18 & 0 & 43 & 10 & 165 & 1 & -1 & 10 & 1 \\
\hline 6 & -22479 & 19 & 0 & 37 & 6 & 174 & 1 & -1 & 0 & 1 \\
\hline 6 & -22340 & 2 & 0 & 28 & 10 & 174 & 1 & -1 & 1 & 1 \\
\hline 6 & -22171 & 7 & 0.1 & 28 & 10 & 191 & 1 & -1 & 10 & 1 \\
\hline
\end{tabular}

Tabela 9.8: Tab. de par. ótimos - GA Exec. Padrão - AIS - Melhores 20 Bases 5 e 6 


\begin{tabular}{|c|c|c|c|c|c|c|c|c|c|c|}
\hline base & custo & $-\mathrm{S}$ & $-F$ & $-\mathrm{C}$ & $-\mathrm{H}$ & $-R$ & $-\mathrm{V}$ & $-A$ & $-E$ & $-K$ \\
\hline$\overline{77}$ & -33398 & $\overline{0}$ & 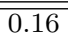 & $\overline{~ 12}$ & 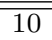 & 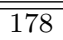 & 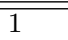 & $\begin{array}{l}-1 \\
\end{array}$ & $\overline{00}$ & 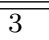 \\
\hline 7 & -33356 & 18 & 0 & 50 & 10 & 160 & 0 & -1 & 0 & 1 \\
\hline 7 & -32451 & 4 & 0.06 & 21 & 10 & 35 & 1 & -1 & 3 & 3 \\
\hline 7 & -32066 & 0 & 0 & 18 & 10 & 99 & 1 & -1 & 0 & 3 \\
\hline 7 & -27573 & 19 & 0 & 20 & 10 & 35 & 1 & -1 & 1 & 1 \\
\hline 7 & -27219 & 2 & 0.07 & 26 & 10 & 38 & 1 & -1 & 3 & 1 \\
\hline 7 & -26704 & 12 & 0.08 & 27 & 5 & 35 & 1 & -1 & 10 & 1 \\
\hline 7 & -26296 & 2 & 0.08 & 16 & 10 & 57 & 1 & -1 & 10 & 1 \\
\hline 7 & -26039 & 9 & 0.08 & 16 & 5 & 57 & 1 & -1 & 0 & 1 \\
\hline 7 & -25772 & 12 & 0 & 16 & 2 & 57 & 1 & -1 & 5 & 1 \\
\hline 7 & -25711 & 5 & 0 & 16 & 10 & 53 & 1 & -1 & 6 & 1 \\
\hline 7 & -24099 & 5 & 0 & 15 & 5 & 118 & 1 & -1 & 0 & 1 \\
\hline 7 & -23761 & 12 & 0.17 & 17 & 10 & 138 & 1 & -1 & 0 & 1 \\
\hline 7 & -23642 & 10 & 0 & 20 & 10 & 144 & 1 & -1 & 2 & 1 \\
\hline 7 & -23614 & 13 & 0 & 18 & 10 & 113 & 1 & -1 & 10 & 1 \\
\hline 7 & -23503 & 3 & 0 & 15 & 5 & 132 & 1 & -1 & 0 & 1 \\
\hline 7 & -23291 & 11 & 0.13 & 23 & 5 & 157 & 1 & -1 & 2 & 1 \\
\hline 7 & -22990 & 0 & 0.09 & 24 & 4 & 131 & 1 & -1 & 5 & 1 \\
\hline 7 & -22753 & 11 & 0 & 20 & 5 & 144 & 1 & -1 & 0 & 1 \\
\hline 7 & -22723 & 12 & 0 & 24 & 10 & 131 & 1 & -1 & 0 & 1 \\
\hline 8 & -35498 & 1 & 0.09 & 26 & 10 & 26 & 1 & -1 & 0 & 3 \\
\hline 8 & -35477 & 1 & 0 & 22 & 10 & 19 & 0.94 & -1 & 7 & 7 \\
\hline 8 & -35371 & 1 & 0 & 6 & 10 & 195 & 0.93 & -1 & 3 & 2 \\
\hline 8 & -35199 & 1 & 0 & 26 & 10 & 26 & 0 & -1 & 0 & 3 \\
\hline 8 & -34919 & 1 & 0.09 & 20 & 10 & 14 & 0.03 & -1 & 0 & 1 \\
\hline 8 & -34919 & 1 & 0.09 & 20 & 10 & 19 & 0.03 & -1 & 0 & 1 \\
\hline 8 & -34787 & 1 & 0 & 21 & 9 & 30 & 0 & -1 & 0 & 3 \\
\hline 8 & -34777 & 1 & 0 & 20 & 10 & 19 & 0 & -1 & 0 & 1 \\
\hline 8 & -34344 & 1 & 0.09 & 14 & 10 & 10 & 1 & -1 & 0 & 1 \\
\hline 8 & -34240 & 1 & 0.04 & 26 & 10 & 26 & 0.35 & -1 & 7 & 3 \\
\hline 8 & -33946 & 1 & 0.15 & 8 & 10 & 109 & 1 & -1 & 0 & 3 \\
\hline 8 & -33885 & 1 & 0 & 14 & 10 & 61 & 0 & -1 & 6 & 1 \\
\hline 8 & -33718 & 1 & 0 & 21 & 1 & 188 & 0.96 & -1 & 4 & 1 \\
\hline 8 & -33703 & 1 & 0.27 & 12 & 10 & 48 & 0 & -1 & 0 & 10 \\
\hline 8 & -33480 & 1 & 0 & 9 & 10 & 13 & 0 & -1 & 0 & 1 \\
\hline 8 & -33088 & 1 & 0.06 & 7 & 10 & 9 & 0 & -1 & 10 & 1 \\
\hline 8 & -31586 & 1 & 0.09 & 21 & 1 & 77 & 0.96 & -1 & 0 & 1 \\
\hline 8 & -30492 & 1 & 0.01 & 21 & 1 & 169 & 0.96 & -1 & 0 & 1 \\
\hline 8 & -29113 & 1 & 0 & 21 & 10 & 91 & 0.96 & -1 & 0 & 1 \\
\hline 8 & -24908 & 1 & 0 & 21 & 1 & 90 & 1 & -1 & 3 & 1 \\
\hline
\end{tabular}

Tabela 9.9: Tab. de par. ótimos - GA Exec. Padrão - AIS - Melhores 20 Bases 7 e 8 


\begin{tabular}{lllllllllll} 
base & custo & $-\mathrm{S}$ & $-\mathrm{F}$ & $-\mathrm{C}$ & $-\mathrm{H}$ & $-\mathrm{R}$ & $-\mathrm{V}$ & $-\mathrm{A}$ & $-\mathrm{E}$ & $-\mathrm{K}$ \\
\hline \hline 9 & -34869 & 1 & 0.03 & 22 & 10 & 64 & 0.23 & -1 & 9 & 1 \\
9 & -34851 & 1 & 0 & 41 & 10 & 22 & 0 & -1 & 10 & 3 \\
9 & -34798 & 1 & 0.03 & 21 & 10 & 117 & 0 & -1 & 5 & 7 \\
9 & -34755 & 1 & 0.03 & 47 & 10 & 155 & 0.34 & -1 & 0 & 4 \\
9 & -34751 & 1 & 0.07 & 36 & 10 & 3 & 0.37 & -1 & 8 & 7 \\
9 & -34639 & 1 & 0 & 3 & 10 & 58 & 1 & -1 & 10 & 3 \\
9 & -34524 & 1 & 0 & 23 & 10 & 188 & 0 & -1 & 10 & 1 \\
9 & -34207 & 1 & 0.03 & 25 & 10 & 16 & 1 & -1 & 10 & 3 \\
9 & -34105 & 1 & 0.04 & 23 & 10 & 161 & 0.6 & -1 & 0 & 3 \\
9 & -34026 & 1 & 0.04 & 38 & 10 & 180 & 0 & -1 & 0 & 1 \\
9 & -34007 & 1 & 0 & 19 & 10 & 148 & 1 & -1 & 10 & 3 \\
9 & -34005 & 1 & 0.09 & 37 & 10 & 85 & 0 & -1 & 0 & 1 \\
9 & -33971 & 1 & 0.04 & 30 & 10 & 196 & 0.15 & -1 & 0 & 1 \\
9 & -33860 & 1 & 0.37 & 32 & 10 & 101 & 0.21 & -1 & 3 & 7 \\
9 & -33654 & 1 & 0.03 & 17 & 10 & 64 & 0.23 & -1 & 9 & 1 \\
9 & -33552 & 1 & 0 & 30 & 5 & 93 & 0 & -1 & 0 & 1 \\
9 & -33263 & 1 & 0 & 24 & 10 & 69 & 0 & -1 & 7 & 3 \\
9 & -33212 & 1 & 0.05 & 29 & 10 & 120 & 1 & -1 & 0 & 3 \\
9 & -33197 & 1 & 0 & 31 & 7 & 29 & 0.73 & -1 & 3 & 1 \\
9 & -25410 & 1 & 0.11 & 41 & 10 & 48 & 1 & -1 & 0 & 1 \\
\hline \hline
\end{tabular}

Tabela 9.10: Tab. de par. ótimos - GA Exec. Padrão - AIS - Melhores 20 Base 9 


\begin{tabular}{lllllllll} 
base & custo & $-\mathrm{L}$ & $-\mathrm{M}$ & $-\mathrm{N}$ & $-\mathrm{V}$ & $-\mathrm{S}$ & $-\mathrm{E}$ & $-\mathrm{H}$ \\
\hline \hline 1 & -23599 & 0.01 & 0.24 & 500 & 0 & 0 & 46 & $\mathrm{i}$ \\
1 & -23590 & 0.01 & 0.02 & 500 & 0 & 0 & 33 & 19 \\
1 & -23379 & 0.01 & 0.52 & 500 & 0 & 0 & 30 & $\mathrm{i}$ \\
1 & -23320 & 0.1 & 0 & 500 & 0 & 0 & 47 & $\mathrm{t}$ \\
1 & -23306 & 0.01 & 0.25 & 500 & 0 & 0 & 87 & $\mathrm{t}$ \\
1 & -23277 & 0.01 & 0.4 & 500 & 0 & 0 & 30 & $\mathrm{i}$ \\
1 & -23273 & 0.01 & 0 & 500 & 0 & 0 & 25 & $\mathrm{i}$ \\
1 & -23214 & 0.01 & 0.42 & 500 & 0 & 0 & 30 & $\mathrm{i}$ \\
1 & -23180 & 0.01 & 0.11 & 500 & 0 & 0 & 13 & 20 \\
1 & -23171 & 0.01 & 0.47 & 500 & 0 & 0 & 30 & $\mathrm{i}$ \\
1 & -23163 & 0.07 & 0.43 & 500 & 0 & 0 & 45 & $\mathrm{t}$ \\
1 & -23153 & 0.01 & 0 & 500 & 0 & 0 & 21 & $\mathrm{t}$ \\
1 & -23145 & 0.01 & 0.48 & 500 & 0 & 0 & 30 & $\mathrm{i}$ \\
1 & -23091 & 0.01 & 0.19 & 500 & 0 & 0 & 8 & $\mathrm{i}$ \\
1 & -23084 & 0.01 & 0.44 & 500 & 0 & 0 & 28 & $\mathrm{i}$ \\
1 & -22970 & 0.01 & 0.16 & 500 & 0 & 0 & 46 & $\mathrm{i}$ \\
1 & -22913 & 0.01 & 0.45 & 500 & 0 & 0 & 30 & $\mathrm{i}$ \\
1 & -22802 & 0.01 & 0.02 & 500 & 0 & 0 & 29 & $\mathrm{i}$ \\
1 & -22776 & 0.01 & 0.43 & 500 & 0 & 0 & 30 & $\mathrm{i}$ \\
1 & -22517 & 0.01 & 0.46 & 500 & 0 & 0 & 20 & $\mathrm{i}$ \\
\hline 2 & -23245 & 0.04 & 0.12 & 500 & 0 & 0 & 13 & $\mathrm{t}$ \\
2 & -23155 & 0.05 & 0.17 & 500 & 0 & 0 & 39 & $\mathrm{i}$ \\
2 & -23148 & 0.05 & 0.18 & 500 & 0 & 0 & 13 & $\mathrm{t}$ \\
2 & -23028 & 0.01 & 0.1 & 500 & 0 & 0 & 49 & 19 \\
2 & -22823 & 0.05 & 0.06 & 500 & 0 & 0 & 13 & $\mathrm{t}$ \\
2 & -22761 & 0.01 & 0.65 & 500 & 0 & 0 & 42 & 20 \\
2 & -22744 & 0.05 & 0.09 & 500 & 0 & 0 & 13 & $\mathrm{t}$ \\
2 & -22718 & 0.09 & 0 & 500 & 0 & 0 & 40 & 20 \\
2 & -22601 & 0.06 & 0.12 & 500 & 0 & 0 & 13 & 20 \\
2 & -22592 & 0.05 & 0 & 500 & 0 & 0 & 23 & 20 \\
2 & -22575 & 0.05 & 0.13 & 500 & 0 & 0 & 13 & $\mathrm{t}$ \\
2 & -22562 & 0.01 & 0.12 & 500 & 0 & 0 & 13 & $\mathrm{t}$ \\
2 & -22562 & 0.01 & 0.12 & 500 & 0 & 0 & 1 & 19 \\
2 & -22426 & 0.05 & 0.02 & 500 & 0 & 0 & 13 & $\mathrm{t}$ \\
2 & -22393 & 0.01 & 0.11 & 500 & 0 & 0 & 13 & 20 \\
2 & -22308 & 0.05 & 0.14 & 500 & 0 & 0 & 13 & $\mathrm{t}$ \\
2 & -22279 & 0.05 & 0.12 & 500 & 0 & 0 & 10 & $\mathrm{t}$ \\
2 & -22279 & 0.05 & 0.12 & 500 & 0 & 0 & 1 & 19 \\
2 & -22279 & 0.05 & 0.12 & 500 & 0 & 0 & 23 & $\mathrm{t}$ \\
2 & -22069 & 0.05 & 0.16 & 500 & 0 & 0 & 13 & $\mathrm{t}$ \\
\hline \hline & & & & & & & & \\
1 & & & & & &
\end{tabular}

Tabela 9.11: Tab. de par. ótimos - GA sensível ao custo - NN - Melhores 20 - Bases 1 e 2 


\begin{tabular}{lllllllll} 
base & custo & $-\mathrm{L}$ & $-\mathrm{M}$ & $-\mathrm{N}$ & $-\mathrm{V}$ & $-\mathrm{S}$ & $-\mathrm{E}$ & $-\mathrm{H}$ \\
\hline \hline 3 & -23086 & 0.18 & 0 & 500 & 0 & 0 & 32 & 20 \\
3 & -23057 & 0.09 & 0.18 & 500 & 0 & 0 & 56 & $\mathrm{t}$ \\
3 & -23014 & 0.21 & 0 & 500 & 0 & 0 & 32 & 20 \\
3 & -22997 & 0.01 & 0 & 500 & 9 & 0 & 45 & $\mathrm{t}$ \\
3 & -22934 & 0.22 & 0 & 500 & 0 & 0 & 32 & 20 \\
3 & -22855 & 0.19 & 0.03 & 500 & 0 & 0 & 32 & $\mathrm{t}$ \\
3 & -22784 & 0.01 & 0.04 & 500 & 0 & 0 & 51 & $\mathrm{i}$ \\
3 & -22723 & 0.15 & 0 & 500 & 0 & 0 & 32 & 20 \\
3 & -22696 & 0.19 & 0.02 & 500 & 0 & 0 & 32 & 20 \\
3 & -22695 & 0.17 & 0.08 & 500 & 0 & 0 & 72 & $\mathrm{t}$ \\
3 & -22554 & 0.06 & 0 & 500 & 0 & 0 & 5 & $\mathrm{t}$ \\
3 & -22530 & 0.01 & 0.11 & 500 & 0 & 0 & 13 & 20 \\
3 & -22379 & 0.01 & 0 & 500 & 0 & 0 & 1 & 20 \\
3 & -22357 & 0.19 & 0.04 & 500 & 0 & 0 & 32 & 20 \\
3 & -22206 & 0.17 & 0 & 500 & 0 & 0 & 37 & 18 \\
3 & -22206 & 0.1 & 0 & 500 & 0 & 0 & 47 & $\mathrm{t}$ \\
3 & -22116 & 0.09 & 0.12 & 500 & 0 & 0 & 56 & $\mathrm{t}$ \\
3 & -22088 & 0.09 & 0 & 500 & 0 & 0 & 32 & 20 \\
3 & -21855 & 0.09 & 0 & 500 & 0 & 0 & 53 & $\mathrm{t}$ \\
3 & -21181 & 0.19 & 0 & 500 & 0 & 0 & 22 & 20 \\
\hline 4 & -23989 & 0.11 & 0 & 500 & 0 & 0 & 22 & $\mathrm{i}$ \\
4 & -23986 & 0.01 & 0.03 & 500 & 0 & 0 & 20 & 19 \\
4 & -23893 & 0.03 & 0 & 500 & 0 & 0 & 37 & 19 \\
4 & -23867 & 0.01 & 0.22 & 500 & 0 & 0 & 44 & 19 \\
4 & -23830 & 0.01 & 0.11 & 500 & 0 & 0 & 13 & 20 \\
4 & -23827 & 0.01 & 0 & 500 & 0 & 0 & 1 & 20 \\
4 & -23700 & 0.01 & 0.01 & 500 & 6 & 0 & 46 & 19 \\
4 & -23673 & 0.03 & 0.16 & 500 & 0 & 0 & 44 & 19 \\
4 & -23607 & 0.01 & 0.04 & 500 & 0 & 0 & 34 & 20 \\
4 & -23596 & 0.01 & 0.02 & 500 & 6 & 0 & 42 & 19 \\
4 & -23595 & 0.01 & 0.18 & 500 & 0 & 0 & 34 & 20 \\
4 & -23504 & 0.01 & 0.06 & 500 & 0 & 0 & 33 & 20 \\
4 & -23404 & 0.01 & 0.07 & 500 & 0 & 0 & 34 & 20 \\
4 & -23396 & 0.01 & 0.19 & 500 & 0 & 0 & 37 & 20 \\
4 & -23318 & 0.01 & 0.05 & 500 & 0 & 0 & 1 & 20 \\
4 & -23124 & 0.01 & 0.02 & 500 & 0 & 0 & 46 & 19 \\
4 & -22958 & 0.01 & 0.04 & 500 & 0 & 0 & 42 & 19 \\
4 & -22904 & 0.01 & 0.06 & 500 & 0 & 0 & 44 & 19 \\
4 & -22842 & 0.01 & 0.16 & 500 & 0 & 0 & 44 & 20 \\
4 & -22639 & 0.01 & 0.16 & 500 & 0 & 0 & 34 & 19 \\
\hline \hline & & & & & & & & \\
3
\end{tabular}

Tabela 9.12: Tab. de par. ótimos - GA sensível ao custo - NN - Melhores 20 - Bases 3 e 4 


\begin{tabular}{lllllllll} 
base & custo & $-\mathrm{L}$ & $-\mathrm{M}$ & $-\mathrm{N}$ & $-\mathrm{V}$ & $-\mathrm{S}$ & $-\mathrm{E}$ & $-\mathrm{H}$ \\
\hline \hline 5 & -24140 & 0.35 & 0 & 500 & 0 & 0 & 36 & $\mathrm{t}$ \\
5 & -24056 & 0.13 & 0.07 & 500 & 0 & 0 & 13 & 20 \\
5 & -24021 & 0.09 & 0.31 & 500 & 4 & 0 & 33 & $\mathrm{i}$ \\
5 & -24019 & 0.12 & 0.26 & 500 & 4 & 0 & 33 & $\mathrm{i}$ \\
5 & -23989 & 0.09 & 0.3 & 500 & 4 & 0 & 33 & $\mathrm{i}$ \\
5 & -23912 & 0.09 & 0.25 & 500 & 4 & 0 & 33 & $\mathrm{i}$ \\
5 & -23897 & 0.09 & 0.28 & 500 & 4 & 0 & 33 & $\mathrm{i}$ \\
5 & -23826 & 0.09 & 0.16 & 500 & 4 & 0 & 33 & $\mathrm{i}$ \\
5 & -23752 & 0.09 & 0.32 & 500 & 4 & 0 & 33 & $\mathrm{i}$ \\
5 & -23721 & 0.06 & 0.13 & 500 & 0 & 0 & 63 & $\mathrm{t}$ \\
5 & -23720 & 0.06 & 0.19 & 500 & 0 & 0 & 39 & $\mathrm{t}$ \\
5 & -23636 & 0.09 & 0.24 & 500 & 4 & 0 & 33 & $\mathrm{i}$ \\
5 & -23520 & 0.01 & 0.86 & 500 & 0 & 0 & 15 & $\mathrm{i}$ \\
5 & -23315 & 0.07 & 0.26 & 500 & 4 & 0 & 33 & $\mathrm{i}$ \\
5 & -23297 & 0.09 & 0.22 & 500 & 4 & 0 & 33 & $\mathrm{i}$ \\
5 & -23162 & 0.09 & 0.26 & 500 & 5 & 0 & 33 & $\mathrm{i}$ \\
5 & -23154 & 0.04 & 0 & 500 & 0 & 0 & 39 & $\mathrm{t}$ \\
5 & -22807 & 0.06 & 0 & 500 & 0 & 0 & 34 & $\mathrm{t}$ \\
5 & -22472 & 0.1 & 0 & 500 & 0 & 0 & 34 & $\mathrm{t}$ \\
5 & -21938 & 0.09 & 0.26 & 500 & 4 & 0 & 43 & $\mathrm{i}$ \\
\hline 6 & -23621 & 0.15 & 0.07 & 500 & 0 & 0 & 9 & 20 \\
6 & -23489 & 0.12 & 0.07 & 500 & 0 & 0 & 9 & 20 \\
6 & -23479 & 0.01 & 0.02 & 500 & 0 & 0 & 33 & 19 \\
6 & -23388 & 0.01 & 0.07 & 500 & 0 & 0 & 9 & 20 \\
6 & -23200 & 0.11 & 0 & 500 & 0 & 0 & 60 & 20 \\
6 & -23129 & 0.13 & 0.03 & 500 & 0 & 0 & 9 & $\mathrm{t}$ \\
6 & -23008 & 0.13 & 0.05 & 500 & 0 & 0 & 9 & 20 \\
6 & -22947 & 0.23 & 0.07 & 500 & 0 & 0 & 9 & 20 \\
6 & -22877 & 0.13 & 0.1 & 500 & 0 & 0 & 9 & 20 \\
6 & -22817 & 0.02 & 0 & 500 & 0 & 0 & 24 & $\mathrm{i}$ \\
6 & -22715 & 0.13 & 0.04 & 500 & 0 & 0 & 9 & 20 \\
6 & -22674 & 0.01 & 0.16 & 500 & 0 & 0 & 80 & 18 \\
6 & -22673 & 0.01 & 0.46 & 500 & 0 & 0 & 21 & $\mathrm{i}$ \\
6 & -22627 & 0.03 & 0.07 & 500 & 0 & 0 & 9 & 20 \\
6 & -22604 & 0.1 & 0 & 500 & 0 & 0 & 47 & $\mathrm{t}$ \\
6 & -22596 & 0.01 & 0.12 & 500 & 0 & 0 & 42 & 18 \\
6 & -22517 & 0.12 & 0.04 & 500 & 0 & 0 & 10 & 20 \\
6 & -22216 & 0.01 & 0.04 & 500 & 0 & 0 & 10 & 18 \\
6 & -22190 & 0.01 & 0.11 & 500 & 0 & 0 & 13 & 20 \\
6 & -21442 & 0.13 & 0.07 & 500 & 0 & 0 & 5 & 20 \\
\hline \hline & & & & & & & & \\
5
\end{tabular}




\begin{tabular}{|c|c|c|c|c|c|c|c|c|}
\hline base & custo & $-\mathrm{L}$ & $-\mathrm{M}$ & $-\mathrm{N}$ & $-\mathrm{V}$ & $-\mathrm{S}$ & $-E$ & $-\mathrm{H}$ \\
\hline 7 & -24371 & 0.01 & 0.15 & 500 & 0 & 0 & $\overline{54}$ & 20 \\
\hline 7 & -24339 & 0.07 & 0.1 & 500 & 5 & 0 & 51 & 20 \\
\hline 7 & -24153 & 0.01 & 0.02 & 500 & 0 & 0 & 33 & 19 \\
\hline 7 & -24153 & 0.02 & 0 & 500 & 0 & 0 & 9 & 20 \\
\hline 7 & -24078 & 0.11 & 0 & 500 & 0 & 0 & 9 & 20 \\
\hline 7 & -24006 & 0.01 & 0.06 & 500 & 0 & 0 & 34 & 19 \\
\hline 7 & -23820 & 0.07 & 0 & 500 & 0 & 0 & 9 & 20 \\
\hline 7 & -23779 & 0.01 & 0.13 & 500 & 0 & 0 & 11 & 20 \\
\hline 7 & -23649 & 0.03 & 0 & 500 & 0 & 0 & 9 & 20 \\
\hline 7 & -23634 & 0.01 & 0.04 & 500 & 0 & 0 & 9 & 20 \\
\hline 7 & -23529 & 0.01 & 0.01 & 500 & 0 & 0 & 9 & 20 \\
\hline 7 & -23500 & 0.01 & 0.11 & 500 & 0 & 0 & 13 & 20 \\
\hline 7 & -23450 & 0.01 & 0.19 & 500 & 0 & 0 & 22 & 20 \\
\hline 7 & -23365 & 0.01 & 0.03 & 500 & 0 & 0 & 9 & 20 \\
\hline 7 & -23341 & 0.01 & 0.1 & 500 & 0 & 0 & 9 & 20 \\
\hline 7 & -23321 & 0.01 & 0.06 & 500 & 0 & 0 & 9 & 20 \\
\hline 7 & -23289 & 0.04 & 0 & 500 & 0 & 0 & 9 & 20 \\
\hline 7 & -23241 & 0.01 & 0.21 & 500 & 0 & 0 & 18 & 20 \\
\hline 7 & -23047 & 0.01 & 0.02 & 500 & 0 & 0 & 9 & 20 \\
\hline 7 & -22880 & 0.01 & 0 & 500 & 0 & 0 & 9 & 20 \\
\hline 8 & -23217 & 0.03 & 0.11 & 500 & 0 & 0 & 9 & 20 \\
\hline 8 & -23168 & 0.01 & 0.19 & 500 & 0 & 0 & 30 & i \\
\hline 8 & -23141 & 0.01 & 0.13 & 500 & 0 & 0 & 9 & 20 \\
\hline 8 & -23132 & 0.01 & 0.17 & 500 & 0 & 0 & 9 & 20 \\
\hline 8 & -23088 & 0.07 & 0 & 500 & 0 & 0 & 50 & 20 \\
\hline 8 & -23025 & 0.01 & 0.1 & 500 & 0 & 0 & 9 & 20 \\
\hline 8 & -22960 & 0.01 & 0.06 & 500 & 0 & 0 & 34 & 20 \\
\hline 8 & -22910 & 0.12 & 0 & 500 & 0 & 0 & 51 & 20 \\
\hline 8 & -22798 & 0.01 & 0.01 & 500 & 0 & 0 & 9 & 20 \\
\hline 8 & -22771 & 0.01 & 0.07 & 500 & 0 & 0 & 9 & 20 \\
\hline 8 & -22724 & 0.01 & 0.05 & 500 & 0 & 0 & 9 & 20 \\
\hline 8 & -22596 & 0.01 & 0.46 & 500 & 0 & 0 & 28 & $\mathrm{i}$ \\
\hline 8 & -22581 & 0.01 & 0.06 & 500 & 0 & 0 & 34 & 19 \\
\hline 8 & -22554 & 0.01 & 0.08 & 500 & 0 & 0 & 22 & 20 \\
\hline 8 & -22484 & 0.01 & 0.18 & 500 & 0 & 0 & 1 & 20 \\
\hline 8 & -22394 & 0.01 & 0.04 & 500 & 0 & 0 & 9 & 20 \\
\hline 8 & -22148 & 0.01 & 0 & 500 & 0 & 0 & 18 & 20 \\
\hline 8 & -22062 & 0.01 & 0.11 & 500 & 0 & 0 & 10 & 20 \\
\hline 8 & -22040 & 0.01 & 0.09 & 500 & 0 & 0 & 9 & 20 \\
\hline 8 & -21508 & 0.01 & 0.21 & 500 & 0 & 0 & 9 & 20 \\
\hline
\end{tabular}

Tabela 9.13: Tab. de par. ótimos - GA sensível ao custo - NN - Melhores 20 - Bases 7 e 8 


\begin{tabular}{lllllllll} 
base & custo & $-\mathrm{L}$ & $-\mathrm{M}$ & $-\mathrm{N}$ & $-\mathrm{V}$ & $-\mathrm{S}$ & $-\mathrm{E}$ & $-\mathrm{H}$ \\
\hline \hline 9 & -23472 & 0.01 & 0 & 500 & 9 & 0 & 36 & $\mathrm{t}$ \\
9 & -23466 & 0.05 & 0 & 500 & 0 & 0 & 1 & $\mathrm{t}$ \\
9 & -23466 & 0.05 & 0 & 500 & 0 & 0 & 1 & $\mathrm{t}$ \\
9 & -23445 & 0.01 & 0.02 & 500 & 0 & 0 & 33 & 19 \\
9 & -23431 & 0.13 & 0 & 500 & 0 & 0 & 1 & $\mathrm{t}$ \\
9 & -23161 & 0.09 & 0.04 & 500 & 0 & 0 & 1 & $\mathrm{t}$ \\
9 & -23147 & 0.01 & 0.03 & 500 & 0 & 0 & 61 & $\mathrm{t}$ \\
9 & -23137 & 0.13 & 0.11 & 500 & 0 & 0 & 15 & $\mathrm{i}$ \\
9 & -23108 & 0.09 & 0.01 & 500 & 0 & 0 & 1 & $\mathrm{t}$ \\
9 & -23096 & 0.19 & 0.07 & 500 & 0 & 0 & 9 & $\mathrm{i}$ \\
9 & -23054 & 0.01 & 0.12 & 500 & 0 & 0 & 14 & 19 \\
9 & -22989 & 0.01 & 0.12 & 500 & 0 & 0 & 13 & 20 \\
9 & -22902 & 0.09 & 0.02 & 500 & 0 & 0 & 1 & $\mathrm{t}$ \\
9 & -22897 & 0.13 & 0 & 500 & 0 & 0 & 23 & 17 \\
9 & -22842 & 0.01 & 0.08 & 500 & 0 & 0 & 3 & $\mathrm{t}$ \\
9 & -22700 & 0.05 & 0.12 & 500 & 0 & 0 & 13 & 19 \\
9 & -22662 & 0.03 & 0 & 500 & 0 & 0 & 1 & $\mathrm{t}$ \\
9 & -22617 & 0.01 & 0.06 & 500 & 0 & 0 & 34 & 19 \\
9 & -22615 & 0.28 & 0 & 500 & 0 & 0 & 37 & $\mathrm{i}$ \\
9 & -22361 & 0.01 & 0.07 & 500 & 0 & 0 & 7 & $\mathrm{t}$ \\
9 & -22184 & 0.09 & 0 & 500 & 0 & 0 & 11 & $\mathrm{t}$ \\
\hline \hline
\end{tabular}

Tabela 9.14: Tab. de par. ótimos - GA sensível ao custo - NN - Melhores 20 - Base 9 


\begin{tabular}{|c|c|c|c|}
\hline $\begin{array}{l}\text { Desenvolv. } \\
(2,3, . ., 7)\end{array}$ & $\begin{array}{l}\text { Validação } \\
(8,9,1)\end{array}$ & $\begin{array}{l}\text { Total } \\
(1,2, . ., 9)\end{array}$ & Parâmetros ótimos estáveis \\
\hline$\overline{-23.191}$ & -23.101 & -23.161 & $\begin{array}{l}\text {-D -Q weka...local.K2 - -P } 8 \text {-S BDeu } \\
\text {-E weka ...SimpleEstimator - -A } 1.0\end{array}$ \\
\hline-23.582 & -23.309 & -23.491 & $\begin{array}{l}\text {-D -Q weka...local.K2 - -P } 7 \text {-S ENTROPY } \\
\text {-E weka...SimpleEstimator - -A } 1.0\end{array}$ \\
\hline-23.591 & -22.631 & -23.271 & $\begin{array}{l}\text {-D -Q weka...local.K2 - -P } 8 \text {-S ENTROPY } \\
\text {-E weka...SimpleEstimator - -A } 1.0\end{array}$ \\
\hline-23.724 & -23.404 & -23.617 & $\begin{array}{l}\text {-D -Q weka...local.K2 - -P } 6 \text {-S ENTROPY } \\
\text {-E weka...SimpleEstimator - -A } 1.0\end{array}$ \\
\hline-23.831 & -23.419 & -23.694 & $\begin{array}{l}\text {-D -Q weka...local.K2 - -P } 7 \text {-S BDeu } \\
\text {-E weka...SimpleEstimator - -A } 1.0\end{array}$ \\
\hline-23.977 & -23.828 & -23.927 & $\begin{array}{l}\text {-D -Q weka...local.K2 - -P } 6 \text {-S BDeu } \\
\text {-E weka...SimpleEstimator - -A } 1.0\end{array}$ \\
\hline-24.901 & -24.696 & -24.833 & $\begin{array}{l}\text {-D -Q weka...local.K2 - -P } 8 \text {-S AIC } \\
\text {-E weka...SimpleEstimator - -A } 1.0\end{array}$ \\
\hline-24.901 & -24.696 & -24.833 & $\begin{array}{l}\text {-D -Q weka...local.K2 - -P } 15 \text {-S AIC } \\
\text {-E weka...SimpleEstimator - -A } 1.0\end{array}$ \\
\hline-24.901 & -24.696 & -24.833 & $\begin{array}{l}\text {-D -Q weka...local.K2 - -P } 6 \text {-S AIC } \\
\text {-E weka...SimpleEstimator - -A } 1.0\end{array}$ \\
\hline-24.901 & -24.696 & -24.833 & $\begin{array}{l}\text {-D -Q weka...local.K2 - -P } 14 \text {-S AIC } \\
\text {-E weka...SimpleEstimator - -A } 1.0\end{array}$ \\
\hline-24.901 & -24.696 & -24.833 & $\begin{array}{l}\text {-D -Q weka...local.K2 - -P } 16 \text {-S AIC } \\
\text {-E weka...SimpleEstimator - -A } 1.0\end{array}$ \\
\hline-24.901 & -24.696 & -24.833 & $\begin{array}{l}\text {-D -Q weka...local.K2 - -P } 7 \text {-S AIC } \\
\text {-E weka...SimpleEstimator - -A } 1.0\end{array}$ \\
\hline-24.901 & -24.696 & -24.833 & $\begin{array}{l}\text {-D -Q weka...local.K2 - -P } 17 \text {-S AIC } \\
\text {-E weka...SimpleEstimator - -A } 1.0\end{array}$ \\
\hline-24.901 & -24.696 & -24.833 & $\begin{array}{l}\text {-D -Q weka...local.K2 - -P } 12 \text {-S AIC } \\
\text {-E weka...SimpleEstimator - -A } 1.0\end{array}$ \\
\hline-24.901 & -24.696 & -24.833 & $\begin{array}{l}\text {-D -Q weka...local.K2 - -P } 11 \text {-S AIC } \\
\text {-E weka...SimpleEstimator - -A } 1.0\end{array}$ \\
\hline-24.901 & -24.696 & -24.833 & $\begin{array}{l}\text {-D -Q weka...local.K2 - -P } 13 \text {-S AIC } \\
\text {-E weka...SimpleEstimator - -A } 1.0\end{array}$ \\
\hline-24.901 & -24.696 & -24.833 & $\begin{array}{l}\text {-D -Q weka...local.K2 - -P } 9 \text {-S AIC } \\
\text {-E weka...SimpleEstimator - -A } 1.0\end{array}$ \\
\hline-24.901 & -24.696 & -24.833 & $\begin{array}{l}\text {-D -Q weka...local.K2 - -P } 18 \text {-S AIC } \\
\text {-E weka...SimpleEstimator - -A } 1.0\end{array}$ \\
\hline-24.901 & -24.633 & -24.812 & $\begin{array}{l}\text {-D -Q weka...local.K2 - -P } 5 \text {-S AIC } \\
\text {-E weka...SimpleEstimator - -A } 1.0\end{array}$ \\
\hline-24.901 & -24.696 & -24.833 & $\begin{array}{l}\text {-D -Q weka...local.K2 - -P } 10 \text {-S AIC } \\
\text {-E weka...SimpleEstimator - -A } 1.0\end{array}$ \\
\hline
\end{tabular}

Tabela 9.15: Tabela de parâmetros ótimos estáveis BN sensível ao custo 


\begin{tabular}{|c|c|c|c|c|c|c|c|c|c|}
\hline estratégia & base & custo & $-\mathrm{L}$ & $-\mathrm{M}$ & $-\mathrm{N}$ & $-\mathrm{V}$ & $-\mathrm{S}$ & $-\mathrm{E}$ & $-\mathrm{H}$ \\
\hline padrao & 1 & -30544 & 0.13 & 0.41 & 500 & 0 & 0 & 6 & 20 \\
\hline padrao & 1 & -30199 & 0.17 & 0.07 & 500 & 0 & 0 & 1 & 20 \\
\hline padrao & 1 & -30140 & 0.19 & 0.46 & 500 & 0 & 0 & 9 & 20 \\
\hline padrao & 3 & -37595 & 0.65 & 0.05 & 500 & 0 & 0 & 21 & 20 \\
\hline padrao & 3 & -35378 & 0.69 & 0.03 & 500 & 21 & 0 & 38 & 20 \\
\hline padrao & 3 & -32451 & 0.5 & 0 & 500 & 10 & 0 & 68 & 20 \\
\hline padrao & 3 & -32047 & 0.72 & 0.11 & 500 & 0 & 0 & 1 & 20 \\
\hline padrao & 3 & -31418 & 0.5 & 0.26 & 500 & 22 & 0 & 44 & 20 \\
\hline padrao & 4 & -36402 & 0.13 & 0.05 & 500 & 0 & 0 & 1 & 20 \\
\hline padrao & 4 & -35779 & 0.09 & 0.03 & 500 & 0 & 0 & 1 & 20 \\
\hline padrao & 4 & -35462 & 0.13 & 0.03 & 500 & 0 & 0 & 1 & 20 \\
\hline padrao & 4 & -35404 & 0.13 & 0 & 500 & 0 & 0 & 1 & 20 \\
\hline padrao & 4 & -34939 & 0.1 & 0.03 & 500 & 0 & 0 & 1 & 20 \\
\hline padrao & 5 & -40463 & 0.94 & 0.04 & 500 & 0 & 0 & 0 & 20 \\
\hline padrao & 5 & -40463 & 0.94 & 0.04 & 500 & 0 & 0 & 0 & 20 \\
\hline padrao & 5 & -37818 & 0.34 & 0.64 & 500 & 0 & 0 & 1 & 20 \\
\hline padrao & 5 & -37113 & 0.8 & 0.62 & 500 & 29 & 0 & 38 & 20 \\
\hline padrao & 5 & -34376 & 0.2 & 0.04 & 500 & 0 & 0 & 1 & 20 \\
\hline padrao & 5 & -33910 & 0.2 & 0 & 500 & 0 & 0 & 7 & 20 \\
\hline padrao & 6 & -34207 & 0.45 & 0 & 500 & 7 & 0 & 31 & 20 \\
\hline padrao & 6 & -34207 & 0.45 & 0 & 500 & 7 & 0 & 31 & 20 \\
\hline padrao & 6 & -30358 & 0.87 & 0.08 & 500 & 27 & 0 & 82 & 20 \\
\hline padrao & 6 & -30298 & 0.21 & 0.56 & 500 & 13 & 0 & 54 & 20 \\
\hline padrao & 6 & -29943 & 0.45 & 0.08 & 500 & 0 & 0 & 41 & 20 \\
\hline padrao & 7 & -35863 & 0.39 & 0.04 & 500 & 0 & 0 & 37 & 20 \\
\hline padrao & 7 & -35863 & 0.39 & 0.04 & 500 & 0 & 0 & 37 & 20 \\
\hline padrao & 7 & -33606 & 0.89 & 0 & 500 & 2 & 0 & 20 & 20 \\
\hline padrao & 7 & -32618 & 0.79 & 0.1 & 500 & 2 & 0 & 20 & 20 \\
\hline padrao & 7 & -30887 & 0.8 & 0 & 500 & 2 & 0 & 20 & 20 \\
\hline padrao & 8 & -37260 & 0.79 & 0.79 & 500 & 0 & 0 & 59 & 20 \\
\hline padrao & 8 & -35863 & 0.39 & 0.04 & 500 & 0 & 0 & 37 & 20 \\
\hline padrao & 8 & -34372 & 0.74 & 0 & 500 & 21 & 0 & 36 & 20 \\
\hline padrao & 8 & -33233 & 0.11 & 0.06 & 500 & 0 & 0 & 0 & 20 \\
\hline padrao & 8 & -31425 & 0.71 & 0 & 500 & 21 & 0 & 46 & 20 \\
\hline padrao & 9 & -34167 & 0.56 & 0 & 500 & 0 & 0 & 19 & 20 \\
\hline
\end{tabular}

Tabela 9.16: Tab. NN - Verificação - Melhores GA Padrão com H $=20$ 


\begin{tabular}{|c|c|c|c|c|c|c|c|c|c|}
\hline estratégia & base & custo & $-\mathrm{L}$ & $-\mathrm{M}$ & $-\mathrm{N}$ & $-\mathrm{V}$ & $-\mathrm{S}$ & $-\mathrm{E}$ & $-\mathrm{H}$ \\
\hline cost & 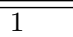 & -24793 & 0.01 & ב0.02 & 500 & 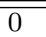 & 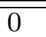 & 29 & 20 \\
\hline cost & 1 & -24793 & 0.01 & 0.02 & 500 & 0 & 0 & 29 & 20 \\
\hline cost & 1 & -23963 & 0.01 & 0.46 & 500 & 0 & 0 & 20 & 20 \\
\hline cost & 1 & -23963 & 0.01 & 0.46 & 500 & 0 & 0 & 24 & 20 \\
\hline cost & 1 & -23963 & 0.01 & 0.46 & 500 & 0 & 0 & 26 & 20 \\
\hline cost & 1 & -23963 & 0.01 & 0.46 & 500 & 0 & 0 & 36 & 20 \\
\hline cost & 1 & -23963 & 0.01 & 0.46 & 500 & 0 & 0 & 40 & 20 \\
\hline cost & 1 & -23885 & 0.01 & 0.16 & 500 & 0 & 0 & 46 & 20 \\
\hline cost & 1 & -23825 & 0.01 & 0.45 & 500 & 0 & 0 & 30 & 20 \\
\hline cost & 1 & -23452 & 0.01 & 0.43 & 500 & 0 & 0 & 30 & 20 \\
\hline cost & 2 & -24389 & 0.05 & 0.16 & 500 & 0 & 0 & 13 & 20 \\
\hline cost & 2 & -22620 & 0.05 & 0.12 & 500 & 0 & 0 & 1 & 20 \\
\hline cost & 2 & -22620 & 0.05 & 0.12 & 500 & 0 & 0 & 16 & 20 \\
\hline cost & 2 & -22620 & 0.05 & 0.12 & 500 & 0 & 0 & 16 & 20 \\
\hline cost & 2 & -22620 & 0.05 & 0.12 & 500 & 0 & 0 & 17 & 20 \\
\hline cost & 2 & -22620 & 0.05 & 0.12 & 500 & 0 & 0 & 19 & 20 \\
\hline cost & 2 & -22620 & 0.05 & 0.12 & 500 & 0 & 0 & 23 & 20 \\
\hline cost & 2 & -22620 & 0.05 & 0.12 & 500 & 0 & 0 & 3 & 20 \\
\hline cost & 2 & -22620 & 0.05 & 0.12 & 500 & 0 & 0 & 7 & 20 \\
\hline cost & 2 & -22620 & 0.05 & 0.12 & 500 & 0 & 0 & 9 & 20 \\
\hline cost & 4 & -22842 & 0.01 & 0.16 & 500 & 0 & 0 & 54 & 20 \\
\hline cost & 5 & -26834 & 0.09 & 0.26 & 500 & 4 & 0 & 33 & 20 \\
\hline cost & 5 & -26834 & 0.09 & 0.26 & 500 & 4 & 0 & 34 & 20 \\
\hline cost & 5 & -26834 & 0.09 & 0.26 & 500 & 4 & 0 & 35 & 20 \\
\hline cost & 5 & -26834 & 0.09 & 0.26 & 500 & 4 & 0 & 36 & 20 \\
\hline cost & 5 & -26834 & 0.09 & 0.26 & 500 & 4 & 0 & 37 & 20 \\
\hline cost & 5 & -26834 & 0.09 & 0.26 & 500 & 4 & 0 & 39 & 20 \\
\hline cost & 5 & -26834 & 0.09 & 0.26 & 500 & 4 & 0 & 43 & 20 \\
\hline cost & 5 & -26834 & 0.09 & 0.26 & 500 & 4 & 0 & 43 & 20 \\
\hline cost & 5 & -26086 & 0.09 & 0.26 & 500 & 4 & 0 & 31 & 20 \\
\hline cost & 5 & -25839 & 0.09 & 0.26 & 500 & 4 & 0 & 30 & 20 \\
\hline cost & 9 & -23544 & 0.07 & 0 & 500 & 0 & 0 & 1 & 20 \\
\hline cost & 9 & -23252 & 0.09 & 0 & 500 & 0 & 0 & 4 & 20 \\
\hline cost & 9 & -23252 & 0.09 & 0 & 500 & 0 & 0 & 4 & 20 \\
\hline cost & 9 & -23252 & 0.09 & 0 & 500 & 0 & 0 & 48 & 20 \\
\hline cost & 9 & -23252 & 0.09 & 0 & 500 & 0 & 0 & 5 & 20 \\
\hline cost & 9 & -23252 & 0.09 & 0 & 500 & 0 & 0 & 50 & 20 \\
\hline cost & 9 & -23252 & 0.09 & 0 & 500 & 0 & 0 & 54 & 20 \\
\hline cost & 9 & -23252 & 0.09 & 0 & 500 & 0 & 0 & 58 & 20 \\
\hline cost & 9 & -23252 & 0.09 & 0 & 500 & 0 & 0 & 61 & 20 \\
\hline cost & 9 & -23252 & 0.09 & 0 & 500 & 0 & 0 & 7 & 20 \\
\hline
\end{tabular}

Tabela 9.17: Tab. NN - Verificação - Melhores GA Cost com H $=20$ 


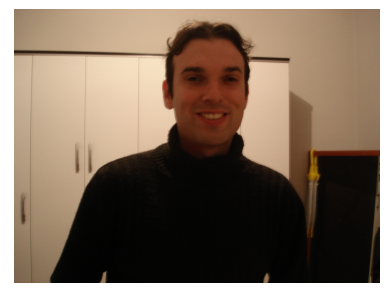

Manoel Fernando Alonso Gadi
- Responsável por metodologia, pesquisa e desenvolvimento para o todo Grupo Santander - locado em Milton Keynes - Inglaterra, de 2008 a atual;

- Coordenador de Modelagem Estatística para Brasil e América Latina, Banco Santander, de 2007 a 2008 ;

- Supervisor de Análise de Portifólio, Banco ibi, de 2006 a $2007 ;$

- Gerente de Prevenção à Fraude, Banco Santander divisão de cartões, 2005;

- Analista Sr. de Modelagem Estatística, Credicard Banco, de 2002 a 2005;

- Bacharel em Ciência da Computação, IME-USP em 2002;

- Monitor de disciplina, IME-USP, de 2000 a 2002;

- Experiência de 5 anos em bancos;

- E-mail: mgadi@bol.com.br;

- Principais áreas de interesse:

- Inteligência Artificial - Reconhecimento de Padrões;

- Modelagem Estatística - Credit Scoring, Behaviour Scoring, Collection Scoring e Fraud Scoring;

- Prevenção e detecção de fraude;

- Precificação de cateiras via Cadeias de Markov;

- Precificação de ativos em carteira de ações;

- Análise de informação semi-estruturada e desestruturada através de algoritmos;

- Dança de Salão. 